\title{
Plant genetic diversity in tropical lowland rainforest transformation systems in Sumatra (Indonesia)
}

Dissertation

zur Erlangung des mathematisch-naturwissenschaftlichen Doktorgrades

"Doctor rerum naturalium"

an der Georg-August-Universität Göttingen

vorgelegt von

Natalie Breidenbach

geboren in Mainz

Göttingen, 2016 
1. Gutachter: Prof. Dr. Reiner Finkeldey

2. Gutachter: Prof. Dr. Holger Kreft

Tag der mündlichen Prüfung: 23.05.2016 
I started out in search of ordinary things How much of a tree bends in the wind?

-Jim Cain-

Bill Callahan

To my grandmother Änne Althausen 



\section{CONTENTS}

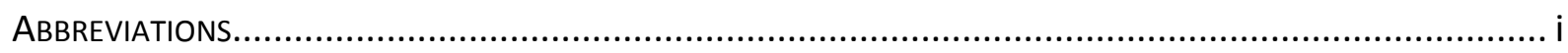

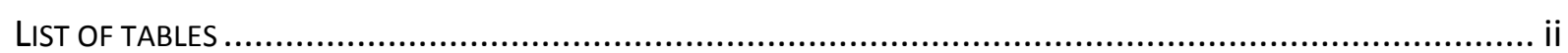

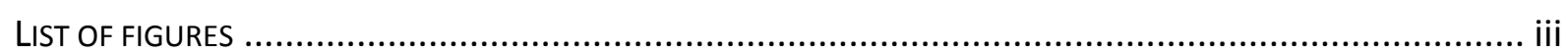

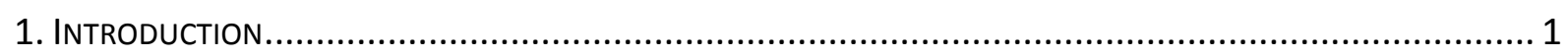

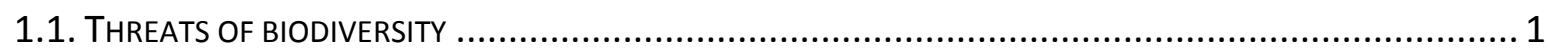

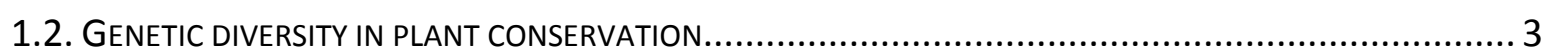

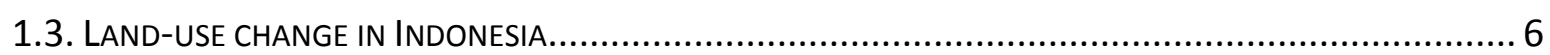

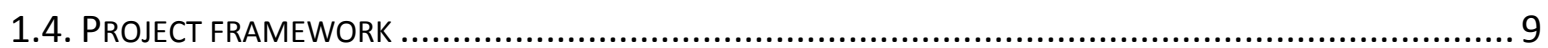

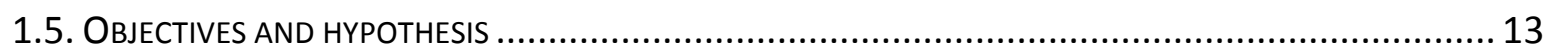

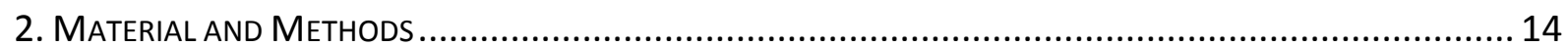

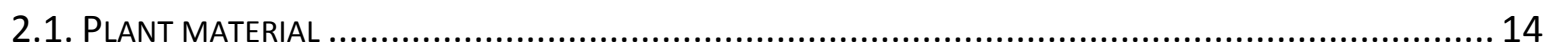

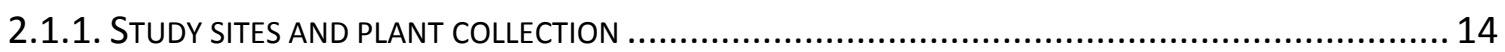

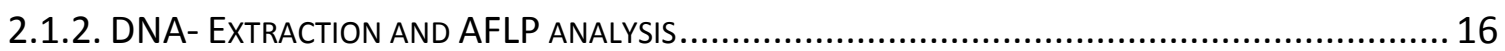

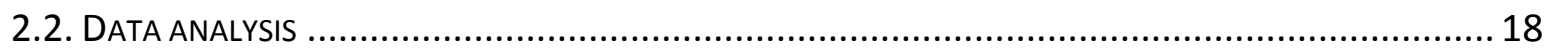

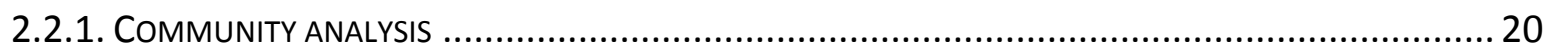

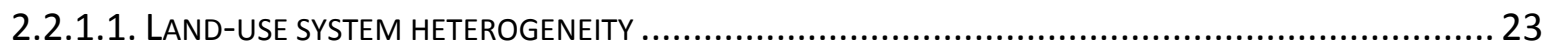

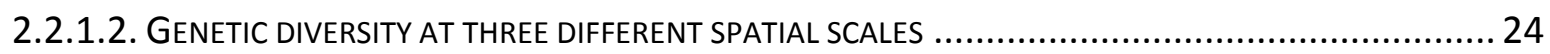

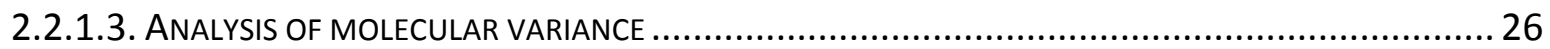

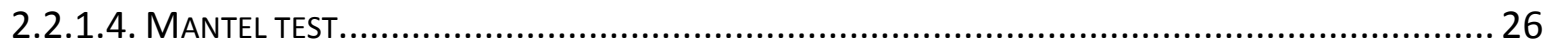

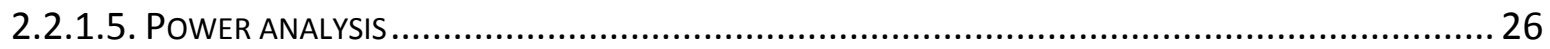

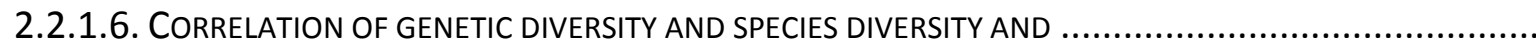

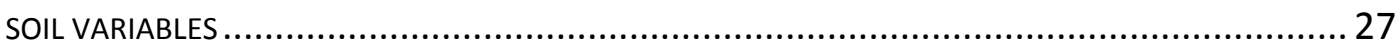

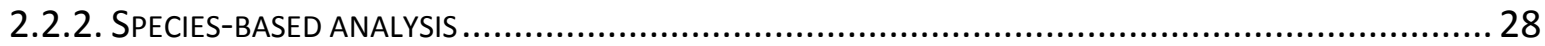

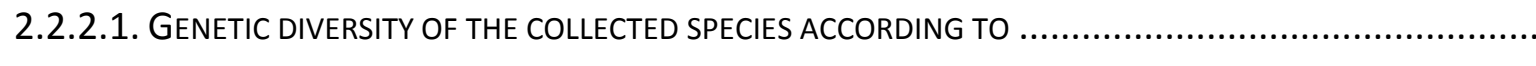

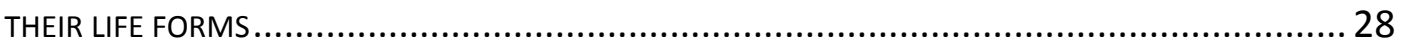

2.2.2.2. GENETIC STRUCTURE OF FREQUENTLY COLLECTED SPECIES ............................................... 28

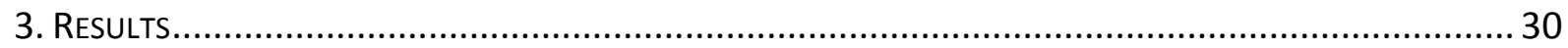

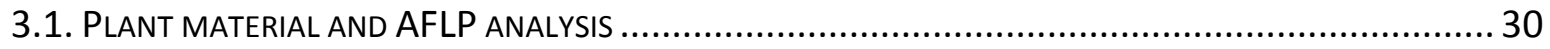

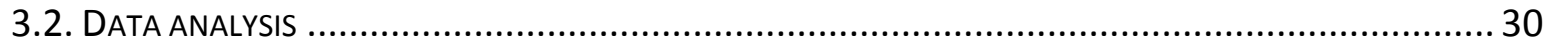

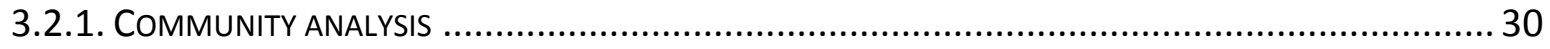

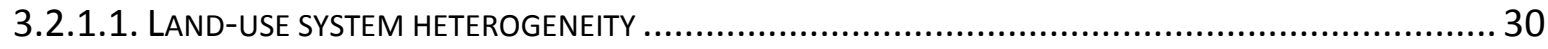

3.2.1.2. GeNETIC DIVERSITY AT THREE DIFFERENT SPATIAL SCALES .............................................. 31

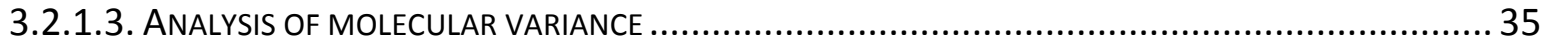

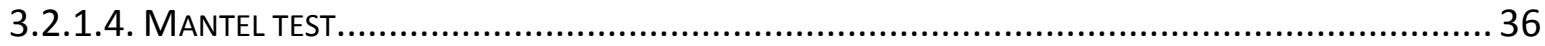


3.2.1.6. CORRELATION OF GENETIC DIVERSITY AND SPECIES DIVERSITY AND

SOIL VARIABLES 37

3.2.2. SPECIES-BASED ANALYSIS. 39

3.2.2.1. GENETIC DIVERSITY OF THE COLLECTED SPECIES ACCORDING TO

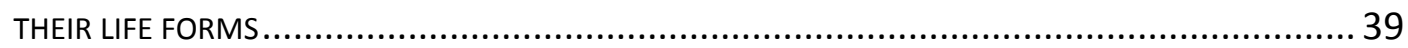

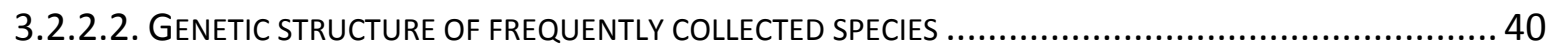

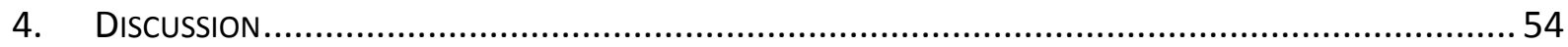

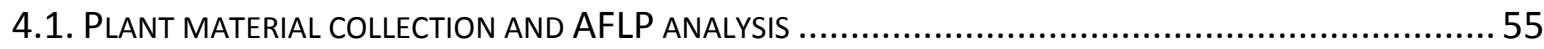

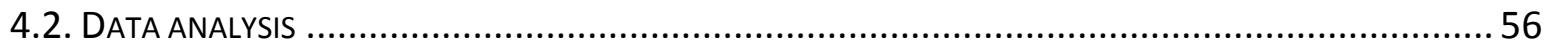

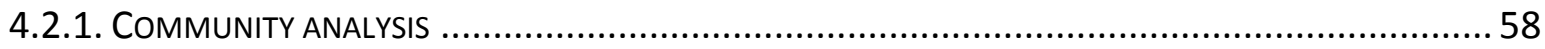

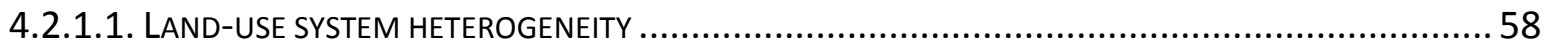

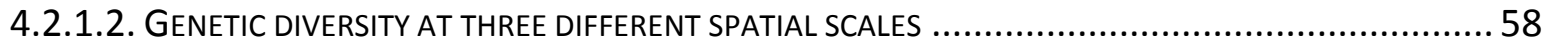

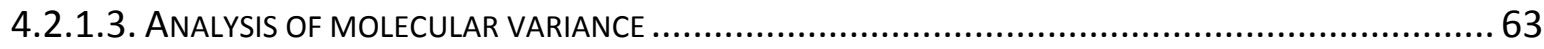

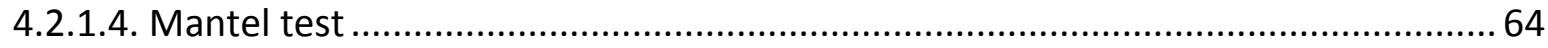

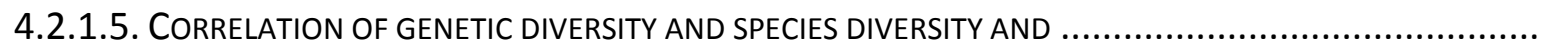



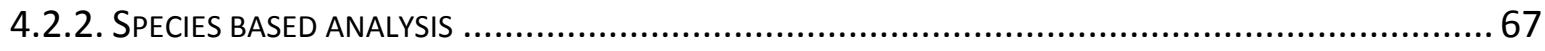

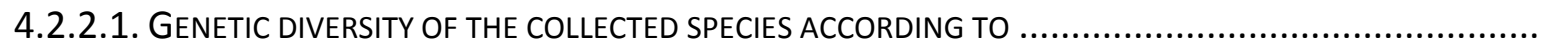

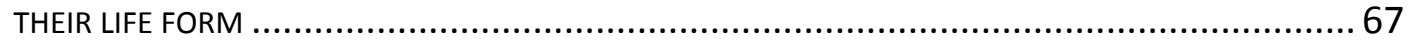

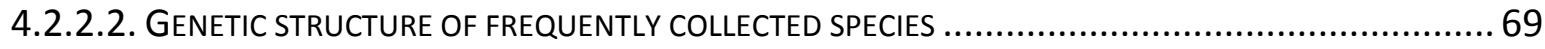

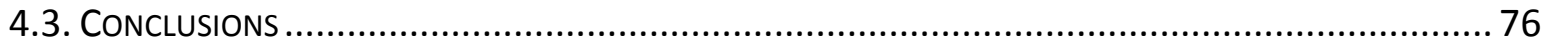

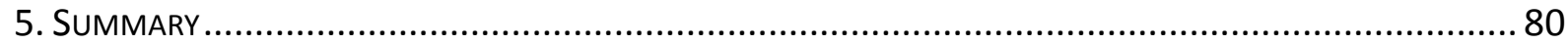

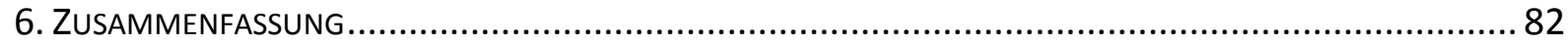

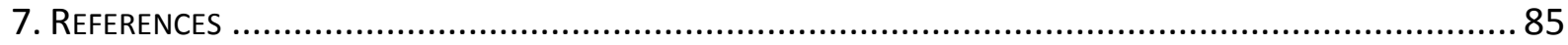

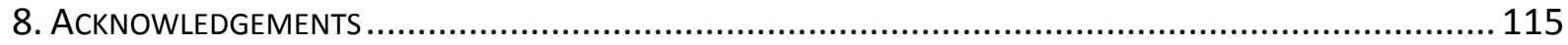

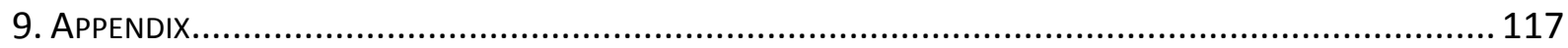

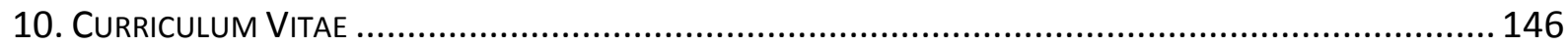




\section{ABBREVIATIONS}

AIC

AFLP

AMOVA

ANOVA

Appr.

a. s. I.

bp

C

${ }^{\circ} \mathrm{C}$

CIFOR

$\mathrm{CO}_{2} \mathrm{eq}$

D

$\mathrm{DBH}$

DNA

e.g.

FAO

GLMM

$\mathrm{HCV}$

i.e.

I

$\mathrm{mM}$

$\min$

Mha

PCoA

PCR

PES

PPL

RSPO

sec

SSR
Akaike Information Criterion

Amplified Length Polymorphism

Analysis of Molecular Variance

Analysis of Variance

approximately

above sea level

Base Pair

Morisita-Horn Index

Degree Celsius

Center for International Forestry Research

Carbondioxide equivalents, greenhouse gases measure (FAO)

Simpson Index

Diameter Breast Height

Deoxyribonucleic Acid

for example

Food and Agriculture Organization of the United Nations

Generalized Linear Mixed effect Model

High Conservation Value

that means

Shannon Index

mili Mol

minutes

Million hectare

Principal Component Analysis

Polymerase Chain Reaction

Payment for Ecosystem Services

Percentage of Polymorphic Loci

Roundtable on Sustainable Palm Oil

seconds

Simple Sequence Repeat 


\section{LIST OF TABLES}

Table 1: List of the in detail analysed dominant species with their life form category, region.

Table 2: AMOVA results of genetic fragment pool distance for each land-use system 36

Table 3: Contribution of each group in the two systems forest and jungle rubber separated by region. 40

Table 4: Pairwise $\phi_{\text {Рт }}$ of Hopea mengerawan 41

Table 5: Pairwise $\phi_{\mathrm{PT}}$ of Shorea ovalis

Table 6: AMOVA results of Shorea ovalis, Hopea mengerawan, Artocarpus elasticus and Croton argrarius of the collected plots

Table 7: Pairwise $\phi_{\mathrm{PT}}$ of Endospermum malayanum

Table 8: AMOVA (999 permutations) results of Endospermum malayanum, Hymenodictyon orixense and Macaranga bancana.. 43

Table 9: Molecular diversity indices of Macaranga bancana 44

Table 10: AMOVA results of Porterandia anisophylla, Alstonia scholaris, Aporosa nitida and Parkia speciosa. 46

Table 11: AMOVA results of Elaeis guineensis and Hevea brasiliensis.

Table 12: AMOVA results of Melastoma malabathricum, Clidemia hirta, Asystasia gangetica and Spermacoce alata 50

Table 13: AMOVA results of three grass species Centotheca lappacea, Axonopus compressus and Scleria bancana. 52

Table 14: Pairwise $\phi_{\text {Рт }}$ of Goniophlebium verrucosum 53

Table 15: AMOVA results of three fern species, Dicranopteris linearis, Goniophlebium verrucosum and Nephrolepis acutifolia 


\section{LIST OF FIGURES}

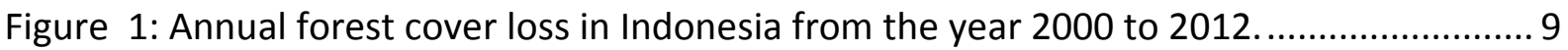

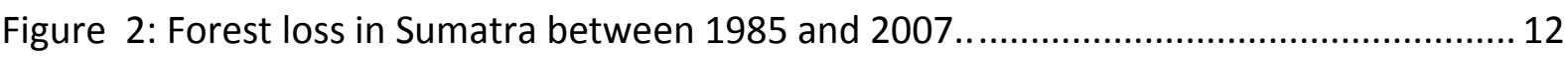

Figure 3: Pictures of the four investigated land-use systems ........................................... 12

Figure 4: Design (CRC 990, EFForTS, modified) for all 32 plots............................................ 16

Figure 5: Plot names with the respective diversity level and overview of all calculations.... 20

Figure 6: Illustration of the input file for the fragment pool approach ............................... 22

Figure 7: Illustration of the input file for the clone fragment pool matrix ............................ 23

Figure 8: The heterogeneity of each land-use system in the two regions............................. 31

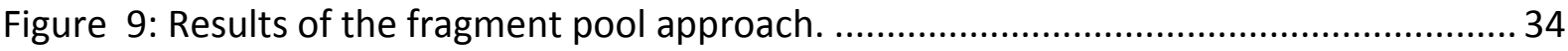

Figure 10: Results of the species approach using the Shannon Index................................... 34

Figure 11: Results of the species approach using the Morisita-Horn index. .......................... 35

Figure 12: Genetic diversity of the absolute effective turnover species using the fragment

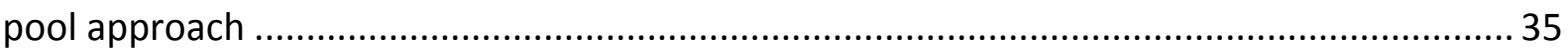

Figure 13: Correlation between genetic diversity and species diversity .............................. 38

Figure 14: Shannon Index per species grouped after life form. ......................................... 39

Figure 15: Neighbour Joining dendrogram of the tree species Artocarpus elasticus (A), Croton $\operatorname{agrarius}(\mathrm{B})$.

Figure 16: Neighbour Joining dendrogram of the tree species Hymenodictyon orixense (A), Macaranga bancana (B)

Figure 17: Neighbour Joining dendrogram of the tree species Alstonia scholaris (A), Aporosa nitida (B), Parkia speciosa (C), Porterandia anisophylla (D)

Figure 18: Neighbour Joining dendrogram of the crop species Elaeis guineensis (A) and Hevea brasiliensis (B).

Figure 19: Neighbour Joining dendrogram of the herb species Asystasia gangetica (A),

Clidemia hirta (B), Melastoma malabathricum (C) and Spermacoce alata (D).

Figure 20: Neighbour Joining dendrogram of the grass species Axonopus compressus (A),

Centotheca lappacea (B), Scleria bancana (C).

Figure 21: Neighbour Joining dendrogram of the fern species Dicranopteris linearis (A), and Nephrolepis acutifolia (B). 



\section{INTRODUCTION}

\subsection{THREATS OF BIODIVERSITY}

Forests currently cover $31 \%$ of the global land area and are one of the most important ecosystems as they provide crucial ecosystem services. For instance, they produce oxygen and store more carbon than the entire atmosphere (FAO 2010). Tropical forests harbour two thirds of the terrestrial species, while covering only approximately $5 \%$ of the global surface (Gardner et al. 2009). Additionally, on a landscape scale, scattered trees play an important role in ecosystem functioning and biodiversity of a wide range of plant and animal groups in terrestrial ecosystems (Manning et al. 2006; Kettle 2014).

Human land-use often affect adversely the natural distribution and habitat conditions of plants and animals. Between 1700 and 2000, $39 \%$ of the global ice-free land was transformed by human activities (Ellis et al. 2010). The main conversion of forest in temperate regions happened already before 1700 and is until now in stagnation. On the contrary, tropical regions experience transformation to used-land from 1900 onwards with an increasing rate at the end of the $20^{\text {th }}$ century (Ellis et al. 2010). Most tropical regions are on one side categorized as biodiversity hotspots and on the other side have an above-average human population growth rate (Cincotta et al. 2000). Biodiversity hotspots are characterized by, a high number of endemic species, high species richness and increased habitat loss (Myers 1988). Furthermore, in tropical regions (Africa, Asia and Latin America) deforestation occurred for the last three decades at high rates, due to the expansion of agricultural used land, logging and mining activities (Lambin et al. 2003; FAO 2010). Agricultural expansion alone caused the deforestation of intact (55\%) and disturbed (28\%) forests across the tropics within two decades (1980-2000) (Gibbs et al. 2010). Consequently, the most diverse ecosystems are under increasing danger of biodiversity degradation and species extinction, due to human expansion (Cincotta et al. 2000; Brooks et al. 2006; Sloan et al. 2014).

FAO (2010) reported a net forest loss in the years from 2000 to 2010 between 4 million (maximum) to 600000 (minimum) hectares per year depending on the region. Other factors like climate change, pollution and invasive species represent an additional threat to biodiversity in temperate (Lindner et al. 2010) and tropical regions (Sodhi \& Brook 2006). Furthermore, human activities are enhancing these factors. For instance, agriculture and deforestation, combined, are responsible for $24 \%$ of greenhouse gas emissions worldwide 
INTRODUCTION

(COP21 2015) which is associated with climate change (FAO 2010). Deforestation is not only responsible for habitat and biodiversity loss, but also influences climatic factors, like local precipitation rate, which again influences biodiversity (Werth \& Avissar 2005; Stork et al. 2009). Synergistic interactions of biodiversity change drivers, such as land-use change and climate change, become irrelevant if one driver caused severe changes, for example the landuse change from a forest to a monoculture (Sala et al. 2000). For instance, species in the northern and southern hemisphere respond to climate change by shifting their distribution range to habitats with more fitting conditions (Parmesan \& Yohe 2003), but land-use change causes an alteration of the processes of the whole ecosystem (Laliberté \& Tylianakis 2012). Hence, habitat loss effects various species at different trophic levels in different time and spatial dimensions (Schulze et al. 2004; Tscharntke et al. 2005; Ewers \& Didham 2006; Krauss et al. 2010).

Theoretically, consequences of habitat loss at the intraspecific diversity level are the loss of genetic diversity due to genetic drift, inbreeding and isolation by distance for small population sizes, but empirical studies do not always proof this theory (Kramer et al. 2008; Lesser et al. 2013; Sampson et al. 2014). The genetic consequences on habitat loss and population fragmentation depend on the reproduction system, dispersal strategy, dispersal range on the investigated plant, which differs highly among species (Hamrick et. al. 1979; Hamrick et al. 1992; Ewers \& Didham 2006; Sebbenn et al. 2008). Consequently, in tropical forests land-use change is expected to have higher relevance than climate change as a threat for biodiversity (Chapin III et al. 2000; Sala et al. 2000) and is the highest concern for tropical forest biodiversity conservation (Sodhi et al. 2004; Koh \& Sodhi 2010; Gibson et al. 2011).

Managing and conserving natural ecosystems are necessary (Sloan et al. 2014). Unfavourably, tropical forest management has various definitions and goals, e.g. timber production, management of ecosystem processes or of species and communities, which can result in contradictory techniques (Simberloff 1999). Suggestions for sustainable management and monitoring programs of particular forest areas are mainly according to data about species richness, particular indicator species and ecosystem processes (Lindenmayer 1999; Noss 1999; Simberloff 1999; Fridman 2000; Rametsteiner \& Simula 2003; Wilson et al. 2005), and have not always been sufficient and successful (Simberloff 1999). Economic and social aspects are increasing the complexity, hence difficulty, of sustainable management of tropical forests (Wilcove et al. 2013). Pearce et al. (2003) compare the two long term management 
approaches sustainable timber management and sustainable forest management in economic and ecological goals. Their analysis showed that sustainable forest management could only be successful if it is able to compete financially with sustainable timber management and other conventional land-use systems. For that, they suggest to determine universally usable values of biodiversity and ecosystem processes of an ecosystem and introduce compensations for the affected people.

\subsection{GENETIC DIVERSITY IN PLANT CONSERVATION}

The Section "Genetic Resources for Food and Agriculture" of the Food and Agriculture Organization of the United Nations (FAO) define threats on genetic diversity such as the low commercially use varieties of crops and livestock, increasing population pressure, loss of natural habitats and environmental degradation and climate change (FAO 2015a).

Lande (1988) highlighted the importance of genetic and demographic information of species for its conservation management. Population genetic analyses can reveal e.g. gene flow limitations, isolated populations and dispersal range, which has great implications on the survival of species, especially endangered or rare ones. Considering the species genetic information's concerning landscape management can help to maintain and even increase its viability (Li \& Jin 2007; Bozzano et al. 2014; Thomas et al. 2014). Species have to adapt to the environmental changes, thus, investigating their effect on genetic resources, provides information about the survival probabilities and conservation requirements of the species (Sthultz et al. 2009; Leimu et al. 2010). Genetic diversity of plants is not only important for the survival of the plant itself, but also influences other levels of organization within the ecosystem (Bailey et al. 2009).

Conducted research in temperate and boreal zones based on single species, is mainly concentrating on their potential to adapt to environmental changes like climate change or occurring pests. The investigated species either have an economic value, e.g. certain species of the genera Fagus and Quercus (Paludan-Müller et al. 1999; Muir et al. 2004; Vornam et al. 2011; Seifert et al. 2012; Müller et al. 2015), or are a rare and endangered species, e.g. certain species of the genus Pinus (Jorgensen \& Hamrick 1997; Bower 2008; Lesser et al. 2013). In tropical regions ongoing deforestation and the resulting fragmentation of remaining habitats can cause a reduced gene flow, which may impact the genetic population structure of plant species (Manel et al. 2003), and increase their extinction probability (Lira et al. 2003). 
INTRODUCTION

Commonly important timber tree species are investigated regarding their genetic diversity consequences of fragmentation (Wickneswari \& Cannon 2011).

Depending on the gene flow of the species, the fragmentation of populations can have currently no effect (Torre et al. 2008; Finger et al. 2012). A reason for that can be, that the disturbance and habitat loss are younger than the investigated individuals (Collevatti et al. 2001; Farwig et al. 2007; Fuchs \& Hamrick 2010) or there are no gene flow limitations for the species (Ganzhorn et al. 2015). For many species, the consequences of habitat fragmentation are reduced gene flow followed by an alteration of genetic structure (Hamilton 1999; Honnay \& Jacquemyn 2007; da Silva et al. 2008). For instance, mature individuals of the tropical Prunus africana showed high genetic diversity in remaining forest patches, but seedling showed reduced genetic diversity (Farwig et al. 2007). On the contrary, the wind-pollinated Castanopsis sclerophylla showed an increase in pollen flow rate after forest fragmentation due to the removal of trees acting as a barrier (Wang et al. 2012). The results of the two studies with differences in the life history traits of the species, sampling design, age of individual and disturbance, show the dependency of genetic diversity on these factors, which are necessary to consider in the interpretation of results.

In regions with high deforestation and land-use change rates like Indonesia, areas with natural vegetation are declining daily. The increasing area of secondary forest and the attempt of remaining connectivity among remaining natural habitats, adds as a problem for predicting parameters to assess habitats of conservational value (HCV) (RSPO 2013). Barlow et al. (2007) compared 15 taxa in species richness, species turnover similarity between primary and secondary forest habitats. Genetic diversity, as a parameter, was not included although it provides valuable information on the impact of land-use change. The high number of factors influencing the genetic structure of plants combined with political, social and traditions in tropical regions increase the difficulties of maintaining tropical forests ecosystem services and predicting the quality of areas (Sodhi et al. 2004; Kettle 2014). Laurance et al. (2012) showed that protected areas are highly depending on the surrounding habitat and their connectivity to each other. It is necessary to consider the specific characteristics of protected areas to increase the probability of conservation success (Symes et al. 2015). Laurence and Symes emphasize the importance of the factors population genetics can provide information about, but do not include genetic diversity as a parameter. 
The following research areas consider genetic diversity as one level within biodiversity and an influenced and influencing parameter within an ecosystem, mainly conducted in non-tropical regions. Compared to population genetics, which combines phenotypic parameters with genetic data, landscape genetics considers ecological factors increasing or decreasing connectivity of populations of one species, hence is a more integrated approach. Landscape genetic studies consider landscape features as factors influencing genetic structure of a given organism (Holderegger \& Wagner 2008). Identifying environmental barriers and possible connectivity limitations in a fragmented landscape can support predictions of future distribution range and conservation management (Manel et al. 2003; Storfer et al. 2007; Balkenhol et al. 2015), whereas this approach is until now, more used in animal research (Dyer 2015). Eckert \& Dyer (2012) suggest evaluating the fitness of a landscape, by combining geographical information of the distribution range with genotypic and phenotypic information of a species to evaluate more precisely its fitness status.

Interactions between the intraspecific diversity of one species and other species in the community are investigated in community genetics (Agrawal 2003). For instance, the genetic variation of a plant species in association with insect pests or insect pollinators is investigated to understand better community dynamics to conserve the insect species (Neuhauser et al. 2003; Wimp et al. 2005). In Vellend (2005) the simulation results show that locality size and immigration rate influence both genetic and species diversity. Furthermore, moderate environmental heterogeneity can lead to a positive genetic-species diversity correlation (Vellend 2005; Vellend \& Geber 2005). Empirical studies using experimental designs test the correlation of genetic and species diversity interacting with ecological processes (Hughes et al. 2008), e.g. invasiveness (Vellend et al. 2009) and soil resources (Avolio \& Smith 2013).

Studies investigating genetic diversity of plants and plant species diversity showed that both diversities are influenced by ecological processes but are not necessarily correlated. Empirical studies at non-controlled conditions found mostly no significant association between genetic and species diversity (Wehenkel et al. 2009; Taberlet et al. 2012 ). The mean genetic diversity of several tree species in Germany did not correlate with the degree of disturbance of the habitat (Wehenkel et al. 2006). In contrast, results by He et al. (2008) suggested the positive correlation between genetic and species diversity, showing one diversity level could be a predictor for the other. 
INTRODUCTION

Recently, Hand et al. (2015) introduced landscape community genomics, as a possibility to combine abiotic and biotic factors influencing evolutionary processes, based on genome wide neutral and adaptive variation analysis, which is able to provide more information with one molecular method.

In general, the mentioned research areas, correlating abiotic, biotic and ecological with the genetic diversity of a species never include the genetic diversity of several species as a community in one ecosystem and the change due to different land-use systems. Kahilainen and colleagues (2014) recommend the cautious interpretation of species and genetic diversity correlation for conservation management, due to the high variation in the results, depending on the different investigated ecosystems. However, investigations regarding changes in the genetic structure of tropical taxa due to fragmentation and habitat loss mainly rely on the information of single species compared in natural and unnatural habitats (Nason \& Hamrick 1997; Torre et al. 2008). Kashimshetty et al. (2015) simulated different outcomes in population structure of different species after fragmentation events in tropical lowland rainforests. The results showed the high dependency on pollen dispersal, forest fragment size, logging frequency and life history of a species. Thus, a generalization about conserving genetic resources of a plant community based on one is not reliable. In regions of highly fragmented landscapes like the tropics, the genetic information about the whole plant community can improve the sustainable management of remaining natural vegetation to conserve the ecosystem services of a forest.

\subsection{LAND-USE CHANGE IN INDONESIA}

Two biodiversity hotspots in the tropics belong to Indonesia: Sunda-land (Sumatra, Java and Kalimantan) and Wallacea (remaining Indonesian islands) (Myers et al. 2000). In Indonesia the area of forest cover loss nearly quadrupled in 11 years (Figure 1, Margono et al. 2014). Hansen et al. (2013) estimated the globally highest forest loss with 2 Mha forest loss in the years 2011 to 2012 for Indonesia. The different results in these two studies are caused by the different methodology and the definition for forest (percentage of canopy cover). Furthermore, the naturalness of remaining areas of natural vegetation (canopy cover of the forest) differs within and among the Indonesian islands, e.g. 0-5 \% in Java, 5-10\% in Sumatra and 10-100 \% in Kalimantan (Sloan et al. 2014). 77.4 Mha (34.6\%) of the remaining forest in Kalimantan, Sumatra, Sulawesi, Moluccas and Papua are located within areas of industrial use concessions 
(Abood et al. 2015). Only $13 \%$ of protected areas in Indonesia are covered with forest (FAO 2014). Brun et al. (2015) showed that for protected areas in Indonesia, managed for biodiversity conservation, from 2000 onwards the pressure of logging concession are increasing and effectiveness can only be guaranteed with more strict categories than currently applied.

Since the 1970's the two crop species oil palm (Elaeis guineensis Jacq.) and rubber (Hevea brasiliensis (Willd. ex A. Juss.) Müll. Arg.) evolved into the major crop species planted in monoculture (both species) and agroforest (rubber) in Sumatra (Noordwijk et al. 2008; Villamor et al. 2013).

E. guineensis is currently considered as the major threat to biodiversity in Southeast Asia (Wilcove \& Koh 2010). E. guineensis cultivation is intensively managed due to the absence of other woody species in the monoculture and, the frequent use of fertilizer and herbicides (Agamuthu \& Broughton 1985; Villamor et al. 2013). E. guineensis was introduced in Indonesia in the beginning of the $20^{\text {th }}$ century. In the last 25 years the oil palm production area in Indonesia increased from 673000 to 7 Mha and since 2008 the country is the largest producer of palm oil worldwide (FAO 2014). Furthermore, Indonesia intends to double the production of palm oil from 2010 to 2020 (Koh \& Ghazoul 2010). Albeit, Indonesia already has currently the globally highest $\mathrm{CO}_{2}$ eq emissions from the agricultural sector (FAO 2014).

$H$. brasiliensis is another important non-native crop tree species in Indonesia, where it was introduced around 1900. Rubber was primarily produced in an agroforestry system, called 'jungle rubber', which is an integrated complex agricultural system within secondary forest vegetation and can be seen as more sustainable rubber production (Michon \& Foresta 1995; Gouyon et al. 1993). Due to increasing human population density shifting cultivation was replaced by jungle rubber. However, after planting rubber seedlings at already slashed and burned sites, the vegetation could grow again to an intermediate and sustainable land-use system (Gouyon et al. 1993; Michon \& de Foresta 1995). In jungle rubber, the rubber production is lower than in a monoculture, which forces farmers to reduce the density of nonrubber species and disqualifies the system as a biodiversity refuge (Lawrence 1996).

Between 1993-2005 rubber production was shifted from agroforest to monoculture (Villamor et al. 2013). The rubber producing area increased from 1.9 Mha in 1990 to 3.6 Mha in 2013 (FAO 2014). Rubber cultivated in monoculture is more an intensive land-use system than 
INTRODUCTION

jungle rubber, but less than oil palm due to the occurrence of shrub species in the plantations (Villamor et al. 2013).

Consequences of land-use change are complex (Lambin et al. 2003). Land-use change and the agricultural intensification in Indonesia have a global effect on biodiversity and human welfare with an extent which can only be estimated (Foley et al. 2005; Newbold et al. 2015). Laurance et al. (2014) anticipate the high pressure for tropical ecosystems due to the high pace and magnitude of expansion of agriculture with severe impacts for environment and human welfare in the future. Local land-use change consequences are habitat loss and fragmentation and result in the decline of species diversity and change of plant species composition (Laumonier 1997; Turner 1999; Koh \& Wilcove 2008; Laumonier et al. 2010). Environmental change of natural habitats increases the proportion of invasive species. Fragmentation and degradation of habitats leads to mosaic landscapes with habitats of changing suitability, which differs for each taxa (Koh \& Ghazoul 2010). Within the remnant forest patches this can lead to species isolation and increased edge effects (Murcia 1995; Ewers et al. 2007). Pollination networks, important for gene flow in plants, are altered by the habitat disturbance and the connectivity among patches (Hadley \& Betts 2012; Breed et al. 2015). The habitat loss leads to the reduction of population size of a species, which can result into local extinction due to reduced fitness caused by inbreeding, genetic drift and isolation (Lande 1988; Oostermeijer et al. 2003). Environmental change of natural ecosystems increases the proportion of invasive species (Didham et al. 2007). Land-use change in Indonesia causes the alteration of ecosystem functioning in plants and other organisms of various trophic levels (Steffan-Dewenter et al. 2007; Laliberté et al. 2010; Aerts \& Honnay 2011; Laliberté \& Tylianakis 2012; Barnes et al. 2014), alteration of soil (Hassler et al. 2015; Allen et al. 2015; Guillaume et al. 2015) and climatic (Sala et al. 2000) conditions. With high agricultural intensity, the increased use of fertilizer, herbicides and insecticides (Tilman et al. 2002) leads to the degradation of ecosystems and diversity (Fitzherbert et al. 2008). Possible synergistic effects of land-use change drivers complicate the identification of indicators leading to vulnerability and extinction but also the resilience of tropical species (Stork et al. 2009) 


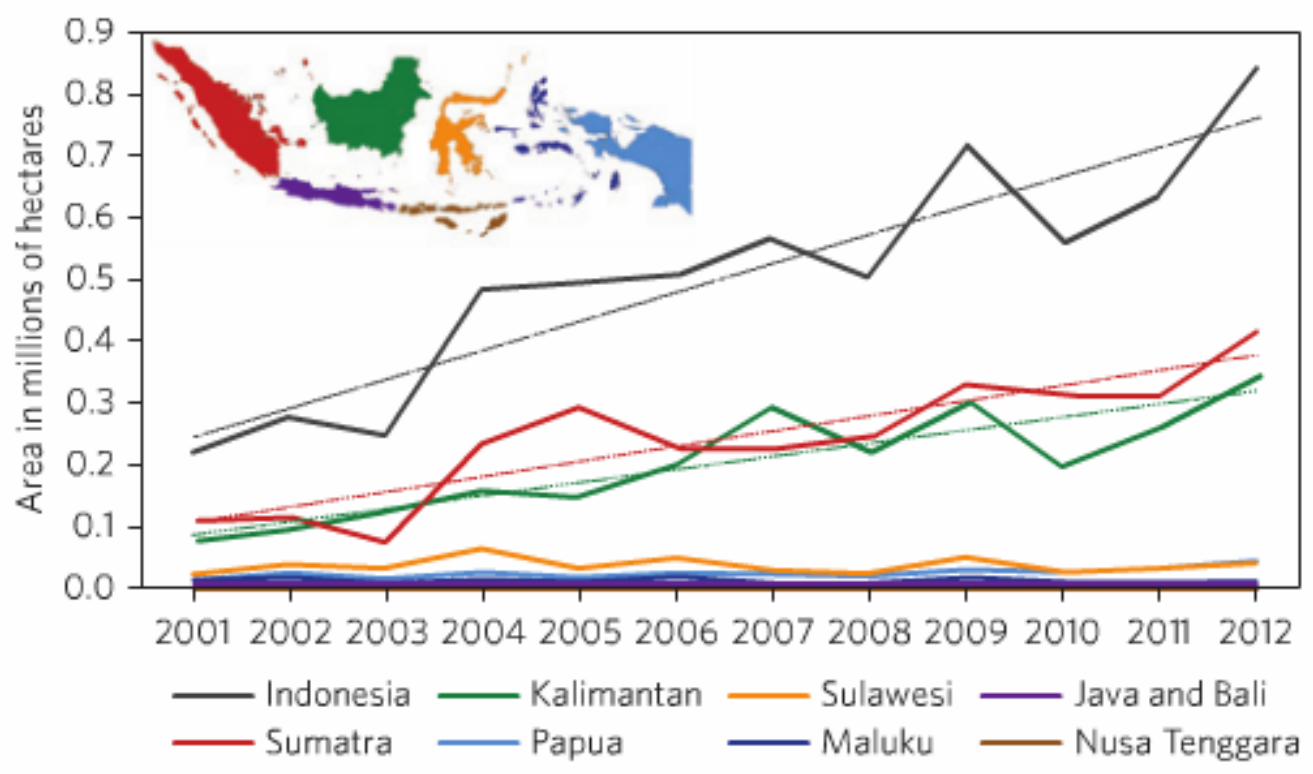

Figure 1: Annual forest cover loss in Indonesia from the year 2000 to 2012. (Source: Margono et al. 2014)

\subsection{PROJECT FRAMEWORK}

This project is part of the interdisciplinary collaboration project 'EFForTS' ("Ecological and Socioeconomic Functions of Tropical Lowland Rainforest Transformation Systems", CRC 990) in Sumatra Indonesia (Drescher et al. 2016). Sumatra experienced the highest deforestation rate of Indonesian islands and has two areas of extreme deforestation, the provinces Riau and Jambi (Miettinen et al. 2011). The legally protected forest accounts for only $29 \%$ of the total remaining forest in Sumatra and the remaining patches with high biodiversity value are endangered due to the agricultural expansion and illegal logging (Laumonier et al. 2010). The natural vegetation in Jambi province, tropical lowland Dipterocarpaceae-rainforest $(<150 \mathrm{~m}$ a. s. I.) (Laumonier 1997; Laumonier et al. 2010) is degraded and critically endangered (Figure 2). In Jambi province forest cover of $75 \%$ in 1973 decreased to $30 \%$ in 2005, the percentage of agroforestry with rubber was at $11 \%$, monocultures increased from 3-40\% (Ekadinata \& Vincent 2011). Thus, conservation management to protect the natural lowland rainforest are not adequate and need to be improved in Sumatra (Laumonier et al. 2010). The aim of the long-term research project 'EFForTS' is to investigate the consequences of land-use change and intensification on biodiversity, environmental processes and human welfare in Jambi Province. For that three land-use system jungle rubber, oil palm plantation and rubber plantation are compared with old growth forest in two regions in Jambi province (Figure 3). 
As described above, each system differs in the agricultural intensity: jungle rubber < rubber plantation < oil palm plantation.

The present study is investigating the change of genetic diversity in dominant plant species due to land-use change. Genetic diversity is a fundamental aspect of biodiversity and can help to understand processes influencing trophic and species interactions within the ecosystem dynamics (Whitham et al. 2006) and provide resources for adaptation to environmental changes (Whitham et al. 2008). Genetic diversity of dominant or keystone species have an influence not only at the population level, but also at the ecosystem level (Whitham et al. 2003; Hughes et al. 2008; Crawford \& Rudgers 2013). Lowe et al. (2015) pointed out three major aspects one has to consider investigating the genetic consequences of forest fragmentation 1. only individuals younger than the disturbance event will give sufficient information 2. the response is depending reproduction system and life history trait of each species and 3. disturbance type, natural vegetation and scale are influencing the response. All three points were considered in either sampling or analysis method. 1. by determining dominant species independently on each plot, due to the natural heterogeneity of each plot the different age structures in trees were taken into account. 2. life form and available history traits were considered in the calculations. 3. jungle rubber, rubber plantation and oil palm plantation present three levels of agricultural intensity, all transformed from natural lowland rainforest.

In the present study, AFLP markers (Amplified Fragment Length Polymorphism) were used which are commonly used for genetic diversity investigations (Vos et al. 1995; Meudt 2007). The combination of PCR technology and restriction enzymes produces from the total genome DNA, different fragments, which number and size depend on the individual species. Prior knowledge about the species DNA sequence is not necessary. Fragments of the same size can origin in different regions of the DNA, thus, this method is called anonymous. This is a major advantage of the method especially for polyploid species (Després et al. 2003; Goldman et al. 2004) and tropical species, for which taxonomic identification are often ambiguous (Mace et al. 1999; Kremer et al. 2005). Furthermore, considering the expected high number of species in this study, the advantage of the anonymous marker AFLP was preferred to the more polymorphic and codominant marker Simple Sequence Repeat (SSR). A disadvantage of the AFLP method is the dominance of the fragments, homozygote and heterozygote individuals cannot be distinguished. Analyses are based on presence and absence of a fragment only 
(Nybom 2004; Bonin et al. 2007). Albeit, Mariette et al. (2002) simulated that the whole genome approach and the high number of loci, can compensate the low information of each loci. Further, Whitlock (2014) reviewed that correlations between ecological responses and genetic diversity are depending on the marker type (neutral or adaptive). Using the whole genome marker AFLP (Amplified Fragment Length Polymorphism) in this study avoid the conflict between the different assumptions of processes underlying neutral and adaptive marker investigations.

Species diversity and genetic diversity are expected to respond to parallel land-use change processes (Vellend \& Geber 2005). A positive correlation between genetic and species diversity might not be always the case, which can lead to contradictory conservation plans for the two levels of biodiversity (Kahilainen et al. 2014). The genetic diversity was correlated with the diversity of other species (plants, mycorrhiza and prokaryotes) to obtain a better understanding about responses and dynamics as a response to land-use change.

On one side, as species in more heterogeneous environments, like a tropical rainforest, have higher genetic diversity (Frankel 1995), it is expected, that woody species show higher genetic diversity than the non-woody species in converted habitats. On the other side, tree species, which are the dominant life form in tropical forests and have a large distribution range with a low density, are expected to be more affected by habitat fragmentation (Young et al. 1996; Jennings et al. 2001).

Genetic diversity of plants is not often included in conservation management plans, mainly due to the workload and financial limitations in biodiversity conservation research. Differences in gene flow characteristics among species cause the unreliability of conservational management suggestions for a plant community based on the genetic information of one or few species.

The combination of the anonymous AFLP marker and the applied sampling strategy in this study, provide a relatively cheap and very flexible approach of genetic diversity assessments of the dominant plant community. This study introduces a universal applicable method to estimate differences in genetic diversity and genetic differentiation between plant communities of different locations and land-use systems. These results can support the identification of habitats of high conservational value (HCV) and conservation management of threatened landscapes. 


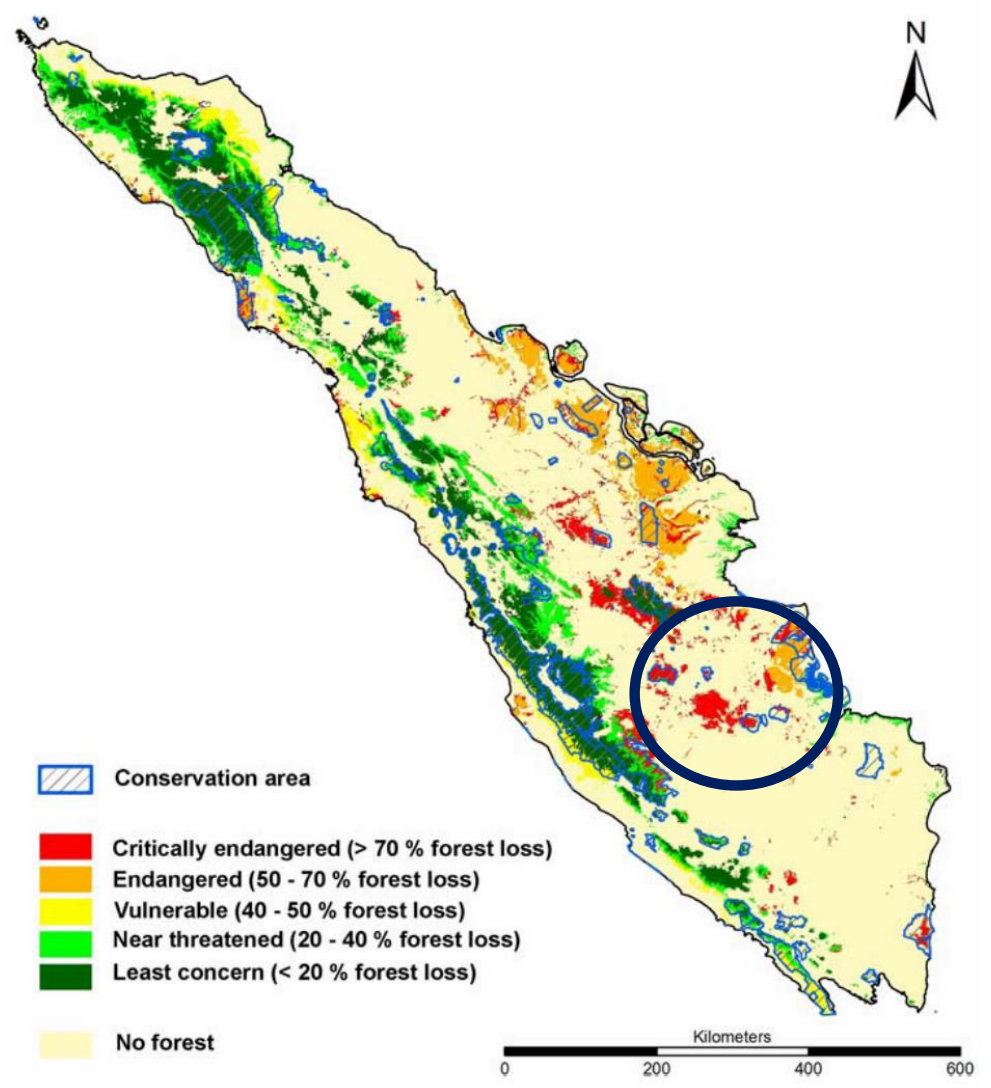

Figure 2: Forest loss in Sumatra between 1985 and 2007. Blue circle presents Jambi province. Red areas with more than $70 \%$, orange $50-70 \%$,yellow $40-50 \%$, light green $20-40 \%$ and dark green less than $20 \%$ forest loss, beige no forest. Source: Laumonier 2010 (Fig.5, modified).
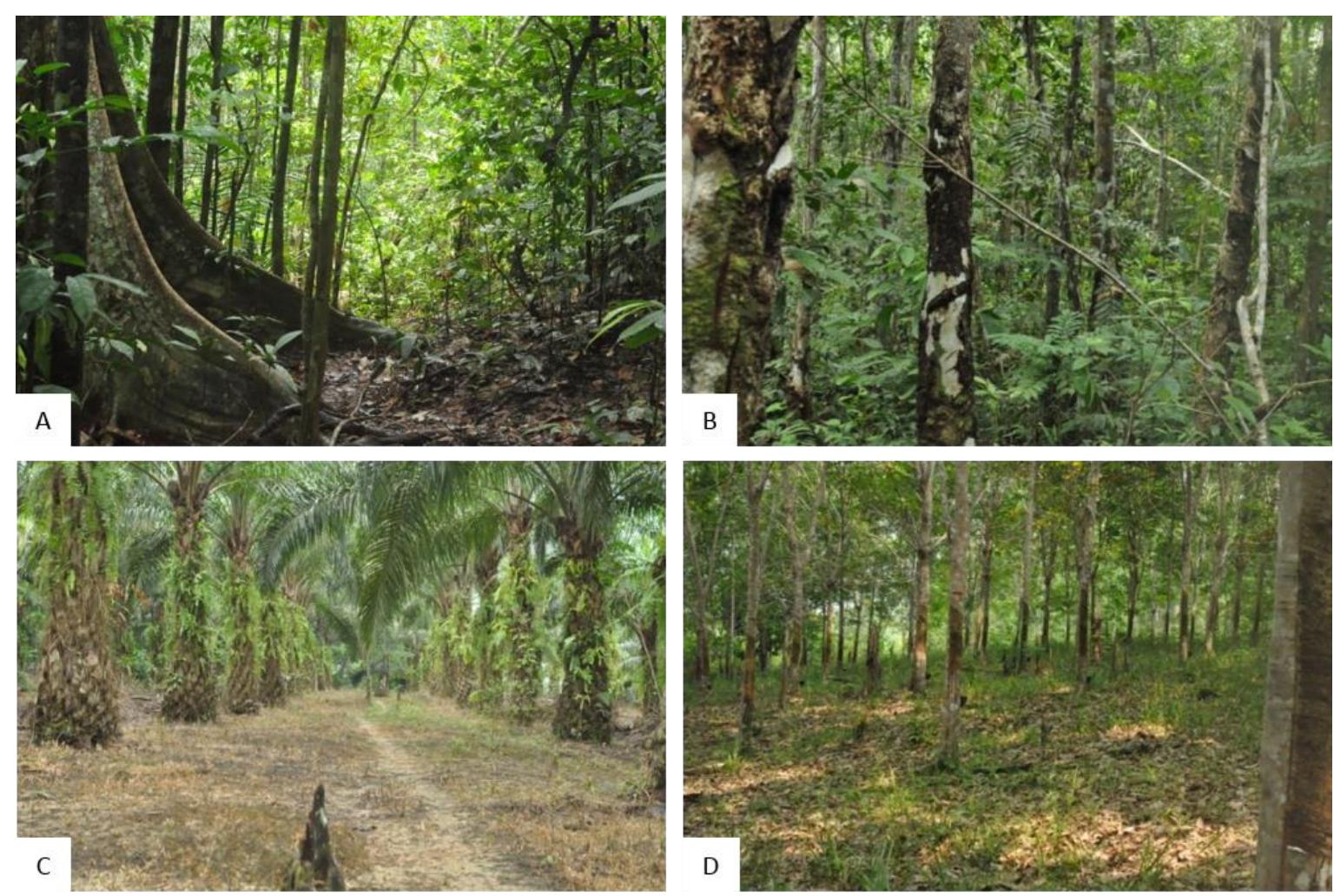

Figure 3: The four investigated land-use systems: old growth forest (A), jungle rubber (B), oil palm plantation (C), rubber plantation (D) 


\subsection{OBJECTIVES AND HYPOTHESIS}

The objectives of the present study are:

- to investigate the genetic diversity of ten dominant plant species in each plot and landuse system

- to assess genetic differentiation within and among the land-use systems

- to assess the genetic diversity differences among different life forms

- to find correlation between genetic diversity and other diversity parameter

- to compare fine-scale genetic structure of frequent species with a community-based assessment

The following hypotheses were tested:

1. The spectrum of plant species with the highest biomass ("dominant plant species") does not overlap between different land-use systems; different plant species dominate the four land-use systems and differs partially among plots, both within and between the two regions.

2. The overall intraspecific diversities of dominant plant species decline from old growth tropical lowland rainforest to rubber and oil palm plantations and differ significantly between the plots within and among regions.

3. The genetic differentiation of the dominant plant community varies with life form and species-specific life history traits. 


\section{MATERIAL AND Methods}

\subsection{Plant MATERIAL}

\subsubsection{STUDY SITES AND PLANT COLLECTION}

As part of the EFForTS-project four land-use systems in Jambi Province, Sumatra, were investigated: old-growth forest, jungle rubber, rubber plantation and oil palm plantation. Each of the four investigated land-use systems had four replicates in two regions, which resulted in a total number of 32 sampling plots. One region was named after the national park "Bukit Dua Belas" and the other one after the forest restoration concession "Harapan". The minimum distance between the two regions was approximately $55 \mathrm{~km}$. Further details can be found in the EFForTS introduction article Drescher et al. (2016) and each plot location (GPS, Global Positioning System) in Appendix 3.

In each of these $50 \times 50 \mathrm{~m}$ plots, ten vascular plant species, dominant by biomass, were selected using the angle count technique "Bitterlich-Method" (Kramer \& Akca 2008). The "Bitterlich-Method" is usually used to estimate the basal area per hectare of a forest stand based on the tree trunk diameter, without a defined sample area (Kramer \& Akca 2008). For this, every tree trunk diameter, in a $360^{\circ}$ radius, is measured at breast height as an angle from a given position. The technique is applied at several positions within the tree-dominated plots, and all trees above a defined diameter value are counted. The total biomass per hectare can then be derived from that count data (Kramer \& Akca 2008).

However, in this project the "Bitterlich-Method" was used to determine the ten dominant species in forest and jungle rubber by measuring the trunk diameter at 16 positions in each plot (Figure 4). Overall, the 48 largest species (three per position) were determined. In the following order, nine individuals were sought: If e.g. for the largest species at position one, nine other individuals could not be found, individuals of the largest species from position 11 were sought. All species with the highest biomass of all 16 positions were checked. If not enough individuals could be found the species with the second highest biomass were checked at position one. This continued to the third largest species at each position until ten species with each ten individuals were found. In the plantation systems, the same 16 positions (Figure 4) were used to determine the dominant species by identifying the species with the shortest distance to each position. If for the closest dominant species nine other individuals could not 
be found the same, procedure as in the tree-dominated systems was carried out. Woody species were in general preferred but were seldom dominant in the plantations. Uniform and objective criteria were used to identify sampled species and the individual species composition in each plot.

From each selected species, leaf material of ten plants was sampled, dried in sealed plastic bags with silica gel and shipped to the German laboratory of the Section Forest Genetics and Forest Tree Breeding, Göttingen University. To decrease the risk of clone sampling, the collected individuals of the plantation species had a minimum distance of $10 \mathrm{~m}$ to each other. Because of the high number of individuals of the two crop species Hevea brasiliensis and Elaeis guineensis samples were chosen randomly in every plantation and jungle rubber plot. If necessary, individuals were also sampled in the surroundings of the tree-dominated plots (up to $300 \mathrm{~m}$ distance). For species identification from all individuals besides the crop species, herbarium specimen were collected, dried and stored at Jambi University. Species identification was carried out with the support of CRC990- subproject B06, Kebun Raya Bogor and the herbarium staff of the Restoration concession "Harapan". 


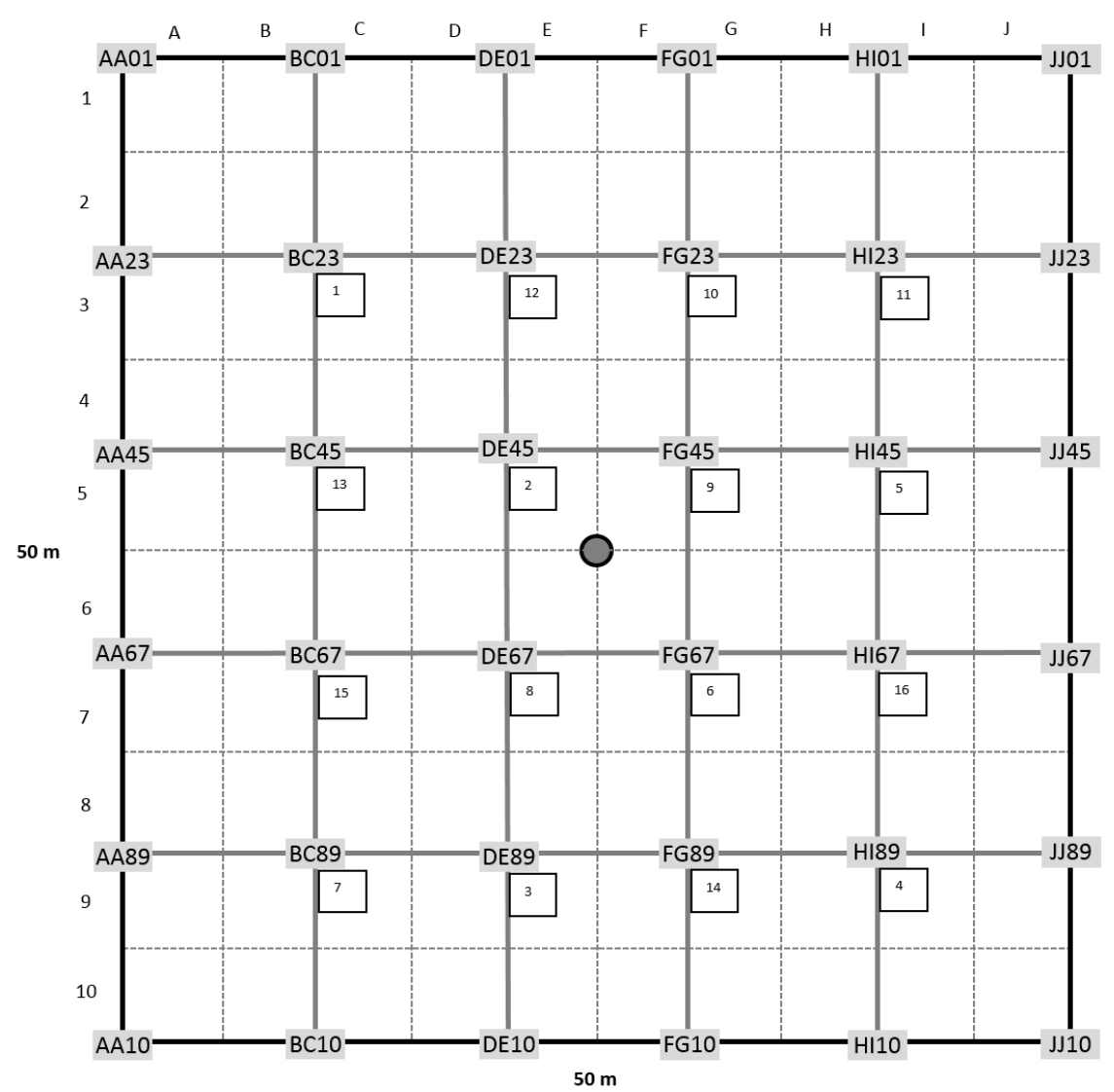

Figure 4: Design (CRC 990, EFForTS, modified) for all 32 plots. Letter-number combination presents a marking stick for orientation. Framed numbers present the 16 positions, where the dominant plant determinations were carried out.

\subsubsection{DNA- EXTRACTION AND AFLP ANALYSIS}

Total DNA was extracted from approximately $1 \mathrm{~cm}^{2}$ dried leaf material using the DNeasy 96 Plant Kit (Qiagen, Hilden, Germany) following the manufactory's instructions. The amount and the quality of the DNA were analyzed by $0.8 \%$ agarose gel electrophoresis with $1 \mathrm{x}$ TAE as running buffer (Sambrook et al 1989). DNA was stained with Roti ${ }^{\circledR}$ Safe and visualized by UV illumination. The DNA was stored at $-20^{\circ} \mathrm{C}$.

The AFLP analysis was performed according to the protocol of Vos et. al. (1995) with minor modifications, all samples were analyzed with the same primer/enzyme combination. The digestion/ligation was carried out simultaneously with the EcoRI/Msel primer combination and incubated overnight. The Restriction-Ligation mixture contained $4 \mu$ I DNA (appr. $20 \mathrm{ng}$ ), $1.2 \mu \mathrm{l} 10 \times \mathrm{T}_{4}$ Ligase Buffer (400 mM Tris- $\mathrm{HCl}, 100$ mM MgCl 2,100 mM DTT, 5mM ATP, pH 7.8; Thermo Science, Lithuania), $49.99 \mathrm{mM} \mathrm{NaCl}, 2.5 \mathrm{mM}$ Msel and $2.5 \mathrm{mM}$ EcoRI restriction enzymes (Thermo Science, Lithuania), $0.6 \mathrm{mg} / \mu \mathrm{l}$ BSA (Thermo Science, Lithuania), 4 Units 
EcoRI and 0.8 Units of Msel adapter (Sigma Aldrich, United States), 0.3 Units $\mathrm{T}_{4}$ Ligase (Thermo Science, Lithuania) and $3.02 \mu \mathrm{l} \mathrm{H}_{2} \mathrm{O}$.

The in water diluted Restriction-Ligation product $(4 \mu \mathrm{l})$ was mixed with $1.5 \mu \mathrm{l} 10 \mathrm{x}$ buffer

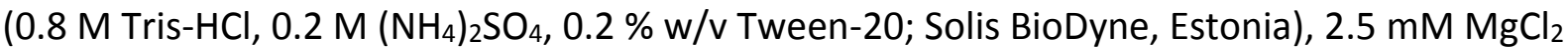
(Sigma Aldrich, United States), 0.16 mM dNTP (Thermo Science, Lithuania), 0.08 mM M03 and 0.06 mM E01 primer (Thermo Science, Lithuania), 1 Unit Taq Polymerase (Qiagen, Hilden, Germany) and $0.65 \mu \mathrm{l} \mathrm{H}_{2} \mathrm{O}$, for the pre-selective PCR reaction. The following second PCR reaction contained $2 \mu \mathrm{l}$ of the in water diluted pre-selective PCR product, $1.5 \mu \mathrm{l} 10 \mathrm{x}$ buffer (0.8 M Tris- $\mathrm{HCl}, 0.2 \mathrm{M}\left(\mathrm{NH}_{4}\right)_{2} \mathrm{SO}_{4}, 0.2 \% \mathrm{w} / \mathrm{v}$ Tween-20; Solis BioDyne, Estonia), $2.5 \mathrm{mM} \mathrm{MgCl} 2$ (Sigma Aldrich, United States), 0.16 mM dNTP (Thermo Science, Lithuania), 0.08 mM E35 and 0.2 mM M63 primer (Thermo Science, Lithuania), 1 Unit Taq Polymerase (Qiagen, Hilden, Germany) and $0.81 \mu \mathrm{l} \mathrm{H}_{2} \mathrm{O}$.

In the pre-selective PCR the primer E01/M03 (Keygene N.V. nomenclature) combination was used, with one selective nucleotide $A / G$, and in the selective PCR the primer combination E35/M63, with three selective nucleotides ACA/GAA. Pre-selective and selective PCR-program protocols were carried out according to the protocol of Kuchma (2010). The pre-selective PCR reaction started with $72{ }^{\circ} \mathrm{C}$ for $2 \mathrm{~min}$, followed by $94{ }^{\circ} \mathrm{C}$ for $10 \mathrm{sec}, 56^{\circ} \mathrm{C}$ for $30 \mathrm{sec}$ and $72{ }^{\circ} \mathrm{C}$ for $2 \mathrm{~min}(20 \mathrm{cycles})$, and the final extension step at $60{ }^{\circ} \mathrm{C}$ for $30 \mathrm{~min}$. The selective PCR reaction started with $94{ }^{\circ} \mathrm{C}$ for $2 \mathrm{~min}$, the cycles consist of $94{ }^{\circ} \mathrm{C}$ for $10 \mathrm{sec}$, annealing temperature for $30 \mathrm{sec}$ and $2 \mathrm{~min}$ at $72{ }^{\circ} \mathrm{C}$. The annealing temperature started at $65^{\circ} \mathrm{C}$ in the first cycle and declined subsequently for the next 9 cycles by $1{ }^{\circ} \mathrm{C}$. Followed by 23 cycles with an annealing temperature at $56^{\circ} \mathrm{C}$. The duration of the final extension step was $30 \mathrm{~min}$ at $60^{\circ} \mathrm{C}$.

The restriction and selective PCR products were checked for quality (presence of DNA and approximately correct fragment size) with 16 randomly chosen samples per plate using agarose gel electrophoresis (see above). For fragment detection, the selective amplification reactions contained a fluorescent dye 6-FAM labelled E35 primer. The PCR reaction of all samples was carried out with the PTC 200, Pelmer thermal cycler (MJ Research). The waterdiluted selective PCR products were separated on the ABI genetic analyzer (3130, ABI PRISM) and sized using standard GENSCAN 500 ROX. Fragment scoring within the fragment size range of 75-400 bp was carried out with the program GeneMapper 4.1. (Applied Biosystems). 
The species specificity of reproducibility of AFLP profiles was assessed with two samples of each species by duplicate independent DNA extractions and PCR reactions. Only unambiguous and reproducible fragments were used for further analysis. If the maximum number of samples of a species were ten, all reaction steps were repeated from digestion/ligation step onwards, fragments were only considered if occurring in both repetitions.

\subsection{DATA ANALYSIS}

Land-use intensity, the individual life form and spatial range of a species might have an influence on genetic diversity patterns of a plant species. The following analyses (Figure 5) were carried out to assess genetic plant diversity in the different land-use systems with several possible explanatory factors. The different land-use intensities were represented by the four land-use systems forest, jungle rubber, oil palm and rubber plantation, the different life forms by the categories crop species, tree, grass, herb and fern. The spatial aspect was considered by calculating genetic diversity and differentiation of the plant populations at three different spatial scales: within plot ( $\alpha$-level), within land-use system ( $\beta$-level) and within region ( $\gamma$-level). The individual AFLP presence-absence (1-0) matrices of the 104 successfully genotyped species were the data for all analyses.

Two approaches were carried out to assess the genetic diversity structure of the dominant species depending on different land-use systems: 1. a community analysis, based on all analysed species within a plot and 2. a species analysis were based on the life form and history traits of each species.

Two different indices were used for the analyses: the differentiation index Morisita-Horn (C) (Horn 1966) and the entropy index Shannon Index (I, Equation 2) (Shannon \& Weaver 1949; Lewontin 1972). For the following reasons the two indices were used and compared. The Morisita-Horn index (Equation 1) considers the number of shared fragments in ratio to the overall number of fragments which occur in the two compared samples and is independent of sample size, i.e. here number of fragments (Wolda 1981). Furthermore, this index is similar to the genetic dissimilarity index Dice/ Nei-Li (Equation 3) (Nei \& Li 1979), which considers the number of shared fragments relative to the overall number of fragments in the two compared individuals, but gives more weight to the presence of fragments than Morisita-Horn (Bonin et al. 2007). The Morisita-Horn index ranges from 0 (identical) to 1 (no similarity). Morisita-Horn 
dissimilarity calculations were carried out with the function "vegdist" in the R-package "vegan" (Oksanen et al. 2015).

The Shannon Index is depending on the number of samples (Goodman 1975) and number of loci within a species, which was a disadvantage when calculating genetic diversity at three different scales, hence with increasing sample size. Furthermore, the number of loci differed among the species. The Shannon Index is an infinitive index with 0 when no difference is detectable.

The Shannon Information Index (I) was developed by Shannon \& Weaver (1949) and modified by Lewontin (1972) for genetic data. The Shannon Information Index (I) for all analyses was calculated with the program PopGene 1.32 (Yeh et al 1997).

Equation 1: Morisita-Horn dissimilarity for binary data. A number of fragments in sample one, B number of fragment in sample two. $J$ is the number of shared fragments.

Morisita-Horn dissimilarity Index for binary data: $\quad C=(A+B-2 J) /(A+B)$

Equation 2: Shannon Information index. $\mathrm{p}_{\mathrm{i}}$ is the frequency of a fragment present in one individual

Shannon Information Index:

$I=-\sum p_{i} \log p_{i}$

Equation 3: Dice/ Nei-Li for binary data. A number of fragments in sample 1, B number of fragment in sample 2. J number of shared fragments.

Dice/ Nei-Li:

$J /[J+((A-J)-(B-J)) / 2]$ 


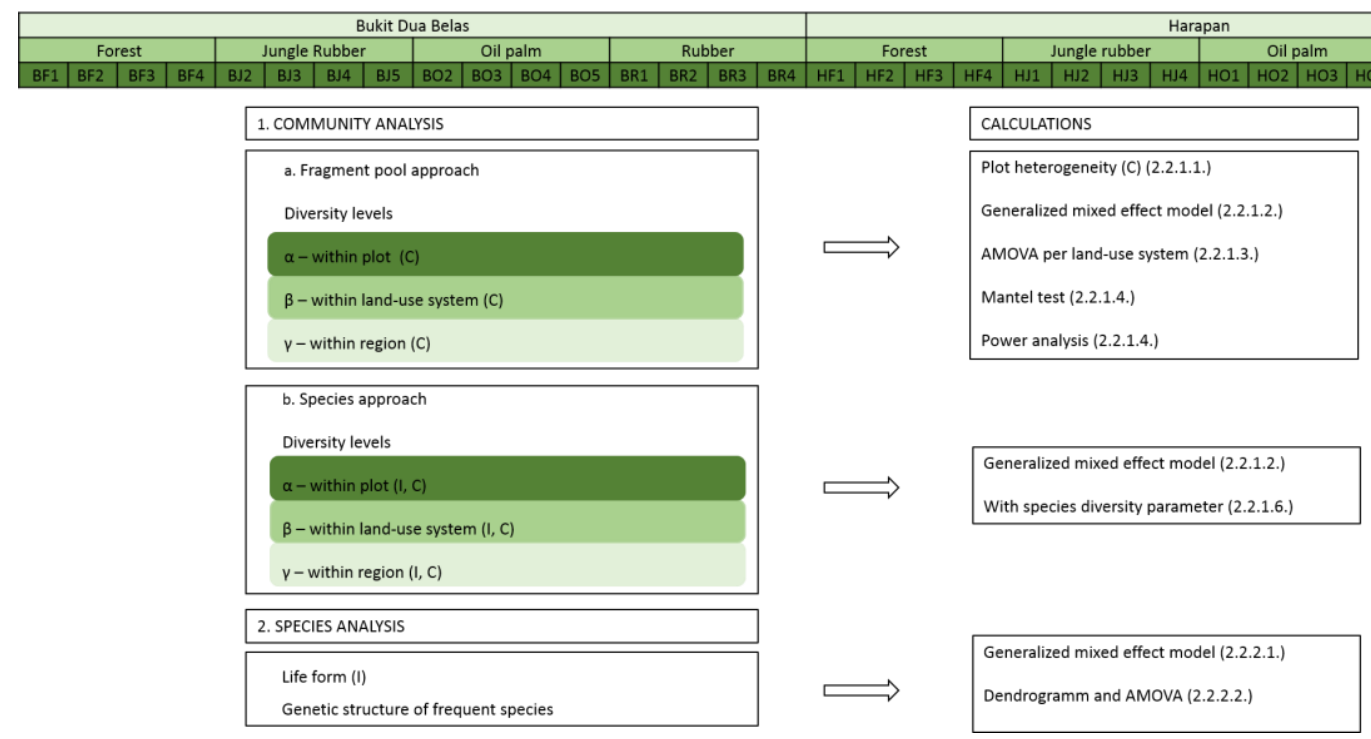

Figure 5: Plot names with the respective diversity level $(\alpha-, \beta-, \gamma$-diversity, indicated by colours) in the upper table: B: Bukit Dua Belas, H: Harapan, F: Forest, J: Jungle Rubber, O: Oil Palm, R: Rubber. Overview of all calculations for the (1.) community and (2.) species analysis. (a.) Fragment pool and (b.) species approach calculations were carried out to assess diversity at the three diversity levels. A mixed fixed effect model (GLMM) was fitted for Morisita-Horn distances (C) and Shannon Index (I) results. AMOVA calculations per land-use system with Morisita-Horn index (C) using the fragment pool approach. For the species analyses, calculations the Shannon Index (I) per life form was used, and AMOVA and Dendrogramm analysis were carried out. The respective chapters are in brackets.

\subsubsection{COMMUNITY ANALYSIS}

In the community analyses, the particular characteristics of each species were not considered. The plant communities in each land-use system were investigated for significant differences in mean genetic diversity and differentiation and genetic variation. Furthermore, genetic diversity was correlated to parameter such as other species diversity in the four land-use systems.

For the community analysis, two main approaches were carried out: a. fragment pool approach and b. species approach. The fragment pool approach represents the opportunity to compare genetic differentiation of individuals among plots and land-use systems based on raw data, without comparing fragments of different species. The fragment pool approach considers every fragment as a unit for calculating diversity. The total number of fragments occurring in all plots and species (9411 fragments for all 104 species) presents the total number of fragments, which potentially can occur in a plot. Like in phylogenetic analyses (Robinson \& Harris 1999) fragments are assumed to be independent units. 
Figure 6 illustrates an example of the fragment pool approach with seven species and four plots. Species one, three and seven occurs in forest plot 1, species seven is shared with jungle rubber plot 1. Oil palm plot 3 and rubber plot 6 share species four and six, species five only occurs in rubber plot 6 .

The individual AFLP 1-0 matrix consist of the specific amplified fragment, followed by a conversion into presence " 1 " and absence " 0 " of the fragment with a particular size. The 100 individuals per plot were combined into ten fragment pools per plot (Figure 6). Every plot was presented by ten rows with each successively ten individuals with their individual 1-0 order. The first row contained successively the first individuals, each with the respective 1-0 AFLP matrix, of every species collected in this plot. Each fragment was placed in one column. The second row contained all second individuals, each with the respective 1-0 AFLP matrix, of every species collected in this plot. Hence, the 1-0 AFLP fingerprint of the second individual of the same species were in the same columns as the first individual. This was continued for all ten individuals and ten species for all plots. In the following these rows are called fragment pools. If the species occurred again in a different plot the 1-0 matrix for these individuals were accordingly placed into the same columns. This concept was followed for all 104 species and 32 plots.

The pairwise Morisita-Horn dissimilarity based on the fragment pool approach makes it possible to compare plots and land-use systems genetically while simultaneously considering differences in species composition. To compare dissimilarities among plots and land-use systems only due to the genetic structure of the species, the species effect was accounted for by the following procedure. A second input file was built were all individuals were considered to be clones, i.e. all fragments of the occurring species in each plot were present (Figure 7). Based on these clone fragment pools the Morisita-Horn pairwise distance matrix was calculated. Herewith, the resulting distances between the clone fragment pools are only due to the species differences and the genetic diversity is zero.

The deduction result between the two pairwise distance matrices, fragment pool matrix and the clone fragment pool matrix, corresponds to the pairwise genetic fragment pool distance matrix. This pairwise genetic fragment distance matrix was used for all following fragment pool calculations, except the plot heterogeneity calculation. Differences among individuals within plots, within land-use systems and within regions are determined by the number of 
fragments shared by two fragment pools (for calculation details for each level see section

2.2.1.2.).

For the species approach, the two indices Shannon Index and Morisita-Horn were calculated for each species at the three levels within plot, within land-use system and within region, respectively (for calculation details for each level see section 2.2.1.2.).

\begin{tabular}{|c|c|c|c|c|c|c|c|}
\hline $\begin{array}{l}\text { Fragment pool } \\
\text { Forest plot } 1\end{array}$ & $\begin{array}{l}\text { Species } 1 \\
|10111100|\end{array}$ & $\begin{array}{l}\text { Species } 2 \\
|0000000000|\end{array}$ & $\begin{array}{l}\text { Species } 3 \\
|10111111100|\end{array}$ & $\begin{array}{l}\text { Species } 4 \\
\text { |0000000000| }\end{array}$ & $\begin{array}{l}\text { Species } 5 \\
100000\end{array}$ & $\begin{array}{l}\text { Species } 6 \\
\mid 0000000000000\end{array}$ & $\begin{array}{l}\text { Species } 7 \\
|101111100|\end{array}$ \\
\hline Forest plot 1 & |111111100| & |0000000000| & |10111110110| & |0000000000| & |00000| & |0000000000000| & | 101001100| \\
\hline Forest plot 1 & |10111111| & $|0000000000|$ & $10001011100 \mid$ & $|0000000000|$ & | $00000 \mid$ & |0000000000000| & | 101011100| \\
\hline Forest plot 1 & |10111110| & $|0000000000|$ & | 10111101100| & |0000000000| & | $00000 \mid$ & |00000000000000| & | 101110100| \\
\hline Forest plot 1 & |10111000| & |0000000000| & 10110000111| & $0000000000 \mid$ & |00000| & |00000000000000| & | \\
\hline Forest plot 1 & $.0101100 \mid$ & |0000000000| & $.0111101111 \mid$ & 0000000000| & |00000| & |0000000000000| & | 101111010| \\
\hline Forest plot 1 & |10100100| & |0000000000| & |11000111100| & $|0000000000|$ & |00000| & |0000000000000| & | 101111011| \\
\hline Forest plot 1 & |111111101| & |0000000000| & |10101000100| & $|0000000000|$ & |00000| & |0000000000000| & |101111111| \\
\hline Forest plot 1 & |00011100| & |0000000000| & 10100111011| & 0000000000 & |00000| & |00000000000000| & |101001100| \\
\hline Forest plot 1 & 11111110| & |0000000000| & 10111110111| & 0000000000| & |00000| & |00000000000000| & |10111000 \\
\hline Jungle rubber plot 1 & $|00000000|$ & |1110111100| & |00000000000| & |0000000000| & |00000| & |00000000000000| & |111001100| \\
\hline Jungle rubber plot 1 & $|00000000|$ & |1011110011| & |00000000000| & |0000000000| & |00000| & |00000000000000| & |010111100| \\
\hline Jungle rubber plot 1 & |00000000| & |1011110111| & | $00000000000 \mid$ & 0000000000| & |00000| & 10000000000000 & 100111100| \\
\hline Jungle rubber plot 1 & |00000000| & $|0001101100|$ & | $00000000000 \mid$ & $|0000000000|$ & | $00000 \mid$ & |0000000000000| & | 101011100| \\
\hline ungle rubber plot 1 & |00000000| & $|1101111100|$ & 00000000000 & |0000000000| & |00000| & |00000000000000| & |101101100| \\
\hline Jungle rubber plot 1 & |00000000| & |1011001100| & |00000000000| & $|0000000000|$ & |00000| & |0000000000000| & | 101111000| \\
\hline Jungle rubber plot 1 & |00000000| & $|1011011010|$ & $00000000000 \mid$ & | $0000000000 \mid$ & |00000| & |00000000000000| & 101001110| \\
\hline Jungle rubber plot 1 & $|00000000|$ & |1010011100| & |00000000000| & |0000000000| & |00000| & |00000000000000| & | \\
\hline Jungle rubber plot 1 & $|00000000|$ & |1011110110| & D0000000000| & |0000000000| & |00000| & |00000000000000| & |101011100| \\
\hline Jungle rubber plot 1 & |00000000| & |1000110110| & $|00000000000|$ & 0000000000| & |00000| & |00000000000000| & | 101111001 | \\
\hline Oil palm plot 3 & |00000000| & |0000000000| & | $00000000000 \mid$ & |1111110110| & | $00000 \mid$ & |1011110001010| & | $000000000 \mid$ \\
\hline Oil palm plot 3 & |00000000| & 0000000000| & $00 \mid$ & & |00000| & 이 & 证 \\
\hline Oil palm plot 3 & | $00000000 \mid$ & |0000000000| & | $00000000000 \mid$ & |1010110110| & |00000| & |1011100111100| & | $000000000 \mid$ \\
\hline Oil palm plot 3 & $|00000000|$ & $|0000000000|$ & $|00000000000|$ & | 1011110111 & | $00000 \mid$ & | $1010101011100 \mid$ & | $000000000 \mid$ \\
\hline Oil palm plot 3 & $|00000000|$ & $|0000000000|$ & |00000000000| & | 1011110001| & |00000| & |1011110011111| & $|000000000|$ \\
\hline Oil palm plot 3 & 100000 & 10| & ol & $\mid 10$ & |00000| & |10 & 00000000| \\
\hline Oil palm plot 3 & $|00000000|$ & |0000000000| & $00000000000 \mid$ & 1011001011 | & |00000| & |1110001111001| & $|000000000|$ \\
\hline Oil palm plot 3 & $|00000000|$ & |0000000000| & |00000000000| & |1110011100| & |00000| & | & $|000000000|$ \\
\hline Oil palm plot 3 & $|00000000|$ & 10000000| & 10000| & 0 이 & |00000| & |10001 & $|000000000|$ \\
\hline Oil palm plot 3 & $|00000000|$ & $|0000000000|$ & 000 & 11001 & |00000| & $10 \mid$ & $|000000000|$ \\
\hline Rubber plot 6 & $|00000000|$ & $|0000000000|$ & | $00000000000 \mid$ & | 1011001001 | & |10100| & |0111110101010| & | $000000000 \mid$ \\
\hline Rubber plot 6 & $|00000000|$ & |0000000000| & |00000000000| & | $1001101100 \mid$ & |11100| & |0101010101010| & $|000000000|$ \\
\hline Rubber plot 6 & $|00000000|$ & ol & 100| & $11 \mid$ & |101 & |0011101010101| & $|000000000|$ \\
\hline Rubber plot 6 & 100000 & & & & |10101| & & 1000 \\
\hline Rubber plot 6 & $|00000000|$ & $|0000000000|$ & | $00000000000 \mid$ & | 10111111111 & $|11100|$ & |0010101010111| & | $000000000 \mid$ \\
\hline Rubber plot 6 & $|00000000|$ & |0000000000| & | $00000000000 \mid$ & | 1011000111| & |11110| & |0111010101011| & | $000000000 \mid$ \\
\hline Rubber plot 6 & $|00000000|$ & 00000000| & $00000000000 \mid$ & | $1010011100 \mid$ & |11101| & |01010| & | $000000000 \mid$ \\
\hline Rubber plot 6 & & & & & & D101001| & \\
\hline Rubber plot 6 & $|00000000|$ & $|0000000000|$ & |00000000000| & |101 & |00111| & 1011 | & \\
\hline Rubber plot 6 & $|00000000|$ & $|0000000000|$ & |00000000000| & | $1011111100 \mid$ & |00110| & |0011110101010| & $|000000000|$ \\
\hline
\end{tabular}

Figure 6: Illustration of the input file for the fragment pool approach with one plot of each land-use system randomly chosen from the eight possible plots and seven species. |101111100| presents the 1-0 matrix of one particular individual of the collected species with certain number of fragments, each fragment is in the input file one column. $|00000|$ if a species does not occur in the plot all respective columns are filled with zeros. 


\begin{tabular}{|c|c|c|c|c|c|c|c|}
\hline gment pool & Species 1 & ecies 2 & Species 3 & Species 4 & Species 5 & Species 6 & Species 7 \\
\hline & |111111111| & |0000000000| & |111111111111| & & & |0000000000000| & \\
\hline Forest plot 1 & |11111111| & |0000000000| & 111111111111| & | $0000000000 \mid$ & | $00000 \mid$ & |00000000000000| & |111111111| \\
\hline Forest plot 1 & |111111111| & |0000000000| & |111111111111| & | $0000000000 \mid$ & | $00000 \mid$ & |0000000000000| & |111111111| \\
\hline Forest plot 1 & |111111111| & |0000000000| & $|111111111|$ & |0000000000| & | $00000 \mid$ & |00000000000000| & 111| \\
\hline Forest plot 1 & |111111111 & |0000000000| & $11111111111 \mid$ & |0000000000| & |00000| & |0000000000000| & $1111 \mid$ \\
\hline Forest plot 1 & |111111111| & |0000000000| & [11111111 & | $0000000000 \mid$ & | $00000 \mid$ & 00000 & |11111 | \\
\hline Forest plot 1 & |11111111| & |0000000000| & |111111111111| & |0000000000| & |00000| & |0000000000000| & |111111111| \\
\hline Forest plot 1 & |111111111| & |0000000000| & |111111111111| & |0000000000| & |00000| & |0000000000000| & |1111111111| \\
\hline Forest plot 1 & |111111111 | & | $0000000000 \mid$ & $|1111111111|$ & | $0000000000 \mid$ & |00000| & |00000000000000| & |11111 | \\
\hline Forest plot 1 & |11111111| & |0000000000| & |1111111111| & 0000000000 & | $00000 \mid$ & |0000000000000| & |111111111 \\
\hline Ingle rubber plot 1 & |00000000| & |11111111111| & 0000000000 & 0000000000 & | $00000 \mid$ & 100000 & |111111111| \\
\hline Jungle rubber plot 1 & |00000000| & |11111111111| & |00000000000| & |0000000000| & | $00000 \mid$ & |0000000000000| & |111111111| \\
\hline Jungle rubber plot 1 & |00000000| & |11111111111| & |00000000000| & |0000000000| & | $00000 \mid$ & |0000000000000| & |111111111| \\
\hline ngle rubber plot 1 & $|00000000|$ & |11111111111| & $00000000000 \mid$ & |0000000000| & |00000| & |0000000000000| & $111 \mid$ \\
\hline Jungle rubber plot 1 & |00000000| & |11111111111| & 00000000000| & 0000000000 & | $00000 \mid$ & |0000000000000| & 1111111111| \\
\hline Jungle rubber plot 1 & |00000000| & |1111111111| & 00000000000 | & $0000000000 \mid$ & | $00000 \mid$ & |00000000000000| & 11111111| \\
\hline Jungle rubber plot 1 & |00000000| & |11111111111| & 00000000000| & 100000 & | $00000 \mid$ & $100 \mathrm{c}$ & $111 \mid$ \\
\hline Jungle rubber plot 1 & | $00000000 \mid$ & |1111| & 00000000000| & 1000 & |00000| & 1000 & \\
\hline er plot 1 & |00000000| & |11111111111| & |00000000000| & | $0000000000 \mid$ & |00000| & |0000000000000| & |1111111111| \\
\hline Jungle rubber plot 1 & |00000000| & |11111111111| & |00000000000| & |0000000000| & | $00000 \mid$ & |0000000000000| & |111111111| \\
\hline Oil palm plot 3 & | $00000000 \mid$ & | $0000000000 \mid$ & 00000000000| & $1111111111 \mid$ & |00000| & |1111 & | $000000000 \mid$ \\
\hline Oil palm plot 3 & |00000000| & |0000000000| & |00000000000| & |11111111111| & | $00000 \mid$ & |111111111111111| & | $000000000 \mid$ \\
\hline Oil pal & | $00000000 \mid$ & 이 & 이 & & |00000| & .11 & 100 \\
\hline Oil palm plot 3 & $|00000000|$ & |0000000000| & 00000000000| & |1111 & | $00000 \mid$ & |111 & | $000000000 \mid$ \\
\hline Oil palm plot 3 & |00000000| & |0000000000| & $00000000000 \mid$ & $1111111111 \mid$ & | $00000 \mid$ & |1111 & | $000000000 \mid$ \\
\hline Oil palm plot 3 & |00000000| & |0000000000| & | $00000000000 \mid$ & |11111111111| & | $00000 \mid$ & |11111111111111| & | $000000000 \mid$ \\
\hline Oil palm plot 3 & $|00000000|$ & |0000000000| & |00000000000| & |1111111111| & |00000| & |111111111111111| & $|000000000|$ \\
\hline Oil palm plot 3 & | $00000000 \mid$ & |0000000000| & 00000000000 & 11. & | $00000 \mid$ & $11 \mid$ & 100000 \\
\hline plot 3 & 100000 & | & 이 & & 이 & & \\
\hline Oil palm plot 3 & | $00000000 \mid$ & | $0000000000 \mid$ & 00000000000| & $11 \mid$ & | $00000 \mid$ & $11 \mid$ & | $000000000 \mid$ \\
\hline Rubber plot 6 & |00000000| & $|0000000000|$ & | $00000000000 \mid$ & |11111111111| & |11111| & |11111111111111| & | $000000000 \mid$ \\
\hline Rubber plot 6 & $|00000000|$ & |0000000000| & |00000000000| & |1111111111| & |11111| | & |111111111111111| & $|000000000|$ \\
\hline Rubber plot 6 & | $00000000 \mid$ & |0000000000| & |00000000000| & |1. & |11111| & $111 \mid$ & $|000000000|$ \\
\hline Rubber plot 6 & |00000000| & $|0000000000|$ & 00000000000 | & 11] & |11111| & |1111 & 100000 \\
\hline Rubber plot 6 & 1000000 & & & & |11111| & .1111 | & 100 \\
\hline Rubber plot 6 & |00000000| & |0000000000| & 0000| & 11111| & |11111| & $111111 \mid$ & 100 \\
\hline Rubber plot 6 & $|00000000|$ & |0000000000| & |00000000000| & 11| & |11111| & :11| & 이 \\
\hline Rubber plot 6 & |00000000| & |0000000000| & |00000000000| & |1111111111| | & |11111| & |11111111111111| & |000000000| \\
\hline Rubber plot 6 & |00000000| & |0000000000| & 000 & $11 \mid$ & |11111| & & 10000 \\
\hline & & $00 \mid$ & & & |11111| & |111111111111111| & 100000 \\
\hline
\end{tabular}

Figure 7: Illustration of the input file for the clone fragment pool matrix calculation with one plot of each land-use system randomly chosen from the eight possible plots and seven species. |111111111| presents the exact same number of fragments of the original individual of the collected species with certain number of fragments, each fragment is in the input file one column. $|00000|$ if a species does not occur in the plot all respective columns are filled with zeros.

\subsubsection{LAND-USE SYSTEM HETEROGENEITY}

Land-use system heterogeneity calculation was conducted as a visualization of the investigated plots. Differences between all plots were due to different species composition and genetic dissimilarity among the individuals of the occurring species. The pairwise fragment pool distance matrix was used to calculate the dispersion or variance within each plot and among all plots. The heterogeneity of the land-use systems was visualized using the mean value of dispersion of each plot in a Principal Component Analysis (PCoA) (Gower 1966). The calculation was conducted by using the function "betadisper" in the R-package "vegan" (Oksanen et al. 2015). The graph was built with the R-package "ggplot2" (Wickham 2009). 


\subsubsection{GENETIC DIVERSITY AT THREE DIFFERENT SPATIAL SCALES}

Patterns of genetic structure at different spatial scales of plant species differ due to their different life strategies. Tree species are expected to have higher diversity within a population than short living species but lower population differentiation (Austerlitz et al. 2000). Hence, in this project the tree-dominated systems are expected to have higher within plot diversity with increased, but similar, diversity values with extended spatial scale ( $\beta$ - and $\gamma$ - level). The herbaceous species in the plantations are expected to have lower within population diversity than trees but increased diversity values at $\beta$ - and $\gamma$ - level due to the higher differentiation of populations. To assess genetic diversity with increasing population size of the dominant species and to test the genetic diversity dependency on the land-use system, different spatial scales were determined. The different spatial scales are presented by the three levels: the lowest, $\alpha$-level, corresponds to the diversity within each plot, the $\beta$-level to diversity within each land-use system and the highest, $\gamma$-level to the diversity within each region (Figure 5).

\section{a. fragment pool approach}

For the fragment pool approach, the $\alpha$-level differentiation was calculated by taking the mean of the pairwise genetic fragment pool distance matrix values within each plot. The $\beta$-diversity values represented the genetic distance of the individuals in one plot have to all other individuals of the same species within the land-use system. The $\beta$-diversity level was calculated by taking the mean values of the pairwise genetic fragment pool matrix within each land-use system e.g. of the pairwise genetic distance values from all forty forest fragment pools in the region Harapan. The $\gamma$-diversity level was based on the mean values of the pairwise genetic fragment pool matrix within each region. The results were ten mean values per plot for the fragment pool for all three diversity levels, respectively.

Increasing the population size by using the three spatial scales included the species dominant in only one plot, too. To investigate the differences in genetic differentiation of the species occurring more than once the true $\beta$-diversity was calculated and fitted to a GLMM. True $\beta$ diversity, is defined as $\alpha$ - diversity deducted from $\gamma$-diversity and not as a designated area larger than $\alpha$, as conducted for the within land-use system $\beta$-diversity level for the community and species approach. True $\beta$-diversity was calculated with $\beta=\nu-\alpha$ following Whittaker (1960). 


\section{b. species approach}

The species approach was presented by the two indices Shannon Index (I) (Shannon \& Weaver 1949; Lewontin 1972) and Morisita-Horn dissimilarity (Horn 1966). The $\alpha$-level diversity, using the Shannon Index, was calculated for the ten individuals per plot, respectively. Using the Morisita-Horn dissimilarity the $\alpha$-level was calculated by taking the mean of the pairwise distance matrix values of the ten individuals per plot for each species. The Shannon Index $\beta$ diversity was calculated based on all individuals of a species present within a land-use system. For the $\beta$-level differentiation the means of the pairwise distances of all individuals per species within each land-use system were taken. The Shannon Index at the $y$-level was based on all individuals of the same species within one region. For the Morisita-Horn species approach the means of the pairwise distance were taken of all individuals of the same species within the region. Consequently, at the $\beta$ - and $\gamma$-level, diversity changed only for the species dominant in more than one plot within each land-use system and region. The number of values per plot using the species approach was equal to the number of species genotyped successfully.

The nine data sets, $\alpha$-, $\beta$ - and $\gamma$-diversity level for the Morisita-Horn and the Shannon Index per species and for the fragment pool approach, were checked for normal distribution using the Kolmogorov-Smirnov test (Stephens 1979) for continuous data in STATISTICA version 12 (StatSoft Inc., Tulsa, USA). The three diversity levels based on the fragment pool approach and species approach (Shannon Index and Morisita-Horn) were graphed using R-package "reshape2" (Wickham 2007). Differences among the land-use systems for the community and species approach at the three $\alpha$-, $\beta$ - and $\gamma$-diversity levels were assessed using a generalized mixed fixed effect model (GLMM) in the R-package nlme (Pinheiro et al 2015). Model of the best fit were chosen based on the Akaike Information Criterion (AIC): the land-use system as the fixed variable and the plots nested in a region as the random effects. The results of the mixed effect models were generalized for multivariate comparisons with the function "glht" of the R-package "multcomp" (Hothorn et al. 2008). A two-sample t-test (Student 1908) was carried out with all nine data sets to test for differences among the four land-use systems and the two regions using STATISTICA version 12 (StatSoft Inc., Tulsa, USA). Furthermore, in STATISTICA the Kolmogorov-Smirnov test (Stephens 1979) as a non-parametric test was used to confirm the t-test results for the not normally distributed data sets. 


\subsubsection{ANALYSIS OF MOLECULAR VARIANCE}

To calculate the variance within plots and regions, the function "amova" in the R package "ade4" (Dray \& Dufour 2007) was used to conduct analysis of molecular variance (AMOVA) based on the pairwise genetic fragment distance matrix per land-use system, respectively. The function calculated the ten fragment pools per plot as one population and were distinguished between the two regions Bukit Dua Belas and Harapan. Significance was tested with the function "randtest" based on the Monte Carlo test with 999 permutations.

\subsubsection{MANTEL TEST}

Population structure of plant species is depending on multiple factors. In fragmented and heterogeneous landscapes pollen and seed dispersal, thus gene flow, can be constrained which leads to isolation and structuring of populations (Luque et al. 2012; Ruiz-Gonzalez et al. 2015). Due to limited gene flow with increasing geographic distance, genetic differentiation among populations may increase (van Strien et al. 2015). Based on the pairwise genetic fragment pool distance matrix and pairwise geographic distance matrix per plot, the correlation between genetic differentiation among individuals of the same species in different plots and the geographic distance among plots was tested. The geographic position of each plot was used for calculating the geographic pairwise distance. The mantel test was carried out using the software PassaGe2 (Rosenberg \& Anderson 2011) with 9999 permutations. If plots did not share species, hence did not have a genetic distance, these two plots were not considered in the calculations (value = not available). The analysis was carried out once for the complete data set and once for the two regions Bukit Dua Belas and Harapan separately.

\subsubsection{POWER ANALYSIS}

To answer the question how many plots would have to be sampled, to detect significant differences if the land-use systems were an actual effect, the function "power.anova.test" of the R-package "stats" was used for a balanced one-way ANOVA. The calculation is depending on the number of groups (land-use system), number of samples within groups (plots) and the variance within and among the groups. The analysis was carried out for a significance level of 0.05 and a power of $80 \%$. For the species approach the test was carried out with the Shannon 
Index per species and for the fragment pool approach the three levels of $\alpha-, \beta-$, $\checkmark$ - differentiation.

\subsubsection{CORRELATION OF GENETIC DIVERSITY AND SPECIES DIVERSITY AND SOIL VARIABLES}

Shannon Index values per species and plot based on the AFLP matrices were tested for correlation with total plant species diversity per plot, $\mathrm{C} / \mathrm{N}$ ratio per plot, arbuscular mycorrhiza species diversity and prokaryotic species diversity.

Plant species diversity was provided by the subproject B06 ("Taxonomic, phylogenetic, functional and biogeographic diversity of vascular plants in rainforest transformation systems on Sumatra (Indonesia)") (Rembold \& Kreft unpublished data). The data is based on number of tree species over $10 \mathrm{~cm}$ dbh in the tree dominated land-use systems, plus all vascular plant species in five subplots. Furthermore, all species within the five subplots in each plot were registered. Based on this data the Simpson diversity index (1-D) was calculated per plot using the R-package "vegan". C/N ratios per plot were provided by subproject A04 ("Stock, turnover and functions of carbon in heavily weathered soils under lowland rainforest transformation systems"), which were measured from a soil mixture of all horizons to the maximum depth of $100 \mathrm{~cm}$ in one pit per plot (Guillaume et al. 2015). Taxonomic units abundance data of the mycorrhiza species was provided by subproject B07 ("Functional diversity of mycorrhizal fungi along a tropical land-use gradient"), which observed and identified taxonomical units using barcoding (Edy 2015). The Simpson Index, used as the diversity index in the correlation, was calculated using the R-package "vegan". For archaeal and bacteria diversity the Simpson Index values (Schneider et al. 2015) were provided by subproject B02 ("Impact of rainforest transformation on phylogenetic and functional diversity of soil prokaryotic communities in Sumatra (Indonesia)"), which observed and identified taxonomical units using bar-coded amplicon sequencing prokaryotic 16S rRNA genes (Schneider et al. 2015). R-package Hmisc (Harrell 2015) was used to test for significant correlation (Pearson test, 999 permutations) between genetic diversity (Shannon Index) and the three other parameters. Visualization of the correlation was carried out with the graphic R-package ggplot2 (Wickham 2009) . 


\subsubsection{SPECIES-BASED ANALYSIS}

Species were categorized regarding their life form and history traits. Common species occurring in at least three plots were analysed separately, to compare these results with the community analysis.

\subsubsection{GENETIC DIVERSITY OF THE COLLECTED SPECIES ACCORDING TO THEIR LIFE FORMS}

Plants were separated by life form into trees, shrubs, grasses, herbs, ferns and the two crop species oil palm and rubber. The Shannon index (Lewontin 1972) values per species were used to test for significant differences among the life form groups.

Tree species were grouped into three categories regarding their typical habitat and occurrence. The three categories were 1. secondary; typical species for secondary rainforests, 2. pioneer; typical species for open and early successional habitats and 3. Generalists; common species with high abundancy in tropical lowland rainforests. This categorization was carried out based on the ecological information of Prosea books (PROSEA 5(1-3), 6, 12(1-3), 14, 15(2)) and www.asianplant.net (in May 2015). If the information of the species was not available, the description of the genera was considered. To investigate the dependency of genetic diversity of the life forms on the land-use system, the values were fitted into a GLMM using the R-package nlme (Pinheiro et al 2015). The following parameters were used in the GLMM: plots were nested in the region as random factors and life form was a fixed factor. The following calculation was the pairwise multiple comparisons Tukey test with the function "glht" of the R-package "multcomp" (Hothorn et al. 2008).

\subsubsection{GENETIC STRUCTURE OF FREQUENTLY COLLECTED SPECIES}

Species, frequently dominant in plots, were chosen for a more detailed analysis, disregarding the land-use system. For all species the Reynold distance matrix and 10000 bootstraps was calculated using AFLPsurv 1.0 (Vekemans 2002). These bootstraps were used to build a Neighbour Joining tree with the two functions "neighbour" and "consense" belonging to the program Phylip 3.7. (Felsenstein 2009). For visualization of the dendrogram the software TreeView 1.6.6. was used (Page 1996). The dendrograms with only three populations are less informative; hence, they were only calculated for species occurring in more than three plots. 
Furthermore, GenAlEx 6.501 (Peakall \& Smouse 2006; Peakall \& Smouse 2012) was used to calculate $\phi_{\mathrm{PT}}$ (similar to $\mathrm{FST}_{\mathrm{ST}}$ for binary data) and carry out the AMOVA analysis with 999 permutations for each chosen species. For categorization of the tree species groups see section 2.2.2.1. For the most common tree species Macaranga bancana the expected heterozygosity $\left(\mathrm{H}_{\mathrm{e}}\right)$, Percentage of Polymorphic Loci (PPL) was calculated for each plot using GenAlEx 6.501 (Peakall \& Smouse 2006; Peakall \& Smouse 2012).

Table 1: List of the in detail analysed dominant species according to their life form category, region (Bukit Dua Belas (B), Harapan $(\mathrm{H})$ ) and land-use system (forest $(\mathrm{F})$, jungle rubber $(\mathrm{J})$, oil palm $(\mathrm{O})$ and rubber $(\mathrm{R})$ ). Number of plots is the total number of plots, which were considered in the calculations.

\begin{tabular}{lllll}
\hline Species & Group & Region & System & Nr. of plots \\
\hline Aporosa nitida & Tree (Generalist) & B, H & F & 5 \\
Alstonia scholaris & Tree (Generalist) & B, H & J, R & 9 \\
Gironniera nervosa & Tree (Generalist) & B, H & F & 4 \\
Porterandia anisophylla & Tree (Generalist) & B, H & F & 6 \\
Endospermum malayanum & Tree (Pioneer) & B & F, J & 3 \\
Hymenodictyon orixense & Tree (Pioneer) & B, H & J & 4 \\
Macaranga bancana & Tree (Pioneer) & B, H & F, J, R & 12 \\
Artocarpus elasticus & Tree (Secondary) & B, H & J & 6 \\
Croton agrarius & Tree (Secondary) & B, H & F & 5 \\
Hopea megerawan & Tree (Secondary) & $\mathrm{H}$ & $\mathrm{F}$ & 3 \\
Shorea ovalis & Tree (Secondary) & $\mathrm{H}$ & $\mathrm{F}$ & 3 \\
Elaeis guineensis & Crop & $\mathrm{B}, \mathrm{H}$ & $\mathrm{O}$ & 8 \\
Hevea brasiliensis & Crop & $\mathrm{B}, \mathrm{H}$ & $\mathrm{J}, \mathrm{R}$ & 16 \\
Asystasia indica & Herb & $\mathrm{B}, \mathrm{H}$ & $\mathrm{O}, \mathrm{R}$ & 9 \\
Clidemia hirta & Herb & $\mathrm{B}, \mathrm{H}$ & $\mathrm{O}, \mathrm{R}$ & 14 \\
Melastoma malabrathicum & Herb & $\mathrm{B}, \mathrm{H}$ & $\mathrm{O}, \mathrm{R}$ & 11 \\
Spermacoce alata & Herb & $\mathrm{B}, \mathrm{H}$ & $\mathrm{O}, \mathrm{R}$ & 3 \\
Axonopus compressus & Grass & $\mathrm{B}, \mathrm{H}$ & $\mathrm{O}, \mathrm{R}$ & 15 \\
Centotheca lappacea & Grass & $\mathrm{B}, \mathrm{H}$ & $\mathrm{O}, \mathrm{R}$ & 14 \\
Scleria bancana & Grass & $\mathrm{B}, \mathrm{H}$ & $\mathrm{O}, \mathrm{R}$ & 9 \\
Dicranopteris linearis & Fern & $\mathrm{B}, \mathrm{H}$ & $\mathrm{O}, \mathrm{R}$ & 5 \\
Goniophlebium verrucosum & Fern & $\mathrm{H}$ & $\mathrm{O}$ & 3 \\
Nephrolepis acutifolia & Fern & $\mathrm{B}, \mathrm{H}$ & $\mathrm{O}$ & 7 \\
\hline
\end{tabular}




\section{RESULTS}

\subsection{Plant MATERIAL AND AFLP ANALYSIS}

In all 32 plots, ten dominant plant species were determined and ten plants/species times ten species/plot resulted in a total of 3200 samples for AFLP analysis. Due to different dominance of species in each plot, a total number of 112 species were collected for the study. A species was only considered for the calculations with at least ten successfully genotyped individuals. Low PCR product quality, misidentification of species and/or low reproducibility caused the exclusion of eight species. Seven species per plot was the minimum number representing one plot. The species list can be found in Appendix 1.

\subsection{DATA ANALYSIS}

\subsubsection{COMMUNITY ANALYSIS}

\subsubsection{LAND-USE SYSTEM HETEROGENEITY}

Based on the number of shared species and the genetic distance among the occurring individuals of the same species, all eight plots of each land-use system were grouped together but in different distances (Figure 8). Two groups could be identified, the tree-dominated systems, forest and jungle rubber, as one group and the plantation systems, oil palm and rubber, as the other group. The eight oil palm and jungle rubber plots were very close together and the two regions within each system could not be separated. Forest and rubber plots showed more heterogeneity within the system. One jungle rubber plot and one oil palm plot showed a greater distance to other plots within the land-use system. Jungle rubber shared species with the forest system and with the rubber plantation. 


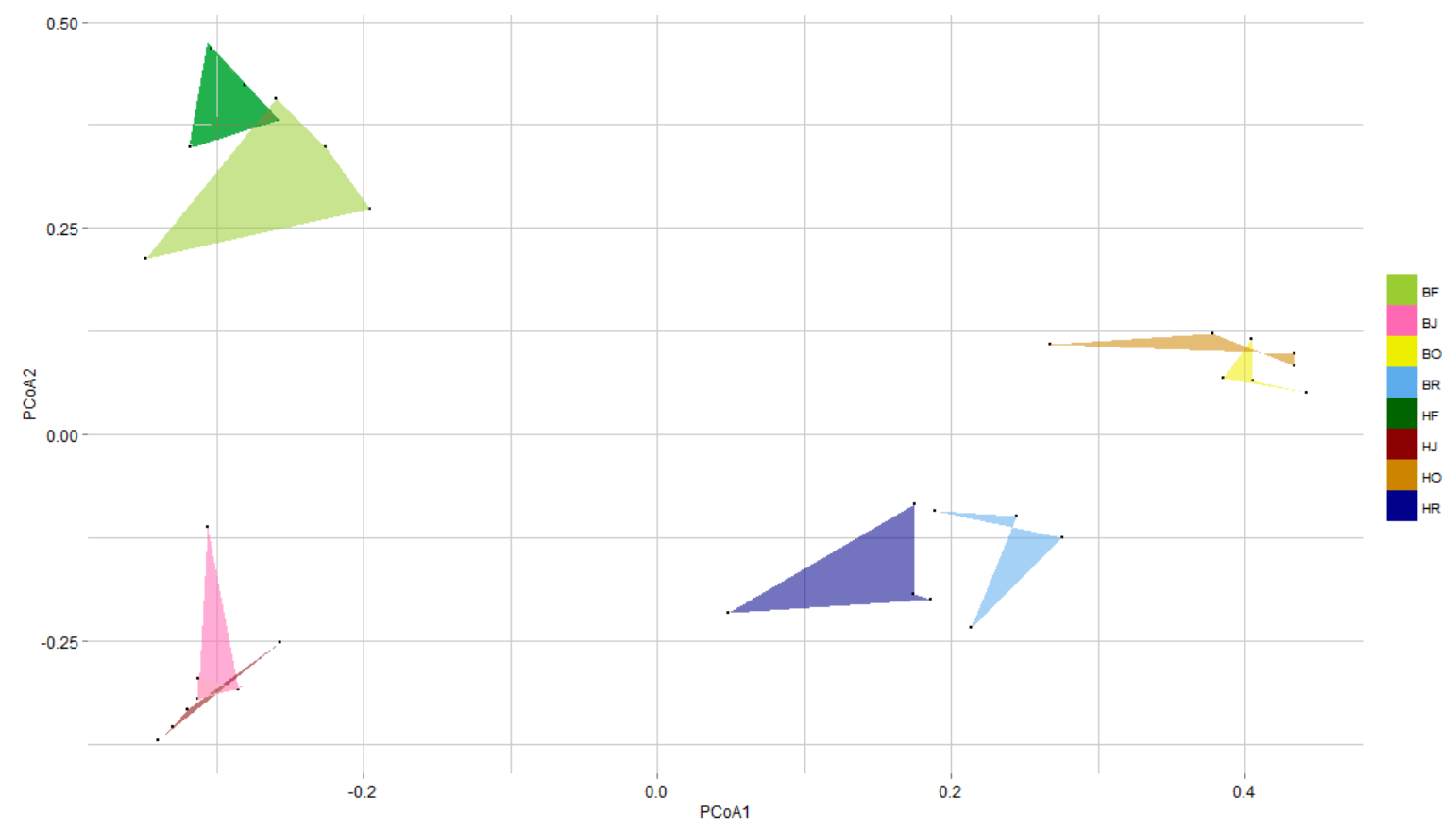

Figure 8: The heterogeneity of each land-use system in the two regions. PCoA of the mean of pairwise Morisita-Horn dissimilarities of all individuals of the dominant species in the four land-use systems forest (green, BF, HF), jungle rubber (red, BJ, HJ), oil palm (yellow, BO, HO), rubber (blue, BR, HR) in two regions Bukit Dua Belas landscape (bright colours) and Harapan landscape (dark colours).

\subsubsection{GENETIC DIVERSITY AT THREE DIFFERENT SPATIAL SCALES}

The species and the fragment pool approach showed for all land-use systems moderate but different differentiation and diversity results. The overall observation at all three spatial scales using the fragment pool and the species approach was very similar differentiation and diversity values in both regions. That observation was confirmed by the GLMM and the t-test with no significant differences for both approaches between the two regions Bukit Dua Belas and Harapan.

\section{a. Fragment pool approach}

The results for the fragment pool approach based on the genetic fragment distances, differed between the four land-use systems (Figure 9). Genetic differentiation at $\alpha$-level showed similarity between forest and jungle rubber and between the two plantation systems. Forest showed higher genetic distance than rubber plantation, but both were at intermediate levels. The mixed effect model at $\alpha$-level suggested no significant differences between all land-use systems except between jungle rubber (highest) and oil palm (lowest). At $\beta$-differentiation the fragment pool approach showed the tree dominated systems, forest and jungle rubber, did 
not have the highest mean pairwise distances to all other fragment pools within the land-use systems. Forest differentiation decreased from $\alpha$ - to $\beta$-level the most and differed significantly from the three other land-use systems. Jungle rubber showed highest differentiation values, oil palm and rubber intermediate values. Oil palm differed significantly from jungle rubber, but not from rubber plantations, neither did rubber and jungle rubber. On $\mathrm{\gamma}$-genetic diversity level the differentiation among all fragment pools was low. All land-use systems had similar distances value. Differentiation at $\gamma$-level was highest for oil palm followed by jungle rubber and rubber. For the forest system $\beta$ - and $\gamma$-level differentiation did not differ. The GLMM suggested only significant differences between forest (lowest) and oil palm (highest). Results of the t-test suggested significant differences among the four land-use systems at all three diversity levels.

The comparison of all three levels of diversity with the fragment pool approach showed that forest species behave different in the three levels than the three land-use systems. From $\alpha-$ level, $\beta$ - and $\gamma$-level the differentiation for forest declined, for jungle rubber in a lesser extent. The two plantation systems showed less change in differentiation at the three diversity levels than the tree-dominated plots. Comparing the plots within each land-use system and within the two regions the degree of variance within each plot seemed to be randomly high or low across all land-use systems (Appendix 8). In all forest plots, genetic fragment distance on $\beta$ and $\gamma$-level were similar. For jungle rubber plots $\alpha$ - and $\beta$-diversity distances were similar and the $\mathrm{Y}$ - diversity results were lower, i.e. heterogeneity within each plot and land-use system was higher than among the land-use systems. Oil palm plantations showed high differentiation on the plot level. For all rubber plots, similar high distances at $\alpha$ - and $\beta$-diversity level and low at $\gamma$-diversity level were observed. In the Harapan region differences among $\alpha-$, $\beta$-and $\gamma$-diversity levels were less than in the Bukit Dua Belas region. Genetic differentiation for the forest plots differed, but not significantly, between the two regions (Appendix 9).

Testing the effect of the land-use system on the genetic distance of only the species occurring in more than one plot showed highest values for the jungle rubber followed by the forest system (Figure 12). The GLMM suggested significant differences among the tree-dominated systems and oil palm plantation with the lowest values. Rubber plantation do not differ significantly from the three other land-use systems. The t-test suggested significant differences between the two plantation systems and among the tree-dominated systems and the two plantation systems. Forest and jungle rubber did not differ significantly. 


\section{b. Species approach}

The $\alpha$-level genetic diversity calculations based on the Shannon Index were moderate but did not differ among all four land-use systems (Figure 10). The results at the $\alpha$-diversity level revealed two groups: forest and jungle rubber with high mean genetic diversity and oil palm and rubber plantations with low mean genetic diversity (Figure 10). The t-test and GLMM suggested both suggested significant differences between these two groups. Species of rubber plantations showed slightly higher mean diversities than oil palm plantation species. Comparing genetic diversity on plot level and separated by region, there was no visible difference between the two regions (Appendix 10). The variability of intraspecific diversity among the different species sampled within plots in each system was higher than the variation between sites and regions. The land-use system did not seem to have an effect on the variability within a plot (Appendix 10). Diversity at the $\beta$-level increased compared to $\alpha$-level for all four land-use systems but differences of the mean among them decreased (Figure 10). Variance within all land-use systems was high. Mixed effect model suggested the same significant differences as at the $\alpha$-level, between the two tree-dominated systems and the two plantation systems. The t-test suggested significant differences between forest and the plantation systems, jungle rubber and rubber plantation but not between jungle rubber and oil palm plantation. Genetic diversity differences among the four land-use systems at $\gamma^{-}$ diversity level were low, hence GLMM and t-test suggested both no significant differences among them. Mean value for jungle rubber is slightly higher than the forest mean values. Compared to the $\beta$-level the variance within jungle rubber, oil palm and rubber plantation decreased.

Comparing genetic diversity based on the Shannon Index plot- and region- wise, from $\alpha$ - to $\gamma$ level the mean values increased for all 32 plots (Appendix 10). Variance within each plot differed but was in general high. Variability within each plot and land-use system was much higher than variability of the fragment pool approach.

The species approach showed very similar mean distances for the four land-use systems at all three diversity levels based on the Morisita-Horn Index (Figure 11). Variance within each landuse system was for all three levels high. The t-test and the GLMM suggested no significant differences among all four land-use systems at three levels. 


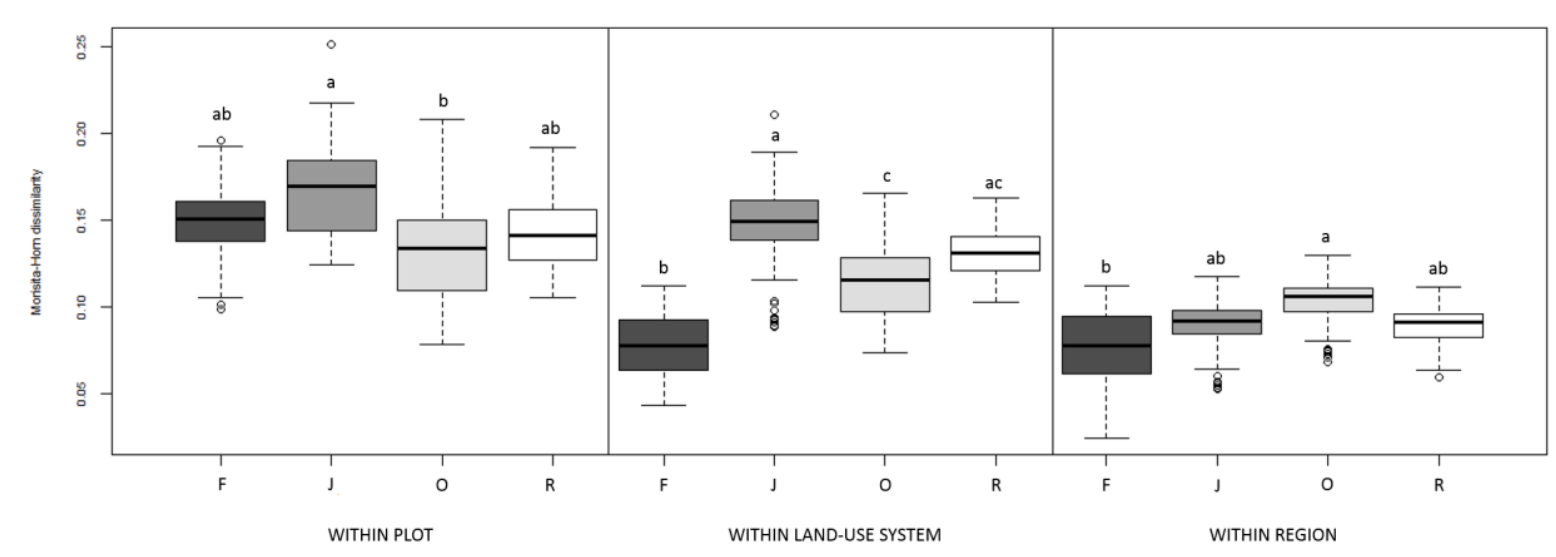

Figure 9: Results of the fragment pool approach using the Morisita-Horn dissimilarity (C). Shown is the genetic differentiation per land-use system $\mathrm{F}$ (forest), J (jungle rubber), O (oil palm plantation) and R (rubber plantation) for the three spatial levels $\alpha$-(within plot), $\beta$ - (within land-use system), $\gamma$ - (within region). Significant differences indicated by letters $(p<0.01)$.

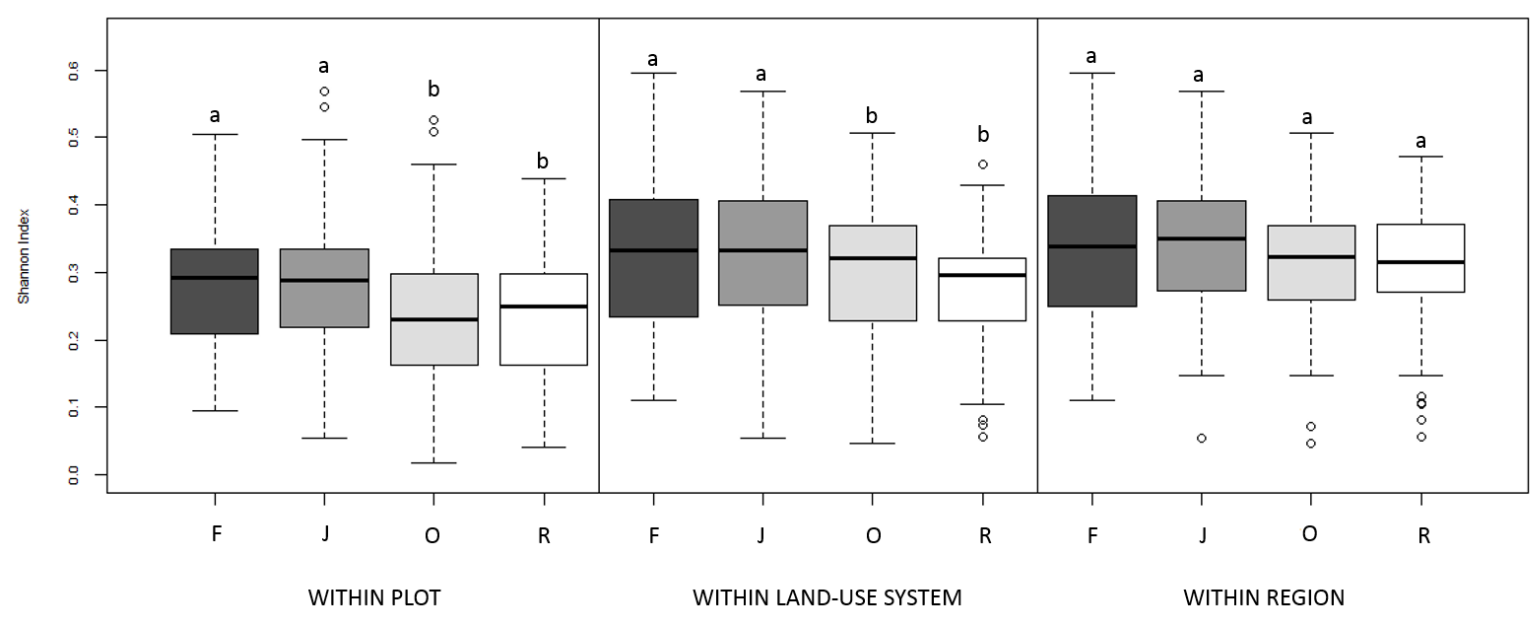

Figure 10: Results of the species approach using the Shannon Index (I). Shown is the genetic differentiation per land-use system $F$ (forest), J (jungle rubber), O (oil palm plantation) and R (rubber plantation) for the three spatial levels $\alpha$-(within plot), $\beta$ - (within land-use system), $\gamma$ - (within region). Significant differences indicated by letters $(p<0.01)$. 


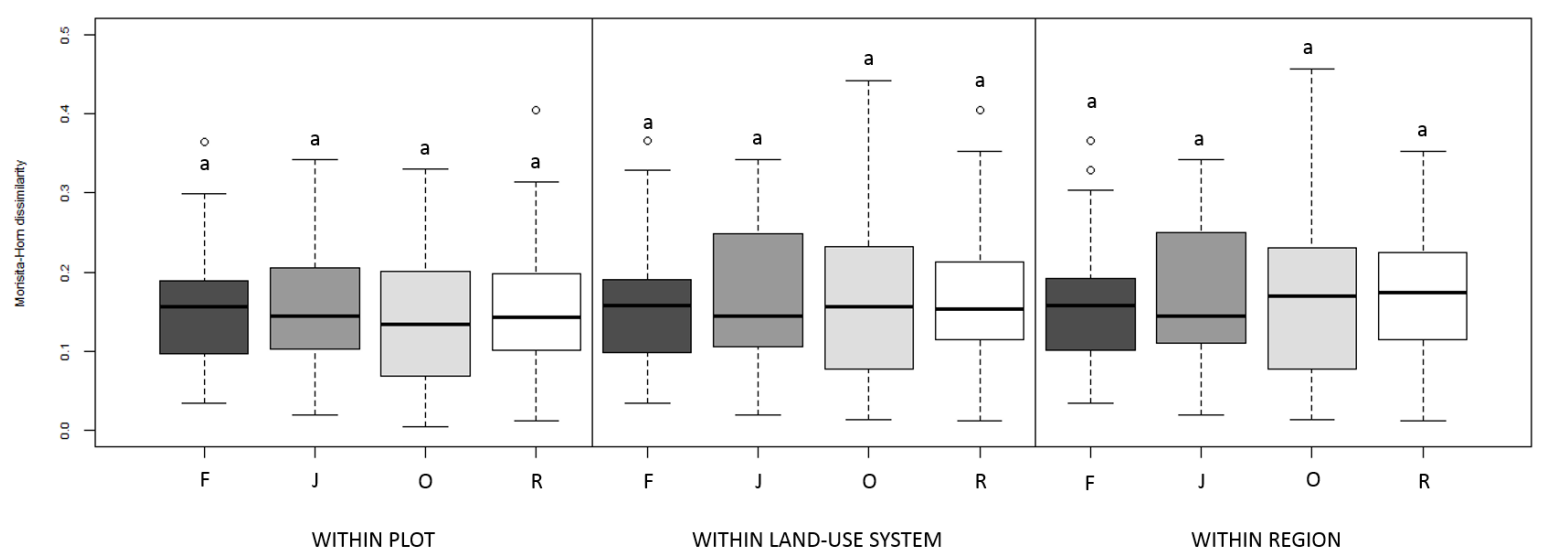

Figure 11: Results of the species approach using the Morisita-Horn dissimilarity (C). Shown is the genetic differentiation per land-use system $\mathrm{F}$ (forest), J (jungle rubber), $\mathrm{O}$ (oil palm plantation) and R (rubber plantation) for the three spatial levels $\alpha$ (within plot), $\beta$ - (within land-use system), $\gamma$ - (within region). Significant differences indicated by letters $(p<0.01)$.

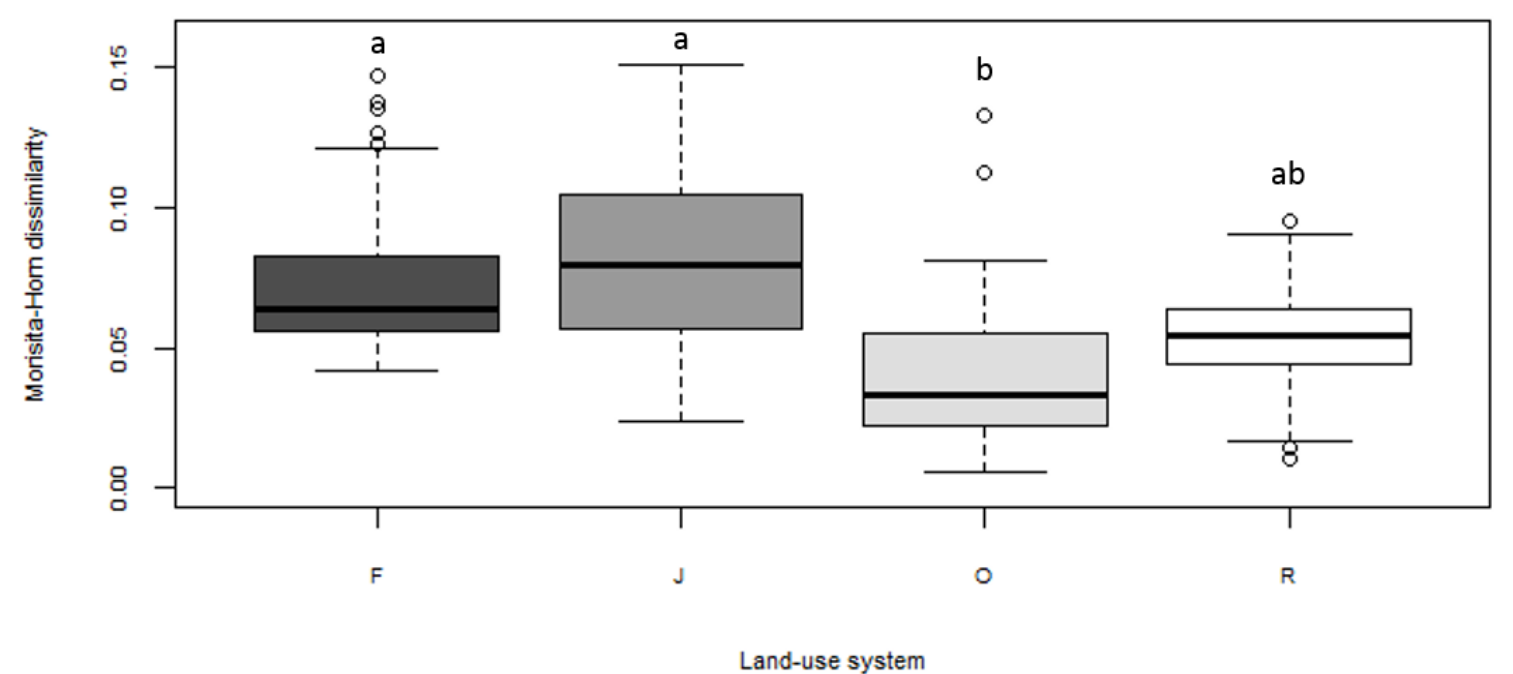

Figure 12: Genetic diversity of the absolute effective turnover species of the fragment pool approach using the MorisitaHorn dissimilarity $(C)$. Shown are the absolute values of the results $(\beta=\gamma-\alpha)$. The four land-use systems forest $(F)$, jungle rubber $(J)$, oil palm plantation $(O)$, rubber plantation $(R)$. Significant differences indicated by letters $(p<0.01)$.

\subsubsection{ANALYSIS OF MOLECULAR VARIANCE}

The fragment pool approach showed similar variance at the three spatial levels (within plot, within region, among region) for all four land-use systems. The AMOVA test showed no significant differences between the two regions for all land-use systems (Table 2). Variance among plots and within plots were within each land-use system were significantly different 
but the values were very similar $\left(\phi_{\mathrm{PT}}\right.$ : forest 0.56 , jungle rubber 0.51 , oil palm 0.59 , rubber $0.41)$.

Table 2: AMOVA results of genetic fragment pool distance for each land-use system. df: degrees of freedom, SS: sum of squares, $\sigma$ : estimated variance, PV [\%]: percentage of variance, $\phi_{\mathrm{PT}}$ : proportion of the variance among populations (plots) relative to the total variance, $p$-value, n.a.: not available.

\begin{tabular}{clllllll}
\hline Land-use system & Source & $\mathbf{d f}$ & $\mathbf{S S}$ & $\boldsymbol{\sigma}$ & $\mathbf{P V}[\%]$ & $\boldsymbol{\phi}_{\mathrm{PT}}$ & $\mathbf{p}$ \\
\hline Forest & Among region & 1 & 2.1488 & 0.0125 & 4 & n.a. & 0.224 \\
Forest & Within region & 6 & 9.8856 & 0.1523 & 52 & n.a. & 0.001 \\
Forest & Within plots & 72 & 8.9697 & 0.1245 & 43 & n.a. & 0.001 \\
Forest & Total & 79 & 21.0041 & 0.2894 & 100 & 0.5695 & n.a. \\
\hline Jungle rubber & Among region & 1 & 1.4547 & -0.00839 & -3 & n.a. & 0.633 \\
Jungle rubber & Within region & 6 & 10.7419 & 0.16438 & 54 & n.a. & 0.001 \\
Jungle rubber & Within plots & 72 & 10.5441 & 0.14644 & 48 & n.a. & 0.001 \\
Jungle rubber & Total & 79 & 22.7407 & 0.30244 & 100 & 0.5157 & n.a. \\
\hline Oil palm & Among region & 1 & 2.2465 & 0.0114 & 4 & n.a. & 0.290 \\
Oil palm & Within region & 6 & 10.7394 & 0.1668 & 56 & n.a. & 0.001 \\
Oil palm & Within plots & 72 & 8.7424 & 0.1214 & 40 & n.a. & 0.001 \\
Oil palm & Total & 79 & 21.7285 & 0.2996 & 100 & 0.5948 & n.a. \\
\hline Rubber & Among region & 1 & 1.1932 & 0.0048 & 2 & n.a. & 0.240 \\
Rubber & Within region & 6 & 5.9957 & 0.0858 & 39 & n.a. & 0.001 \\
Rubber & Within plots & 72 & 9.4021 & 0.1305 & 58 & n.a. & 0.001 \\
Rubber & Total & 79 & 16.5910 & 0.2223 & 100 & 0.4125 & n.a. \\
\hline
\end{tabular}

\subsubsection{MANTEL TEST}

Different genetic structure of the occurring dominant species within the regions effected the results of the isolation by distance test. The pairwise genetic distance matrix and geographic distance based on all 320 fragment pools showed a correlation which was slightly negative $(r=-0.024, p<0.001)$. Results for the Bukit Dua Belas region based on 160 fragment pools showed a negative $(r=-0.156, p<0.001)$. The test for the Harapan region showed a positive correlation $(r=0.27, p<0.001)$.

\subsubsection{POWER ANALYSIS}

The power analysis calculated the necessary number of plots for significant results, if the effects suggested by the mixed effect model are the real effects. Results suggest for the species approach using the Shannon Index, a plot number of 39 per land-use system. At $\beta$ level using the Morisita-Horn Index per species 303 plots and at $\gamma$-level 390 plots would be 
necessary. For the fragment pool approach its 10 plots per land-use system at $\alpha$-level, 3 plots at $\beta$-level and 9 plots at $\gamma$-level.

\subsubsection{CORRELATION OF GENETIC DIVERSITY AND SPECIES DIVERSITY AND SOIL VARIABLES}

Differences among the four land-use systems were not only observed for plant genetic diversity, but also for species composition, geographic distances, plant species diversity, arbuscular mycorrhiza diversity, prokaryotic diversity and $\mathrm{C} / \mathrm{N}$ - ration in the soil. Genetic diversity of dominant plant species showed significant correlation with the species diversity of each plot (Figure $13 \mathrm{~A}$ ). Tree species showed the highest genetic diversity and they were the dominant life form in forest and jungle rubber plots. Forest showed the highest plant species diversity, followed by the jungle rubber. The correlation was significant, but not highly (Pearson test, $r=0.19, p<0.01$ ).

Pearson test for a correlation between $\mathrm{C} / \mathrm{N}$ ratio per plot and genetic diversity was not significant ( $r=0.04, p=0.427)$. Data about heterogeneity of soil nutrition concentrations in every plot was not available.

Genetic diversity of dominant plant species showed significant correlation with the species diversity of arbuscular mycorrhiza of each plot (Figure $13 \mathrm{~B}$ ). Forest showed highest diversity followed by rubber plantations. Species abundances were not observed in all jungle rubber plots and the oil palm plot BO5 (NA in the calculations). Pearson test results (999 permutations) showed a lower correlation and lower significance than with the plant species diversity $(r=0.17, p<0.05)$.

The correlation among plant genetic diversity and bacteria diversity was negative and significant $(r=-0.15, p=0.016)$. Archaea diversity was very slightly correlated to genetic diversity and the test results were not significant $(r=0.09, p=0.134)$. The two prokaryotic groups differed in their diversity patterns among the land-use systems (Figure $13 C$ and $D$ ). 

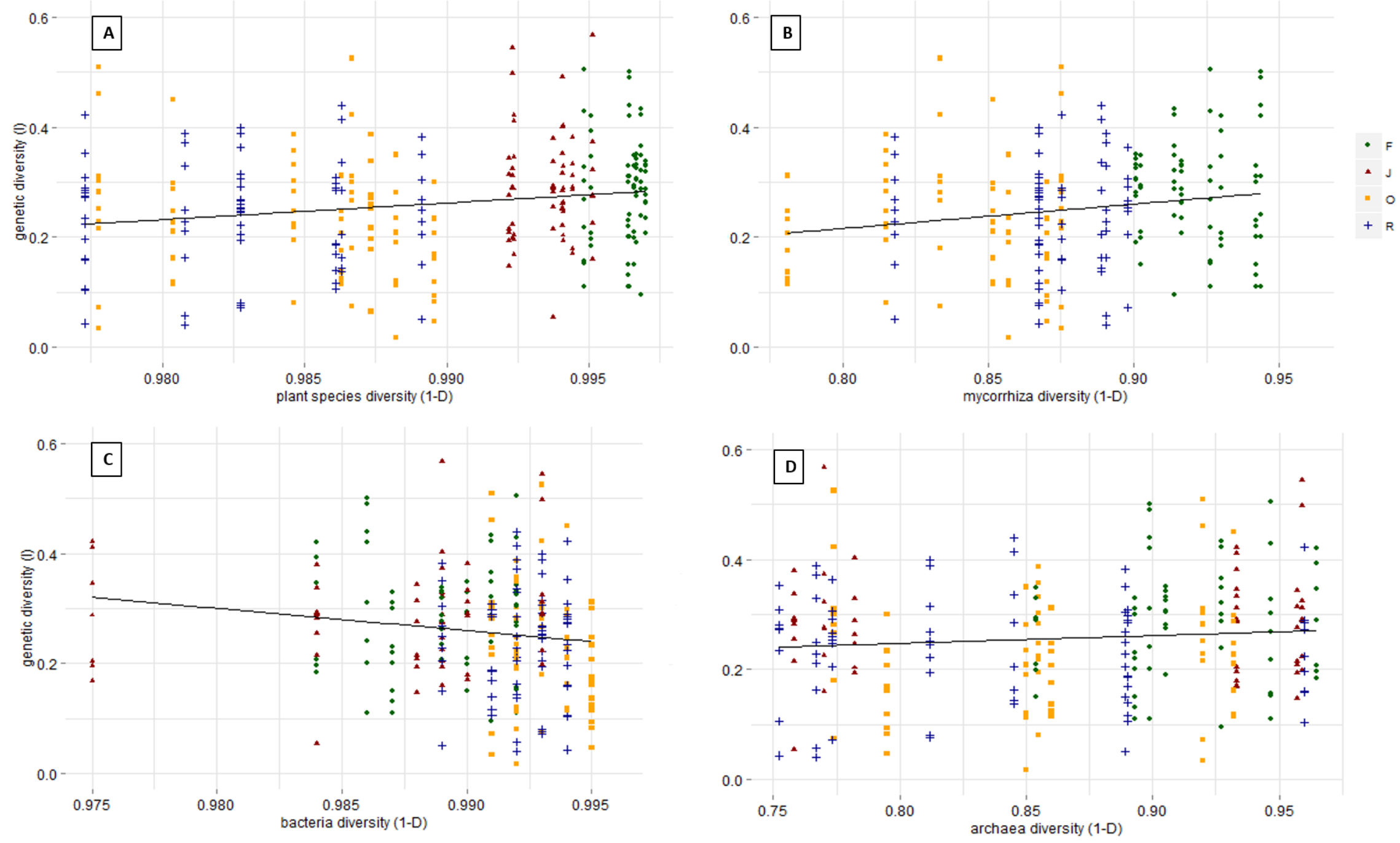

Figure 13: Correlation between genetic diversity (Shannon Index) of the respective species in each plot and A. the plant species diversity, B. the arbuscular mycorrhiza species diversity, C. the soil bacteria taxonomic unit diversity and D. the soil archaea taxonomic unit diversity in the Simpson Index (1-D), respectively. Land-use systems are coloured in green (forest), red (jungle rubber), yellow (oil palm) and blue (rubber). For the land-use system jungle rubber the mycorrhiza species data was not available. 


\subsubsection{SPECIES-BASED ANALYSIS}

Genetic structure and diversity calculations of the single species analysis showed the high variability among species, even within each life form and land-use system.

\subsubsection{GENETIC DIVERSITY OF THE COLLECTED SPECIES ACCORDING TO THEIR LIFE FORMS}

Each life form group differed in its variability in genetic diversity. Woody plant species showed the highest genetic diversity of all groups. Shrub and fern species showed similar results to the tree species. Grass species and the two crop species Hevea brasiliensis and Elaeis guineensis showed the lowest genetic diversity (Figure 14). Variance within each plant groups was very high except the crop and shrub species group, which were only presented by two and eleven species, respectively. Mean genetic diversity differed within the same life form group, but different among the land-use systems only little. Grouping tree species regarding their habitat requirements, "generalist" species showed highest genetic diversities, followed by group "secondary". H. brasiliensis individuals showed lowest genetic diversity. Groups "generalist" and "secondary" content the most variable species. Contribution of each group differed in forest and jungle rubber and the two regions (Table 3). The group "generalist" was the dominant group in both system in the Harapan region, in Bukit Dua Belas the second. In the region Bukit Dua Belas, forest plots were dominated by the group "secondary", jungle rubber plots by the group "pioneer". The group "secondary" accounted only for $11 \%$ in jungle rubber.

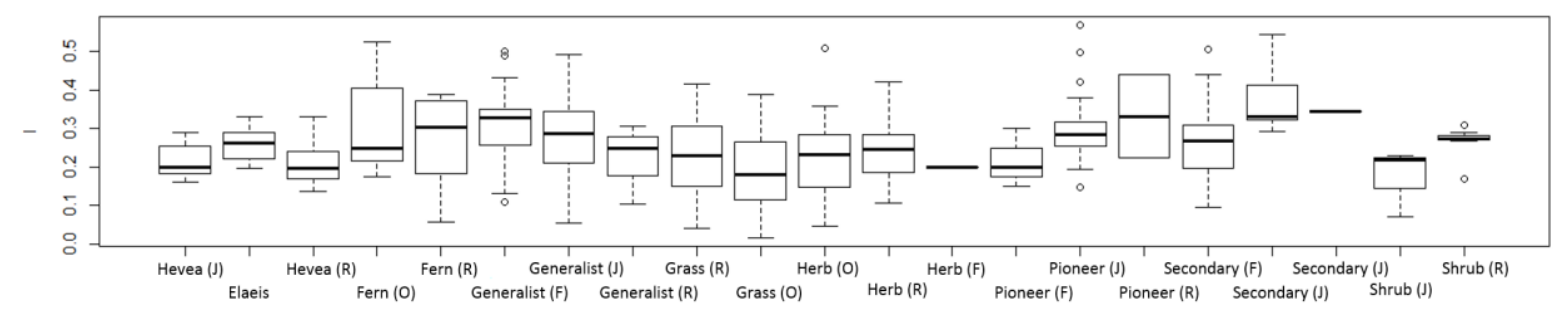

Figure 14: Shannon Index (I) per species grouped after life form (crop, fern, tree, grass, herb and shrub) and land-use system forest $(F)$, jungle rubber $(\mathrm{J})$, oil palm $(\mathrm{O})$ and rubber $(\mathrm{R})$. Trees were separated after their life history trait (generalist, pioneer and secondary). 
Table 3: Contribution of each group in the two systems forest and jungle rubber separated by region. Proportion in percent [\%] and total number of observations included in the calculation per system and region (rubber was excluded).

\begin{tabular}{llllll}
\hline System & Region & Observations & Generalist [\%] & Pioneer [\%] & Secondary [\%] \\
\hline Forest & Bukit Dua Belas & 32 & 44 & 9 & 47 \\
Jungle rubber & Bukit Dua Belas & 28 & 32 & 57 & 11 \\
Forest & Harapan & 35 & 60 & 0 & 40 \\
Jungle rubber & Harapan & 26 & 50 & 38.5 & 11.5 \\
\hline
\end{tabular}

\subsubsection{GENETIC STRUCTURE OF FREQUENTLY COLLECTED SPECIES}

Population structure analysis of single species incompletely reflected the results of the plant community results on $\beta$ - and $\gamma$-diversity levels. The species showed variance like Shannon genetic diversity per species on $\alpha$-diversity level. Variance among populations (AMOVA results) cannot be compared among the species, since they were relative to overall variance within each species. $\Phi_{\mathrm{PT}}$ values showed tendencies between tree values and herbaceous species. Tree species showed high variance in differentiation (e.g. secondary: 0.049 to 0.368 , Table 6) but lower than herbaceous species (herbs: 0.113 to 0.384 and grasses: 0.06 to 0.423, Table 12 and ).

\section{Group "secondary":}

All four species showed differentiation among plots but only Croton agrarius showed differentiation among regions. A. elasticus did not show differentiation between the two regions, plots of different regions paired together with high bootstrap values (Figure $15 \mathrm{~A}$ ). C. agrarius showed clear structure between the two regions, but the clustering of the plots within the Harapan region was not supported by high bootstrap values (Figure $15 \mathrm{~B}$ ). $\mathrm{H}$. mengerawan showed low differentiation between the three plots but all significant (Table 4). S. ovalis showed very low differentiation and medium significance, HF4 and HF2 were not significantly different (Table 5). Variance among populations was lowest for S. ovalis and highest for $C$. agrarius, results for all four species were significant (Table 6). 

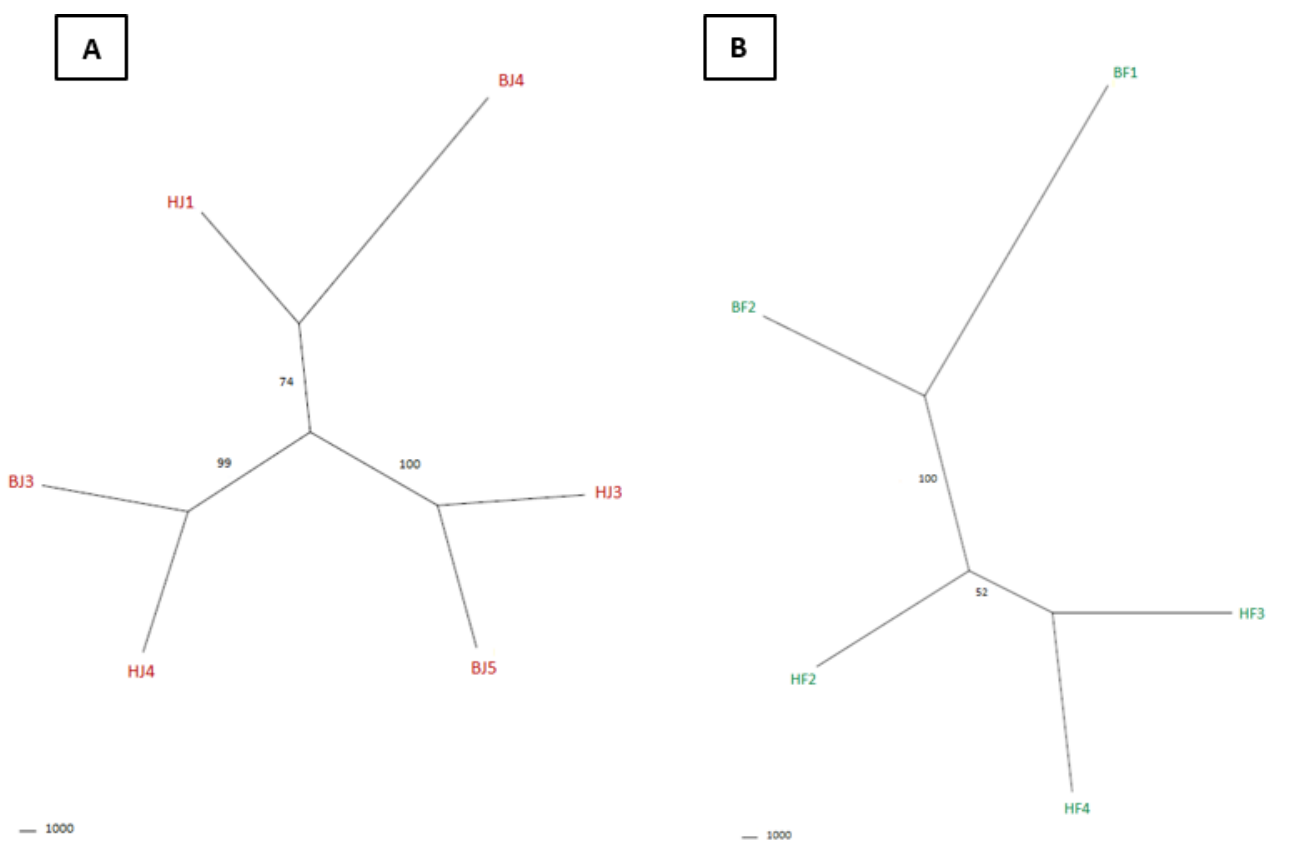

Figure 15: Neighbour Joining dendrogram based on Reynolds distance based on the pairwise genetic distance matrix per plot where the species occurred (10000 permutations, bootstrap values in [\%]). Colours are indicating the land-use system where the species was sampled: forest (F) in green and jungle rubber $(\mathrm{J})$ in red in the two regions Bukit Dua Belas (B) and Harapan (H). Shown are the tree species Artocarpus elasticus (A), Croton agrarius (B).

Table 4: Pairwise $\phi_{\mathrm{PT}}$ of Hopea mengerawan in three forest (F) plots in Harapan (H). Significance levels ( $p$-value): $p<0.05^{*}$, $\mathrm{p}<0.01^{* *}, \mathrm{p}<0.001^{* * *}$

\begin{tabular}{ccc|c} 
HF1 & HF2 & HF3 & \\
\hline & $* *$ & $* * *$ & HF1 \\
0.157 & & $* *$ & HF2 \\
0.160 & 0.078 & & HF3
\end{tabular}

Table 5: Pairwise $\phi_{\text {Рт }}$ of Shorea ovalis in three forest (F) plots in Harapan (H). Significance levels (p-value): n.s. not significant, $\mathrm{p}<0.05^{*}, \mathrm{p}<0.01^{* *}, \mathrm{p}<0.001^{* * *}$

\begin{tabular}{ccc|c} 
HF2 & HF3 & HF4 & \\
\hline & $* *$ & n.s. & HF2 \\
0.080 & & $* *$ & HF3 \\
0.013 & 0.053 & & HF4
\end{tabular}


Table 6: AMOVA results of Shorea ovalis, Hopea mengerawan, Artocarpus elasticus and Croton agrarius of the collected plots. df: degrees of freedom, SS: sum of squares, EV: estimated variance, PV: percentage of variance, $\phi_{\mathrm{PT}}$ : proportion of the variance among populations relative to the total variance, n.a.: not available.

\begin{tabular}{llllllll}
\hline Species & Source & df & SS & EV & PV [\%] & 申PT & p \\
\hline S. ovalis & Among plot & 2 & 30.267 & 0.512 & 5 & 0.049 & $<0.004$ \\
S. ovalis & Within plot & 27 & 270.300 & 10.011 & 95 & n.a. & n.a. \\
S. ovalis & Total & 29 & 300.567 & 10.523 & 100 & n.a. & n.a. \\
\hline H. mengerawan & Among plot & 2 & 14.133 & 0.422 & 13 & 0.129 & $<0.001$ \\
H. mengerawan & Within plot & 27 & 76.800 & 2.844 & 87 & n.a. & n.a. \\
H. mengerawan & Total & 29 & 90.933 & 3.267 & 100 & n.a. & n.a. \\
\hline A. elasticus & Among plot & 5 & 316.337 & 4.598 & 18 & 0.178 & $<0.001$ \\
A. elasticus & Within plot & 49 & 1038.972 & 21.204 & 82 & n.a. & n.a. \\
A. elasticus & Total & 54 & 1355.309 & 25.801 & 100 & n.a. & n.a. \\
\hline C. agrarius & Among plot & 4 & 288.800 & 6.160 & 37 & 0.368 & $<0.001$ \\
C. agrarius & Within plot & 45 & 477.000 & 10.600 & 63 & n.a. & n.a. \\
C. agrarius & Total & 49 & 765.800 & 16.760 & 100 & n.a. & n.a. \\
\hline
\end{tabular}

\section{Group "pioneer":}

Tree species of the pioneer group showed weak but significant differentiation among the analysed plots. Hymenodictyon orixense showed no differentiation between the two regions, but the Bukit Dua Belas plot showed more distance to the other three plots. However, bootstrap values did not suggest high reliability (Figure $16 \mathrm{~A}$ ). Macaranga bancana was the most dominant tree species besides the crop species Hevea brasiliensis. For M. bancana the two forest plots showed more distance to all other plots (100\% bootstraps), but all other plots did not cluster into the land-use system or region (Figure 16 B). E. malayanum showed significant differentiation among all three plots but the $\phi_{\text {PT }}$ value was higher among the jungle rubber plots and forest plot BF1 (Table 7). Differentiation was significant for all three species but low (Table 8). M. bancana was the most abundant non-crop species of the whole data set and was chosen for a more detailed analysis of the population structures (Table 9). In general no pattern differentiation among the three land-use systems. Compared to Bukit Dua Belas higher values for Nei's gene diversity and Percentage of Polymorphic loci (PPL) was found in the Harapan region in all three land-use systems. The two forest plots in the region Bukit Dua Belas showed lower values for gene diversity and PPL (BF1 $=0.22, \mathrm{BF} 2=0.27$ ). $\mathrm{F}_{\mathrm{ST}}$ for all 12 population based on 999 permutations was not significant $(p=0.226)$. 


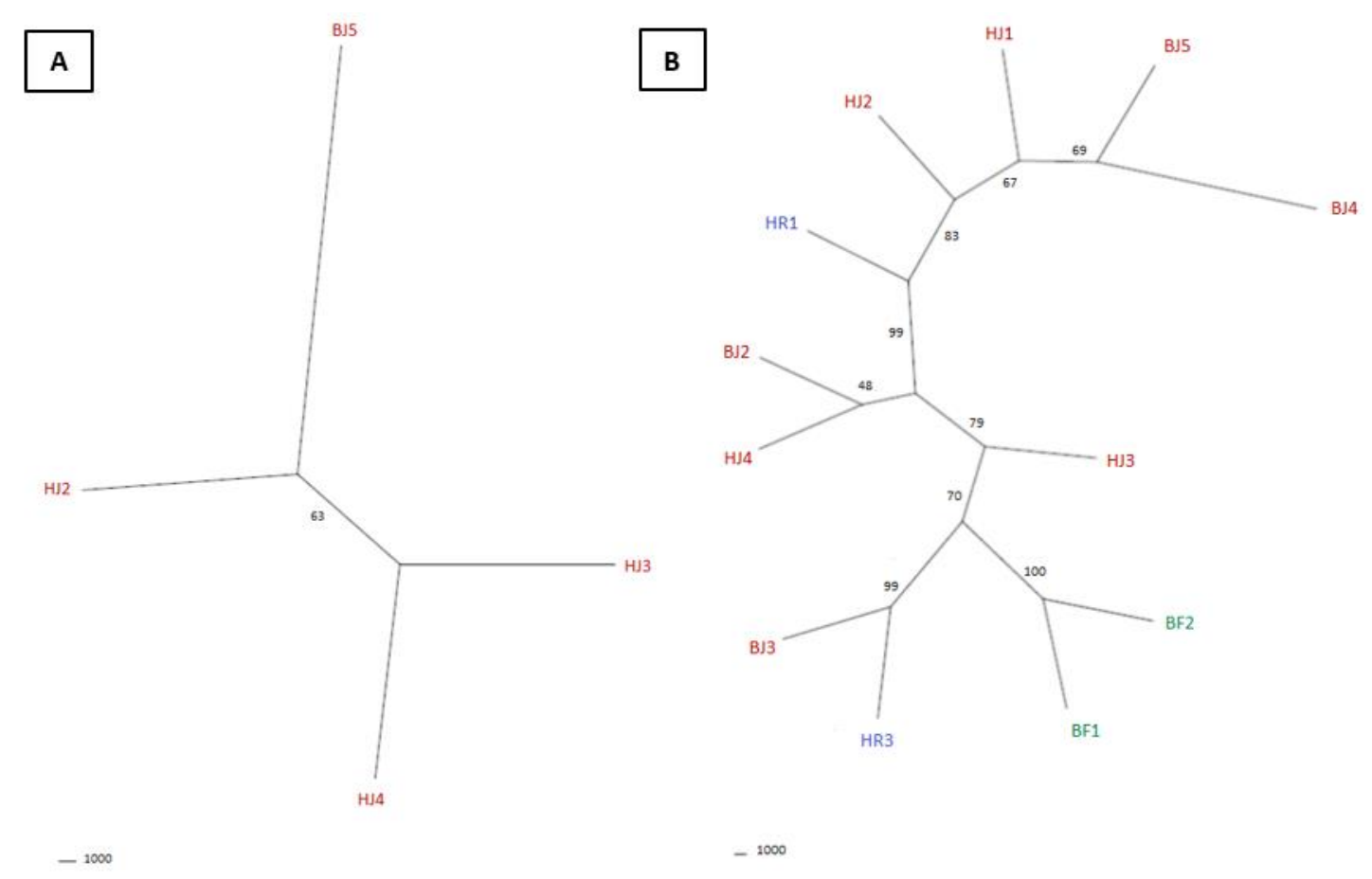

Figure 16: Neighbour Joining dendrogram based on Reynolds distance based on the pairwise genetic distance matrix per plot where the species occurred (10000 permutations, bootstrap values in [\%]). Colours are indicating the land-use system where the species was sampled: forest $(F)$ in green, jungle rubber $(J)$ in red and rubber plantation $(R)$ in blue in the two regions Bukit Dua Belas (B) and Harapan (H). Shown are the tree species Hymenodictyon orixense (A), Macaranga bancana (B).

Table 7: Pairwise $\phi_{\mathrm{PT}}$ of Endospermum malayanum in one forest (F) and two jungle rubber (J) plots in Bukit Dua Belas (B). Significance levels ( $p$-value): n.s. not significant, $p<0.05^{*}, p<0.01^{* *}, p<0.001^{* * *}$

\begin{tabular}{ccc|c} 
BJ3 & BJ5 & BF1 & \\
\hline & $* *$ & $* * *$ & BJ3 \\
0.063 & & $* * *$ & BJ5 \\
0.236 & 0.184 & & BF1
\end{tabular}

Table 8: AMOVA (999 permutations) results of Endospermum malayanum, Hymenodictyon orixense and Macaranga bancana. $\mathrm{df}$ : degrees of freedom, SS: sum of squares, EV: estimated variance, PV: percentage of variance, $\phi_{\mathrm{PT}}$ : proportion of the variance among populations relative to the total variance, n.a.: not available.

\begin{tabular}{llllllll}
\hline Species & Source & df & SS & Est. Var. & PV [\%] & 中PT & p \\
\hline E. malayanum & Among plot & 2 & 63.800 & 2.110 & 16 & 0.163 & $<0.001$ \\
E. malayanum & Within plot & 27 & 291.600 & 10.800 & 84 & n.a & n.a. \\
E. malayanum & Total & 29 & 355.400 & 12.910 & 100 & n.a. & n.a. \\
\hline H. orixense & Among plot & 3 & 51.750 & 0.667 & 6 & 0.059 & $<0.001$ \\
H. orixense & Within plot & 36 & 380.800 & 10.578 & 94 & n.a. & n.a. \\
H. orixense & Total & 39 & 432.550 & 11.245 & 100 & n.a. & n.a. \\
\hline M. bancana & Among plot & 11 & 918.482 & 7.093 & 35 & 0.350 & $<0.001$ \\
M. bancana & Within plot & 107 & 1408.678 & 13.165 & 65 & n.a. & n.a. \\
M. bancana & Total & 118 & 2327.160 & 20.258 & 100 & n.a. & n.a. \\
\hline
\end{tabular}


Table 9: Molecular diversity indices of Macaranga bancana in the two regions Bukit Dua Belas (B) and Harapan (H), in the three land-use systems forest $(F)$, jungle rubber $(J)$ and rubber plantation (R) based on AFLP matrix. N: Number of individuals, $\mathrm{N}$ loc: number of loci, $\mathrm{N}$ loc plot: number of polymorphic loci within each plot, PPL: Percentage of Polymorphic Loci, He: Nei's gene diversity, S.E. $\left(\mathrm{H}_{\mathrm{e}}\right)$ : standard error of Nei's gene diversity

\begin{tabular}{|c|c|c|c|c|c|c|}
\hline Plot & $\mathbf{N}$ & $\mathbf{N ~ l o c}$ & $\mathbf{N}$ loc plot & PPL [\%] & $\mathbf{H}_{\mathbf{e}}$ & S.E.( $\left.\mathbf{H}_{\mathbf{e}}\right)$ \\
\hline BJ2 & 10 & 120 & 97 & 81 & 0.25880 & 0.01503 \\
\hline BJ3 & 10 & 120 & 87 & 73 & 0.19942 & 0.01614 \\
\hline BJ4 & 10 & 120 & 101 & 84 & 0.26976 & 0.01530 \\
\hline BJ5 & 10 & 120 & 107 & 89 & 0.31087 & 0.01428 \\
\hline BF1 & 10 & 120 & 93 & 77 & 0.21797 & 0.01532 \\
\hline BF2 & 10 & 120 & 103 & 85 & 0.27369 & 0.01460 \\
\hline HR1 & 10 & 120 & 97 & 81 & 0.27546 & 0.01560 \\
\hline HR3 & 10 & 120 & 113 & 94 & 0.37206 & 0.01260 \\
\hline HJ1 & 10 & 120 & 109 & 91 & 0.35644 & 0.01295 \\
\hline HJ2 & 10 & 120 & 102 & 85 & 0.31832 & 0.01472 \\
\hline HJ3 & 10 & 120 & 112 & 93 & 0.30099 & 0.01322 \\
\hline HJ4 & 9 & 120 & 108 & 90 & 0.33330 & 0.01444 \\
\hline
\end{tabular}

Group "generalist":

A. scholaris clustered neither into regions nor into the land-use systems. Bootstrap values showed only low support for the clustering in the dendrogram (Figure $17 \mathrm{~A}$ ). For A. nitida the two regions were separated from each other. Within Bukit Dua Belas BF1 and BF2 showed highly supported separation from the third plot (Figure $17 \mathrm{~B}$ ). G. nervosa did not show separation between the two regions (Figure $17 \mathrm{C}$ ). For $P$. anisophylla the two regions are clearly separated from each other. Within the region Bukit Dua Belas forest plot BF1 is more distant to BF3 and BF4, within Harapan HF4 and HF2 are closer (Figure 17 D). Variance among plots of all four species are significant, among plots variance was lowest for $A$. scholaris (Table 10). 

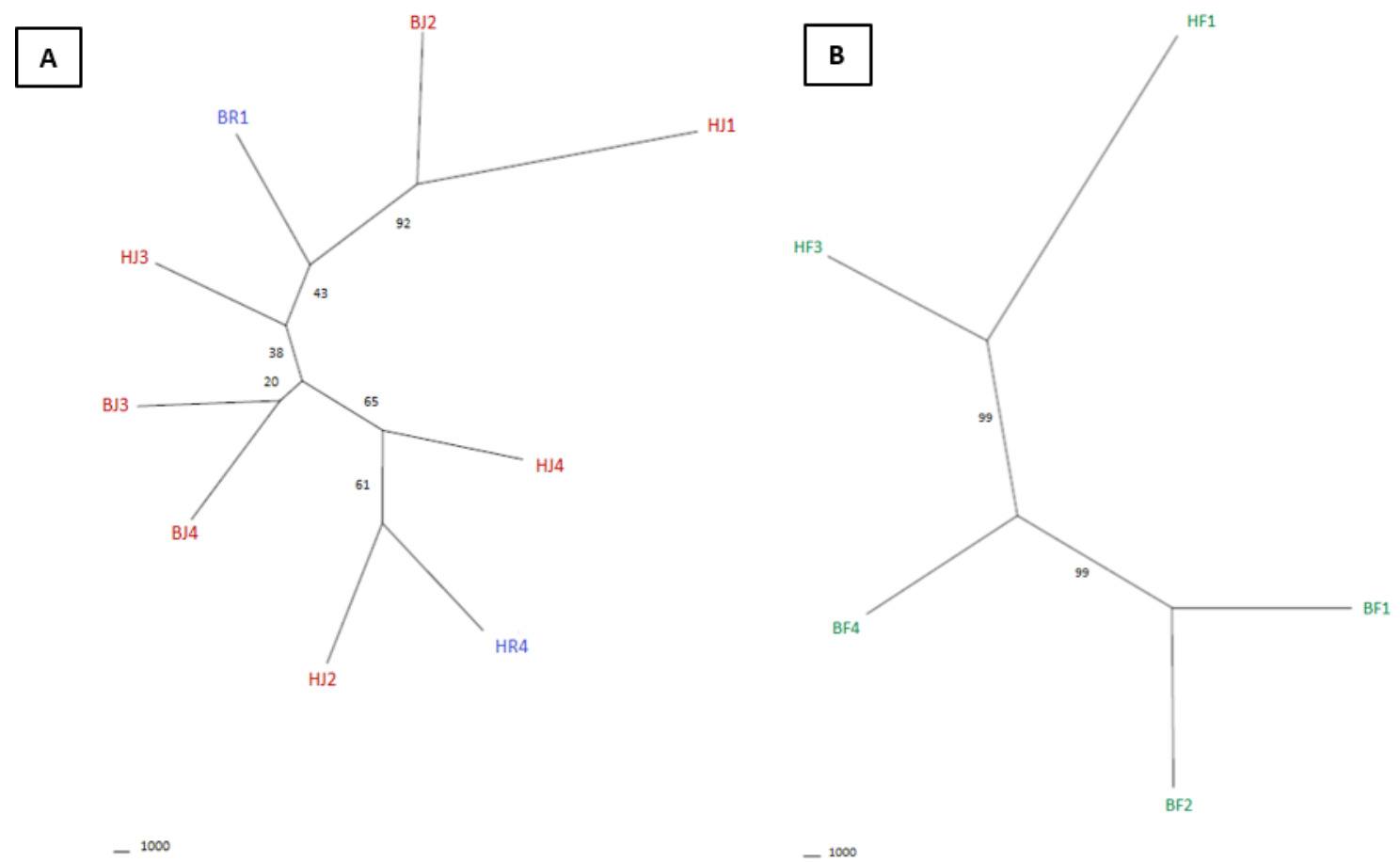

$-1000$
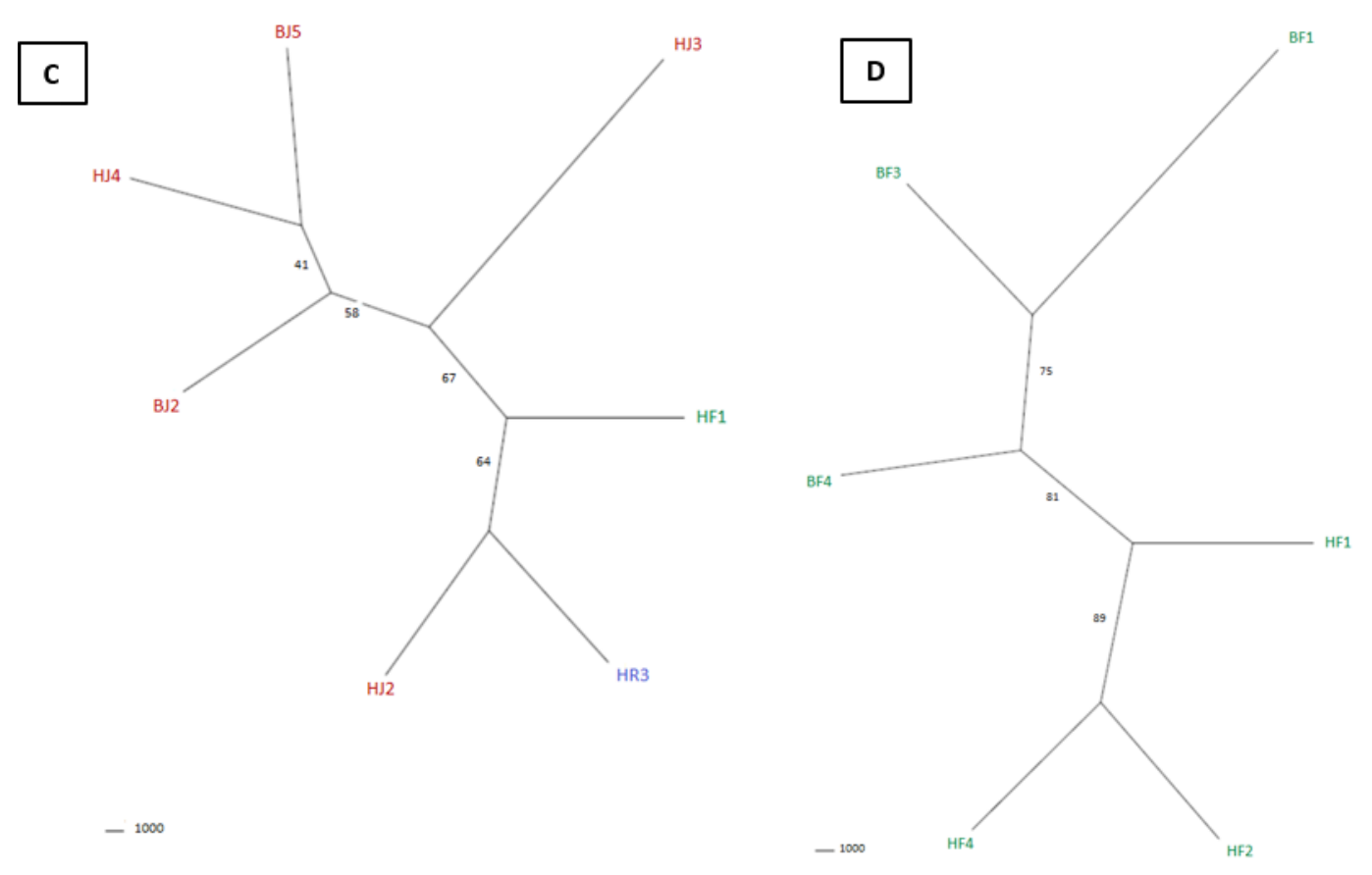

Figure 17: Neighbour Joining dendrogram based on Reynolds distance based on the pairwise genetic distance matrix per plot where the species occurred (10000 permutations, bootstrap values in [\%]). Colours are indicating the land-use system where the species was sampled: forest $(F)$ in green, jungle rubber $(J)$ in red and rubber plantation $(R)$ in blue in the two regions Bukit Dua Belas (B) and Harapan (H). Shown are the tree species Alstonia scholaris (A), Aporosa nitida (B), Parkia speciosa (C), Porterandia anisophylla (D) 
Table 10: AMOVA results of Porterandia anisophylla, Alstonia scholaris, Aporosa nitida and Parkia speciosa. df: degrees of freedom, SS: sum of squares, EV: estimated variance, PV: percentage of variance, $\phi_{\mathrm{PT}}$ : proportion of the variance among populations relative to the total variance, n.a.: not available.

\begin{tabular}{llllllll}
\hline Species & Source & df & SS & Est. Var. & PV [\%] & $\boldsymbol{\phi}_{\mathrm{PT}}$ & $\mathbf{p}$ \\
\hline P. anisophylla & Among plot & 5 & 117.070 & 1.735 & 21 & 0.214 & $<0.001$ \\
P. anisophylla & Within plot & 53 & 337.133 & 6.361 & 79 & n.a. & n.a. \\
P. anisophylla & Total & 58 & 454.203 & 8.096 & 100 & n.a. & n.a. \\
\hline A. scholaris & Among plot & 8 & 215.200 & 0.946 & 5 & 0.051 & $<0.001$ \\
A. scholaris & Within plot & 81 & 1412.300 & 17.436 & 95 & n.a. & n.a. \\
A. scholaris & Total & 89 & 1627.500 & 18.382 & 100 & n.a. & n.a. \\
\hline A. nitida & Among plot & 4 & 107.480 & 1.896 & 19 & 0.193 & $<0.001$ \\
A. nitida & Within plot & 45 & 356.000 & 7.911 & 81 & n.a. & n.a. \\
A. nitida & Total & 49 & 463.480 & 9.807 & 100 & n.a. & n.a. \\
\hline P. speciosa & Among plot & 6 & 73.371 & 0.791 & 16 & 0.155 & $<0.001$ \\
P. speciosa & Within plot & 63 & 271.8 & 4.314 & 84 & n.a. & n.a. \\
P. speciosa & Total & 69 & 345.171 & 5.106 & 100 & n.a. & n.a. \\
\hline
\end{tabular}

Crop species:

All oil palm and rubber plantations and jungle rubber plots were considered in the two dendrograms for Hevea brasiliensis and Elaeis guineensis. E. guineensis did not separate into regions either, but two plots in each region were more distant to all other plots (BO2 and $\mathrm{BO} 5$ in Bukit Dua Belas and HO1 and HO4 in Harapan, Figure 18 A). H. brasiliensis did not show clustering for region or land-use system (Figure $18 \mathrm{~B}$ ). Furthermore, the bootstrap values suggested low support for this tree version. The variance of both crop species among the plots were low but significant (Table 11). 


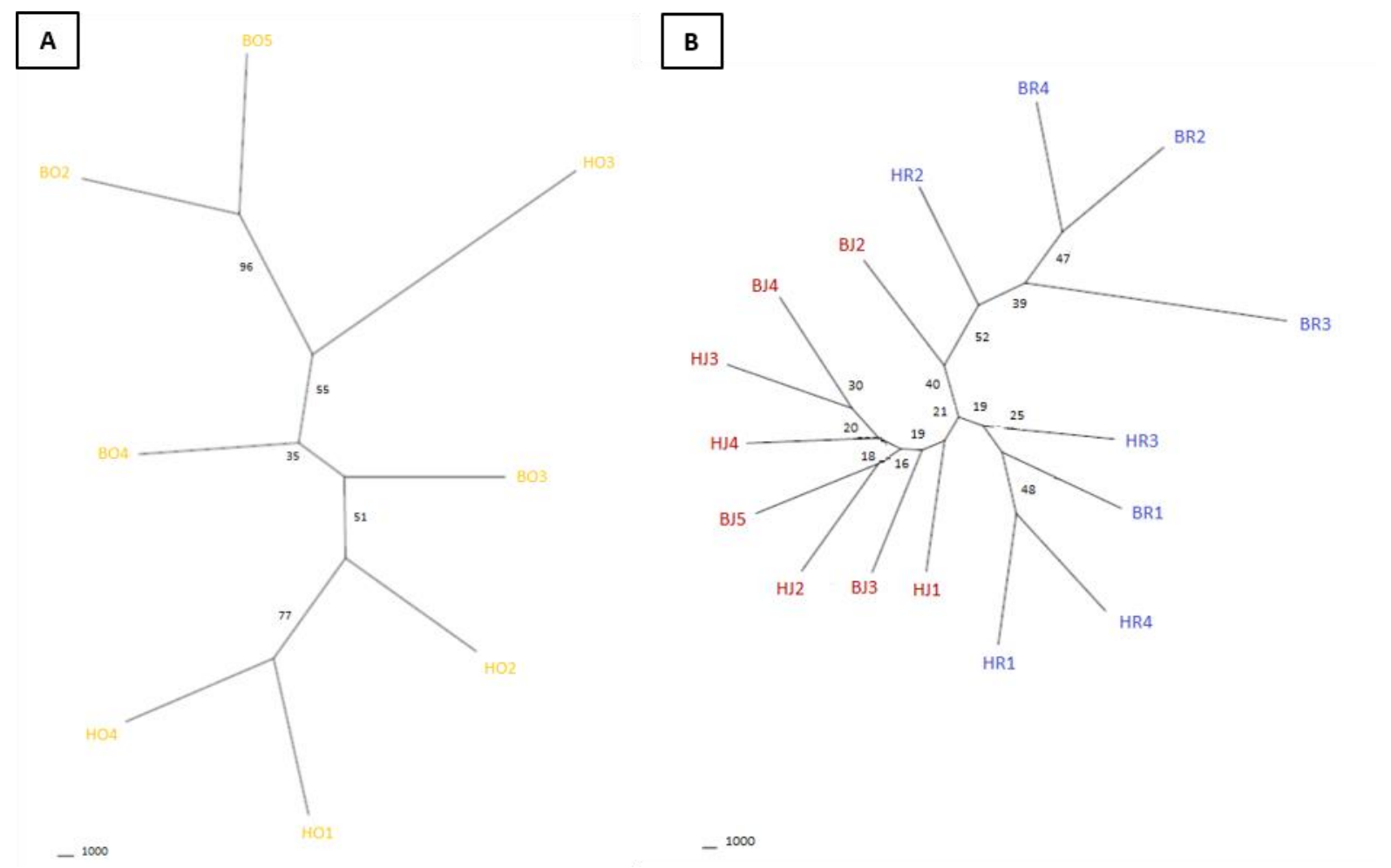

Figure 18: Neighbour Joining dendrogram based on Reynolds distance based on the pairwise genetic distance matrix per plot where the species occurred (10000 permutations, bootstrap values in [\%]). Colours are indicating the land-use system where the species was sampled: jungle rubber $(\mathrm{J})$ in red, oil palm plantation $(\mathrm{O})$ in yellow and rubber plantation $(\mathrm{R})$ in blue in the two regions Bukit Dua Belas (B) and Harapan (H). Shown are the crop species Elaeis guineensis (A) and Hevea brasiliensis (B).

Table 11: AMOVA results of Elaeis guineensis and Hevea brasiliensis. df: degrees of freedom, SS: sum of squares, EV: estimated variance, $\mathrm{PV}$ : percentage of variance, $\phi_{\mathrm{PT}}$ : proportion of the variance among populations relative to the total variance, n.a.: not available.

\begin{tabular}{llllllll}
\hline Species & Source & df & SS & Est. Var. & PV [\%] & 申PT & p \\
\hline E. guineensis & Among plot & 7 & 136.025 & 1.100 & 12 & 0.115 & $<0.001$ \\
E. guineensis & Within plot & 72 & 607.000 & 8.431 & 88 & n.a. & n.a. \\
E. guineensis & Total & 79 & 743.025 & 9.531 & 100 & n.a. & n.a. \\
\hline H. brasiliensis & Among plot & 15 & 166.006 & 0.514 & 8 & 0.080 & $<0.001$ \\
H. brasiliensis & Within plot & 144 & 853.700 & 5.928 & 92 & n.a. & n.a. \\
H. brasiliensis & Total & 159 & 1019.706 & 6.442 & 100 & n.a. & n.a. \\
\hline
\end{tabular}

Herb species:

All herb species clustered neither after land-use system nor after region. Plots of rubber and oil palm plantations and of the two regions paired together without visible pattern. $A$. gangetica plots did not cluster after land-use system or region (Figure 19 A). Single plots from two different regions group together (e.g. $\mathrm{HO} 1$ and BO2). C. hirta showed similar results, landuse system and regions are mixed but single plots grouped together with high bootstrap 
values (e.g. BO2 and BO5, HR3 and BO3, Figure 19 B). M. malabathricum showed no differences among regions and land-use system and bootstraps values are low for the dendrogram (Figure $19 \mathrm{C}$ ). For S. alata the plots $\mathrm{HO} 1$ and $\mathrm{HO} 4$ paired together and were separated from the other oil palm and rubber plot. The rubber plot (BR4) paired with $\mathrm{HO}$, but with large distance (Figure $19 \mathrm{D}$ ).

Variance among populations was highest for A. gangetica and lowest for M. malabathricum. AMOVA results were significant for all four species (Table 12). 

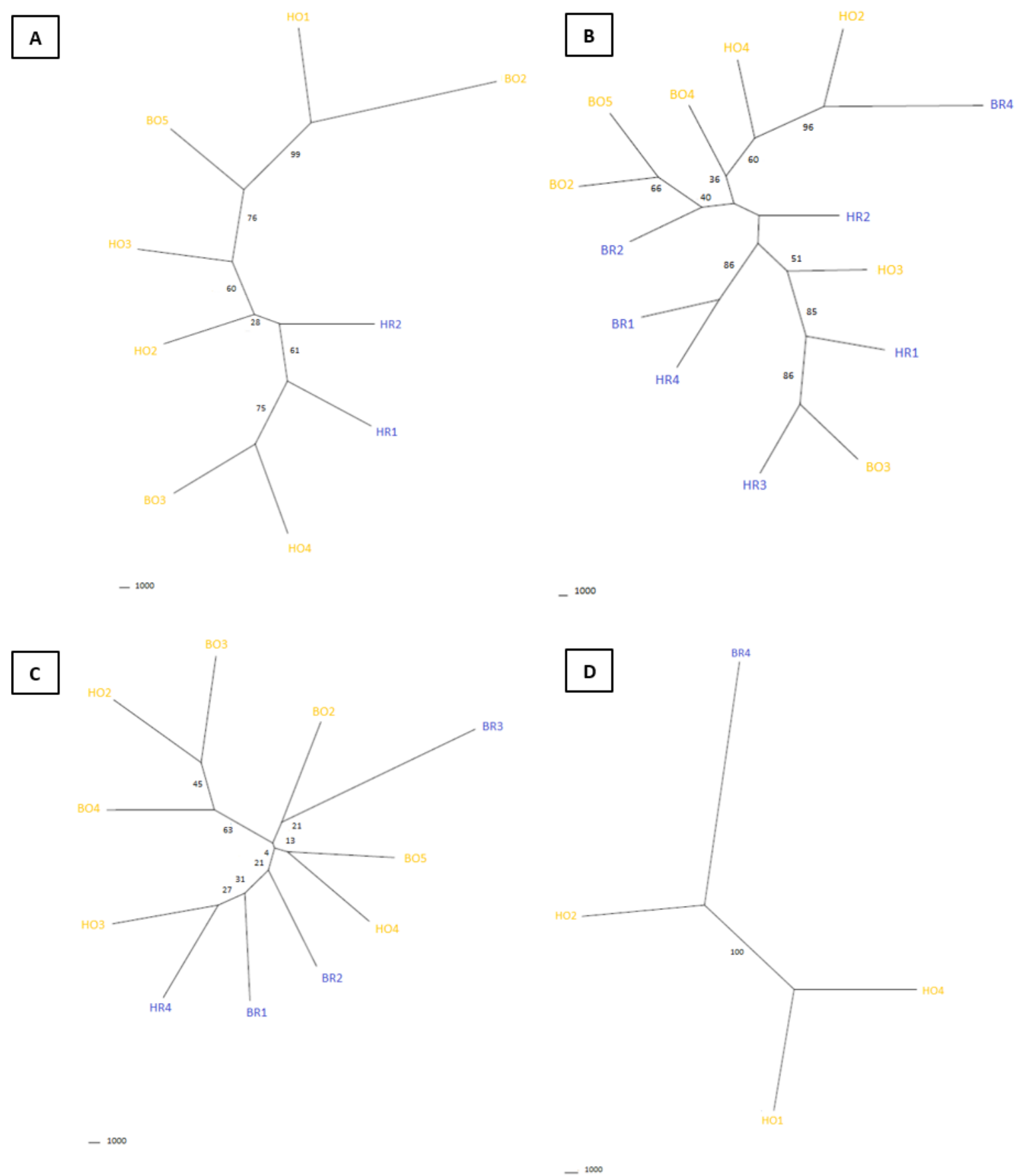

Figure 19: Neighbour Joining dendrogram based on Reynolds distance based on the pairwise genetic distance matrix per plot where the species occurred (10000 permutations, bootstrap values in [\%]). Colours are indicating the land-use system where the species was sampled: oil palm plantation $(\mathrm{O})$ in yellow and rubber plantation $(\mathrm{R})$ in blue in the two regions Bukit Dua Belas (B) and Harapan (H). Shown are the herb species Asystasia gangetica (A), Clidemia hirta (B), Melastoma malabathricum (C) and Spermacoce alata (D). 
Table 12: AMOVA results of Melastoma malabathricum, Clidemia hirta, Asystasia gangetica and Spermacoce alata. df: degrees of freedom, SS: sum of squares, EV: estimated variance, PV: percentage of variance, $\phi_{\mathrm{PT}}$ : proportion of the variance among populations relative to the total variance, n.a.: not available.

\begin{tabular}{llllllll}
\hline Species & Source & df & SS & Est. Var. & PV [\%] & \$PT & p \\
\hline M. malabathricum & Among plot & 10 & 292.413 & 1.656 & 11 & 0.113 & $<0.001$ \\
M. malabathricum & Within plot & 97 & 1259.550 & 12.985 & 89 & n.a. & n.a. \\
M. malabathricum & Total & 107 & 1551.963 & 14.641 & 100 & n.a. & n.a. \\
\hline C. hirta & Among plot & 13 & 301.666 & 1.435 & 13 & 0.134 & $<0.001$ \\
C. hirta & Within plot & 122 & 1130.643 & 9.268 & 87 & n.a. & n.a. \\
C. hirta & Total & 135 & 1432.309 & 10.703 & 100 & n.a. & n.a. \\
\hline A. gangetica & Among plot & 8 & 428.000 & 4.614 & 39 & 0.385 & $<0.001$ \\
A. gangetica & Within plot & 81 & 595.900 & 7.357 & 61 & n.a. & n.a. \\
A. gangetica & Total & 89 & 1023.900 & 11.971 & 100 & n.a. & n.a. \\
\hline S. alata & Among plot & 3 & 70.525 & 1.767 & 23 & 0.232 & $<0.001$ \\
S. alata & Within plot & 36 & 210.100 & 5.836 & 77 & n.a. & n.a. \\
S. alata & Total & 39 & 280.625 & 7.603 & 100 & n.a. & n.a. \\
\hline
\end{tabular}

Grass species:

None of the grass species grouped within the land-use systems or regions. A. compressus and C. lappacea were the most common grass species occurring in 15 and 14 plots, respectively. $A$. compressus had the highest $\phi_{\text {PT }}$ value of all analysed species ( 
Table 13), although the lowest Shannon Index (Appendix 2). Furthermore, the two crop plantations were not separated (Figure $20 \mathrm{~A}$ ). C. lappacea showed a tendency $(60 \%$ bootstraps) for separation after region except one oil palm plot of the region Harapan which was grouped with the Bukit Dua Belas plots (Figure 20 B). Plots with S. bancana of both crop species paired together without visible pattern (Figure $20 \mathrm{C}$ ).

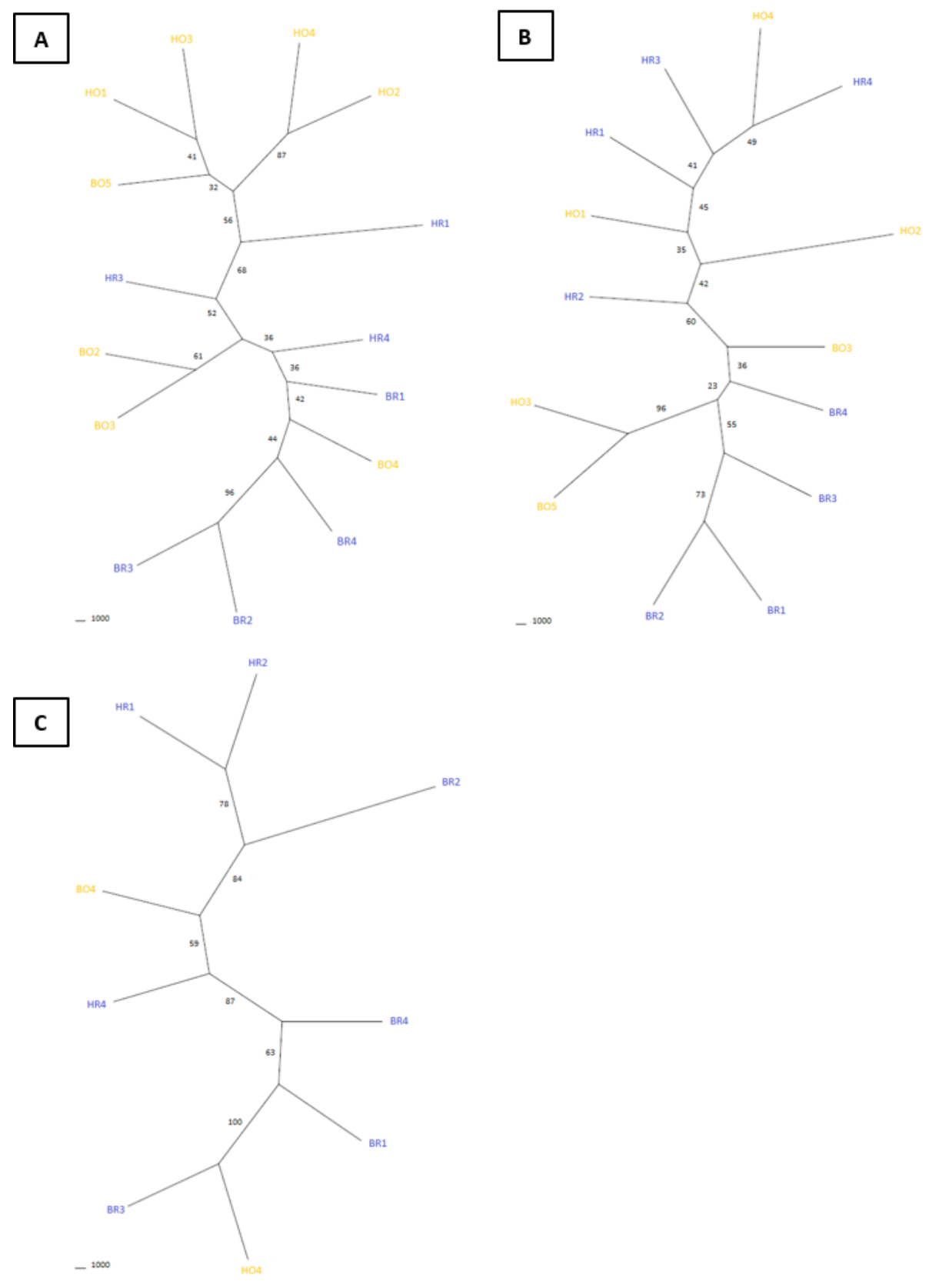

Figure 20: Neighbour Joining dendrogram based on Reynolds distance based on the pairwise genetic distance matrix per plot where the species occurred (10000 permutations, bootstrap values in [\%]). Colours are indicating the land-use system where the species was sampled: oil palm plantation $(\mathrm{O})$ in yellow and rubber plantation $(\mathrm{R})$ in blue in the two regions Bukit Dua Belas (B) and Harapan (H). Shown are the grass species Axonopus compressus (A), Centotheca lappacea (B), Scleria bancana (C). 
Table 13: AMOVA results of three grass species Centotheca lappacea, Axonopus compressus and Scleria bancana. df: degrees of freedom, SS: sum of squares, EV: estimated variance, PV: percentage of variance, $\phi_{\mathrm{PT}}$ : proportion of the variance among populations relative to the total variance, n.a.: not available.

\begin{tabular}{llllllll}
\hline Species & Source & df & SS & Est. Var. & PV [\%] & $\boldsymbol{\phi}_{\mathrm{PT}}$ & $\mathbf{p}$ \\
\hline C. lappacea & Among plot & 3 & 101.093 & 0.685 & 6 & 0.063 & $<0.001$ \\
C. lappacea & Within plot & 136 & 1387.250 & 10.200 & 94 & n.a. & n.a. \\
C. lappacea & Total & 139 & 1488.343 & 10.886 & 100 & n.a. & n.a. \\
\hline A. compressus & Among plot & 14 & 129.894 & 0.826 & 42 & 0.423 & $<0.001$ \\
A. compressus & Within plot & 133 & 150.025 & 1.128 & 58 & n.a. & n.a. \\
A. compressus & Total & 147 & 279.919 & 1.954 & 100 & n.a. & n.a. \\
\hline S. bancana & Among plot & 8 & 450.156 & 4.703 & 34 & 0.337 & $<0.001$ \\
S. bancana & Within plot & 81 & 748.500 & 9.241 & 66 & n.a. & n.a. \\
S. bancana & Total & 89 & 1198.656 & 13.944 & 100 & n.a. & n.a. \\
\hline
\end{tabular}

Fern species:

The three fern species showed, similar to all other species groups, no region or land-use cluster. D. linearis did not separate between regions. The two rubber plots in Bukit Dua Belas separated with high support (70 \%) from the three other plots. Furthermore, the one rubber plantation of the region Harapan paired together with one oil palm plot of Bukit Dua Belas (92\%) (Figure 21 A). N. acutifolia results showed low support of the dendrogram (highest bootstrap value, $55 \%$ ) and both regions did not separate (Figure 21 B). G. verrucosum showed significant but very low differentiation among the plots (Table 14). Variance among populations for all three fern species was very low but significant (Table 15). 


\section{A}

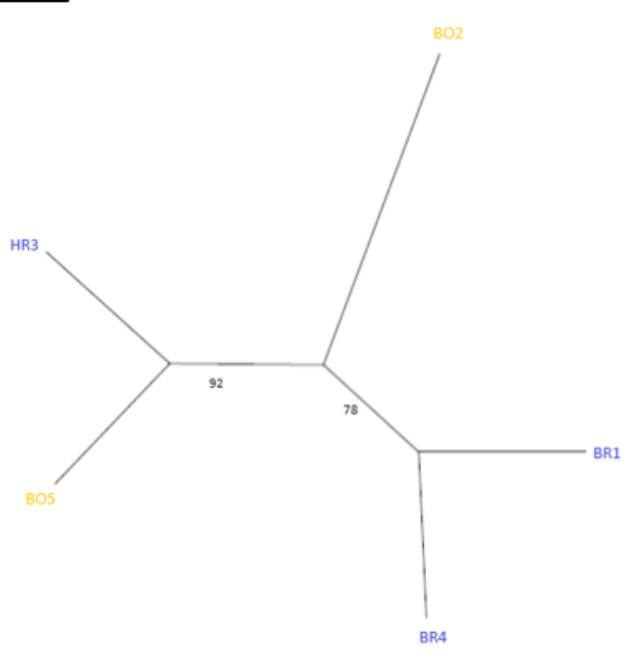

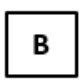

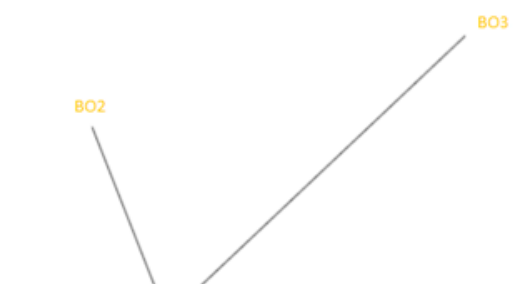

Figure 21: Neighbour Joining dendrogram based on Reynolds distance based on the pairwise genetic distance matrix per plot where the species occurred (10000 permutations, bootstrap values in [\%]). Colours are indicating the land-use system where the species was sampled: oil palm plantation $(\mathrm{O})$ in yellow and rubber plantation $(\mathrm{R})$ in blue in the two regions Bukit Dua Belas (B) and Harapan (H). Shown are the fern species Dicranopteris linearis (A), and Nephrolepis acutifolia (B).

Table 14: Pairwise $\phi_{\text {PT }}$ of Goniophlebium verrucosum in three oil palm (O) plots in Harapan (H). Significance levels ( $p$-value): n.s. not significant, $\mathrm{p}<0.05^{*}, \mathrm{p}<0.01^{* *}, \mathrm{p}<0.001^{* * *}$

\begin{tabular}{ccc|c}
$\mathrm{HO} 3$ & $\mathrm{HO} 2$ & $\mathrm{HO} 1$ & \\
\hline & $* *$ & $* * *$ & $\mathrm{HO} 3$ \\
0.023 & & $* *$ & $\mathrm{HO} 2$ \\
0.050 & 0.024 & & $\mathrm{HO} 1$
\end{tabular}

Table 15: AMOVA results of three fern species, Dicranopteris linearis, Goniophlebium verrucosum and Nephrolepis acutifolia. df: degrees of freedom, SS: sum of squares, EV: estimated variance, PV: percentage of variance, $\phi_{\mathrm{PT}}$ : proportion of the variance among populations relative to the total variance, n.a.: not available.

\begin{tabular}{llllllll}
\hline Species & Source & df & SS & Est. Var. & PV [\%] & 中PT & p \\
\hline D. linearis & Among plot & 4 & 176.080 & 1.972 & 8 & 0.075 & $<0.01$ \\
D. linearis & Within plot & 45 & 1093.400 & 24.298 & 92 & n.a. & n.a. \\
D. linearis & Total & 49 & 1269.480 & 26.270 & 100 & n.a. & n.a. \\
\hline G. verrucosum & Among plot & 2 & 79.880 & 1.005 & 3 & 0.032 & $<0.01$ \\
G. verrucosum & Within plot & 26 & 786.189 & 30.238 & 97 & n.a. & n.a. \\
G. verrucosum & Total & 28 & 866.069 & 31.243 & 100 & n.a. & n.a. \\
\hline N. acutifolia & Among plot & 6 & 67.343 & 0.383 & 5 & 0.049 & $<0.001$ \\
N. acutifolia & Within plot & 63 & 465.500 & 7.389 & 95 & n.a. & n.a. \\
N. acutifolia & Total & 69 & 532.843 & 7.772 & 100 & n.a. & n.a. \\
\hline
\end{tabular}




\section{DISCUSSION}

In the present study, the genetic diversity of dominant plant species in four different land-use systems in Sumatra Indonesia was investigated. The three land-use systems, oil palm, rubber and jungle rubber and the natural vegetation of an old growth tropical lowland rainforest are reflecting different agricultural intensities with different plant compositions and genetic diversity of the dominant plant species. Each land-use system was investigated with a community based and a species based approach. The mixed effect model was used to test for significant differences among the four land-use systems in genetic diversity of the plant community at three spatial scales: within each plot, within each land-use system and within each region. For the species analysis, frequently sampled species were investigated in detail regarding their genetic structure depending on their land-use system and life form.

Results indicate that land-use change per se does not have an effect on genetic diversity. Genetic diversity and the differentiation with increasing spatial scale, depends highly on life form, population density, gene flow, migration and evolutionary history (Hamrick et al. 1992), which is reflected in this project by the high variability within each plot and within the life form groups.

The fragment pool approach presents a method, which is able to calculate genetic differentiation of a plant community within and among land-use systems without comparing different species directly. Further, results of Mantel test and AMOVA show that basic population genetic analyses can be carried out with fragment pool approach as well. Due to the high genetic diversity, the highest potential of conserving genetic resources was shown by forest and jungle rubber. Jungle rubber with high genetic diversity but lower species diversity than forest may represent a buffer zone between natural vegetation and agricultural areas. The two plantation systems showed relatively high genetic diversity levels of non-native species, thus are not qualified as potential areas for conserving genetic resources of natural vegetation.

Until now, the genetic studies, mostly based on single species, conducted for conservation purposes shown various results (Kramer et al. 2008). In an era of fast and vast land-use change in the tropics, an applicable and effective method for identifying biodiversity hotspots and determining protected areas is necessary (Andam et al. 2008). For animal and plant diversity such methods have already been developed, but genetic diversity is usually not included 
(Souto et al. 2015). To increase effectiveness of conservation management in the tropics, threats need to be identified and cost effective standardization of monitoring and research activities introduced (Sheil 2001).

The present study is not entitled to provide detailed genetic patterns of fragmented species, but provide an example for a universally applicable method to assess genetic diversity differences of dominant plant species in different areas and land-use systems.

In the following discussion the sampling design, the molecular marker and analyses measures will be discussed, followed by the community analyses, were genetic diversity was investigated at three spatial scales and correlated with other ecosystem factors such as species diversity. In the second part, the species based analyses of the frequently collected species distinguished by the life form are discussed. Finally community and species based analysis are compared.

\subsection{Plant MATERIAL COLLECTION AND AFLP ANALYSIS}

Dominant species are expected to have highest influence on the ecosystem and represent them the most (Grime 2001; Avolio et al. 2011). For conservation purposes, it would be best to investigate every species to be able to consider their characteristics. That being impossible, due to time and financial limitations, investigating dominant species of an ecosystem is a reasonable compromise. Using the "Bitterlich-Method" to choose the dominant tree species in every plot assures the randomization and objectivity of the selection. Selecting species with only ten individuals in or close to the $50 \times 50$ m plot means neglecting large trees with low densities. Outcrossing species which recently declined in their population size, e.g. due to deforestation, are assumed to be most threatened by genetic consequences of forest fragmentation (Aguilar et al. 2008). Albeit, a larger investigation area could not be defined, due to the small jungle rubber patches, still remaining in the area. Hence, with increasing plot size, it would become difficult to distinguish the populations. Furthermore, even with smaller tree heights but with higher number of individuals understorey species are still dominant in the investigated plots. In addition, the disturbance degree in the forest plots was very different and in the plots of Bukit Dua Belas there were only fewer high trees than in Harpan. The percentage of trees with a DBH above $10 \mathrm{~cm}$ and height above $15 \mathrm{~m}$ was 55 in Bukit Dua Belas and 86 in Harapan (Rembold et al. unpublished). Finally, to be able to combine the 


\section{DISCUSSION}

results of this analysis with other subprojects of the EFForTS project, the sampling area needed to be the same as in other subprojects.

\subsection{DATA ANALYSIS}

Due to the dominant nature of AFLP markers, the availability of analytical methods that could be used in this study is already limited (see below). Since, the goal of this study was to compare genetic diversity of plant communities, three aspects needed to be considered during the analysis, which lead to use of AFLPs as a molecular marker and Morisita-Horn and ShannonIndex as the diversity measures.

First, AFLP fragments of different species could not be compared since the origins of fragments of the same size are unknown. Second, the different number of samples taken per species, and most importantly third, every species has its unique number of fragments, which varied highly among the collected species.

Two approaches are common for population/unit structure analysis using AFLP data, presence and absence of bands and allele frequencies at each locus (Kosman \& Leonard 2005). Frequency based approach could not be used here and thus are not discussed, due to the different number of samples taken per species (Mba \& Tohme 2005). They are only reliable with high number of samples and with outcrossing species (Mba \& Tohme 2005; Meudt \& Clarke 2007), but information on this is unknown for most collected species. Commonly used indices based on presence and absence of bands/fragments and commonly used are Jaccard's coefficient (Jaccard 1908), Simple Matching coefficient (Sokal and Michener 1958), Dice/ NeiLi (Nei \& Li 1979; Mba \& Tohme 2005). Jaccard and Dice/ Nei-Li coefficients take the number of present fragments and number of differences in presence into account, but Dice/ Neil-Li puts more weight on the presence of fragments (Bonin et al. 2007). Simple matching coefficient considers both similarity of two samples due to presence and absence of fragments (Bonin et al. 2007). All three indices are dependent on the total number of fragments occurring in a given species, which is not important when calculating differentiation among individuals of one species. Since the possible number of polymorphic loci increases with higher number of fragments, this would bias the results when comparing different species. Thus, the MorisitaHorn dissimilarity index (Horn 1966) was used for the both approaches, i.e. fragment-pool and species approach, at $\alpha-, \beta$ - and $\gamma$-level. Morisita-Horn does not depend on the sample size (Wolda 1981) and does not change in the behaviour with the level of dissimilarity (e.g. very 
close to zero) like other indices (Linton et al. 1981; Wolda 1981). Some studies suggest the Bray-Curtis Index to be more accurate, but in the R-package vegan (Oksanen et al. 2015) BrayCurtis and Morisita-Horn indices for binary data are calculated with the same formula (Oksanen et al. 2015). To the author's knowledge, until now studies about plant genetic structure did not use the Morisita-Horn dissimilarity. Hence, for a better comparison with other studies the Shannon Index (Shannon \& Weaver 1949) was also used as a common genetic diversity measure. In this project several species with a high variation in fragment number were compared, which can lead to a bias using the Shannon Information Index. Further, the Morisita-Horn index is widely used as a $\beta$-diversity index and the Shannon Index as an $\alpha$-diversity index in ecology, both were compared at the three different scales. In ecology, "differentiation" and "diversity" are used as a synonym when calculating $\beta$-diversity (Koleff et al. 2003). In population genetics, Fst or Gst measure the differentiation among collections regarding their composition with accounting for the geographical location of each individual (Gregorius 2010). By calculating the two indices, diversity and differentiation, the project tries to benefit from the advantages of both.

The different results, increasing genetic diversity and decreasing genetic differentiation, in the present study, are not surprising due to different nature of the two indices, diversity and differentiation (White 1986). The results per species by calculating the Morisita-Horn index per species had similar results for all three diversity levels. One reason can be the high variability of differentiation within a species and among the species, which reduces the chance of detecting differences among the land-use systems. The power analysis suggests that for this approach a 10 times higher number of plots per land-use system would be necessary to have significant results if the tested effects are the real effects, confirming the above mentioned explanation. The Shannon Index decreases this problem by calculating the index per locus of a species and takes the mean for the whole species or population. Therefore, the Shannon index is depending on the number of individuals (Goodman 1975). Which is again not a problem when comparing populations of one species, i.e. individuals have the same number of loci. Calculating the Morisita-Horn index with the fragment pool approach is avoiding both, high variability and number of fragments, by calculating the differentiation between individuals of the same species and having automatically a mean value of the variation between the different species. 


\section{DISCUSSION}

One could argue to increase the number of samples to 25 (Namkoong et al. 1996) or 50 (Frankel 1995) and follow suggestions of traditional population geneticists, to avoid the Shannon Index limitation, but considering the size of forest and jungle rubber patches and tree densities, these numbers could not be achieved in this project. The GLMM results are preferred to the t-test results because, in contrast to the latter one, GLMM is robust to the violation of normal distribution and the independence of the variables (Lindstrom \& Bates 1988; Baayen et al. 2008). In this study, the independency of genetic diversity of each species in the respective plot could not be guaranteed. Species sampled in several plots might interact regarding gene flow, which influenced the intraspecific diversity level of interacting species plots and the diversity values would not be independent.

\subsubsection{COMMUNITY ANALYSIS}

\subsubsection{LAND-USE SYSTEM HETEROGENEITY}

The first hypothesis, that the dominant species composition in each land-use system is unique, could only be partly confirmed. The two plantation systems shared several species and were very similar in dominant species composition. The fragment pool approach is able to display the different species compositions of each plot using the AFLP matrices (Figure 8). As expected jungle rubber plots present a bit the intermediate system between forest and rubber plantations, having trees as the dominant life form and sharing with the rubber plantation at least one species. Structure and species composition in jungle rubber and forest are depending on the degree of disturbance (Laumonier 1997). Due to management in some rubber plantation plots, one or two tree species occurred dominant in the plots. Dominant species of the plantations systems might occur in jungle rubber and forest but not as dominant in biomass.

\subsubsection{GENETIC DIVERSITY AT THREE DIFFERENT SPATIAL SCALES}

The level of genetic differentiation among populations may accumulate with geographic distance and may be influenced by environmental heterogeneity such as the presence of gene flow barriers in fragmented landscapes (Duforet-Frebourg \& Blum 2014; Wang \& Bradburd 2014). Further, land-use intensities itself can cause genetic differentiation of life-history traits among population in different land-use systems (Völler et al. 2013). Theoretical predictions of 
high differentiation and low genetic diversity of tree populations in a fragmented landscape due to limited gene flow and genetic drift could not always be confirmed (Kramer et al. 2008). In this project, three spatial scales (within plot, within land-use system, within region) were investigated, to assess the mean genetic differentiation and diversity of the dominant plant species and the dependency on the land-use systems. The three spatial scales represent areas with different spatial sizes, thus, different geographic distances among individuals were considered by calculating genetic differentiation among individuals within the same and different plots. The tree-dominated systems were expected to have high local ( $\alpha$-level) genetic diversity and lower differentiation on a larger scale ( $\gamma$-level) and the plantation systems dominated by vegetative growing species may show the opposite pattern. A generalized mixed effect model was used to test for significant differences of genetic diversity among the four land-use systems at the three spatial scales, respectively.

Mean differentiation (Morisita-Horn dissimilarity) with the species approach did not detect any differences among the land-use systems at all three spatial scales. The species approach using the Shannon Index showed significant differences among the highest (tree-dominated systems) and lowest (plantation systems) diversities for $\alpha$ - and $\beta$-level. At $\gamma$-level no significant differences could be detected. For the fragment pool approach significant differences at $\alpha$ level could be detected between jungle rubber with highest genetic differentiation and oil palm plantation with the lowest. At $\beta$-level, forest showed lowest differentiation levels and were significantly different to all other land-use systems. At $y$-level differentiation of the dominant plants in oil palm plantations were highest, in forest lowest. Jungle rubber and rubber plantation showed intermediate differentiation levels. Due to the non-significant results for the species approach using the Morisita-Horn index, only the Shannon Index and the fragment pool approach are discussed in detail.

For the fragment pool approach, the observed decreasing level of differentiation with increasing number of compared individuals and increasing geographic distance among them was not expected. Especially because the mean genetic diversity values calculated with the Shannon Index increased from $\alpha$ - to $\gamma$-diversity level. Greater changes from $\alpha$ - to $\beta$ / $\gamma$-level, using both the fragment pool and species approach, in the plantation systems compared to the tree-dominated systems, can be explained by the higher similarity in the species composition and the differences in gene flow between non-woody and woody species (Hamrick et al. 1992; Austerlitz et al. 2000). 


\section{DISCUSSION}

The contradictory results of mean genetic differentiation and diversity are due to the dependency on the nature of the index and on the dominant species composition with their abundance within and among land-use systems. The differences are very plainly shown by the results of the fragment pool approach, where the variation of genetic diversity among the species compared to the Shannon Index, was reduced. Using the fragment pool approach, the total number of loci of all species occurring in the respective plot/land-use system/region were included in every distance calculation. Hence, with increasing spatial scale, the number of loci is increased what decreased the weight of the genetic differentiation among individuals of the species dominant in only one plot on the mean differentiation among fragment pools. The genetic distance among fragment pools stayed the similar due to the high number of species sampled only once, but the number of fragments increased. Even the species effect (presence of a species) was deleted by calculating the fragment clone distance matrix; the increasing number of fragments had a mathematical effect, which lowered the overall differentiation level. Extreme similarity or dissimilarity within species influenced the mean results the most.

On the contrary, for the species dominant in only one plot using the Shannon Index the genetic diversity level remains the same at all three levels, which explains the increasing variance at $\beta$-and $\gamma$-level. The effect of species with extreme values are in the mean values per plot or land-use system are not apparent.

The different abundance of species and their particular genetic differentiation intensify the effect of the indices. The differences between $\alpha$ - and $\beta$-level are based on the species which occurred in more than one plot within the land-use system. For the forest $38 \%$ (13 species of 34) of the tree species dominant in the system occurred in more than one plot, in jungle rubber $24 \%$ (8 species of 33) and in the two plantation systems it is $45 \%$ (19 species of 42 ). Eight of the 13 forest species showed a decreased genetic differentiation within the land-use system than within the plot. Two of these species showed decreased genetic diversity using the Shannon Index as well, but due to the high variance within the land-use systems these results were not visible in that approach. Differences between $\gamma$ - and $\beta$-level were based on an even more reduced number of species. The land-use systems oil palm and rubber plantations share seven species. Forest and jungle rubber share three species, Macaranga bancana (Miq.) Müll.Arg., Endospermum malayanum (Pax \& K.Hoffm) Chatterjee and Parkia speciosa Hassk., with each other. M. bancana was also dominant in two rubber plantations in 
the Harapan region, P. speciosa in one rubber plantation in Harapan. E. malayanum only occurred in the Bukit Dua Belas region. Together, a maximum of two plots of different landuse systems per species were shared. Hence, for most species in tree-dominated systems the differentiation or diversity results did not change from the $\beta$-level to the $\gamma$-level. On the contrary, the seven species shared by the plantations, occurred in the most of the 16 plots. Hence, more populations were considered in the analyses and the changes were higher.

To summarize, the main disadvantage of the high variance within the land-use system when comparing the mean values per species using the Shannon Index can be avoided using the fragment pool approach. Although, the disadvantage of the fragment pool is the high effect of extreme values, which increases the high effect of potential outliers and the decreasing influence of each loci with increasing scale. Due to the increased number of loci considered with increasing spatial scale, the three diversity levels are only comparable with care. This needs to be taken into account when analysing data of the two indices.

As expected, mean genetic diversity is depending on the species dominating the respective land-use system but not on the land-use system. The fragment pool results suggest that for the forest species the lowest mean differentiation among individuals within the land-use system. The lower genetic differentiation among individuals of different plots compared to individuals within plot showed that these species belong to one population with low genetic differentiation. The reduced genetic differentiation may be a consequence of population fragmentation associated limited gene flow and genetic drift (Young et al. 1996). Jungle rubber species showed higher mean differentiation than forest species, which can be due to the higher proportion of species with higher population density. The Shannon Index results do not suggest differences between jungle rubber and forest and low differences to the plantation systems. That suggests that species dominant in jungle rubber might have experienced limitation of gene flow too. Differences in mean genetic diversity and differentiation between single plots and the regions could be detected, although not significantly (Appendix 10). The forest plots in the region Harapan seem to be more homogeneous in mean genetic diversity. Despite low genetic differentiation, these four forest plots might be of higher conservational value than the forest plots in Bukit Dua Belas because the populations of the species seem more continuous and larger. Individuals in BF1 and BF2 showed higher differentiation to all other individuals of shared species than all other plots. The increased differentiation might indicate that the two plots were experiencing limitations 


\section{DISCUSSION}

in gene flow (Hahn et al. 2013; Wang \& Bradburd 2014). In the plantations dominant species from all three life forms (herb, grass, fern) are mainly invasive and/or colonizing species, hence adapted to disturbance (DeWalt \& Hamrick 2004; Ootsuki et al. 2012). Furthermore, they developed strategies to avoid genetic consequences of small population sizes (e.g. genetic drift). All introduced species have already been introduced in Indonesia decades before this study and due to their fast growth abilities and short life span, genetic consequences of bottlenecks could not be detected here (Baker \& Dyer 2011).

The species actually relevant at the $\beta$-level with their genetic differentiation can be observed in the analysis of absolute effective species turnover, which considers only the differentiation of species occurring more than once (Tuomisto 2010). In this project the species which occurred in more than one plot within a land-use system. The results show again the high variability within each land-use system. Genetic differentiation depends highly on the occurring individuals but in general, the plots of plantation systems showed higher similarity than the plots of the tree-dominated systems. The dependency on $\alpha$ - and $\gamma$-level can lead to wrong assumptions about the $\beta$-level genetic differentiation (Tuomisto \& Ruokolainen 2008). Still, analysing the absolute effective species turnover gives information of the genetic differentiation change of species occurring more than once. Furthermore, the difference between the two ways of calculating $\beta$-diversity shows the importance of locally dominating species for assessing the community genetic diversity. A reason for the results might be that the land-use system is not explaining the variable for calculated genetic diversity levels and the sample number included in the calculations was reduced.

Assuming land-use has an effect on genetic diversity, the power analysis suggested in order to get significant results of the species approach (Shannon Index/ Morisita-Horn) at the $\alpha$ level 39/80 plots per land-use systems would be necessary, while only 10 plots would be required for the fragment pool approach. The results show that calculation of the Shannon index with small population sizes can lead to wrong estimations of the genetic diversity when comparing different ecosystems. That confirms the already discussed limitations of the Shannon Index with small sample sizes.

The results of the genetic diversity and differentiation show the dependency on the species with their genetic diversity and its influencing factors. The fragment pool approach is able to detect differences among plots and land-use systems regarding their genetic diversity and combined with other diversity parameters the identification of habitats of high conservational 
concern can be improved. Nevertheless, the calculation of genetic diversity using the Shannon Index has high informative value. Using both indices increases the quality of the results. Plantation systems do not show signs of genetic diversity loss, concerning the analysed species, but since the dominant species are mostly invasive in Indonesia, the plantation systems could not be identified as habitats with high conservation value. However, despite differences in mean genetic differentiation that were detected using the fragment pool approach, a generalization about each land-use system is not possible. On the contrary, results confirm the heterogeneity of genetic diversity among plant species.

\subsubsection{ANALYSIS OF MOLECULAR VARIANCE}

Analysis of molecular variance (AMOVA) shows that the highest variance in differentiation is within the region, except rubber plantations. This result confirms the results of the GLMM, the degree of differentiation cannot be distinguished among the land-use systems. The AMOVA of jungle rubber could not calculate reliable results (negative percent values among regions); hence, they need to be interpreted cautiously. For the tree-dominated systems, this result does not meet the theoretical expectations of within population variance. The theoretical expectations are based on single species studies in other tropical regions. Widespread tropical pioneer species, showed $87-90 \%$ of their variation within populations (Russell et al. 1999b; Lacerda et al. 2001). Similar level of variance to the tree-dominated systems, showed an isolated, endangered species (55 \%) in a fragmented landscape (Lira et al. 2003) and an introduced species in Africa (40 \%) (Muluvi et al. 1999). Even the community based analysis cannot be compared with single species, they are given examples for a variance range for tropical trees with high or low density in fragmented regions. In jungle rubber, which is dominated by pioneer species, the within plot variance is much lower (48\%). The most abundant pioneer species Macaranga bancana showed $65 \%$ of within population variance. The expectation, that trees have higher genetic variation than species with shorter longevity and contain most of the variation within the population (Hamrick \& Loveless 1989; Hamrick et al. 1992) could not be confirmed in this project (within plot variance $43 \%$ forest and $48 \%$ jungle rubber). Two possibilities can explain this pattern, first the low genetic differentiation of the tree-dominated systems, or second the spatial area of a population (one plot) is too small and the entire region itself can be considered as one population. With the second case the within population variance would be highest. Furthermore, regions only contribute a small 


\section{DISCUSSION}

percentage to the total variation within the land-use systems and are not significantly different, which is also concurrent with the GLMM result.

\subsubsection{Mantel test}

The correlation of the genetic distance with the geographic distance showed different results for the two regions, which can be explained by the specific gene flow patterns of the occurring species. In contrast to Harapan species, Bukit Dua Belas species do not seem to experience limitations in gene flow. Although the correlation is significant, only $27 \%$ (without crop species) of the collected species occurred more than three times, which is necessary for this calculation. The positive correlation for the Harapan region might be due to the very homogeneous Harapan forest plots, which share several species and are more closely related than to the species they share with jungle rubber. The forest plots in Bukit Dua Belas are very heterogeneous and do not share as many species as Harapan forest plots. However, forest plots in Harapan have a higher geographic distance to the transformed systems than in Bukit Dua Belas. Again, these results show the higher influence of species characteristics and species presence than of land-use system on plant genetic diversity.

Assuming high within population genetic diversity in tropical tree species (Loveless \& Hamrick 1984; Aldrich et al. 1998; Fuchs \& Hamrick 2010), the results lead to the conclusion that the analysed forest tree species already experienced severe consequences of fragmentation and disturbance in the old growth forest. Species of primary forests need to be analysed to confirm the suggested status of the forest plots investigated here. The impact of the possible related tree individuals on the genetic differentiation per plot could not be assessed. Studies about tropical tree species either sample across a wider spatial range (Silva et al. 2008; Ismail et al. 2012; Sampson et al. 2014) or use codominant markers and expected heterozygosity as the genetic diversity index (Collevatti et al. 2001; Finger et al. 2011). Using a data set with a larger distance between individuals, the genetic diversity might increase for the tree species. Plantation management needs to be changed to better meet the requirements of native species, so that the dominance of invasive species can be reduced (Didham et al. 2007). The use of herbicides, fertilizer and the frequency of disturbance give the fast colonizing species an advantage so that other species are not able to compete.

Summarizing the results of the land-use system comparison, mean genetic diversity patterns cannot be explained only by the factor land-use system. Many factors, mainly the specific life 
history traits of a species, are influencing genetic diversity, which could not be considered in this study. The most interesting result for the community approach is that different genetic diversity levels in each land-use system could be detected using a small number of samples using the fragment pool approach.

\subsubsection{CORRELATION OF GENETIC DIVERSITY AND SPECIES DIVERSITY AND SOIL VARIABLES}

Changes of abiotic and biotic factors can indirectly influence changes of genetic diversity of plants and plants can influence ecosystem processes (Bailey et al. 2009).

Soil condition and the species diversity of plants, mycorrhiza and prokaryotes were tested for correlation with the plant genetic diversity to test if one parameter can be an indicator of the other. Soil condition, mycorrhiza diversity and soil prokaryotic diversity changed due to the conversion of forest too (Schneider et al. 2015; Allen et al. 2015; Guillaume et al. 2015; Edy 2015). As expected, the closest correlation was between plant species diversity and genetic diversity of plants. Genetic and species diversity is expected to decline with decreasing forest fragment size (Wright 1940; Ewers \& Didham 2006). Plant species diversity is clearly decreasing from forest to jungle rubber to the plantation systems (Rembold et al. unpublished), which is not the case for the plant genetic diversity.

Correlations between tree species diversity and genetic diversity of one tree species could not be found (Wehenkel et al. 2009). Vellend \& Geber (2005) suggested three theoretically possible ways genetic and species diversity can be connected, I. parallel effects on immigration of species, genetic drift and selection. II. strong genotypes influencing species diversity and III. species diversity is influencing selection of a given genotype. The second and third case are possible when comparing the same species composition in a competitive situation (Vellend 2006). In this study, land-use effects species diversity and genetic diversity, which represent the first case. Due to different species compositions in all plots, not all species interact and case II and III cannot be investigated. Oil palm and rubber plantation had the highest overlap of species composition but no pattern was visible that lower or higher species diversity had an impact on the genetic diversity of a species. The variation within the two land-use systems oil palm and rubber plantation was high for all four species diversity calculations. Probably management of the plantations and other environmental parameter are mainly influencing species composition and the genetic diversity of the dominant species. Case II and III could 


\section{DISCUSSION}

only be detected if all other possible factors influencing genetic and species diversity can be excluded which is only possible in controlled experiments. To detect the direct influence of the both diversities to one another, species composition should stay the same with increasing diversity, which is in reality never the case (Vellend \& Geber 2005).

In addition, no clear genetic diversity but clear species diversity decline was found, when comparing species diversity with the genetic diversity of three bat species in fragmented habitats in Malaysia (Struebig et al. 2011). The authors argued that the fragmentation effect of species diversity for bat species depends on their different life history traits.

Schweitzer et al. (2004) observed that polyphenol concentrations in Populus fremontii L., are determined by genetic variation and influences nitrogen mineralization rate. Nitrogen concentration and mineralization rate is depending available bacteria and fungi species in the soil. This would mean that the genetic variation of the tree species is influencing the nitrogen uptake, what could give certain individuals an advantage. In this study, polyphenol concentration was not investigated, but the changes in soil-nitrogen cycle leads to the conclusion that the nitrogen availability for plants differ among the land-use systems (Allen et al. 2015).

Nevertheless, Avolio \& Smith (2013) suggested, that different responses of the two species and genetic diversity levels on environmental heterogeneity are responsible for non-existent correlation between species and genetic diversity. It is not possible to compare results of the competition studies here, since the species analysed here belong to several trophic levels. Species $\alpha$-diversity can influence genetic differentiation ( $\beta$-diversity) and vice versa (Kahilainen et al. 2014), but for this analysis the data in this study was not yet available and will be carried out at a later point. However, the parallel mechanisms influencing species and genetic diversity are in this case land-use change and its consequences.

Correlations to species diversity of mycorrhiza and prokaryotes show the variation of species in their responses to land-use change. The mentioned correlations do not mean that one factor is causing the other one but already these four correlations show the manifold parameters within the complex ecosystem tropical rainforest, which is changing due to landuse change. Plants do not only have to adapt to the abiotic changes (e.g. consequences of erosion, precipitation) and the changes of their associated species (e.g. mycorrhiza diversity), habitat conditions and competition changes (species diversity), they also experience the effects of their declining population density. 
However, the fast changes demand high genetic diversity to survive the increasing heterogeneity of habitats. Wrong categorising of an ecosystem only based on species diversity and abiotic factors can lead to the wrong assumption about a conservational important hotspot. It is necessary to define indicator parameters for the identification of ecosystems, which are able to conserve species and ecosystem services in time of immense human impact on natural resources. In particular because the results of this study show that species diversity of plants and other organisms cannot explain genetic diversity in different land-use systems.

\subsubsection{SPECIES BASED ANALYSIS}

\subsubsection{GENETIC DIVERSITY OF THE COLLECTED SPECIES ACCORDING TO THEIR LIFE FORM}

Using $\alpha$-genetic diversity it was not possible to distinguish all four land-use systems. The variability showed the high dependency on the collected species and their life history strategies in each plot. The life forms and life history strategies of the species were, as expected, distributed for the four land-use systems but not the genetic diversity. Trees dominated forest and jungle rubber and non-woody species the plantation systems. Species evolved into their own ecological, partly with other species overlapping, niche within the ecosystem (May \& Arthur 1972). Landscape dynamics, ecosystem heterogeneity and the niche size is influencing the community similarity regarding their phylogenetic and intraspecific variance (Violle et al. 2012; Parks \& Beiko 2012; Gascuel et al. 2015). The combination of genetic diversity and ecological niche factors can provide information of past and future range dynamics of a species (Fordham et al. 2014). However, species adapted to light and disturbance, have an advantage in the three transformed systems. Forest plots were very heterogeneous in light availability. Pioneer species, dominant in forest plots too, have lower genetic diversity and are more distant to individuals in jungle rubber. Only very common species ("generalists") have highest genetic diversity in the forest. Results indicate that species belonging to other life form groups experience the effects of a bottleneck or founder effects. On the other hand, Nevo (1978) found higher genetic diversity in common species compared to rare and specified species, thus it cannot be excluded that "generalists" do not experience bottleneck effects. Population density seemed to be more important than habitat requirements on genetic diversity, the niche requirements are deciding about species 


\section{DISCUSSION}

presence (Laumonier 1997). Primary forest needs to be investigated to confirm that the low genetic diversity of the forest species analysed here is indeed low.

A tropical forest is temporally and spatially (horizontally and vertically) very heterogeneous, and one main factor influencing this is the light availability (Chazdon et. al 1996). Plant species adapt to different conditions via different life history strategies. Hence, tree species in this project were separated into three groups: pioneers, generalists and secondary species (Okuda et al. 2003). Pioneer species are early successional species, growing fast, adapted to conditions of sudden appearance of light after natural and small unnatural disturbances (Chazdon et. al 1996; Bazzaz \& Pickett 1980). In contrast, late successional species, here called "secondary", are growing more slowly and are more shade tolerant during growing phase. Besides differences in water and nutrient use, light requirements of "pioneer" and "secondary" species differ in individual density, fruiting age, fruiting frequency and seed longevity (Bazzaz \& Pickett 1980). These parameters have high influence on genetic patterns. A high number of collected species belong to climax species, but have a larger tolerance range of light availability. These species were combined here as "generalists". Jungle rubber, as an agroforest system, experiences regular disturbances and differs in the species composition to old growth forest.

Abundance of the species belonging to the three groups differed between forest and jungle rubber. In the forest, pioneer trees were not dominant (Harapan) or only with a small proportion of species (Bukit Dua Belas). Forest is dominated by species from the secondary and generalist group, jungle rubber with pioneer and generalist species. In Harapan the group "generalist" were the most abundant group. The dominance, in biomass, shift from late successional species in primary forest to pioneer species in disturbed forests was also observed in Malaysian lowland forests (Okuda et al. 2003). Finding "generalists" as the most abundant group in forest and jungle rubber indicate a highly degraded status of the forest. Species of the groups "pioneer" and "secondary" showed higher genetic diversity in jungle rubber than in forest, "generalists" showed higher diversity in forest. The two "pioneer" species collected in rubber plantations had the highest genetic diversity of that group. Regarding the four ecosystems, no significant differences in mean genetic diversity could be detected in the three groups, which is not surprising due to the high variability of genetic diversity within each group. More accurate results could have been achieved by grouping th 
species based on their reproduction system, but this information could not be obtained for most of the collected species.

\subsubsection{GENETIC STRUCTURE OF FREQUENTLY COLLECTED SPECIES \\ Group "secondary":}

A surprising result was that species of the "secondary" group showed lowest genetic diversity in the forest systems. An explanation can be that the occurring "secondary" individuals in jungle rubber are remnants of the time before the logging event and the effects of use are not detectable yet in the dominant (oldest individuals). It is also possible that species of the group already experienced already in the forest the effects of forest fragmentation and have a decreased genetic diversity. Furthermore, individuals of forest are highly related to each other due to the highly fragmented forest and the loss of potential mating partners. Inbreeding coefficient cannot be calculated with reliability using AFLPs, hence the explanation could not be confirmed in this study. Both Dipterocarpaceae species $H$. mengerawan and S. ovalis showed very low differentiation among the plots, hence, there do not seem to be dispersal limitations among them. Dipterocarpaceae are assumed to be sensitive to fragmentation due to their dependency on animals as dispersal vectors, heavy seeds and their low population density ( $\mathrm{Ng}$ et al. 2006). It is reported that Dipterocarpaceae have a weak self-incompability system and apomixis is possible (Ng et al. 2006), although this family is a mainly outcrossing species and pollen is the main contributor to gene flow (Appanah \& Turnbull 1998, Finkeldey \& Hattemer 2007). Cao et al. (2006) investigated two Shorea (Dipterocarpaceae) species, also threatened by deforestation in Indonesia, using AFLPs. The detected genetic diversity (Shannon Index) showed similar values, but lower within population variance as the values of the species Shorea ovalis, investigated in this project. Studies confirm the different effect of land-use change on species. A Malayan study about Shorea ovalis spp. sericea observed only little differences in genetic diversity between natural forest and logged forest stands analysing three different tree size categories, but the overall gene diversity was six times higher than in this study $\left(\mathrm{H}_{\mathrm{e}}=0.185\right)$ ( $\mathrm{Ng}$ et al. 2009). A comparison of three species confirmed that the degree of isolation for Dipterocarpaceae depends on their dispersal vectors, especially pollen carrying insects (Kettle et al. 2011). Even with large differences between species, the low genetic diversity within each plot can lead to the assumption of a low number of potential 


\section{DISCUSSION}

mating partners. Also the age of the sampled individuals is influencing genetic differentiation, after logging the remaining individuals are younger and their relationship to each other is closer (Ng et al. 2009)

Artocarpus elasticus (Moraceae) and Croton argyratus (Euphorbiaceae) are species used by humans. $C$. argyratus was dominant in the forest and $A$. elasticus in jungle rubber. $C$. argyratus showed separation between the two regions and highest differentiation among the populations $\left(\phi_{\mathrm{PT}}=0.368\right)$. A. elasticus showed low differentiation among the plots and no separation between the regions. The jungle rubber species does not seem to experience consequences of fragmentation. There was no other study about genetic patterns of $A$. elasticus and C. argyratus available. A comparison of several Artocarpus species in cultivar in several regions of the world showed close relationships between the two Artocarpus species, which were analysed in this study. Due to vegetative propagation of Artocarpus cultivars, the genetic diversity was considerably lower than in this study (Zerega et al 2006). S. ovalis and C. argyratus show similar genetic diversity per plot but the opposite results in differentiation among populations. To confirm the differences between the two Dipterocarpaceae species and the two used species, individuals of $H$. mengerawan and $S$. ovalis need to be compared in both regions. Still for all four species the low genetic diversity in each plot leads to the conclusion that genetic diversiy has been lost in these populations.

\section{Group "pioneer":}

Species of the "pioneer" group also showed high variability in the degree of differentiation among plots. There was separation between jungle rubber and forest but rubber plantations and regions could not be distinguished. The two forest plots are geographically and genetically very close to each other. That one jungle rubber plot BJ3 and rubber plantation plot are grouped together was surprising because $\phi_{\text {PT }}$ values also showed high differentiation between these two plots. Higher differentiation of the individuals in the rubber plantation plots to the individuals in jungle rubber plots can be explained by the larger geographic distances to other individuals. Two species were dominant in rubber plantations Parkia speciosa, a fruiting tree, which is used by humans, and Macaranga bancana, a fast growing pioneer tree. Overall, no signs of gene flow limitation among the two regions or land-use systems were detected. 
M. bancana is closely associated with ants, which protect them against herbivores, but seed dispersal vectors are several bird or squirrel species (Bänfer et al. 2004), pollinators are mainly thrips species (Guicking et al. 2013). Genetic diversity for M. bancana was high in all plots $\left(I_{\text {mean }}=0.44\right)$. Macaranga species are mainly distributed along streets and rivers and forest gaps (pers. obs., Murase et al 2003) and showed increased abundance due to forest fragmentation (Bänfer et al. 2006; Guicking et al. 2013). Phylogeographic analyses of Macaranga species in South East Asia suggests, wide dispersal ranges and possible hybridization events in the past (Bänfer et al. 2006). Guicking et al. (2013) expect that thrips are able to manage large flight distances in open habitats, which are typical for pioneer species like Macaranga. These factors might be a reason for the high genetic diversity of M. bancana, but also can explain the low differentiation among plots, land-use systems and regions. $M$. bancana and $C$. argyratus showed highest differentiation of all tree species among plots. The presence of "pioneer" species and their colonizing of new habitats are part of spatial and temporal dynamics of succession in a landscape. Furthermore, for conservation plans information about disturbance length, distances to other patches of populations within the landscape and patch lifespan are crucial (Bossuyt \& Honnay 2006).

\section{Group "generalist":}

Similar to the other species, the four analysed species of the "generalist" group showed variability in their differentiation among plots and regions. Aporosa nitida and Porterandia anisophylla plots separated into the two regions, Parkia speciosa and Alstonia scholaris did not show any differentiation among regions or land-use system.

Due to the edible fruits, some farmers do not cut $P$. speciosa individuals in rubber plantations, thus higher abundance and increased genetic diversity was expected. Nevertheless, $P$. speciosa showed very low genetic diversity $(I=0.10)$ in rubber plantations. Ratnam \& Boyle (2000) suggested that harvesting fruits has a higher impact on genetic diversity and regeneration of $P$. speciosa than logging. Logging itself does not reduce the genetic diversity of a species but the gene pool of naturally regenerated progenies differs compared to the parental individuals (Ratnam \& Boyle 2000). Over time, this result could lead to lower genetic diversity of a population. Furthermore, isolation by distance could be a reason for the lower Shannon Index in rubber plantations and forest plots. 
Comparable studies could not be found for neither the species, nor the genus of the collected species.

$P$. anisophylla showed highest differentiation among plots of the four generalists analysed in detail and separated between the two regions with a high reliability (80\%). Individuals in the Bukit Dua Belas region showed lower genetic diversity than the individuals in Harapan even though the abundance was similar. A. scholaris is a very common species, which can explain the low differentiation among the plots and relatively high genetic diversities per plot. $A$. nititda showed separation between the two regions but also clear separation of BF1 and BF2 from the third forest plot in Bukit Dua Belas. Differentiation was similar to P. speciosa which has similar habitat requirements (Prosea book).

The analysed individuals of all species in plot BF1 and BF2, independent from their life history traits, showed greater distance to the individuals of the same species in other plots. BF1 and BF2 distance cannot be explained by the geographic distance but the habitat of these two plots differs from all other forest plots. The plots are located surrounded by disturbed and partly complete logged areas. Furthermore, the plots are on top of a crest surrounded by small creeks and very heterogeneous vegetation and habitats.

Primary and secondary forests differ in their proportion of pioneer and late successional species and the proportion of large trees (above $20 \mathrm{~m}$ ) (Gouyon et al. 1993). Most of the secondary forest in Sumatra belonged to jungle rubber (Gouyon et al. 1993). The high number of "secondary" species and suggests a high degree of disturbance of the forest plots in this study. "Generalists" and "secondary" species occur in a very similar proportion in the forest.

\section{Crop species:}

Low genetic diversity and low differentiation of the two crop species were expected. Oil palm and rubber are both non-native in Indonesia. Rubber was brought to Asia 1876 (Wickham seeds) from the Amazonian basin (Besse et al. 1994). Cultivation is conducted by vegetative propagation of the clones. $\mathrm{H}$. brasiliensis is an outcrossing species but the seed yield is very low, due to inbreeding depression (Lespinasse et al. 2000). Mean genetic diversity did not differ between the jungle rubber and rubber plantation, probably due to the similar age and the same available planting material. Rubber clones originated from the Amazonian basin 
used outside South America showed similar high relationships among the samples and did not decrease extremely compared to wild rubber (Besse et al. 1994). Explanations for the opposing phenomena of inbreeding depression and not too extreme decline of genetic diversity were not suggested in that paper. Clones from other populations were brought to Asia (Clement-Demange 2007), but it is not clear which one was brought to Indonesia. Probably the planting material, used in all plots, is originated from the same clone.

The used planting material for Indonesian plantations are from breeding projects and are based on two groups, " $A$ " and "B" carried out by the Indonesian Oil Palm Research Institute (IOPRI) (Purba et al. 2000). Comparing four populations from four different origins in Africa of the IOPRI total number of Percentage of Polymorphic Loci was $61 \%$, which is only a little higher than the results of this study. The lower results lead to the conclusion that the planting material in the analysed plantations originated from one or two of the four populations. BO2 and $\mathrm{BO} 5$ showed high distance to all other individuals from both regions (bootstraps 99\%). It is also possible that $\mathrm{BO} 2$ and $\mathrm{BO} 5$ differ in age, planting year or planting material. The oldest sampled plot $\mathrm{HO} 1$ showed also with $\mathrm{HO} 4$ higher distance to other plots. Oil palm showed higher differentiation among the plots than rubber individuals, probably due to the different production of planting material. Oil palm seeds are planted and for rubber clonal propagation is carried out.

Herb species:

Herbs are expected to have a lower genetic diversity and higher differentiation among populations than trees due to smaller dispersal range and shorter life cycle span (Hamrick et al. 1979). No herb species analysed in detail, showed any structure between the two regions but significant differentiation among plots. Clidemia hirta, Asystasia gangetica are both invasive and introduced species, Melastoma malbrathicum and Spermacoce alata are pioneer species. Only M. malabrathicum is native in Indonesia (Gross 1993). All three A. gangetica populations showed high variance among the plots but the plots did not separate into the two regions. $M$. malabrathicum showed lowest differentiation of the four selected herb species. M. malabrathicum is mainly outcrossing and the dependency on pollinators supports the stability of the genetic diversity level (Gross 1993). S. alata is an outcrossing species but vegetative growth can occur too. S. alata showed second highest differentiation but the 


\section{DISCUSSION}

genetic diversity within each plot was very low, which leads to the conlcusion that vegetative growth was the main reproduction strategy in the analysed plots.

Furthermore, $A$. gangetica is a polyploid species, which gives advantages under adaptation pressure (Pandit et al. 2006) and increases genetic diversity when using a whole genome molecular marker system like AFLPs. As colonizing species, all four species are highly adapted to disturbed habitats. The founder effect, i.e. the loss of genetic variation due to a small population size, occurs e.g. when plants are introduced. The loss of genetic variation can be reduced with a high population growth rate (Allendorf \& Luikart 2007). Genetic diversity and differentiation among populations are low, thus populations do not seem isolated but founder effects might contribute to the low genetic diversity.

C. hirta showed similar results in other tropical countries, were it was introduced, low genetic diversity but no detectable differentiation among populations due to probable high gene flow rates and maybe multiple introductions in Hawaiian Islands (DeWalt \& Hamrick 2004).

\section{Grass species:}

Axonopus compressus is native in tropical America and was introduced to Indonesia around 1900. Sexual reproduction and vegetative growth is common (Holm et al 1977).

Centotheca lappacea and Scleria bancana are native in Asia. A. compressus and C. lappacea are considered as invasive species (Jagoe n.d.; Ramana et al. 2014; Holm et al. 1977) . All three species do not separate into the land-use systems but differ significantly among the sampled plots. A. compressus and S. bancana showed in contrast high differentiation among the plots. Although no studies about the reproduction system of $A$. compressus are available, the very low genetic diversity of $A$. compressus, the high differentiation among plots and being an invasive species suggest that vegetative growth and apomixis are the dominant reproduction systems for the analysed individuals. Too little is known about $A$. compressus to explain the different genetic patterns compared to the second invasive species $C$. lappacea, which shows high genetic diversity and low differentiation among the plots. A detailed study about $C$. lappacea at the same research sites as this project but including jungle rubber also showed no differentiation among land-use systems or region and low differentiation among plots (Hodac et al. 2016). Scleria bancana belonging to the Cyperaceae is considered as a colonizing species 
and reproduces via seeds and rhizomes (Bryson \& Carter 2008). Hence, shows the same features as the non-native invasive grass species.

\section{Fern species:}

The three analysed fern species showed no effect of the two regions and low differentiation among plots. Only Dicranopteris linearis was dominant in a rubber plantation, the other two were epiphytic growing on oil palm. Genetic diversity differed among the fern species like all other life forms. Three aspects are influencing ferns in their genetic diversity the most, large genome/ polyploidy, their two life-cycle stages and non-sexual reproduction. Due to the two life-cycle stages, gametophyte and sporophyte, two stages of dispersal and reproduction, i.e. higher genetic diversity, can occur. Nevertheless, in both stages non-sexual reproduction can occur which reduces the genetic diversity. The gametophyte can develop into a sporophyte without fertilisation, with self-fertilisation and outcrossing, the sporophyte can grow vegetative via rhizomes (Page 2002). Spores founding a population can be self-fertile showing no genetic diversity, but several strategies lead to some genetic variation in the new population (Schneller et al. 1998; Ootsuki et al. 2012). For the two G. verrucosum and N. acutifolia, no genetic diversity data were available, but considering their epiphytic growth on oil palm, no habitat restriction occurs for the two species in Jambi Province. In contrast to $G$. verrucosum and $D$. linearis, N. acutifolia showed low genetic diversity within each plot. Since samples were taken from oil palms, with maximum distance in each plot, vegetative growth might be unlikely to be the reason for the low level of genetic diversity. Events of selffertilisation of the gametophyte may be higher than in G. verrucosum and D. linearis. Clonal growth is the main reproduction form of $D$. linearis but intergametophytic sexual reproduction occurs and is common at early successional sites in Hawaii (Russell et al. 1999). Genetic diversity was lower than in this study but the populations in Hawaii were more isolated. 


\subsection{CONCLUSIONS}

The present study provides a method to investigate the genetic diversity of dominant plant species due to land-use change. To obtain information about the genetic resources in the remaining forest in the tropics can improve conservation management of natural ecosystems. The first hypothesis, dominating plant species do not overlap among land-use systems, could not be confirmed since rubber and oil palm plantations share several species, but the total species composition and genetic relationship among the individuals let all plots of each landuse system group together.

The second hypothesis that mean genetic diversity declines from forest to jungle rubber to rubber and oil palm plantations was tested with two approaches, species diversity and species differentiation at three spatial scales, and could not be confirmed either. Mean values per plot showed two groups in genetic diversity: the tree-dominated group with high genetic diversity and the plantation systems with low genetic diversity.

Mean differentiation, the third hypothesis, showed no significant differences among the landuse systems. Furthermore, results indicate the dependency of genetic diversity on life form and life history traits of each species. The results could show different patterns of differentiation comparing the three spatial scales in each land-use system.

The analysis of dominant species is a possibility to identify areas of high genetic value. The plantation systems are seldom dominated by native non-colonizing species and are not potential habitats for preserving genetic diversity. Species in the forest plots already experienced the consequences of habitats loss and fragmentation, which shows the urge of the necessity for effective conservation management plans of remaining forest in Sumatra. Comparing forest and jungle rubber, the level of genetic diversity of the agroforest system is higher and does not decline like the forest on the larger scale. This study identifies jungle rubber as a buffer ecosystem with potential of partly conserving genetic diversity, like other studies already suggested regarding species diversity (Michon \& de Foresta 1995; Michon \& Foresta 1996; Laumonier 1997; Beukema et al. 2007; Laumonier et al. 2010a). Agroforestry systems cannot replace natural forest, but can be buffer zones between natural vegetation and agricultural used systems. Agroforest systems have the advantage of being a traditional land-use system of the local population and has more acceptance than unused forest (Michon \& Foresta 1995). Nevertheless, in forests, species richness is higher and species composition is different (Laumonier 1997; Rembold unpublished). The amount of primary forest species, 
which an agroforest patch can contain, depends on their age and distance to natural forests. If these two factors are taken systematically into account they can be buffer zones among agricultural used land and natural forest and provide a genetic resources reservoir (Laumonier 1997). Villamor (2012) could simulate that with payment for ecosystem services (PES) and low land cover change, species richness can be stabilized, carbon emission can be reduced and the profitability of jungle rubber increased in Jambi Province. Compared to rubber, palm oil agriculture is a higher threat to biodiversity in Indonesia (Koh \& Wilcove 2008). Furthermore, oil palm is in Indonesia usually cultivated in monocultures, which lowers the proportion of agroforest system in the region. This situation is enhanced due to the conversion of rubber plantations and agroforest with rubber to oil palm monocultures (Corley \& Tinker 2003). Hence, the main focus should be developing sustainable agroforest systems with oil palm. Nevertheless, competition for light, nutrients, water and the human yield expectations make it more difficult to establish agroforest systems with oil palm than with rubber. Environmental impacts induced by the rapid expansion of oil palm in Indonesia, need to be reduced and managed (Laurance et al. 2010). The non-profit organization Roundtable on Sustainable Palm Oil (RSPO) mentioned in their criteria and principles (RSPO 2013), that habitats with High Conservation Value (HCV) should be maintained and considered in the management plan of an oil palm plantation (RSPO 2013). The international Convention on Biological Diversity defined the Aichi Biodiversity Targets, where genetic diversity is included too (https://www.cbd.int/sp/targets/). However, criteria how to identify HCV or Aichi biodiversity in each ecosystem, were not defined. The theoretical design of Koh et al. (2009) tries to find a compromise between conservational and economic interests in a tropical landscape. The planned mosaic landscape contains forest fragments, continuous forest, monocultures and agroforestry parts. Agroforest presents buffer zones and increases connectivity between HCV habitats (e.g. primary forest). In the overall landscape, biodiversity, ecosystem function and human welfare is assured. Koh et al. (2009) refers to HCV of the RSPO when describing the protected areas.

Rules and indicators for HCV habitats would give the possibility to design landscapes with effective palm oil (or other crops) productivity, buffer zones and areas of natural forest. Adding genetic diversity information of the plant community to the indicators of HCV habitats when, e.g. determining protected areas or designing a mosaic landscape with protected and used areas, would increase the probability of succeeding in conserving genetic resources. 


\section{DISCUSSION}

Besides the mosaic model, enrichment planting is another possibility to increase connectivity of forest patches and improve ecological and biodiversity parameters in oil palm plantations (Teuscher et al. unpublished). In any sustainable management of the mosaic landscape, HCV or enrichment planting of monocultures, genetic resources have to be considered too. In economically used plants, the preservation of genetic resources is already considered (Rao \& Hodgkin 2002). They mainly have been investigated in terms of the genetic consequences of deforestation; but it does not cover the complete species diversity in tropical forests (Wickneswari \& Cannon 2011). The conservation of forest genetic resources uses two approaches, in situ (on site) and ex situ (off site), to preserve genetic resources of endangered and/ or important species (FAO 2014). Current strategies do not consider species of noneconomic but ecosystem functioning value. The overall estimation for conservation plans of natural vegetation and forest are based on results of single species (Namkoong 1999, FAO 2014). Namkoong et al. (1996) show the high variation of genetic diversity threats but also the high number of developed conservation practices, which is considering the diversity of countries and forest requirements. Albeit the variability is also a difficulty. Porter-Bolland et al. (2012) found that in all tropical regions, protected areas are not adequately managed, due to the high pressure of many factors, e.g. agricultural expansion, infrastructure development and human population growth, enhancing deforestation. Cross-country monitoring and uniformed conservation goals like the Aichi Targets and strategic plan (https://www.cbd.int) may increase data reliability and conservation success (Morales-Hidalgo et al. 2015).

Genetic diversity needs to be included in the defining criteria of HCVs, to improve the sustainability of ecosystem and biodiversity conservation plans. Instead of estimations and maybe neglecting important local species, the fragment pool approach is analysing dominant species in different ecosystems or different regions regarding their genetic diversity can also give an overview of the genetic diversity level of several areas and help to choose which species might be important in its genetic pattern and ecological role within the analysed ecosystem(s). Even with a low number of individuals, results show different behaviour of the plant communities in the different land-use systems. Especially in the highly heterogeneous and fast changing tropical ecosystems, it is necessary to have a universal applicable method to identify HCV habitats. The main disadvantage of the method used in this study, neglecting individuals with low density, can be avoided by extending the analysis in the important areas according to the already existing information. This study showed that the fragment pool 
differentiation analysis of dominant species using AFLPs marker, is an adequate method to identify HCV regarding genetic diversity of plant communities. Including genetic diversity of plants in conservation management plans would increase the chances to conserve biodiversity of natural ecosystems, not only in Indonesia, particularly with regard to future challenges caused by forest loss and climate change. 


\section{SUMMARY}

Forest are covering globally $31 \%$ of the terrestrial area. Tropical rainforests cover $5 \%$ of the terrestrial surface and are biodiversity hotspots due to their high number of endemic species and high species richness. The agricultural expansion increases the deforestation rate in Indonesia to the highest worldwide. Main land-use change drivers in Indonesia are logging, mining activities and the production of rubber (Hevea brasiliensis) and palm oil (Elaeis guineensis), which leads to a forest conversion rate of $20000 \mathrm{~km}^{2} /$ year. Whereas tropical rainforest are an important carbon storage, the global consequences of its conversion, can only be estimated. Local consequences are habitat loss and the fragmentation and degradation of the remnant forest areas. In remaining and degraded forest patches species diversity declines and species composition is altered. Investigations of single species regarding habitat fragmentation effects on genetic diversity of plants showed different responses depending on the specific life history traits of each species. In general, a loss of genetic resources is expected due to genetic drift, reduced gene flow caused by reduced connectivity of remaining forest patches and lower effective population size. This can lead to an altered genetic population structure of the fragmented species, which increases the probability of extinction. The habitat fragmentation effect on the genetic structure was until now only investigated for single species and not for plant communities. In addition, the effect of landuse change on the genetic structure of plants has not been investigated yet.

The aim of this study was to estimate the genetic diversity of dominant plant species in four different agricultural intensities in Sumatra, Indonesia. Using the anonymous AFLP marker, the genetic diversity of ten dominant plant species, with ten individuals respectively, was investigated in four different systems: old growth tropical lowland rainforest, jungle rubber, rubber plantation and oil palm plantation. The four systems were investigated in two regions with four replicates, respectively, which leads to a total of 3200 samples collected in all plots. Due to different species compositions, characterized by different life history traits, a decline of genetic diversity from forest to jungle rubber to rubber plantation to oil palm plantation was expected. Two approaches were carried out, one considering all ten species as a community and second analysing single frequently dominant species. For the community based analysis, two analyses were carried out, one fragment pool approach, were all AFLP fragments of the occurring species were combined in one fragment pool and the 
differentiation was calculated. Moreover, a species approach, where genetic diversity was calculated for each species in all plots, respectively. To test for significant differences among the four systems a mixed effect model was fitted for both approaches. Furthermore, genetic diversity was correlated with the species diversity of plants, mycorrhiza and prokaryotes to test for similar responses to land-use change. For the species based approach frequently collected species were investigated regarding the genetic population structure and differentiation of populations (plots) within and among land-use systems and were grouped according to their life form.

Results of the community analyses with fragment pool and species approach, indicate no direct correlation between genetic diversity of dominant plant species and land-use system. Nevertheless, land-use change caused a different species composition with different characteristics influencing genetic diversity and differentiation. The results identified two levels of genetic diversity, high diversity in the tree-dominated systems and low genetic diversity in the plantation systems. The species based analyses showed a high variability of the different species in their responses to land-use change. Forest species results indicate a loss of genetic diversity. The two plantation systems are dominated by invasive, colonizing species, which are adapted to disturbance. Thus, the mean genetic diversity level of the plantation plots were higher than expected.

The fragment pool approach present an easy and flexible method to estimate the genetic diversity of different land-use systems. The provided results can be used to identify habitats of high conservational value and support conservational management plans of tropical forests. 


\section{ZUSAMMENFASSUNG}

Wälder bedecken $31 \%$ der Landflächen weltweit. Aufgrund ihrer hohen Anzahl an endemischen Arten und ihrem hohen Artenreichtum gehören tropische Regenwälder zu den Biodiversitätshotspots der Welt. Die Ausbreitung von landwirtschaftlich genutzten Flächen führte zu einer verstärkten Degradierung und Waldverlust in Indonesien, die zum heutigen Zeitpunkt global am höchsten ist. Hauptsächliche Ursachen für die Entwaldung des tropischen Regenwaldes in Indonesien sind Holznutzung, Rohstoffabbau und die Produktion von Kautschuk (Hevea brasiliensis) und Palmöl (Elaeis guineensis), daraus folgt eine jährliche Umwandlungsrate von $20000 \mathrm{~km}^{2}$ von natürlichem Regenwald in genutzte Flächen.

Die weltweiten Konsequenzen der Entwaldung können nur geschätzt werden. Lokale Folgen sind Habitatverlust, Fragmentierung und Degradierung von verbleibenden Wäldern. In den verbleibenden Waldfragmenten kommt es zu einer Reduzierung der Artendiversität und einer Veränderung der Artenkombination. Untersuchungen von einzelnen Arten über die Folgen von Habitatfragmentierung auf die genetische Diversität von Pflanzen, zeigen unterschiedliche Ergebnisse, die von den artspezifischen Lebenszyklusstrategien abhängen. Im Allgemeinen ist ein Verlust von genetischen Ressourcen durch genetische Drift und reduzierten Genfluss zu erwarten. Dies entsteht durch die verminderte Austauschkonnektivität der verbleibenden Waldareale und die reduzierte effektive Populationsgröße der dort vorkommenden Arten. Dies kann zu einer Veränderung der genetischen Populationsstruktur der fragmentierten Arten führten, was eine Erhöhung der Wahrscheinlichkeit des Aussterbens der Art zur Folge hat. Der Effekt von HabitatFragmentierung auf die genetische Struktur wurde bisher nur für einzelne Pflanzenarten und nicht für Pflanzengemeinschaften untersucht. Weiterhin wurden keine Studien über die Folgen von Landnutzungsveränderungen auf die genetische Diversität von Pflanzen durchgeführt.

Das Ziel der vorliegenden Studie war die genetische Diversität von dominanten Pflanzenarten in vier verschiedener Systeme mit unterschiedlicher landwirtschaftlicher Intensität in Sumatra, Indonesien, zu untersuchen. Anonyme AFLP Marker wurden genutzt, um die genetische Diversität von zehn dominanten Pflanzenarten, mit jeweils zehn Individuen, in den folgenden vier Landnutzungssystemen abzuschätzen: altgewachsener tropischer Tieflandregenwald, Kautschuk-Dschungel, Kautschukplantage und Palmölplantage. Die vier 
Systeme mit jeweils vier Replikaten, wurden in zwei Regionen untersucht, dies ergab eine Gesamtprobenanzahl von 3200.

Durch unterschiedliche Artenkompositionen, die durch unterschiedliche Eigenschaften charakterisiert sind, wurde ein Abfall von genetischer Diversität von Wald zu KautschukDschungel zu Kautschukplantage zu Palmölplantage erwartet. Bei den Analysen wurden zwei Ansätze verwendet, bei dem Ersten wurde jeder Plot als eine Pflanzengemeinschaft betrachtet und bei dem Zweiten einzelne, häufig dominierende, Arten analysiert. Für die Gemeinschaftsanalyse wurden wiederum zwei Ansätze durchgeführt: Erstens der Fragmentpool-Ansatz, bei dem alle AFLP Fragmente der dominanten Arten in einem Fragment-Pool kombiniert wurden und deren genetische Differenzierung berechnet wurden. Zweitens der Artenansatz, bei dem die genetische Diversität pro Art im jeweiligen Plot berechnet wurde. Um die Landnutzungssystem auf genetische Unterschiede zu testen wurde ein „Mixed effect model“ für beide Ansätze der Gemeinschaftsanalyse benutzt.

Außerdem wurde die genetische Diversität mit der Diversität von Pflanzenarten, Mykorrhizaarten und Prokaryotenarten korreliert, um die Reaktionsähnlichkeit der Parameter auf Landnutzungsveränderungen abzuschätzen. Die häufig dominanten Arten wurden hinsichtlich ihrer Populationsstruktur und der Populationsdifferenzierung innerhalb und zwischen den Landnutzungssystemen untersucht. Weiterhin wurden Arten nach ihrer Lebensform gruppiert und auf signifikante Unterschiede getestet.

Ergebnisse der Gemeinschaftsanalyse mit dem Fragmentpool-Ansatz und dem Artenansatz zeigten keine direkte Korrelation zwischen genetischer Diversität dominanter Pflanzen und dem Landnutzungssystem. Aber aufgrund der Landnutzungsveränderung gibt es unterschiedliche Artenkompositionen im jeweiligen System, die mit ihren unterschiedlichen Eigenschaften, unterschiedliche Diversitäts- und Differenzierungsmuster aufweisen. Die Landnutzungssystem konnten in zwei Gruppen eingeteilt werden, die Baumdominierten Systeme mit hoher genetischer Diversität und die zwei Plantagensysteme mit niedriger genetischer Diversität.

Die Analysen basierend auf den einzelnen häufigen Arten zeigen eine hohe Variabilität in der Artenreaktion auf die Landnutzungsveränderungen. Waldarten weisen unterschiedliche Verlustgrade von genetischer Diversität auf. Plantagen werden hauptsächlich von invasiven, kolonisierenden Arten dominiert, die an Störungen adaptiert sind. Daher zeigten die Plantagenplots im Mittel höhere genetische Diversitätslevel als erwartet. 
Der Fragmentpool Ansatz stellt eine flexible Methode die genetische Diversität von unterschiedlichen Landnutzungssystemen zu schätzen und zu vergleichen. Die Ergebnisse können zur Identifikation von Flächen mit wichtigen Naturschutzstatus genutzt werden und Naturschutzpläne von tropischen Ökosystemen unterstützen. 


\section{REFERENCES}

Abood, S., J. Lee, Z. Burivalova, J. Garcia-Ulloa, and L. Koh (2015) Relative Contributions of the Logging, Fiber, Oil Palm, and Mining Industries to Forest Loss in Indonesia. Conservation Letters 8: 58-67.

Aerts, R., and O. Honnay (2011) Forest restoration, biodiversity and ecosystem functioning. BMC Ecology 11: 1-10.

Agamuthu, P., and W. Broughton (1985) Nutrient cycling within the developing oil palmlegume ecosystem. Agriculture, Ecosystem and Environment 13: 111-123.

Agrawal, AA. (2003) Community genetics: New insights into community ecology by integrating population genetics. Ecology Special Feature: 543-544.

Aguilar, R., M. Quesada, L. Ashworth, Y. Herrerias-Diego, and J. Lobo (2008) Genetic consequences of habitat fragmentation in plant populations: susceptible signals in plant traits and methodological approaches. Molecular Ecology 17: 5177-88.

Aldrich, P., J. Hamrick, P. Chavarriaga, and G. Kochert (1998) Microsatellite analysis of demographic genetic structure in fragmented populations of the tropical tree Symphonia globulifera. Molecular Ecology 7: 933-944.

Allen, K., M. D. Corre, A. Tjoa, and E. Veldkamp (2015) Soil Nitrogen-Cycling Responses to Conversion of Lowland Forests to Oil Palm and Rubber Plantations in Sumatra, Indonesia. PloS one 10: e0133325.

Allendorf, F. W., and G. Luikart (2007) Conservation and the Genetics of Populations. Blackwell Publishing.

Andam, K. S., P. J. Ferraro, A. Pfaff, G. Sanchez-Azofeifa, and J. Robalino (2008) Measuring the effectiveness of protected area networks in reducing deforestation. Proceedings of the National Academy of Sciences 105: 16089-16094.

Appanah, S., J. A. Turnbull (1998) A Review of Dipterocaprs: Taxonomy, ecology and silviculture. Center for International Forestry Research. 


\section{REFERENCES}

Austerlitz, F., S. Mariette, N. Machon, P. Gouyon, B. Godelle (2000) Effects of colonization processes on genetic diversity: differences between annual plants and tree species. Genetics 154: 1309-21.

Avolio, ML, CC Chang, MD Smith (2011) Assessing fine-scale genotypic structure of a dominant species in native grasslands. The American Midland Naturalist 165: 211-224.

Avolio, ML, MD Smith (2013) Correlations between genetic and species diversity: effects of resource quantity and heterogeneity. Journal of Vegetation Science 24: 1185-1194.

Baayen, R. H., D. J. Davidson, D. M. Bates (2008) Mixed-effects modeling with crossed random effects for subjects and items. Journal of Memory and Language 6: 390-412.

Bailey, J., J. A. Schweitzer, F. Úbeda, J. Koricheva, C. J. LeRoy, M. D. Madritch, B. J. Rehill, R. K. Bangert, D. G. Fischer, G. J. Allan, T. G. Witham (2009) From genes to ecosystems: a synthesis of the effects of plant genetic factors across levels of organization. Philosophical Transactions of the Royal Society B: Biological Sciences 364: 1607-1616.

Baker, S., R. Dyer (2011) Invasion genetics of Microstegium vimineum (Poaceae) within the James River Basin of Virginia, USA. Conservation Genetics 12: 793-803.

Balkenhol, N., S. Cushman, A. Storfer, L. Waits (2015) Landscape Genetics: Concepts, Methods, Applications. Wiley.

Barlow, J., T. A. Gardner, I. S. Araujo, T. C. Ávila-Pires, A. B. Bonaldo, J. E. Costa, M. C. Esposito, L. V. Ferreira, J. Hawes, M. I. M. Hernandez, M. S. Hoogmoed, R. N. Leite, N. F. Lo-Man-Hung, J. R. Malcolm, M. B. Martins, L. A. M. Mestre, R. Miranda-Santos, A. L. Nunes-Gutjahr, W. L. Overal, L. Parry, S. L. Peters, M. A. Ribeiro-Junior, M. N. F. da Silva, C. da Silva Motta, C. A. Peres (2007) Quantifying the biodiversity value of tropical primary, secondary, and plantation forests. Proceedings of the National Academy of Sciences of the United States of America 104: 18555-60.

Barnes, A., M. Jochum, S. Mumme, N. Haneda, A. Farajallah, T. Widarto, U. Brose (2014) Consequences of tropical land use for multitrophic biodiversity and ecosystem functioning. Nature Communications 5: 1-7. 
Bazzaz, F. A., S. T. A. Pickett (1980) Physiological Ecology Of Tropical Successsion: A comparative Review. Annual Review of Ecology and Systematics 11: 287-310.

Besse, P., M. Seguin, P. Lebrun, M. H. Chevallier, D. Nicolas, C. Lanaud (1994) Genetic diversity among wild and cultivated populations of Hevea brasiliensis assessed by nuclear RFLP analysis. Theoretical Applied Genetics 88: 199-207.

Beukema, H., F. Danielsen, G. Vincent, S. Hardiwinoto, J. Andel (2007) Plant and bird diversity in rubber agroforests in the lowlands of Sumatra, Indonesia. Agroforestry Systems 70: 217-242.

Bonin, A., D. Ehrich, S. Manel (2007) Statistical analysis of amplified fragment length polymorphism data: a toolbox for molecular ecologists and evolutionists. Molecular Ecology 16: 3737-58.

Bossuyt, B., O. Honnay (2006) Interactions between plant life span, seed dispersal capacity and fecundity determine metapopulation viability in a dynamic landscape. Landscape Ecology 21: 1195-1205.

Bozzano, M., R. Jalonen, E. Thomas, D. Boshier, L. Gallo, S. Cavers, S. Bordacs, P. Smith, J.Loo (2014) Genetic considerations in ecosystem restoration using native tree species. Food and Agriculture Organisation of the United Nations, Rome.

Breed, M. F., K. M. Ottewell, M. G. Gardner, M. H. Marklund, E. E. Dormontt, A. J. Lowe (2015) Mating patterns and pollinator mobility are critical traits in forest fragmentation genetics. Heredity 115: 108-14.

Brooks, T., R. Mittermeier, G. Fonseca, J. Gerlach, M. Hoffmann, J. Lamoreux, C. Mittermeier, J. Pilgrim, A. Rodrigues (2006) Global Biodiversity Conservation Priorities. Science 313: $58-61$.

Brun, C., A. Cook, J. Lee, S. Wich, L. Koh, L. Carrasco (2015) Analysis of deforestation and protected area effectiveness in Indonesia: A comparison of Bayesian spatial models. Global Environmental Change 31: 285-295. 


\section{REFERENCES}

Bryson, C. T., R. Carter (2008) The Significance of Cyperacea as Weeds. In: Sedges: Uses,

Diversity and Systematics of the Cyperaceae. Missouri Botanical Garden Press.

Bänfer, G., B. Fiala, K. Weising (2004) AFLP analysis of phylogenetic relationships among myrmecophytic species of Macaranga (Euphorbiaceae) and their allies. Plant Systematics and Evolution 249: 213-231.

Bänfer, G., U. Moog, B. Fiala, M. Mohamed, K. Weising, F. R. Blattner (2006) A chloroplast genealogy of myrmecophytic Macaranga species (Euphorbiaceae) in Southeast Asia reveals hybridization, vicariance and long-distance dispersal. Molecular Ecology 15: 44094424.

Cao, C.-P., R. Finkeldey, I. Siregar, U. Siregar, O. Gailing (2006) Genetic diversity within and among populations of Shorea leprosula Miq. and Shorea parvifolia Dyer (Dipterocarpaceae) in Indonesia detected by AFLPs. Tree Genetics \& Genomes 2: 225239.

Chapin III, F. S., B. H. Walker, R. J. Hobbs, D. U. Hooper, J. H. Lawton, O. E. Sala, D. Tilman (2000) Consequences of changing biodiversity. Nature 405: 500-504.

Chazdon, R. L., R. W. Pearcy, D. W. Lee and N. Fetcher (1996) Photosynthetic responses to contrasting light environments. In: Tropical forest plant ecophysiology, Chapman and Hall 5-55.

Cincotta, R., J. Wisnewski, R. Engelman (2000) Human population in the biodiversity hotspots. Nature 404: 990-992.

Clément-Demange, A., P. M. Priyadarshan, T. T. Thuy Hoa, P. Venkatachalam (2007) Hevea Rubber Breeding and Genetics. In: Plant Breeding Reviews Volume 29. Wiley Online Library.

Collevatti, R. G., D. Grattapaglia, J. D. Hay (2001) Population genetic structure of the endangered tropical tree species Caryocar brasiliense, based on variability at microsatellite loci. Molecular Ecology 10: 349-356.

COP21 (2015) United Nations conference on climate change. www.cop21.gouv.fr/ 
Corley, R. H. V., P. B. Tinker (2003) The Oil Palm, 4th edition. Blackwell Science.

Crawford, K., J. Rudgers (2013) Genetic diversity within a dominant plant outweighs plant species diversity in structuring an arthropod community. Ecology 94: 1025-1035.

Da Silva, E. F., C. A. Mendes de Oliviveira, A. C. Borges Lins-e-Silva, M. J. Nogueira Rodal (2008) Diversity and Genetic Structure of Natural Fragmented Populations of Tapiria guianensis Aubl. in Northeastern Brazil. Bioremeditation, Biodiversity and Bioavailability 2: $35-40$.

De Padua, L. S., N. Bunyapraphatsara, R. H. M. J. Lemmens (Editors) (1999) Prosea 12 (1) Medicinal and poisonous plants 1. PROSEA Foundation.

Després, L., L. Gielly, B. Redoutet, P. Taberlet (2003) Using AFLP to resolve phylogenetic relationships in a morphologically diversified plant species complex when nuclear and chloroplast sequences fail to reveal variability. Molecular Phylogenetics and Evolution 27: 185-196.

DeWalt, S., Hamrick (2004) Genetic variation of introduced Hawaiian and native Costa Rican populations of an invasive tropical shrub, Clidemia hirta (Melastomataceae). American Journal of Botany 91: 1155-1162.

De Winter, W. P., V. B. Amoroso (Editors) (2003) Prosea 15(2): Ferns and fern allies. PROSEA Foundation.

Didham, R., J. Tylianakis, N. Gemmell, T. Rand, R. Ewers (2007) Interactive effects of habitat modification and species invasion on native species decline. Trends in Ecology \& Evolution 22: $489-496$.

Dransfield J., N. Manokaran (Editors) (1994) Prosea 6: Rattans. PROSEA Foundation.

Dray, S., A.-B. Dufour (2007) The ade4 package: implementing the duality diagram for ecologists. Journal of statistical software 22: 1-20.

Duforet-Frebourg, N., M. Blum (2014) Nonstationary patterns of isolation-by-distance: inferring measures of local genetic differentiation with bayesian kriging. Evolution 68: 1110-1123. 
REFERENCES

Drescher J, K. Rembold, K.Allen, P. Beckschäfer, D. Buchori, Y. Clough, H. Faust, A.M. Fauzi, D. Gunawan, D. Hertel, B. Irawan, I. N. S. Jaya, B. Klarner, C. Kleinn, A. Knohl, M. Kotowska, V. Krishna, C. Leuschner, W. Lorenz, A. Meijide, D. Melati, M. Nomura, C. Pérez-Cruzado, M. M. Qaim, I. Z. Siregar, S. Steinebach, A. Tjoa, T. Tscharntke, B. Wick, K. Wiegand, K. Kreft, S. Scheu (2016) Ecological and socioeconomic functions of tropical lowland rainforest transformation systems.

Philosophical Transaction of the Royal Society 371: 20150275.

Dyer, R. J. (2015) Is there such a thing as landscape genetics? Molecular Ecology 24: 3518-3528.

Eckert, A. J., R. J. Dyer (2012) Defining the landscape of adaptive genetic diversity. Molecular Ecology 21: 2836-2838.

Edy, N. (2015) Community structure of arbuscular mycorrhizal fungi in temperate grassland and tropical land-use systems. Dissertation. Georg-August University of Göttingen.

Ekadinata, A., G. Vincent (2011) Rubber agroforests in a changing landscape: analysis of land use/cover trajectories in Bungo district, Indonesia. Forests, Trees and Livelihoods 20: 3-14.

Ellis, E., K. Goldewijk, S. Siebert, D. Lightman, N. Ramankutty (2010) Anthropogenic transformation of the biomes, 1700 to 2000. Global Ecology and Biogeography 19: 589-606.

Ewers, R. M., R. K. Didham (2006) Confounding factors in the detection of species responses to habitat fragmentation. Biological Reviews 81: 117-142.

Ewers, R., S. Thorpe, R. Didham (2007) Synergistic interactions between edge and area effects in a heavily fragmented landscape. Ecology 88: 96-106.

FAO (2010) Global Forest Resources Assessment 2010. Food and Agriculture Organization of the United Nations.

FAO (2014)The State of World, Opportunities and Challenges ood and Agriculture Organization of the United Nations. Rome 2014 
FAO (2015a) http://www.fao.org/nr/cgrfa/en/ and

FAO (2015b) http://faostat3.fao.org/download/Q/QC/E 20th January 2016

Farwig, N., C. Braun, K. Böhning-Gaese (2007) Human disturbance reduces genetic diversity of an endangered tropical tree, Prunus africana (Rosaceae). Conservation Genetics 9: 317-326.

Felsenstein, J. (2005) PHYLIP(Phylogeny Inference Package) version 3.6 Distributed by the author. Department of Genome Science, University of Washington, Seattle.

Finger, A., C. Kettle, C. Kaiser-Bunbury, T. Valentin, D. Doudee, D. Matatiken, J. Ghazoul. (2011) Back from the brink: potential for genetic rescue in a critically endangered tree. Molecular Ecology 20: 3773-3784.

Finger, A., C. Kettle, C. Kaiser-Bunbury, T. Valentin, J. Mougal, J. Ghazoul (2012) Forest fragmentation genetics in a formerly widespread island endemic tree: Vateriopsis seychellarum (Dipterocarpaceae). Molecular Ecology 21: 2369-2382.

Finkeldey, R., H. H. Hattemer (2007) Tropical Forest Genetics. Springer-Verlag Berlin Heidelberg.

Fitzherbert, E. B., M. J. Struebig, A. Morel, F. Danielsen, C. A. Brühl, P. F. Donald B. Phalan (2008) How will oil palm expansion affect biodiversity? Trends in Ecology \& Evolution 23: 538-545.

Foley, J. A., R. Defries, G. P. Asner, C. Barford, G. Bonan, S. R. Carpenter, F. S. Chapin, M. T. Coe, G. C. Daily, H. K. Gibbs, J. H. Helkowski, T. Holloway, E. A. Howard, C. J. Kucharik, C. Monfreda, J. A. Patz, I. C. Prentice, N. Ramankutty, P. K. Snyder (2005) Global consequences of land use. Science 309: 570-574.

Fordham, D. A., B. W. Brook, C. Moritz, D. Nogués-Bravo (2014) Better forecasts of range dynamics using genetic data. Trends in Ecology \& Evolution 29: 436-43.

Frankel, O. H., A. H. Brown, J. J. Burdon (1995) The Conservation of Plant Biodiversity. Cambridge Universiy Press, Cambridge. 
REFERENCES

Fridman, J. (2000) Conservation of Forest in Sweden: a strategic ecological analysis. Biological Conservation 96: 95-103.

Fuchs, E. J., J. L. Hamrick (2010) Genetic diversity in the endangered tropical tree, Guaiacum sanctum (Zygophyllaceae). The Journal of Heredity 101: 284-91.

Ganzhorn S. M., B. Perez-Sweeney, W. W. Thomas, F.A. Gaiotto, and J.D. Lewis (2015) Effects of fragmentation on density and population genetics of a threatened tree species in a biodiversity hotspot. Endangered Species Research 26: 189-199.

Gardner, T. A., J. Barlow, R. Chazdon, R. M. Ewers, C. A. Harvey, C. A. Peres, N. S. Sodhi. 2009. Prospects for tropical forest biodiversity in a human-modified world. Ecology Letters 12: 561-582.

Gascuel, F., R. Ferrière, R. Aguilée, A. Lambert (2015) How Ecology and Landscape Dynamics Shape Phylogenetic Trees. Systematic Biology 64: 590-607.

Gibbs, H., A. Ruesch, F. Achard, M. Clayton, P. Holmgren, N. Ramankutty, J. Foley (2010) Tropical forests were the primary sources of new agricultural land in the 1980s and 1990s. Proceedings of the National Academy of Sciences 107: 16732-16737.

Gibson, L., T. Ming Lee, L. P. Koh, B. W. Brook, T. A. Gardner6 J. Barlow, C. A. Peres, C. J. A. Bradshaw, W. F. Laurance, T. E. Lovejoy, N. S. Sodhi (2011) Primary forests are irreplaceable for sustaining tropical biodiversity. Nature 478: 378-381.

Goldman, D. H., R. K. Jansen, C. van den Berg, I. J. Leitch, M. F. Fay, M. W. Chase (2004) Molecular and cytological examination of Calopogon (Orchidaceae, Epidendroideae): Circumscription, phylogeny, polyploidy and possible hybrid speciation. American Journal of Botany 91: 707-723.

Goodman, D.(1975) The Theory of Diversity-Stability Relationships in Ecology. The Quaterly Review of Biology 50:237-266.s

Gouyon, A., H. Foresta, P. Levang (1993) Does "jungle rubber" deserve its name? An analysis of rubber agroforestry systems in southeast Sumatra. Agroforestry Systems 22: 181-206. 
Gower, J. (1966) Some distance properties of latent root and vector methods use in multivariate analysis. Biometrika 53: 325-338.

Gregorius, H.-R. (2010) Linking Diversity and Differentiation. Diversity 2: 370-394.

Grime, J. P. (2001) Plant Strategies, Vegetation Processes, and Ecosystem Properties, Second Edition. John Wiley and Sons, Ltd., West Sussex 417.

Gross, C. L. (1993) The breeding system and pollinators of Melastoma affine (Melastomataceae); a pioneer shrub in tropical Australia. Biotropica 25: 468-474.

Guicking, D., B. Fiala, T. Kröger-Kilian, M. Mohamed, K. Weising (2013) High gene flow in two thrips-pollinated South-East Asian pioneer trees: genetic diversity and population structure of Macaranga hypoleuca and M. beccariana (Euphorbiaceae). Botanical Journal of the Linnean Society 173: 606-621.

Guillaume, T., M. Damris, Y. Kuzyakov (2015) Losses of soil carbon by converting tropical forest to plantations: erosion and decomposition estimated by $\delta(13) \mathrm{C}$. Global change biology 21: 3548-60.

Hadley, A., M. Betts (2012) The effects of landscape fragmentation on pollination dynamics: absence of evidence not evidence of absence. Biological Reviews 87: 526-544.

Hahn, T., C. J. Kettle, J. Ghazoul, E. I. Hennig, A. R. Pluess (2013) Landscape composition has limited impact on local genetic structure in mountain clover, Trifolium montanum L. The Journal of Heredity 104: 842-52.

Hamilton, M. B. (1999) Tropical tree gene flow and seed dispersal. Nature 401: 129-130.

Hamrick, J., M. Godt, S. Sherman-Broyles (1992) Factors influencing levels of genetic diversity in woody plant species. New Forests 6: 95-124.

Hamrick, J. L., Y. B. Linhart, J. B. Mitton (1979) Relationships between life history characteristics and electrophoretically detectable genetic variation in plants. Annual Review of Ecology and Systematics 10: 173-200. 


\section{REFERENCES}

Hamrick, J. L., M. D. Loveless (1989) The genetic structure of tropical tree populations: association with reproductive biology. In: The Evolutionary Ecology of plants. Westviw Press, Boulder, CO 129-146.

Hand, B. K., W. H. Lowe, R. P. Kovach, C. C. Muhlfeld, G. Luikart (2015) Landscape community genomics: understanding eco-evolutionary processes in complex environments. Trends in Ecology \& Evolution 30: 161-168.

Hansen, M. P. V. Potapov, R. Moore, M. Hancher, S. A. Turubanova, A. Tyukavina, D. Thau, S. V. Stehman, S. J. Goetz, T. R. Loveland, A. Kommareddy, A. Egorov, L. Chini, C. O. Justice, J. R. G. Townshend (2013) High-Resolution Global Maps of 21st-Century Forest Cover Change. Science 342: 850-853.

Harrell, F. E. Jr., C. Dupont et al. (2015) Hmisc: Harrell Miscellaneous. R package version 3.16-0. http://cran.r-project.org/package=hmisc.

Hassler, E., M. D. Corre, A. Tjoa, M. Damris, S. R. Utami, E. Veldkamp (2015) Soil fertility controls soil-atmosphere carbon dioxide and methane fluxes in a tropical landscape converted from lowland forest to rubber and oil palm. Biogeosciences 12: 5831-5852.

He, T., B. Lamont, S. Krauss, N. Enright, B. Miller (2008) Covariation between intraspecific genetic diversity and species diversity within a plant functional group. Journal of Ecology 96: 956-961.

Hodac, L., F. B. Ulum, N. Opfermann, N. Breidenbach, D.Hojsgaard, S. Sudarmiyati Tjitrosoedirdjo, B. Vornam, R. Finkeldey, E. Hörandl (2016) Population genetic structure and reproductive strategy of the introduced grass Centotheca lappacea in tropical landuse systems in Sumatra. PLOS one e 0147633.

Holderegger, R., H. Wagner (2008) Landscape Genetics. BioScience 58: 199-207.

Holm, L. G., D. L. Plucknett, J. V. Pancho, J. P. Herberger (1977) The world's worst weeds: distribution and ecology. East-West Center/University Press of Hawaii 609.

Honnay, O., H. Jacquemyn (2007) Susceptibility of Common and Rare Plant Species to the Genetic Consequences of Habitat Fragmentation. Conservation Biology 21: 823-831. 
Horn, H. S. (1966) Measurement of" overlap" in comparative ecological studies. The American Naturalist 100: 419-424.

Hothorn, T., F. Bretz, P. Westfall (2008) Simultaneous Inference in General Parametric Models. Biometrical Journal 50: 346-363.

Hughes, R., B. Inouye, M. Johnson, N. Underwood, M. Vellend (2008) Ecological consequences of genetic diversity. Ecology Letters 11: 609-623.

Ismail, S. A., J. Ghazoul, G. Ravikanth, R. U. Shaanker, C. G. Kushalappa, C. J. Kettle (2012) Does long-distance pollen dispersal preclude inbreeding in tropical trees? Fragmentation genetics of Dysoxylum malabaricum in an agro-forest landscape. Molecular Ecology 21: 5484-5496.

Jaccard, P. (1908) Nouvelles recherches sur la distribution florale. Bulletin de la Societé Vaudoise des Sciences Naturelles 37: 547-579.

Jagoe, R. B. (1940). Carpet Grass, Axonopus spp. Gardens Bulletin, S.S. 11: 109-118

Jennings, S., N. Brown, D. Boshier, T. Whitmore, J. Lopes (2001) Ecology provides a pragmatic solution to the maintenance of genetic diversity in sustainably managed tropical rain forests. Forest Ecology and Management 154: 1-10.

Jorgensen, S., J. Hamrick (1997) Biogeography and population genetics of whitebark pine, Pinus albicaulis. Canadian Journal of Forest Research 27: 1574-1585.

Kahilainen, A., M. Puurtinen, J. Kotiaho (2014) Conservation implications of species-genetic diversity correlations. Global Ecology and Conservation 2: 315-323.

Kashimshetty, Y., S. Pelikan, S. H. Rogstad (2015) Variable gene dispersal conditions and spatial deforestation patterns can interact to affect tropical tree conservation outcomes. PloS one 10: e0127745.

Kettle, C. (2014) Fragmentation genetics in tropical ecosystems: from fragmentation genetics to fragmentation genomics. Conservation Genetics 15: 1265-1268. 


\section{REFERENCES}

Kettle, C., P. Hollingsworth, D. Burslem, C. Maycock, E. Khoo, J. Ghazoul (2011) Determinants of fine-scale spatial genetic structure in three co-occurring rain forest canopy trees in Borneo. Perspectives in Plant Ecology, Evolution and Systematics 13: 47-56.

Koh, L. P., J. Ghazoul (2010) Spatially explicit scenario analysis for reconciling agricultural expansion, forest protection, and carbon conservation in Indonesia. Proceedings of the National Academy of Sciences 107: 11140-11144.

Koh, L., P. Levang, J. Ghazoul (2009) Designer landscapes for sustainable biofuels. Trends in Ecology \& Evolution 24: 431-438.

Koh, L., N. Sodhi (2010) Conserving Southeast Asia's imperiled biodiversity: scientific, management, and policy challenges. Biodiversity and Conservation 19: 913-917.

Koh, L., D. Wilcove (2008) Is oil palm agriculture really destroying tropical biodiversity? Conservation Letters 1: 60-64.

Koh, L., J. Ghazoul (2010) A Matrix-Calibrated Species-Area Model for Predicting Biodiversity Losses Due to Land-Use Change. Conservation Biology 24: 994-1001.

Koleff, P., K. Gaston, J. Lennon (2003) Measuring beta diversity for presence-absence data. Journal of Animal Ecology 72: 367-382.

Kosman, E., K. J. Leonard (2005) Similarity coefficients for molecular markers in studies of genetic relationships between individuals for haploid, diploid, and polyploid species. Molecular Ecology 14: 415-424.

Kramer, H., A. Akca (2008) Leitfaden zur Waldmesslehre. J.D. Sauerländer Verlag, Frankfurt am Main

Kramer, A. T., J. L. Ison, M. V. Ashley, H. F. Howe (2008) The paradox of forest fragmentation genetics. Conservation Biology 22: 878-85.

Krauss, J., R. Bommarco, M. Guardiola, R. K. Heikkinen, A. Helm, M. Kuussaari, R. Lindborg, E. Öckinger, M. Pärtel, J. Pino, Juha Pöyry, K. M. Raatikainen, A. Sang, C. Stefanescu, T. Teder, M. Zobel I. Steffan-Dewenter (2010) Habitat fragmentation causes immediate and time-delayed biodiversity loss at different trophic levels. Ecology Letters 13: 597-605. 
Kremer, A., H. Caron, S. Cavers, N. Colpaert, G. Gheysen, R. Gribel, M. Lemes, A. J. Lowe, R. Margis, C. Navarro, F. Salgueiro 2005. Monitoring genetic diversity in tropical trees with multilocus dominant markers. Heredity 95: 274-80.

Kuchma, O. (2010) Genetic processes in Scots pine (Pinus sylvestris L.) in the Chernobyl exclusion zone. Dissertation. Georg-August-University Göttingen.

Lacerda, D. R., M. D. P. Acedo, J. P. L. Filho, M. B. Lovato (2001) Genetic diversity and structure of natural populations of Plathymenia reticulata (Mimosoideae), a tropical tree from the Braszilian Cerrado. Molecular Ecology 8: 1143-1152.

Laliberté, E., J. A. Wells, F. De Clerck, D. J. Metcalfe, C. P. Catterall, C. Queiroz, I. Aubin, S. P. Bonser, Y. Ding, J. M. Fraterrigo, S. McNamara, J. W. Morgan, D. Sánchez Merlos, P. A. Vesk, M. M. May (2010) Land-use intensification reduces functional redundancy and response diversity in plant communities. Ecology letters 13: 76-86.

Laliberté, E., J. Tylianakis. (2012) Cascading effects of long-term land-use changes on plant traits and ecosystem functioning. Ecology 93: 145-155.

Lambin, E. F., H. J. Geist, E. Lepers (2003) Dynamics of land-use and land-cover change in tropical regions. Annual Review of environmental Resources 28: 205-241.

Lande, R. (1988) Genetics and Demography in Biological Conservation. Science 241: 1455-1460.

Laumonier, Y. (1997) The vegetation and Physiography of Sumatra. Kluwer Academic Publishers.

Laumonier, Y., A. Edin, M. Kanninen, A. Munandar (2010a) Landscape-scale variation in the structure and biomass of the hill dipterocarp forest of Sumatra: Implications for carbon stock assessments. Forest Ecology and Management 259: 505-513.

Laumonier, Y., Y. Uryu, M. Stüwe, A. Budiman, B. Setiabudi, O. Hadian (2010b) Eco-floristic sectors and deforestation threats in Sumatra: identifying new conservation area network priorities for ecosystem-based land use planning. Biodiversity and Conservation 19: 11531174. 


\section{REFERENCES}

Laurance, W. F., D. C. Useche, J. Rendeiro, M. Kalka, C. J. A. Bradshaw, S. P. Sloan, S. G. Laurance, M. Campbell, K. Abernethy, P. Alvarez, V. Arroyo-Rodriguez, P. Ashton, J. Benítez.-Malvido, A. Blom, K. S. Bobo, C. H. Cannon, M. Cao, R. Carroll, C. Chapman, R. Coates, M. Cords, F. Danielsen, B. De Dijn, E. Dinerstein, M. A. Donnelly, D. Edwards, F. Edwards, N. Farwig, P. Fashing, P.-M. Forget, M. Foster, G. Gale, D. Harris, R. Harrison, J. Hart, S. Karpanty, W. J. Kress, J. Krishnaswamy, W. Logsdon, J. Lovett, W. Magnusson, F. Maisels, A. R. Marshall, D. McClearn, D. Mudappa, M. R. Nielsen, R. Pearson, N. Pitman, J. van der Ploeg, A. Plumptre, J. Poulsen, M. Quesada, H. Rainey, D.Robinson, C. Roetgers, F. Rovero, F. Scatena, C. Schulze, D. Sheil, T. Struhsaker, J. Terborgh, D. Thomas, R. Timm, J. N. Urbina-Cardona, K. Vasudevan, S. J. Wright, J. C. Arias-G., L. Arroyo, M. Ashton, P. Auzel, D. Babaasa, F. Babweteera, P. Baker, O. Banki, M. Bass, I. Bila-Isia, S. Blake, W. Brockelman, N. Brokaw, C. A. Brühl, S. Bunyavejchewin, J.-T. Chao, J. Chave, R. Chellam, C. J. Clark, J. Clavijo, R. Congdon, R. Corlett, H. S. Dattaraja, C. Dave, G. Davies, B. de Mello Beisiegel, R. de Nazare P. da Silva, A. Di Fiore, A. Diesmos, R. Dirzo, D. Doran-Sheehy, M. Eaton, L. Emmons, A. Estrada, C. Ewango, L. Fedigan, F. Feer, B. Fruth, J. G. Willis, U. Goodale, S. Goodman, J. C. Guix, P. Guthiga, W. Haber, K. Hamer, I.Herbinger, J. Hill, Z. Huang, I F. Sun, K. Ickes, A. Itoh, N. Ivanauskas, B. Jackes, J. Janovec, D. Janzen, M. Jiangming, C. Jin, T. Jones, H. Justiniano, E. Kalko, A. Kasangaki, T. Killeen, H.-B. King, E. Klop, C. Knott, I. Kone , E. Kudavidanage, J. L. da Silva Ribeiro, J. Lattke, R. Laval, R. Lawton, M. Leal, M. Leighton, M. Lentino, C. Leonel, J. Lindsell, L. Ling-Ling, K. E. Linsenmair, E. Losos, A. Lugo, J. Lwanga, A. L. Mack, M. Martins, W. S. McGraw, R. McNab, L. Montag, J. Myers Thompson, J. Nabe-Nielsen, M. Nakagawa, S. Nepal, M. Norconk, V. Novotny, S. O’Donnell, M.Opiang, P. Ouboter, K. Parker, N. Parthasarathy, K. Pisciotta, D. Prawiradilaga, C. Pringle, S. Rajathurai, U. Reichard, G. Reinartz, K. Renton, G. Reynolds, V. Reynolds, E. Riley, M. Rödel, J. Rothman, P. Round, S. Sakai, T. Sanaiotti, T. Savini, G. Schaab, J. Seidensticker, A. Siaka, M. R. Silman, T. B. Smith, S. Soares de Almeida, N. Sodhi, C. Stanford, K. Stewart, E. Stokes, K. E. Stoner, R. Sukumar, M. Surbeck, M. Tobler, T. Tscharntke, A. Turkalo, G. Umapathy, M. van Weerd, J. Vega Rivera, M. Venkataraman, L. Venn, C. Verea, C. Volkmer de Castilho, M. Waltert, B. Wang, D. Watts, W. Weber, P. West, D. Whitacre, K. Whitney, D. Wilkie, S. Williams, D. D. Wright, P. Wright, L. Xiankai, P. Yonzon, F. Zamzani (2012) Averting biodiversity collapse in tropical forest protected areas. Nature 489: 290-294. 
Laurance, W. F., J. Sayer, K. G. Cassman. (2014) Agricultural expansion and its impacts on tropical nature. Trends in Ecology \& Evolution 29: 107-16.

Laurance, W., L. Koh, R. Butler, N. Sodhi, C. Bradshaw, J. Neidel, H. Consunji, J. Vega. (2010) Improving the Performance of the Roundtable on Sustainable Palm Oil for Nature Conservation. Conservation Biology 24: 377-381.

Lawrence, D. C. (1996) Trade-offs between rubber production and maintenance of diversity: the structure of rubber gardens in West Kalimantan, Indonesia. Agroforestry Systems 34: 83-100.

Lemmens, R. H. M. J., I. Soerjanegara, W. C. Wong (Editors) (1995) Prosea 5(2) Timber trees: Minor commercial timbers. PROSEA Foundation.

Lemmens, R. H. M. J., N. Bunyapraphatsara (Editors) (2003) Prosea 12 (3) Medicinal and poisonous plants 3.PROSEA Foundation.

Leimu, R., P. Vergeer, F. Angeloni, N. J. Ouborg (2010) Habitat fragmentation, climate change, and inbreeding in plants. Annals of the New York Academy of Sciences 1195: 84-98.

Lespinasse, D., M. Rodier-Goud, L. Grivet, A. Leconte, H. Legnate, M. Seguin (2000) A saturated genetic linkage map of rubber tree (Hevea spp.) based on RFLP, AFLP, microsatellite, and isozyme markers. Theoretical and Applied Genetics 100: 127-138.

Lesser, M. R., T. L. Parchman, S. T. Jackson (2013) Development of genetic diversity, differentiation and structure over 500 years in four ponderosa pine populations. Molecular Ecology 22: 2640-52.

Lewontin, R. C. (1972) Testing the theory of natural selection. Nature 236: 181-182.

Li, J.-M., Z.-X. Jin (2007) Genetic structure of endangered Emmenopterys henryi Oliv. based on ISSR polymorphism and implications for its conservation. Genetica 133: 227-234.

Lindenmayer, D. B. (1999) Future directions for biodiversity conservation in managed forests: indicator species, impact studies and monitoring programs. Forest Ecology and Management 115: 277-287. 
REFERENCES

Lindner, M., M. Maroschek, S. Netherer, A. Kremer, A. Barbati, J. Garcia-Gonzalo, R. Seidl, S. Delzon, P. Corona, M. Kolström, M. J. Lexer, M. Marchetti (2010) Climate change impacts, adaptive capacity, and vulnerability of European forest ecosystems. Forest Ecology and Management 259: 698-709.

Lindstrom, M. J., D. M. Bates (1988) Newton-Raphson and EM Algorithms for Linear Mixed-Effects Models for Repeated-Measures Data. Journal of the American Statistical Association 83: 1014-1022.

Linton, L. R., R. W. Davies, F. J. Wrona (1981) Resource utilization indices: an assessment. The Journal of Animal Ecology 50: 283-292.

Lira, C. F., S. R. S. Cardoso, P. C. G. Ferreira, M. A. Cardoso, J. Provan (2003) Long-term population isolation in the endangered tropical tree species Caesalpinia echinata Lam. revealed by chloroplast microsatellites. Molecular Ecology 12: 3219-3225.

Loveless, M. D., J. L. Hamrick (1984) Ecological determinants of genetic structure in Plant Populations. Annual Review of Ecology and Systematics 15: 65-95.

Lowe, A. J., S. Cavers, D. Boshier, M. F. Breed, P. M. Hollingsworth (2015) The resilience of forest fragmentation genetics--no longer a paradox--we were just looking in the wrong place. Heredity 115: 97-99.

Luque, S., S. Saura, M.-J. Fortin (2012) Landscape connectivity analysis for conservation: insights from combining new methods with ecological and genetic data. Landscape Ecology 27: 153-157.

Mace, E., C. Gebhardt, R. Lester (1999) AFLP analysis of genetic relationships in the tribe Datureae (Solanaceae). Theoretical and Applied Genetics 99: 634-641.

Manel, S., M. K. Schwartz, G. Luikart, P Taberlet (2003) Landscape genetics: combining landscape ecology and population genetics. Trends in Ecology \& Evolution 18: 189-197.

Manning, A. D., J. Fischer, D. B. Lindenmayer (2006) Scattered trees are keystone structuresimplications for conservation. Biological Conservation 132: 311-321. 
Margono, B. A., P. V. Potapov, S. Turubanova, F. Stolle, M. C. Hansen (2014) Primary forest cover loss in Indonesia over 2000-2012. Nature Climate Change 4:730-735.

Mariette, S., V. le Corre, F. Austerlitz, A. Kremer (2002) Sampling within the genome for measuring within-population diversity: trade-offs between markers. Molecular Ecology 11: 1145-1156.

May, R., R. Arthur (1972) Niche Overlap as a Function of Environmental Variability. Proceedings of the National Academy of Sciences 69: 1109-1113.

Mba, C., J. Tohme. (2005) Use of AFLP markers in surveys of plant diversity. Methods in Enzymology 395: 177-201.

Meudt, H. M., A.C. Clarke (2007) Almost forgotten or latest practice? AFLP applications, analyses and advances. Trends in Plant Science 12: 106-117.

Michon, G., H. de Foresta (1995) Agroforests: an original agroforestry model from smallholder farmers for environmental conservation and sustainable development. In: Traditional Technology for Environmental Conservation and Sustainable Development in the Asian-Pacific Region. University of Tsukuba 52-58.

Michon, G., D. H. Foresta (1995) The Indonesian agro-forest model. In: Conserving Biodiversity outside Protected Areas. The role of tradition agro-ecosystems.IUCN Publication Service Unit: 90-106

Miettinen, J., C. Shi, S. Liew (2011) Deforestation rates in insular Southeast Asia between 2000 and 2010. Global Change Biology 17: 2261-2270.

Morales-Hidalgo, D., S. Oswalt, E. Somanathan (2015) Status and trends in global primary forest, protected areas, and areas designated for conservation of biodiversity from the Global Forest Resources Assessment 2015. Forest Ecology and Management 352: 68-77.

Muir, G., A. Lowe, C. Fleming, C. Vogl. (2004) High Nuclear Genetic Diversity, High Levels of Outcrossing and Low Differentiation Among Remnant Populations of Quercus petraea at the Margin of its Range in Ireland. Annals of Botany 93: 691-697. 


\section{REFERENCES}

Muluvi, G. M., J. I. Sprent, N. Soranzo, J. Provan, D. Odee, G. Folkard, J. W. McNicol, W. Powell (1999) Amplified fragment length polymorphism (AFLP) analysis of genetic variation in Moringa oleifera Lam. Molecular Ecology 8: 463-470.

Murase, K., T. Itioka, M. Nomura, S. Yamane (2003) Intraspecific variation in the status of ant symbiosis on a myrmecophyte, Macaranga bancana, between primary and secondary forests in Borneo. Population Ecology 45: 221-226.

Murcia, C. (1995) Edge effects in fragmented forests: implications for conservation. Trends in Ecology \& Evolution 10: 58-62.

Myers, N. (1988) Threatened biotas: "Hot spots" in tropical forests. The Environmentalist 8: 187-208.

Myers, N., R. A. Mittermeier, C. G. Mittermeier, G. A. B. da Fonseca, J. Kent (2000) Biodiversity hotspots for conservation priorities. Nature 403: 853-858.

Müller, M., S. Seifert, R. Finkeldey (2015) A candidate gene-based association study reveals SNPs significantly associated with bud burst in European beech (Fagus sylvatica L.). Tree Genetics \& Genomes 11: 116.

Namkoong, G. (1999) Genetic conservation strategies: Who needs data? Kluwer Academic Publishers.

Namkoong, G., T. Boyle, H.-R. Gregorius, H. Joly, O. Savolainen, W. Ratnam, A. Young (1996) Testing Criteria and Indicators for Assessing the Sustainability of Forest Management: Genetic Criteria and Indicators. Center for international forestry research 10.

Nason, J. D., J. L. Hamrick (1997) Reproductive and genetic consequences of forest fragmentation: Two case studies of neotropical canopy trees. Heredity 88: 264-276.

Nei, M., W. H. Li (1979) Mathematical model for studying genetic variation in terms of restriction endonucleases. Proceedings of the National Academy of Science 76: 5269-5273.

Neuhauser, C., D. Andow, G. Heimpel, G. May, R. Shaw, S. Wagenius (2003) Community Genetics: Expanding The Synthesis Of Ecology And Genetics. Ecology 84: 545-558. 
Nevo, E. (1978) Genetic Variation in Natural Populations: Patterns and Theory. Theoretical Population Biology 13: 121-177.

Newbold, T. L. N. Hudson, S. L. L. Hill, S. Contu, I. Lysenko, R. A. Senior, L. Börger, D. J. Bennett, A. Choimes, B. Collen, J.Day, A. De Palma, S. Díaz, S. Echeverria-Londono, M. J. Edgar, A. Feldman, M. Garon, M. L. K. Harrison, T. Alhusseini, D. J. Ingram, Y. Itescu, J. Kattge, V. Kemp, L. Kirkpatrick, M. Kleyer, D. Laginha Pinto Correia, C. D. Martin, S. Meiri, M. Novosolov, Y. Pan, H. R. P. Phillips, D. W. Purves, A. Robinson, J. Simpson, S. L. Tuck, E. Weiher, H. J. White, R. M. Ewers, G. M. Mace, J. P. W. Scharlemann, A. Purvi (2015) Global effects of land use on local terrestrial biodiveristy. Nature 520: 45-49.

Ng, K., S. Lee, L. Saw, J. Plotkin, C. Koh (2006) Spatial structure and genetic diversity of three tropical tree species with different habitat preferences within a natural forest. Tree Genetics \& Genomes 2: 121-131.

$\mathrm{Ng}, \mathrm{K}$., S. Lee, S. Ueno (2009) Impact of selective logging on genetic diversity of two tropical tree species with contrasting breeding systems using direct comparison and simulation methods. Forest Ecology and Management 257: 107-116.

Noordwijk, M., D. Suyamto, B. Lusiana, A. Ekadinata, K. Hairiah (2008) Facilitating agroforestation of landscapes for sustainable benefits: Tradeoffs between carbon stocks and local development benefits in Indonesia according to the FALLOW model. Agriculture, Ecosystems \& Environment 126: 98-112.

Noss, R. (1999) Assessing and monitoring forest biodiversity: A suggested framework and indicators. Forest Ecology and Management 115: 135-146.

Nybom, H. (2004) Comparison of different nuclear DNA markers for estimating intraspecific genetic diversity in plants. Molecular Ecology 13: 1143-1155.

Oksanen, J., F. G. Blanchet, R. Kindt, P. Legendre, P. R. Minchin, R. B. O’Hara, G.L. Simpson, P. Solymos, M.H. H. Stevens, H. Wagner (2015) vegan: Community Ecology Package. Rpackage version 2.3-0 http://cran.r-project.org/package=vegan. 


\section{REFERENCES}

Okuda, T., M. Suzuki, N. Adachi, E. Quah, N. Hussein, N. Manokaran (2003) Effect of selective logging on canopy and stand structure and tree species composition in a lowland dipterocarp forest in peninsular Malaysia. Forest Ecology and Management 175: 297-320.

Oostermeijer, J. G. B., S. H. Luijten, J. C. M. Nijs (2003) Integrating demographic and genetic approaches in plant conservation. Biological Conservation 113: 389-398.

Ootsuki, R., H. Sato, N. Nakato, N. Murakami (2012) Evidence of genetic segregation in the apogamous fern species Cyrtomium fortunei (Dryopteridaceae). Journal of Plant Research 125: 605-612.

Page, C. M. (2002) Ecological strategies in fern evolution: a neopteridological overview. Taxon 119: 1-33.

Page, R. D. M. (1996) Tree View: An application to display phylogenetic trees on personal computers 12: 357-358.

Paludan-Müller, G., H. Saxe, J. W. Leverenz (1999) Responses to ozone in 12 provenances of European beech (Fagus sy/vatica): genotypic variation and chamber effects on photosynthesis and dry-matter partitioning. New Phytologist 144: 261,273.

Pandit, M. K., H. T. W. Tan, M. S. Bisht (2006) Polyploidy in invasive plant species in Singapore. Botanical Journal of the Linnean Society 151: 395-403.

Parks, D. H., R. G. Beiko (2012) Measuring community similarity with phylogenetic networks. Molecular Biology and Evolution 29: 3947-58.

Parmesan, C., G. Yohe (2003) A globally coherent fingerprint of climate change impacts across natural systems. Nature 421: 37-42.

Peakall, R., P. E. Smouse (2012) GenAlEx 6.5: genetic analysis in Excel. Population genetic software for teaching and research-an update. Bioinformatics.

Peakall, R., P. Smouse (2006) GenAlEx 6: genetic analysis in Excel. Population genetic software for teaching and research. Molecular Ecology Notes 6: 288-295. 
Pearce, D., F. Putz, J. Vanclay (2003) Sustainable forestry in the tropics: panacea or folly? Forest Ecology and Management 172: 229-247.

Penot, E., G. Wibawa. (n.d.). Complex Rubber Agroforestry Systems in Indonesia: an alternative to low productivity of jungle rubber conserving agroforestry practices and benefits. Rubber Association of Indonesia (GAPKINDO/Indonesia)

Pinheiro, J., D. Bates, D. Debroy, D. Sarkar and R Core Team (2015) nlme: linear and nonlinear mixed effect models. R package version 3.1-122, http://cran.r-project.org/packages=nlme.

Porter-Bolland, L., E. A. Ellis, M. R. Guariguata (2012) Community managed forests and forest protected areas: An assessment of their conservation effectiveness across the tropics. Forest Ecology 268: 6-17.

Purba, A., J. Noyer, L. Baudouin, X. Perrier, S. Hamon, P. Lagoda (2000) A new aspect of genetic diversity of Indonesian oil palm (Elaeis guineensis Jacq.) revealed by isoenzyme and AFLP markers and its consequences for breeding. Theoretical and Applied Genetics 101: 956-961.

Ramana, M., A. Chorghe, P. Prasanna, M. Sanjappa (2014) Centotheca ganeshaiahiana sp. nov. (Poaceae) from Andaman and Nicobar Islands, India. Nordic Journal of Botany 32: $559-562$.

Rametsteiner, E., M. Simula (2003) Forest certification - an instrument to promote sustainable forest management? Journal of Environmental Management 67: 87-98.

Rao, V., T. Hodgkin (2002) Genetic diversity and conservation and utilization of plant genetic resources. Plant Cell, Tissue and Organ Culture 68: 1-19.

Ratnam, W., T. J. Boyle (2000) Effects of logging and other forms of harvesting on genetic diversity in humid tropical forests. In: Forest conservation genetics: Principles and Practice. CSIRO Publishing 115-122. 


\section{REFERENCES}

Robinson, J. P., S. A. Harris (1999) Amplified Fragment Length Polymorphisms and Microsatellites: A phylogenetic perspective. In: Which DNA Marker for Which Purpose? Gillet. E.M Molecular Tools for Biodiversity

Rosenberg, M. S., C.D. Anderson (2011) PASSaGE: pattern analysis, spatial statistics and geographic exegesis. Version 2. Methods in Ecology and Evolution 2: 229-232.

Ruiz-Gonzalez, A., S. A. Cushman, M. J. J. Madeira, E. Randi, B. J. J. Gómez-Moliner (2015) Isolation by distance, resistance and/or clusters? Lessons learned from a forest-dwelling carnivore inhabiting a heterogeneous landscape. Molecular Ecology 24: 5110-5129.

Russell, A. E., T. A. Ranker, C. E. C. Gemmill, D. R. Farrar (1999a) Patterns of Clonal Diversity in Dicranopteris linearis on Mauna Loa, Hawaii. Biotropica 31: 449-459.

Russell, J. R., J. C. Weber, A. Booth, W. Powell, C. Sotelo-Montes, I. K. Dawson (1999b) Genetic variation of Calycophyllum spruceanum in the Peruvian Amazon Basin, revealed by amplified fragmetn length polymorphism (AFLP) analysis. Molecular Ecology 8: 199204.

RSPO (2013) Principles and Criteria for the Production of Sustainable Palm Oil. Endorsed by the RSPO Executive Board and Accepted at the Extraordinary General Assembly by RSPO members April 2013.

Sala, O. F. S. Chapin III, J. J. Armesto, E.Berlow, J. Bloomfield, R. Dirzo, E. Huber-Sanwald, L. F. Huenneke, R. B. Jackson, A. Kinzig, R. Leemans, D. M. Lodge, H. A. Mooney, M. Oesterheld, N. LeRoy Poff, M. T. Sykes, B. H. Walker, M. Walker, D. H. Wall (2000) Global Biodiversity Scenarios for the Year 2100. Science 287: 1770-1774.

Sambrook, J., E.F. Fritsch, T. Maniatis (1989) Molecular cloning: a laboratory manual. Cold Spring Harbor N.Y.

Sampson, J. F., M. Byrne, C. J. Yates, N. Gibson, R. Thavornkanlapachai, S. Stankowski, B. MacDonald, I. Bennett (2014) Contemporary pollen-mediated gene immigration reflects the historical isolation of a rare, animal-pollinated shrub in a fragmented landscape. Heredity 112: 172-81. 
Schneider, D. M. Engelhaupt, K. Allen, S.Kurniawan, V. Krashevska, M. Heinemann, H.Nacke, M. Wijayanti, A. Meryandini, M. D. Corre, S. Scheu, R. Daniel (2015) Impact of lowland rainforest transformation on diversity and composition of soil prokaryotic communities in Sumatra (Indonesia). Frontiers of Microbiology 6: 1-12.

Schneller, J., R. Holderegger, F. Gugerli, K. Eichenberger, E. Lutz (1998) Patterns of Genetic Variation Detected by RAPDs Suggest a Single Origin with Subsequent Mutations and Long-Distance Dispersal in the Apomictic Fern Dryopteris remota (Dryopteridaceae). American Journal of Botany 85: 1038-1042.

Schulze, C., M. Waltert, P. Kessler, R. Pitopang, D. Veddeler, M. Mühlenberg, S. Gradstein, C. Leuschner, I. Steffan-Dewenter, T. Tscharntke (2004) Biodiversity Indicator Groups Of Tropical Land-Use Systems: Comparing Plants, Birds, And Insects. Ecological Applications 14: 1321-1333.

Schweitzer, J.A., J.K. Bailey, B.J. Rehill (2004) Genetically based trait in a dominant tree affects ecosystem processes. Ecology Letters 7: 127-134.

Sebbenn, A., B. Degen, V. Azevedo, M. Silva, A. de Lacerda, A. Ciampi, M. Kanashiro, F. da Carneiro, I. Thompson, M. Loveless (2008) Modelling the long-term impacts of selective logging on genetic diversity and demographic structure of four tropical tree species in the Amazon forest. Forest Ecology and Management 254: 335-349.

Seifert, S., B. Vornam, R. Finkeldey (2012) DNA sequence variation and development of SNP markers in beech (Fagus sylvatica L.). European Journal of Forest Research 131: 17611770.

Shannon, C. E., W. Weaver (1949) The mathematical theory of communication. University of Illinois Press Urbana and Chicago.

Sheil, D. (2001) Conservation and Biodiversity Monitoring in the Tropics: Realities, Priorities, and Distractions. Conservation Biology 15: 1179-1182. 


\section{REFERENCES}

Silva, M., M. Kanashiro, A. Ciampi, I. Thompson, A. Sebbenn (2008) Genetic effects of selective logging and pollen gene flow in a low-density population of the dioecious tropical tree Bagassa guianensis in the Brazilian Amazon. Forest Ecology and Management 255:1548-1558.

Simberloff, D. (1999) The role of science in the preservation of forest biodiversity. Forest Ecology and Management 115: 101-111.

Sloan, S., C. N. Jenkins, L. N. Joppa, D. Gaveau, W. F. Laurance (2014) Remaining natural vegetation in the global biodiversity hotspots. Biological Conservation 177: 12-24.

Sodhi, N., L. Koh, B. Brook, P. Ng (2004) Southeast Asian biodiversity: an impending disaster. Trends in Ecology \& Evolution 19: 654-660.

Sodhi, N. S., B. Brook (2006) Southeast Asian biodiversity in crisis. Cambridge University Press.

Soerjanegara, I., R. H. M. J. Lemmens (Editors) (1994) Prosea 5(1) Timber trees: Major commercial timbers. PROSEA Foundation.

Sokal, R., C. Michener (1958) A statistical method for evaluating systematic relationships. In: Science bulletin, 38. The University of Kansas.

Sosef M. S. M., L. T. Hong, S. Prawirohatmodjo (Editors) (1998) Prosea 5(3) Timber trees: Lesser-known timbers. PROSEA Foundation.

Souto, C. P., P. Mathiasen, M. C. C. Acosta, M. P. P. Quiroga, R. Vidal-Russell, C. Echeverría, A. C. Premoli (2015) Identifying Genetic Hotspots by Mapping Molecular Diversity of Widespread Trees: When Commonness Matters. The Journal of Heredity 106 Suppl 1: 537-45.

Steffan-Dewenter, I. M. Kessler, J. Barkmann, M. M. Bos, D. Buchori, S. Erasmi, H. Faust, G. Gerold, K. Glenk, S. R. Gradstein, E. Guhardja, M. Harteveld, D. Hertel, P. Höhn, M. Kappas, S. Köhler, C. Leuschner, M. Maertens, R. Marggraf, S. Migge-Kleian, J. Mogea, R. Pitopang, M. Schaefer, S. Schwarze, S. G. Sporn, A. Steingrebe, S. S. Tjitrosoedirdjo, S. Tjitrosoemito, A. Tweleh, R. Weber, L. Woltmann, M. Zeller, T.Tscharntke (2007) Tradeoff 
between income, biodiversity, and ecosystem functioning during tropical rainforest conversion and agroforestry intensification. Proceedings of the National Academy of Science 104: 1973-1978.

Stephens, M. (1979) Tests of fit for the logistic distribution based on the empirical distribution function. Biometrika 66: 591-595.

Sthultz, C., C. Gehring, T. Whitham (2009) Deadly combination of genes and drought: increased mortality of herbivore-resistant trees in a foundation species. Global Change Biology 15: 1949-1961.

Storfer, A., M. A. Murphy, J. S. Evans, C.S. Goldberg (2007) Putting the "landscape"in landscape genetics. Heredity 98: 128-142.

Stork, N., J. Coddington, R. Colwell, R. Chazdon, C. Dick, C. Peres, S. Sloan, K. Willis (2009) Vulnerability and Resilience of Tropical Forest Species to Land-Use Change. Conservation Biology 23: 1438-1447.

Strien, M., R. Holderegger, H. Heck (2015) Isolation-by-distance in landscapes: considerations for landscape genetics. Heredity 114: 27-37.

Struebig, M. J., T. Kingston, E. J. Petit, S. C. Le Comber, A. Zubaid, A. Mohd-Adnan, S. J. Rossiter (2011) Parallel declines in species and genetic diversity in tropical forest fragments. Ecology letters 14: 582-90.

Student (1908) The Probable Error of the mean. Biometrika 6.

Symes, W. S., M. Rao, M. B. Mascia, R. L. Carrasco (2015) Why do we lose protected areas? Factors influencing protected area downgrading, downsizing and degazettment (PADDD) in the tropics and sub-tropics. Global Change Biology 22: 656-665.

Taberlet, P. N. E. Zimmermann, T. Englisch, A. Tribsch, R. Holderegger, N. Alvarez, H.Niklfeld, G. Coldea, Z. Mirek, A. Moilanen, W.Ahlmer, P. Ajmone Marsan, E.Bona, M. Bovio, P. Choler, E. Cieslak, L. Colli, V. Cristea, J.-P. Dalmas, B. Frajman, L. Garraud, M. Gaudeul, L. Gielly, W. Gutermann, N. Jogan, A. A. Kagalo, G. Korbecka, P. Küpfer, B. Lequette, D. Roman Letz, S. Manel, G. Mansion, K. Marhold, F. Martini, R. Negrini, F. Nino, O. Paun, M. 


\section{REFERENCES}

Pellecchia, G. Perico, H. Piekos- Mirkowa, F. Prosser, M. Puscas, M. Ronikier, M.

Scheuerer, G. M. Schneeweiss, P. Schönswetter, L. Schratt- Ehrendorfer, F. Schüpfer, A. Selvaggi, K. Steinmann, C. Thiel-Egenter, M. van Loo, M. Winkler, T. Wohlgemuth, T. Wraber, Felix Gugerli and IntraBioDiv Consortium (2012) Genetic diversity in widespread species is not congruent with species richness in alpine plant communities. Ecology Letters 15: 1439-1448.

Thomas, E., R. Jalonen, J. Loo, D. Boshier, L. Gallo, S. Cavers, S. Bordács, P. Smith, M. Bozzano (2014) Genetic considerations in ecosystem restoration using native tree species. Forest Ecology and Management 333: 66-75.

Tilman, D., K. Cassman, P. Matson, R. Naylor, S. Polasky (2002) Agricultural sustainability and intensive production practices. Nature 418: 671-677.

Torre, A., C. López, E. Yglesias, J. Cornelius (2008) Genetic (AFLP) diversity of nine Cedrela odorata populations in Madre de Dios, southern Peruvian Amazon. Forest Ecology and Management 255: 334-339.

Tscharntke, T., A. Klein, A. Kruess, I. Steffan-Dewenter, C. Thies (2005) Landscape perspectives on agricultural intensification and biodiversity - ecosystem service management. Ecology Letters 8: 857-874.

Tuomisto, H. (2010) A diversity of beta diversities: straightening up a concept gone awry. Part 1. Defining beta diversity as a function of alpha and gamma diversity. Ecography 33: 2-22.

Tuomisto, H., K. Ruokolainen (2008) Analyzing or explaining beta diversity? Reply. Ecology 89: 3238-3256.

Van der Vossen, H. A. M., B. E. Umali (Editors) (2002) Prosea 14: Vegetables oils and fats. PROSEA Foundation.

Van Valkenburg, J. L.. C. H., N. Bunyapraphatsara (Editors) (2002) Prosea 12 (2): Medicinal and poisonous plants 2. PROSEA Foundation. 
Vekemans, X. (2002) AFLP-SURV version 1.0.Distribution by the author. Laboratoire de Génétique et Ecologie Végétale, Université de Bruxelles, Belgium.

Vellend, M. (2006) The consequences of genetic diversity in competitive communities. Ecology 87: 304-311.

Vellend, M. (2005) Species diversity and genetic diversity: parallel processes and correlated patterns. The American naturalist 166: 199-215.

Vellend, M., E. Drummond, and H. Tomimatsu (2009) Effects of genotype identity and diversity on the invasiveness and invasibility of plant populations. Oecologia 162: 371-381.

Vellend, M., M. Geber (2005) Connections between species diversity and genetic diversity. Ecology Letters 8: 767-781.

Villamor, G. B. (2012) Flexibility of multi-agent system models for rubber agroforest landscapes and social responses to emerging reward mechanisms for ecosystem services in Sumatra, Indonesia. Dissertation. Rheinischen Friedrich-Wilhelms-Universität Bonn, Bonn.

Villamor, G., R. PontiusJr., M. Noordwijk (2013) Agroforest's growing role in reducing carbon losses from Jambi (Sumatra), Indonesia. Regional Environmental Change 14: 825-834.

Violle, C., B. Enquist, B. McGill, L. Jiang, C. Albert, C. Hulshof, V. Jung, J. Messier (2012) The return of the variance: intraspecific variability in community ecology. Trends in Ecology \& Evolution 27: 244-252.

Vornam, B., O. Gailing, J. Derory, C. Plomion, A. Kremer, R. Finkeldey (2011) Characterisation and natural variation of a dehydrin gene in Quercus petraea (Matt.) Liebl. Plant Biology 13: 881-887.

Vos, P., R. Hogers, M. Bleeker, M. Reijans, T. van de Lee, M. Homes, A. Frijters, J. Pot, J. Peleman, M. Kuiper, M. Zabeau (1995) AFLP: a new technique for DNA fingerprinting. Nucleic Acids Research 23: 4407-4414. 


\section{REFERENCES}

Völler, E., H. Auge, O. Bossdorf, D. Prati (2013) Land use causes genetic differentiation of lifehistory traits in Bromus hordeaceus. Global change biology 19: 892-9.

Wang, I. J., G. S. Bradburd (2014) Isolation by environment. Molecular Ecology 23: 5649-62.

Wang, R., S. G. Compton, Y.-S. S. Shi, X.-Y. Y. Chen (2012) Fragmentation reduces regionalscale spatial genetic structure in a wind-pollinated tree because genetic barriers are removed. Ecology and Evolution 2: 2250-61.

Wehenkel, C., F. Bergmann, H.-R. Gregorius (2006) Is there a trade-off between species diversity and genetic diversity in forest tree communities? Plant Ecology 185: 151-161.

Wehenkel, C., J. Corral-Rivas, H. Castellanos-Bocaz (2009) Is there selection by species diversity in Picea abies L.? Plant Ecology 208: 47-54.

Werth, D., R. Avissar (2005) The local and global effects of Southeast Asian deforestation. Geophysical Research Letters 32. Wiley.

White, M. J. (1986) Segregation and diversity measures in population distribution. Population Index 52: 198-221.

Whitham, T. W. P. Young, G. D. Martinsen, C. A. Gehring, J. A. Schweitzer, S. M. Shuster, G. M. Wimp, D. G. Fischer, J. K. Bailey, R. L. Lindroth, S. Woolbright, C. R. Kus (2003) Community and Ecosystem Genetics: A Consequence of the extended Phenotype. Ecology 84: 559-573.

Whitham, T., J. K. Bailey, J. A. Schweitzer, S. M. Shuster, R. K. Bangert, C. J. LeRoy, E. V. Lonsdorf, G. J. Allan, S. P. DiFazio, B. M. Potts, D. G. Fischer, C. A. Gehring, R.L. Lindroth, J. C. Marks, S. C. Hart, G. M. Wimp, S. C. Wooley (2006) A framework for community and ecosystem genetics: from genes to ecosystems. Nature Reviews Genetics 7: 510-523.

Whitham, T., S. Difazio, J. Schweitzer, S. Shuster, G. Allan, J. Bailey, S. Woolbright (2008) Extending genomics to natural communities and ecosystems. Science (New York, N.Y.) 320: $492-5$. 
Whitlock, R. (2014) Relationships between adaptive and neutral genetic diversity and ecological structure and functioning: a meta-analysis. The Journal of Ecology 102: 857872.

Whittaker, R. H. (1960) Vegetation of the Siskiyou mountains, Oregon and California. Ecological Monographs 30: 279-338.

Wickham, H. (2007) Reshaping data with the reshape package. Journal of Statistical Software.

Wickham, H. (2009) ggplot2: elegant graphics for data analysis. Springer New York

Wickneswari, R., C. Cannon (2011) Managing the Future of Southeast Asia's Valuable Tropical Rainforests. Springer Dordrecht Heidelber London New York.

Wilcove, D., X. Giam, D. Edwards, B. Fisher, L. Koh (2013) Navjot's nightmare revisited: logging, agriculture, and biodiversity in Southeast Asia. Trends in Ecology \& Evolution 28: 531-540.

Wilcove, D., L. Koh (2010) Addressing the threats to biodiversity from oil-palm agriculture. Biodiversity and Conservation 19: 999-1007.

Wilson, K., A. Newton, C. Echeverría, C. Weston, M. Burgman (2005) A vulnerability analysis of the temperate forests of south central Chile. Biological Conservation 122: 9-21.

Wimp, G.M., G.D. Martinsen, K.D. Floate, R.K. Bangert (2005) Plant genetic determinants of arthropod community structure and diversity. Evolution 59: 61-69.

Wolda, H. (1981) Similarity indices, sample size and diversity. Oecologia 50:296-302.

Wright, S. (1940) Breeding Structure of Populations in Relation to Speciation. The American Naturalist 74:232-248.

Yeh, F. C., T. J. B. Boyle (1997) Population genetic analysis of co-dominant and dominant markers and quantitative traits. Belgian Journal of Botany 129:157. 
REFERENCES

Young, A., T. Boyle, T. Brown (1996) The population genetic consequences of habitat fragmentation for plants. Trends in Ecology \& Evolution 11: 413-418.

Zerega, N.J.C., D. Ragone, and T.J. Motley. 2006. Genetic diversity and origins of domesticated breadfruit. In: Darwin's Harvest: New Approaches to the Origins, Evolution, and Conservation of Crops, Columbia University Press, New York. 


\section{ACKNOWLEDGEMENTS}

I would like to express my gratitude to Prof. Dr. Reiner Finkeldey for accepting me as a PhD student, his support and encouragement during the course of my doctoral studies.

I thank Prof. Dr. Holger Kreft for being co-referee of this thesis and Prof. Dr. Niko Balkenhol for being a member of my thesis committee, they support, interest in my project and they help in developing the fragment pool approach.

I also thank Prof. Dr. Elvira Hörandl, Prof. Dr. Dirk Hölscher and Prof. Dr. Martin Ziehe for being members of my examination committee.

I thank my counterparts Dr. Ulfah Siregar, Dr. Sri Rahayu, Dr. Utut Widyastuti, Dr. Bambang Irawan, Hamzah Saidina, Prof. Iskandar Z. Siregar and Prof. Zulkarnain for their support, kindness during my time in Indonesia. Special thanks to Iskandar Z. Siregar for his excellent support in all the administrative problems me and my samples had.

My gratitude goes to my field assistants Yohanes Bayu, Nover, Happy, Davig and Firdaus for their hard work, motivation, tolerating the German work hours and the fun we had ("kna kna kna harus ulang lagi!").

I am very grateful to the village leaders, plot owners, the National park Bukit Dua Belas and the restoration concession "Harapan" (PT REKI) for granting us access to their properties.

I thank the coordination office members of EFForTS in Göttingen: Dr. Barbara Wick and Ivonne Hein; in Bogor: Wolfram Lorenz, Mira Kartikasari and Indri Hapsari Fitriyani; in Jambi: Rizky Febrianty, Megawati Syafni, Yuking Linatra and Muhammad Fahrozi, for their support and help in Germany and Indonesia.

Special thanks to the taxonomy group at PT REKI, Kebun Raya Bogor and Katja Rembold for their support in the plant identification.

I thank Dr. Katja Rembold, Dr. Thomas Guillaume, Dr. Edy Nur and Dr. Dominique Schneider (Martin Engelhaupt) for providing their data for the correlation analyses.

I am very grateful to Alexandra Dolynska and especially to Christine Radler for their excellent help with the lab work.

Thanks to my colleagues within the EFForTS project, it has been and still is priceless sharing the Indonesian and PhD experience with them. Without the neutralization activities, I would not have made it. 


\section{ACKNOWLEDGEMENTS}

Very special thanks to my colleagues of the Section Forest Genetic and Forest Tree Breeding. In great humbleness I would like to mention in never ending gratitude the only well-mannered German “Der Kollege” Dr. Markus Müller aka Fagus markusiana for surviving 3 years sharing an office with me, fun train travels, listening, nodding, his "lack of knowledge" about $99.9 \%$ of my questions and proof-reading my thesis. At least for me, it was a pleasure! Thanks to mi Reina, Laura Cuervo Alarcon for all the serious scientific discussions, teaching me the Colombian sign and verbal language and of course the charity we did together. I thank the former members Dr. Sarah Seifert and Dr. Kathleen Prinz for their kind welcome and help, when I arrived in Göttingen. Dr. Barbara Vornam and PD Dr. Ludger Leinemann for their ideas and reading my thesis. Regina Berkeley for her support in administrative paperwork. I am very happy that I got to know everybody in this working group and would like thank them, together with the already mentioned, for their support and the nice time together: Prof. Dr. Hans Heinrich Hattemer, Prof. Dr. Martin Ziehe, Prof. Dr. Konstantin Krutovsky, Gerold Dinkel, Larissa Kunz, Melanie Schmitt, Devrim Semizer Cuming, Sinan Hagenah, Johanna Ropertz, Dr. Oleksandra Kuchma, Dr. Elizabeth M. Gillet, Nurlan Torokeldiev and Fitri Yola Amandita. I am looking forward to work three more years in this department.

More thanks to my friends B. Mira Kohl, Katherina Vasiliadis and Florian Seefluth. Last but not least, many thanks to my family, especially my twin sister Elena Tennison, for supporting and believing in me.

I thank the Deutsche Forschungsgemeinschaft (DFG) for the financial support of this project, the subproject B 03 of the Collaborative Research Center 990, EFForTS. 


\section{APPENDIX}

Appendix 1: Collected species in alphabetic order. Author names according to www.plantlist.org (May 2015).

\begin{tabular}{|c|c|}
\hline Species & Family \\
\hline Acronychia pendunculata (L.) Miq. & Rutaceae \\
\hline Ageratum conyzoides (L.) L. & Compositae \\
\hline Allophylus cobbe (L.) Raeusch. & Sapindaceae \\
\hline Alseodaphne sp. & Lauraceae \\
\hline Alstonia angustiloba Miq. & Apocynaceae \\
\hline Alstonia scholaris (L.) R. Br. & Apocynaceae \\
\hline Aporosa nitida Merr. & Phyllanthaceae \\
\hline Aporosa sp. II & Phyllanthaceae \\
\hline Archidendron bubalinum (Jack) I. C. Nielsen & Leguminosae \\
\hline Artocarpus elasticus Reinw. ex Blume & Moraceae \\
\hline Artocarpus kemando Miq. & Moraceae \\
\hline Artocarpus sp. I & Moraceae \\
\hline Asystasia indica H.J.Chowdhery \& Av.Bhattacharjee & Acanthaceae \\
\hline Axonopus compressus (Sw.) P.Beauv. & Poaceae \\
\hline Baccaurea sp. I & Phyllanthaceae \\
\hline Baccaurea sp. II & Phyllanthaceae \\
\hline Baccaurea sp. III & Phyllanthaceae \\
\hline Bauhinia semibifida Roxb. & Leguminosae \\
\hline Blechnum orientale $\mathrm{L}$. & Blechnaceae \\
\hline Campnosperma coriaceum (Jack) Hallier f. & Anacardiaceae \\
\hline Campnosperma sp. & Anacardiaceae \\
\hline Centotheca lappacea (L.) Desv. & Poaceae \\
\hline Centrosema pubescens Benth. & Leguminosae \\
\hline Christella dentata (Forssk.) Brownsey \& Jermy & Thelypteridaceae \\
\hline Cleidion sp. & Euphorbiaceae \\
\hline Clerodendrum sp. & Lamiaceae \\
\hline Clidemia hirta (L.) D. Don & Melastomataceae \\
\hline Conarus sp. & Conaraceae \\
\hline Cratoxylum sumatranum (Jack) Blume & Hypericaceae \\
\hline Croton agrarius Baill. & Euphorbiaceae \\
\hline Croton sp. II & Euphorbiaceae \\
\hline Curculigo orchioides Gaertn. & Hypoxidaceae \\
\hline Curculigo sp.II & Hypoxidaceae \\
\hline Dacryodes sp. & Burseraceae \\
\hline Daemonorops sp. & Arecaceae \\
\hline Dicranopteris linearis (Burm. f.) Underw. & Gleicheniaceae \\
\hline Dillenia excels (Jack) Martelli ex Gilg. & Dilleniaceae \\
\hline Elaeis guineensis Jacq. & Arecaceae \\
\hline Endospermum diadenum (Miq.) Airy Shaw & Euphorbiaceae \\
\hline
\end{tabular}


Endospermum sp. II

Euphorbiaceae

Etlingera cf. coccinea (Blume) S. Sakai \& Nagam.

Zingiberaceae

Fagraea racemosa Jack

Gentianaceae

Ficus ribes Reinw. ex Blume

Moraceae

Ficus sp. 1

Moraceae

Ficus sp. II

Moraceae

Ficus sp. III

Moraceae

Gironniera nervosa Planch.

Cannabaceae

Gironniera subaequalis Planch.

Cannabaceae

Glochidion sp.

Goniophlebium verrucosum J. Sm (unresolved)

Gordonia excelsa (Blume) Blume

Phyllanthaceae

Polypodiaceae

Theaceae

Hevea brasiliensis (Willd. ex A.Juss) Müll. Arg.

Euphorbiaceae

Homalanthus sp.

Hopea mengarawan (Miq.) (unresolved)

Euphorbiaceae

Dipterocarpaceae

Horsfielda sp. I

Myristicaceae

Hymenodictyon orixense (Roxb.) Mabb.

Hymenodictyon sp.

Rubiaceae

Imperata cylindrical (L.) Raeusch.

Rubiaceae

Poaceae

Ixonanthes icosandra Jack (unresolved)

Ixonanthaceae

Lantana camara L.

Litsea umbellata (Lour.) Merr.

Verbenacaea

Lygodium cf. salicifolium C.Presl (unresolved)

Lygodium circinatum (Burm. f.) Sw.

Maasia sumatrana (Miq.) Mols, Kessler \& Rogstad

Lauraceae

Lygodiaceae

Lygodiaceae

Annonaceae

Macaranga bancana (Miq.) Müll.Arg.

Euphorbiaceae

Macaranga cf. conifera (Rchb.f. \& Zoll.) Müll.Arg.

Euphorbiaceae

Macaranga gigantea (Rchb.f. \& Zoll.) Müll.Arg.

Macaranga javanica (Blume) Müll.Arg.

Euphorbiaceae

Euphorbiaceae

Macaranga sp.I

Macaranga tanarius (L.)Müll.Arg.

Euphorbiaceae

Euphorbiaceae

Madhuca sp.

Melastoma malabathricum L.

Memecylon sp.

Microcos hirsuta (Korth.) Burret

Mikania micrantha Kunth

Mussaenda frondosa $\mathrm{L}$.

Myristica maxima Warb. (unresolved)

Nephrolepis acutifolia (Desv.) Christ

Otophora amoena (Hassk.) Blume

Ottochloa nodosa sp. I (phenotypic identical with II)

Ottochloa nodosa sp. II (phenotypic identical with I)

Oxalis sp.

Sapotaceae

Melastomataceae

Melastomataceae

Malvaveae

Compositae

Rubiaceae

Myristicaceae

Nephrolepidaceae

Sapindaceae

Poaceae

Poaceae

Oxalidaceae

Sapotaceae

Leguminosae 
Peronema canescens Jack

Phyllanthus reticulatus Poir.

Phyllanthus urinaria $\mathrm{L}$.

Porterandia anisophylla (Jack ex Roxb.) Ridl.

Pternandra caerulescens Jack

Pternandra cordata Baill. (unresolved)

Rauvolfia sumatrana Jack

Rolandra fructicosa (L.) Kuntze

Rosenbergiodendron longiflorum (Ruiz \& Pav.) Fageri.

Santiria acuminata K. Schum. (unresolved)

Santiria laevigata Blume (unresolved)

Santiria rubiginosa Blume (unresolved)

Spatholobus ferrugineus (Zoll. \& Moritzi) Benth.

Sauropus sp.

Scleria ciliaris Nees

Shorea ovalis Blume (unresolved)

Sindora leiocarpa de Wit

Spermacoce alata Aubl.

Stachytarpheta jamaicensis (L.) Vahl

Stenochlaena palustris (Burm. f.) Bedd.

Symplocos fasciculata Zoll. (unresolved)

Syzygium sp. I

Syzygium sp. II

Syzygium sp. III

Tabernaemontana macrocarpa Jack

Taenitis blechnoides (Willd.) Sw.

Vitex pinnata $\mathrm{L}$.

Wendlandia sp.
Lamiaceae

Phyllanthaceae

Phyllanthaceae

Rubiaceae

Melastomataceae

Melastomataceae

Apocynaceae

Compositae

Rubiaceae

Burseraceae

Burseraceae

Burseraceae

Leguminosae

Phyllanthaceae

Cyperaceae

Dipterocarpaceae

Leguminosae

Rubiaceae

Verbenaceae

Blechnaceae

Symplocaceae

Myrtaceae

Myrtaceae

Myrtaceae

Apocynaceae

Pteridaceae

Lamiaceae

Rubiaceae 
Appendix 2: Shannon Index (I, $\alpha-, \beta-, \gamma$ - level), Morisita-Horn Index per species (C, $\alpha-, \beta-, \gamma$ - level), plant category and land-use system for each species per plot. Regions Bukit Dua Belas (B) region Harapan (H). The land-use systems forest (F), jungle rubber (J), oil palm plantation (O), rubber plantation (R). Life form and life history trait (tree) for the species (category).

\begin{tabular}{|c|c|c|c|c|c|c|c|c|c|c|}
\hline Region & Land-use system & Plot & Species & category & I ( $\alpha$-level) & $I$ ( $\beta$-level) & I ( $\gamma$-level) & $C(\alpha$-level) & $C(\beta$-level) & $C(\gamma$-level) \\
\hline B & $\mathrm{F}$ & BF1 & Croton agrarius & secondary & 0.31 & 0.3252 & 0.3252 & 0.22959511 & 0.22253746 & 0.22253746 \\
\hline B & $\mathrm{F}$ & BF1 & Endospermum malayanum & pioneer & 0.2 & 0.2 & 0.355 & 0.0979607 & 0.0979607 & 0.12049988 \\
\hline B & $\mathrm{F}$ & BF1 & Porterandia anisophylla & generalist & 0.13 & 0.2319 & 0.2319 & 0.06774951 & 0.09655705 & 0.09655705 \\
\hline B & $\mathrm{F}$ & BF1 & Acronynchia penduncula & generalist & 0.22 & 0.22 & 0.22 & 0.06790242 & 0.06790242 & 0.06790242 \\
\hline B & $\mathrm{F}$ & BF1 & Tabernaemontana macrocarpa & secondary & 0.11 & 0.11 & 0.11 & 0.03393138 & 0.03393138 & 0.03393138 \\
\hline B & $\mathrm{F}$ & BF1 & Gironniera nervosa & generalist & 0.33 & 0.3263 & 0.3263 & 0.18090628 & 0.18090628 & 0.18090628 \\
\hline B & $\mathrm{F}$ & BF1 & Macaranga bancana & pioneer & 0.3 & 0.3 & 0.4879 & 0.17234721 & 0.17234721 & 0.2984821 \\
\hline B & $\mathrm{F}$ & BF1 & Aporosa nitida & generalist & 0.23 & 0.5254 & 0.5254 & 0.09795998 & 0.14139987 & 0.14139987 \\
\hline B & $\mathrm{F}$ & BF1 & Santiria laevigata & pioneer & 0.15 & 0.15 & 0.15 & 0.05341447 & 0.05341447 & 0.05341447 \\
\hline B & $\mathrm{F}$ & BF2 & Croton agrarius & secondary & 0.24 & 0.3252 & 0.3252 & 0.17635449 & 0.19731822 & 0.19731822 \\
\hline B & $\mathrm{F}$ & BF2 & Syzygium sp. IV & generalist & 0.42 & 0.42 & 0.42 & 0.29819872 & 0.29819872 & 0.29819872 \\
\hline B & $\mathrm{F}$ & BF2 & Microcos hirsuta & generalist & 0.11 & 0.11 & 0.11 & 0.0398458 & 0.0398458 & 0.0398458 \\
\hline B & $\mathrm{F}$ & BF2 & Etlingera coccinea & herb & 0.2 & 0.2 & 0.2 & 0.09827915 & 0.09827915 & 0.09827915 \\
\hline B & $\mathrm{F}$ & $\mathrm{BF} 2$ & Aporosa nitida & generalist & 0.5 & 0.5254 & 0.5254 & 0.20711412 & 0.19081126 & 0.19081126 \\
\hline B & $\mathrm{F}$ & BF2 & Otophora amoena & generalist & 0.49 & 0.49 & 0.49 & 0.26517925 & 0.26517925 & 0.26517925 \\
\hline B & $\mathrm{F}$ & BF2 & Allophylus cobbe & secondary & 0.44 & 0.44 & 0.44 & 0.15882417 & 0.15882417 & 0.15882417 \\
\hline B & $\mathrm{F}$ & BF2 & Maasia sumatrana & secondary & 0.31 & 0.5953 & 0.5953 & 0.15682708 & 0.25972193 & 0.25972193 \\
\hline B & $\mathrm{F}$ & BF3 & Baccaurea sp. III & secondary & 0.2165 & 0.3392 & 0.3392 & 0.1261903 & 0.14027156 & 0.14027156 \\
\hline B & $\mathrm{F}$ & BF3 & Archidendron bubalium & secondary & 0.2675 & 0.3197 & 0.3197 & 0.13732503 & 0.1444981 & 0.1444981 \\
\hline B & $\mathrm{F}$ & BF3 & Porterandia anisophylla & generalist & 0.1567 & 0.2319 & 0.2319 & 0.08157389 & 0.09320228 & 0.09320228 \\
\hline B & $\mathrm{F}$ & BF3 & Gironniera subaqualis & generalist & 0.4281 & 0.4281 & 0.4281 & 0.26574224 & 0.26574224 & 0.26574224 \\
\hline B & $\mathrm{F}$ & BF3 & Maasia sumatrana & secondary & 0.5052 & 0.5953 & 0.5953 & 0.24856024 & 0.30317448 & 0.30317448 \\
\hline B & $\mathrm{F}$ & BF3 & Syzygium sp. II & generalist & 0.3281 & 0.4396 & 0.4396 & 0.19018836 & 0.21989794 & 0.21989794 \\
\hline B & $\mathrm{F}$ & BF3 & Baccaurea sp. I & secondary & 0.1512 & 0.2015 & 0.2015 & 0.07473469 & 0.07935231 & 0.07935231 \\
\hline B & $\mathrm{F}$ & BF3 & Dacryodes sp. & secondary & 0.3019 & 0.3019 & 0.3019 & 0.11605214 & 0.11605214 & 0.11605214 \\
\hline
\end{tabular}




\begin{tabular}{|c|c|c|c|}
\hline B & $\mathrm{F}$ & $\mathrm{BF} 3$ & Alseodaphne sp. \\
\hline B & $\mathrm{F}$ & BF4 & Porterandia_anisophylla \\
\hline B & $\mathrm{F}$ & BF4 & Baccaurea sp. I \\
\hline B & $\mathrm{F}$ & BF4 & Baccaurea sp. II \\
\hline B & $\mathrm{F}$ & BF4 & Baccaurea sp. III \\
\hline B & $\mathrm{F}$ & BF4 & Syzygium sp. II \\
\hline B & $\mathrm{F}$ & BF4 & Archidendron bubalium \\
\hline B & $\mathrm{F}$ & BF4 & Aporosa nitida \\
\hline B & J & BJ2 & Hevea brasiliensis \\
\hline B & J & BJ2 & Parkia speciosa \\
\hline B & J & BJ2 & Macaranga bancana \\
\hline B & J & $\mathrm{BJ} 2$ & Macaranga tanarius \\
\hline B & J & BJ2 & Macaranga conifera \\
\hline B & J & BJ2 & Homalanthus sp. \\
\hline B & J & $\mathrm{BJ} 2$ & Croton sp. II \\
\hline B & J & BJ2 & Endospermum sp. II \\
\hline B & J & BJ2 & Alstonia scholaris \\
\hline B & J & BJ3 & Hevea brasiliensis \\
\hline B & J & BJ3 & Macaranga bancana \\
\hline B & J & BJ3 & Macaranga tanarius \\
\hline B & $J$ & BJ3 & Macaranga javanica \\
\hline B & $J$ & BJ3 & Endospermum malayanum \\
\hline B & $\mathrm{J}$ & BJ3 & Alstonia scholaris \\
\hline B & $\mathrm{J}$ & BJ3 & Atrocarpus elasticus \\
\hline B & $J$ & BJ4 & Hevea brasiliensis \\
\hline B & $J$ & BJ4 & Ficus ribes \\
\hline B & $\mathrm{J}$ & BJ4 & Macaranga bancana \\
\hline B & $\mathrm{J}$ & BJ4 & Alstonia scholaris \\
\hline
\end{tabular}

$\begin{array}{ccccccc}\text { secondary } & 0.1102 & 0.1102 & 0.1102 & 0.03491404 & 0.03491404 & 0.03491404 \\ \text { generalist } & 0.2063 & 0.2319 & 0.2319 & 0.0957365 & 0.10525288 & 0.10525288 \\ \text { secondary } & 0.1832 & 0.2015 & 0.2015 & 0.08269782 & 0.08312432 & 0.08312432 \\ \text { secondary } & 0.1969 & 0.1969 & 0.1969 & 0.07836187 & 0.07836187 & 0.07836187 \\ \text { secondary } & 0.3463 & 0.3392 & 0.3392 & 0.1714677 & 0.16171875 & 0.16171875 \\ \text { generalist } & 0.4209 & 0.4396 & 0.4396 & 0.24663657 & 0.24872134 & 0.24872134 \\ \text { secondary } & 0.2898 & 0.3197 & 0.3197 & 0.14649299 & 0.14884082 & 0.14884082 \\ \text { generalist } & 0.3935 & 0.5254 & 0.5254 & 0.17433046 & 0.18824095 & 0.18824095 \\ \text { crop } & 0.2902 & 0.3192 & 0.3493 & 0.17306164 & 0.15902566 & 0.16118195 \\ \text { generalist } & 0.215 & 0.2523 & 0.2523 & 0.08902704 & 0.10159062 & 0.10159062 \\ \text { pioneer } & 0.3369 & 0.4435 & 0.4879 & 0.20569493 & 0.26358636 & 0.27055347 \\ \text { pioneer } & 0.2833 & 0.307 & 0.307 & 0.11828195 & 0.11912579 & 0.11912579 \\ \text { pioneer } & 0.2542 & 0.2542 & 0.2542 & 0.08985953 & 0.08985953 & 0.08985953 \\ \text { generalist } & 0.0541 & 0.0541 & 0.0541 & 0.01879886 & 0.01879886 & 0.01879886 \\ \text { secondary } & 0.2922 & 0.2922 & 0.2922 & 0.1670767 & 0.1670767 & 0.1670767 \\ \text { pioneer } & 0.38 & 0.38 & 0.38 & 0.19064435 & 0.19064435 & 0.19064435 \\ \text { generalist } & 0.2894 & 0.4278 & 0.4278 & 0.20447539 & 0.24996655 & 0.24807193 \\ \text { crop } & 0.2031 & 0.3192 & 0.3493 & 0.12837825 & 0.13632752 & 0.14301199 \\ \text { pioneer } & 0.1945 & 0.4435 & 0.4879 & 0.12666683 & 0.32006587 & 0.33505853 \\ \text { pioneer } & 0.2888 & 0.307 & 0.307 & 0.12039723 & 0.12012777 & 0.12012777 \\ \text { pioneer } & 0.2635 & 0.2635 & 0.2635 & 0.0902447 & 0.0902447 & 0.0902447 \\ \text { pioneer } & 0.2466 & 0.3452 & 0.355 & 0.09388282 & 0.10564417 & 0.11244253 \\ \text { generalist } & 0.4025 & 0.4278 & 0.4278 & 0.26989619 & 0.2696311 & 0.26290295 \\ \text { secondary } & 0.3293 & 0.3666 & 0.3666 & 0.30622967 & 0.33446168 & 0.33446168 \\ \text { crop } & 0.1599 & 0.3192 & 0.3493 & 0.11435538 & 0.13154467 & 0.14359394 \\ \text { pioneer } & 0.5678 & 0.5678 & 0.5678 & 0.34216486 & 0.34216486 & 0.34216486 \\ \text { pioneer } & 0.2728 & 0.4435 & 0.4879 & 0.17229062 & 0.23989435 & 0.25286856 \\ \text { generalist } & 0.3732 & 0.4278 & 0.4278 & 0.26891875 & 0.26725504 & 0.26002244\end{array}$




\begin{tabular}{|c|c|c|c|c|c|c|c|c|c|c|}
\hline B & $J$ & BJ4 & Santiria rubiginosa & pioneer & 0.2252 & 0.35 & 0.35 & 0.07295943 & 0.07295943 & 0.07295943 \\
\hline B & $\mathrm{J}$ & BJ4 & Atrocarpus elasticus & secondary & 0.3224 & 0.3666 & 0.3666 & 0.32072143 & 0.3413262 & 0.3413262 \\
\hline B & $\mathrm{J}$ & BJ4 & Cordonia excelsa & pioneer & 0.2768 & 0.2768 & 0.2768 & 0.10100091 & 0.10100091 & 0.10100091 \\
\hline B & $J$ & BJ5 & Hevea brasiliensis & crop & 0.2842 & 0.3192 & 0.3493 & 0.15991618 & 0.15180413 & 0.16030591 \\
\hline B & J & BJ5 & Parkia speciosa & generalist & 0.2207 & 0.2523 & 0.2523 & 0.09964189 & 0.1066187 & 0.1066187 \\
\hline B & J & BJ5 & Memecyclon sp. & generalist & 0.4013 & 0.4013 & 0.4013 & 0.19131032 & 0.19131032 & 0.19131032 \\
\hline B & J & BJ5 & Camnosperma coriacea & pioneer & 0.2502 & 0.2502 & 0.2502 & 0.09579579 & 0.09579579 & 0.09579579 \\
\hline B & J & BJ5 & Palaquium sumatranum & generalist & 0.3514 & 0.3514 & 0.3514 & 0.176389 & 0.176389 & 0.176389 \\
\hline B & J & BJ5 & Endospermum malayanum & pioneer & 0.3167 & 0.3452 & 0.355 & 0.12349366 & 0.11967036 & 0.12527562 \\
\hline B & J & BJ5 & Wendlandia sp. & generalist & 0.4923 & 0.4923 & 0.4923 & 0.33729489 & 0.33729489 & 0.33729489 \\
\hline B & J & BJ5 & Hymenodictyon sp. & pioneer & 0.2518 & 0.2518 & 0.2518 & 0.13067626 & 0.13067626 & 0.13067626 \\
\hline B & J & BJ5 & Macaranga bancana & pioneer & 0.2618 & 0.4435 & 0.4879 & 0.17351923 & 0.24735809 & 0.26069861 \\
\hline B & 0 & $\mathrm{BO} 2$ & Elaeis guineensis & crop & 0.332 & 0.3673 & 0.3673 & 0.20053495 & 0.19132879 & 0.19132879 \\
\hline B & 0 & $\mathrm{BO} 2$ & Dicranopteris linearis & fern & 0.3868 & 0.4124 & 0.4447 & 0.20114508 & 0.19420049 & 0.19874006 \\
\hline B & 0 & $\mathrm{BO} 2$ & Clidemia hirta & herb & 0.1941 & 0.2682 & 0.2966 & 0.11478556 & 0.12623517 & 0.13448251 \\
\hline B & 0 & $\mathrm{BO} 2$ & Ottochloa sp. II & grass & 0.3014 & 0.3014 & 0.3014 & 0.27220158 & 0.33349377 & 0.33349377 \\
\hline B & 0 & $\mathrm{BO} 2$ & Axonopus compressus & grass & 0.08 & 0.1527 & 0.1471 & 0.02453178 & 0.04136295 & 0.03971334 \\
\hline B & 0 & $\mathrm{BO} 2$ & Symplocos fasciculata & shrub & 0.218 & 0.218 & 0.218 & 0.07974509 & 0.07974509 & 0.07974509 \\
\hline B & 0 & $\mathrm{BO} 2$ & Melastoma malabathricum & herb & 0.2833 & 0.3685 & 0.3685 & 0.20599086 & 0.24054 & 0.23090035 \\
\hline B & 0 & $\mathrm{BO} 2$ & Asystasia indica & herb & 0.3574 & 0.3451 & 0.3451 & 0.2106745 & 0.19051314 & 0.19051314 \\
\hline B & 0 & $\mathrm{BO} 2$ & Nephrolepis acutifolia & fern & 0.2475 & 0.3104 & 0.3104 & 0.07976101 & 0.08218155 & 0.08218155 \\
\hline B & 0 & $\mathrm{BO} 2$ & Lygodium circinatum & fern & 0.2239 & 0.5066 & 0.5066 & 0.08041286 & 0.1393863 & 0.1393863 \\
\hline B & 0 & $\mathrm{BO3}$ & Elaeis guineensis & crop & 0.2466 & 0.3673 & 0.3673 & 0.14455186 & 0.17121479 & 0.17121479 \\
\hline B & 0 & $\mathrm{BO} 3$ & Centotheca lappacea & grass & 0.3114 & 0.3378 & 0.3294 & 0.29493843 & 0.30150685 & 0.28204903 \\
\hline B & 0 & $\mathrm{BO3}$ & Ottochloa sp. I & grass & 0.1237 & 0.3499 & 0.3499 & 0.12205057 & 0.23050426 & 0.23050426 \\
\hline B & 0 & $\mathrm{BO3}$ & Asystasia indica & herb & 0.136 & 0.3451 & 0.3451 & 0.0808059 & 0.126873 & 0.126873 \\
\hline B & $\mathrm{O}$ & $\mathrm{BO3}$ & Nephrolepis acutifolia & fern & 0.2072 & 0.3104 & 0.3104 & 0.07000901 & 0.07688508 & 0.07688508 \\
\hline B & 0 & BO3 & Christella dentata & fern & 0.1756 & 0.1756 & 0.1756 & 0.05247554 & 0.05247554 & 0.05247554 \\
\hline
\end{tabular}




\begin{tabular}{|c|c|c|c|c|c|c|c|c|c|c|}
\hline B & 0 & $\mathrm{BO} 3$ & Melastoma malabathricum & herb & 0.2331 & 0.3685 & 0.3685 & 0.19861503 & 0.2786617 & 0.28757604 \\
\hline B & 0 & BO3 & Axonopus compressus & grass & 0.1153 & 0.1527 & 0.1471 & 0.03938323 & 0.04314697 & 0.04294485 \\
\hline B & 0 & BO4 & Elaeis guineensis & crop & 0.2993 & 0.3673 & 0.3673 & 0.15469277 & 0.17622592 & 0.17622592 \\
\hline B & 0 & BO4 & Ottochloa sp. I & grass & 0.2664 & 0.3499 & 0.3499 & 0.25610807 & 0.29427426 & 0.29427426 \\
\hline B & 0 & $\mathrm{BO} 4$ & Scleria bancana & grass & 0.1797 & 0.1797 & 0.3608 & 0.13345266 & 0.13345266 & 0.20439315 \\
\hline B & 0 & $\mathrm{BO} 4$ & Lygodium circinatum & fern & 0.525 & 0.5066 & 0.5066 & 0.25811183 & 0.2235595 & 0.2235595 \\
\hline B & 0 & BO4 & Axonopus compressus & grass & 0.074 & 0.1527 & 0.1527 & 0.03086706 & 0.04756962 & 0.03841577 \\
\hline B & 0 & BO4 & Taenitis blechnoides & fern & 0.4226 & 0.4226 & 0.4226 & 0.19901888 & 0.19901888 & 0.19901888 \\
\hline B & 0 & $\mathrm{BO} 4$ & Melastoma malabathricum & herb & 0.3108 & 0.3685 & 0.3685 & 0.23449295 & 0.25367619 & 0.24634601 \\
\hline B & 0 & $\mathrm{BO} 4$ & Clidemia hirta & herb & 0.2814 & 0.2682 & 0.2966 & 0.1400719 & 0.14061424 & 0.14381774 \\
\hline B & 0 & BO4 & Nephrolepis acutifolia & fern & 0.2658 & 0.3104 & 0.3104 & 0.0885791 & 0.08448023 & 0.08448023 \\
\hline B & 0 & BO5 & Elaeis guineensis & crop & 0.1968 & 0.3673 & 0.3673 & 0.1402062 & 0.1926779 & 0.1926779 \\
\hline B & 0 & BO5 & Axonopus compressus & grass & 0.0643 & 0.1527 & 0.1471 & 0.0206378 & 0.05220367 & 0.06389803 \\
\hline B & 0 & BO5 & Dicranopteris linearis & fern & 0.3374 & 0.4124 & 0.4447 & 0.16497836 & 0.17706888 & 0.1867861 \\
\hline B & 0 & BO5 & Asystasia indica & herb & 0.271 & 0.3451 & 0.3451 & 0.1514273 & 0.16654103 & 0.16654103 \\
\hline B & 0 & BO5 & Clidemia hirta & herb & 0.1773 & 0.2682 & 0.2966 & 0.11827243 & 0.13240012 & 0.14585986 \\
\hline B & 0 & BO5 & Centotheca lappacea & grass & 0.2507 & 0.3378 & 0.3294 & 0.18557922 & 0.24970512 & 0.25576955 \\
\hline B & 0 & BO5 & Ottochloa sp. I & grass & 0.3868 & 0.3499 & 0.3499 & 0.330624 & 0.32585318 & 0.32585318 \\
\hline B & 0 & BO5 & Nephrolepis acutifolia & fern & 0.2163 & 0.3104 & 0.3104 & 0.07237057 & 0.08137958 & 0.08137958 \\
\hline B & 0 & BO5 & Melastoma malabathricum & herb & 0.26 & 0.3685 & 0.3685 & 0.22924118 & 0.25408322 & 0.24460773 \\
\hline B & 0 & BO5 & Mikania micrantha & herb & 0.2765 & 0.2765 & 0.2765 & 0.09302217 & 0.09302217 & 0.09302217 \\
\hline B & $\mathrm{R}$ & BR1 & Hevea brasiliensis & crop & 0.2461 & 0.3175 & 0.3493 & 0.13992583 & 0.14911608 & 0.14834949 \\
\hline B & $\mathrm{R}$ & BR1 & Axonopus compressus & grass & 0.0718 & 0.0728 & 0.1471 & 0.03065414 & 0.0273665 & 0.03581648 \\
\hline B & $\mathrm{R}$ & BR1 & Scleria bancana & grass & 0.3058 & 0.3667 & 0.3608 & 0.2203352 & 0.22967929 & 0.22385057 \\
\hline B & $\mathrm{R}$ & BR1 & Melastoma malabathricum & herb & 0.259 & 0.2998 & 0.2998 & 0.21485917 & 0.21402374 & 0.23479787 \\
\hline B & $\mathrm{R}$ & BR1 & Mussaendra frondosa & herb & 0.2924 & 0.2924 & 0.2924 & 0.1237376 & 0.1237376 & 0.1237376 \\
\hline B & $\mathrm{R}$ & BR1 & Dicranopteris linearis & fern & 0.363 & 0.4298 & 0.4447 & 0.19777239 & 0.20413155 & 0.19736245 \\
\hline B & $\mathrm{R}$ & BR1 & Alstonia scholaris & generalist & 0.3062 & 0.3062 & 0.3062 & 0.21057475 & 0.21057475 & 0.2344959 \\
\hline
\end{tabular}




\begin{tabular}{|c|c|c|c|c|c|c|c|c|c|c|}
\hline B & $\mathrm{R}$ & BR1 & Clidemia hirta & herb & 0.253 & 0.2971 & 0.2966 & 0.15657489 & 0.16708887 & 0.16589927 \\
\hline B & $\mathrm{R}$ & BR1 & Imperata cylindrica & grass & 0.2652 & 0.3874 & 0.3874 & 0.15156562 & 0.16330709 & 0.16330709 \\
\hline B & $\mathrm{R}$ & BR1 & Centotheca lappacea & grass & 0.2053 & 0.2963 & 0.3294 & 0.19707402 & 0.21561846 & 0.22931875 \\
\hline B & $\mathrm{R}$ & BR2 & Hevea brasiliensis & crop & 0.3304 & 0.3175 & 0.3493 & 0.17495434 & 0.17050749 & 0.18028367 \\
\hline B & $\mathrm{R}$ & BR2 & Axonopus compressus & grass & 0.0409 & 0.0728 & 0.1471 & 0.01859607 & 0.02105753 & 0.03406856 \\
\hline B & $\mathrm{R}$ & BR2 & Clidemia hirta & herb & 0.2278 & 0.2971 & 0.2966 & 0.1235239 & 0.14357141 & 0.14165659 \\
\hline B & $\mathrm{R}$ & BR2 & Ottochloa sp. II & grass & 0.3881 & 0.3881 & 0.3881 & 0.3132687 & 0.35294662 & 0.35294662 \\
\hline B & $\mathrm{R}$ & BR2 & Centotheca lappacea & grass & 0.2102 & 0.2963 & 0.3294 & 0.19840858 & 0.22267207 & 0.23328942 \\
\hline B & $\mathrm{R}$ & BR2 & Imperata cylindrica & grass & 0.3709 & 0.3874 & 0.3874 & 0.18059511 & 0.1770579 & 0.1770579 \\
\hline B & $\mathrm{R}$ & BR2 & Melastoma malabathricum & herb & 0.2482 & 0.2998 & 0.2998 & 0.20401616 & 0.2106132 & 0.23048947 \\
\hline B & $\mathrm{R}$ & BR2 & Stenoclaena palustris & fern & 0.057 & 0.057 & 0.057 & 0.0117194 & 0.0117194 & 0.0117194 \\
\hline B & $\mathrm{R}$ & BR2 & Scleria bancana & grass & 0.1626 & 0.3667 & 0.3608 & 0.12538239 & 0.19901691 & 0.1931834 \\
\hline B & $\mathrm{R}$ & BR3 & Hevea brasiliensis & crop & 0.2343 & 0.3175 & 0.3493 & 0.14335944 & 0.14983568 & 0.15504906 \\
\hline B & $\mathrm{R}$ & BR3 & Axonopus compressus & grass & 0.0433 & 0.0728 & 0.1471 & 0.01414246 & 0.01975196 & 0.03406028 \\
\hline B & $\mathrm{R}$ & BR3 & Melastoma malabathricum & herb & 0.2734 & 0.2998 & 0.2998 & 0.21393524 & 0.21514008 & 0.23257829 \\
\hline B & $\mathrm{R}$ & BR3 & Conarus sp. & herb & 0.1057 & 0.1057 & 0.1057 & 0.03307115 & 0.03307115 & 0.03307115 \\
\hline B & $\mathrm{R}$ & BR3 & Sauropus sp. & shrub & 0.2744 & 0.3076 & 0.3076 & 0.11750809 & 0.11808223 & 0.11808223 \\
\hline B & $\mathrm{R}$ & BR3 & Ficus sp. & shrub & 0.308 & 0.308 & 0.308 & 0.12679894 & 0.12679894 & 0.12679894 \\
\hline B & $\mathrm{R}$ & BR3 & Santiria acuminata & shrub & 0.2715 & 0.2715 & 0.2715 & 0.11666976 & 0.11666976 & 0.11666976 \\
\hline B & $\mathrm{R}$ & BR3 & Centotheca lappacea & grass & 0.2814 & 0.2963 & 0.3294 & 0.24967388 & 0.24178376 & 0.25403533 \\
\hline B & $\mathrm{R}$ & BR3 & Scleria bancana & grass & 0.3531 & 0.3667 & 0.3608 & 0.31068653 & 0.29562661 & 0.29962213 \\
\hline B & $\mathrm{R}$ & BR4 & Hevea brasiliensis & crop & 0.1944 & 0.3175 & 0.3493 & 0.11441944 & 0.13720835 & 0.13821739 \\
\hline B & $\mathrm{R}$ & BR4 & Scleria bancana & grass & 0.3139 & 0.3667 & 0.3608 & 0.21691597 & 0.23195101 & 0.22434125 \\
\hline B & $\mathrm{R}$ & BR4 & Dicranopteris linearis & fern & 0.3888 & 0.4298 & 0.4447 & 0.2033948 & 0.2067948 & 0.20748378 \\
\hline B & $\mathrm{R}$ & BR4 & Spermacoce alata & herb & 0.3985 & 0.3985 & 0.3985 & 0.18341389 & 0.18341389 & 0.18341389 \\
\hline B & $\mathrm{R}$ & BR4 & Blechnum orientale & fern & 0.0812 & 0.0812 & 0.0812 & 0.02510677 & 0.02510677 & 0.02510677 \\
\hline B & $\mathrm{R}$ & BR4 & Sauropus sp. & shrub & 0.2676 & 0.3076 & 0.3076 & 0.10823602 & 0.1136902 & 0.1136902 \\
\hline B & $\mathrm{R}$ & BR4 & Curculigo orchioides & herb & 0.2452 & 0.2452 & 0.2452 & 0.09888979 & 0.09888979 & 0.09888979 \\
\hline
\end{tabular}




$\begin{array}{llll}\text { B } & \text { R } & \text { BR4 } & \text { Axonopus compressus } \\ \text { B } & \text { R } & \text { BR4 } & \text { Clidemia hirta } \\ \text { B } & \text { R } & \text { BR4 } & \text { Centotheca lappacea } \\ \text { H } & \text { F } & \text { HF1 } & \text { Porterandia anisophylla } \\ \text { H } & \text { F } & \text { HF1 } & \text { Gironniera nervosa } \\ \text { H } & \text { F } & \text { HF1 } & \text { Pternandra cordata } \\ \text { H } & \text { F } & \text { HF1 } & \text { Hopea mengarawan } \\ \text { H } & \text { F } & \text { HF1 } & \text { Aporosa nitida } \\ \text { H } & \text { F } & \text { HF1 } & \text { Ixonanthes icosandra } \\ \text { H } & \text { F } & \text { HF1 } & \text { Gironniera subaqualis } \\ \text { H } & \text { F } & \text { HF1 } & \text { Sindora leocarpa } \\ \text { H } & \text { F } & \text { HF1 } & \text { Parkia speciosa } \\ \text { H } & \text { F } & \text { HF2 } & \text { Palagium gutta } \\ \text { H } & \text { F } & \text { HF2 } & \text { Shorea ovalis } \\ \text { H } & \text { F } & \text { HF2 } & \text { Hopea mengarawan } \\ \text { H } & \text { F } & \text { HF2 } & \text { Gironniera nervosa } \\ \text { H } & \text { F } & \text { HF2 } & \text { Aporosa sp. II } \\ \text { H } & \text { F } & \text { HF2 } & \text { Baccaurea sp. III } \\ \text { H } & \text { F } & \text { HF2 } & \text { Croton agrarius } \\ \text { H } & \text { F } & \text { HF3 } & \text { Palagium gutta } \\ \text { H } & \text { F } & \text { HF3 } & \text { Croton agrarius } \\ \text { H } & \text { F } & \text { HF3 } & \text { Shorea ovalis } \\ \text { H } & \text { F } & \text { HF3 } & \text { Ixonanthes icosandra } \\ \text { H } & \text { F } & \text { HF3 } & \text { Aporosa nitida } \\ \text { H } & \text { F } & \text { HF3 } & \text { Hopea mengarawan } \\ \text { H } & \text { HF3 } & \text { Gironniera nervosa } \\ \text { H } & \text { HF3 } & \text { Baccaurea sp. II } \\ \text { H } & \text { HF3 } & \text { Syzygium sp. II } \\ & & \end{array}$

$\begin{array}{ccccccc}\text { grass } & 0.0751 & 0.0728 & 0.1471 & 0.02983686 & 0.02612792 & 0.03660652 \\ \text { herb } & 0.2217 & 0.2971 & 0.2966 & 0.11141708 & 0.14292277 & 0.14331058 \\ \text { grass } & 0.2505 & 0.2963 & 0.3294 & 0.24295616 & 0.2452703 & 0.25533461 \\ \text { generalist } & 0.2381 & 0.3662 & 0.3662 & 0.1024421 & 0.12641302 & 0.12641302 \\ \text { generalist } & 0.3211 & 0.4134 & 0.4134 & 0.12460613 & 0.14226205 & 0.14226205 \\ \text { generalist } & 0.4225 & 0.4656 & 0.4656 & 0.36395027 & 0.36509084 & 0.36509084 \\ \text { secondary } & 0.095 & 0.2634 & 0.2634 & 0.03969153 & 0.0580908 & 0.0580908 \\ \text { generalist } & 0.2997 & 0.3465 & 0.3465 & 0.12890733 & 0.14494156 & 0.14494156 \\ \text { generalist } & 0.3487 & 0.3839 & 0.3839 & 0.18312959 & 0.18301667 & 0.18301667 \\ \text { generalist } & 0.432 & 0.432 & 0.432 & 0.22552807 & 0.22552807 & 0.22552807 \\ \text { secondary } & 0.3649 & 0.3649 & 0.3649 & 0.13850859 & 0.13850859 & 0.13850859 \\ \text { generalist } & 0.2877 & 0.2877 & 0.3173 & 0.13284699 & 0.13284699 & 0.12282455 \\ \text { generalist } & 0.289 & 0.4032 & 0.4032 & 0.16177986 & 0.1773423 & 0.1773423 \\ \text { secondary } & 0.2938 & 0.3248 & 0.3248 & 0.18984722 & 0.1924304 & 0.1924304 \\ \text { secondary } & 0.1491 & 0.2634 & 0.2634 & 0.06455365 & 0.06849242 & 0.06849242 \\ \text { generalist } & 0.348 & 0.4134 & 0.4134 & 0.16139214 & 0.15873563 & 0.15873563 \\ \text { generalist } & 0.2093 & 0.2093 & 0.2093 & 0.09643123 & 0.09643123 & 0.09643123 \\ \text { secondary } & 0.1992 & 0.1992 & 0.1992 & 0.12480494 & 0.12480494 & 0.12480494 \\ \text { secondary } & 0.3295 & 0.3952 & 0.3952 & 0.19396997 & 0.19970249 & 0.19970249 \\ \text { generalist } & 0.3293 & 0.4032 & 0.4032 & 0.17499857 & 0.18328619 & 0.18328619 \\ \text { secondary } & 0.319 & 0.3952 & 0.3952 & 0.19508068 & 0.1998958 & 0.1998958 \\ \text { secondary } & 0.2646 & 0.3248 & 0.3248 & 0.19341645 & 0.18678047 & 0.18678047 \\ \text { generalist } & 0.2777 & 0.3839 & 0.3839 & 0.15554032 & 0.17101035 & 0.17101035 \\ \text { generalist } & 0.288 & 0.3465 & 0.3465 & 0.15572239 & 0.15764343 & 0.15764343 \\ \text { secondary } & 0.2612 & 0.2634 & 0.2634 & 0.08107251 & 0.07667569 & 0.07667569 \\ \text { generalist } & 0.3316 & 0.4134 & 0.4134 & 0.16117216 & 0.15971882 & 0.15971882 \\ \text { secondary } & 0.2072 & 0.2072 & 0.2072 & 0.09013014 & 0.09013014 & 0.09013014 \\ \text { generalist } & 0.2349 & 0.2349 & 0.2349 & 0.18914055 & 0.18914055 & 0.18914055\end{array}$




\begin{tabular}{|c|c|c|c|}
\hline $\mathrm{H}$ & $\mathrm{F}$ & HF3 & Syzygium sp. III \\
\hline $\mathrm{H}$ & $\mathrm{F}$ & HF4 & Palagium gutta \\
\hline $\mathrm{H}$ & $\mathrm{F}$ & HF4 & Croton agrarius \\
\hline $\mathrm{H}$ & $\mathrm{F}$ & HF4 & Horsfieldia sp. \\
\hline $\mathrm{H}$ & $\mathrm{F}$ & HF4 & Syzygium sp. I \\
\hline $\mathrm{H}$ & $\mathrm{F}$ & HF4 & Porterandia anisophylla \\
\hline $\mathrm{H}$ & $\mathrm{F}$ & HF4 & Ixonanthes icosandra \\
\hline $\mathrm{H}$ & $\mathrm{F}$ & HF4 & Madhuca sp. \\
\hline $\mathrm{H}$ & $\mathrm{F}$ & HF4 & Shorea ovalis \\
\hline $\mathrm{H}$ & $\mathrm{F}$ & HF4 & Pternandra caerulescens \\
\hline H & $\mathrm{J}$ & HJ1 & Hevea brasiliensis \\
\hline $\mathrm{H}$ & $\mathrm{J}$ & HJ1 & Alstonia scholaris \\
\hline $\mathrm{H}$ & $\mathrm{J}$ & HJ1 & Rosenbergiodendron longiflorum \\
\hline $\mathrm{H}$ & $\mathrm{J}$ & HJ1 & Macaranga gigantifolia \\
\hline $\mathrm{H}$ & J & HJ1 & Litsea umbellate \\
\hline $\mathrm{H}$ & $\mathrm{J}$ & HJ1 & Fagraea racemose \\
\hline $\mathrm{H}$ & $\mathrm{J}$ & HJ1 & Cratoxylum sumatranum \\
\hline $\mathrm{H}$ & $\mathrm{J}$ & HJ1 & Macaranga bancana \\
\hline $\mathrm{H}$ & $\mathrm{J}$ & HJ1 & Daemonorops sp. \\
\hline $\mathrm{H}$ & J & HJ2 & Hevea brasiliensis \\
\hline H & $J$ & $\mathrm{HJ} 2$ & Artocarpus kemando \\
\hline $\mathrm{H}$ & $\mathrm{J}$ & $\mathrm{HJ} 2$ & Parkia speciosa \\
\hline $\mathrm{H}$ & $\mathrm{J}$ & $\mathrm{HJ} 2$ & Hymenodictyon orixense \\
\hline $\mathrm{H}$ & J & HJ2 & Alstonia angustiloba \\
\hline $\mathrm{H}$ & J & HJ2 & Alstonia scholaris \\
\hline $\mathrm{H}$ & $\mathrm{J}$ & HJ2 & Macaranga bancana \\
\hline $\mathrm{H}$ & $\mathrm{J}$ & $\mathrm{HJ} 2$ & Cleidion sp. \\
\hline $\mathrm{H}$ & $\mathrm{J}$ & HJ3 & Hevea brasiliensis \\
\hline
\end{tabular}

$\begin{array}{ccccccc}\text { generalist } & 0.3372 & 0.3372 & 0.3372 & 0.1715983 & 0.1715983 & 0.1715983 \\ \text { generalist } & 0.3306 & 0.4032 & 0.4032 & 0.18884151 & 0.18905655 & 0.18905655 \\ \text { secondary } & 0.3066 & 0.3952 & 0.3952 & 0.18122564 & 0.1944852 & 0.1944852 \\ \text { secondary } & 0.3047 & 0.3047 & 0.3047 & 0.15391656 & 0.15391656 & 0.15391656 \\ \text { generalist } & 0.2743 & 0.3241 & 0.3241 & 0.14974753 & 0.14974753 & 0.14974753 \\ \text { generalist } & 0.3417 & 0.3662 & 0.3662 & 0.16330017 & 0.15524052 & 0.15524052 \\ \text { generalist } & 0.3246 & 0.3839 & 0.3839 & 0.16426946 & 0.17145817 & 0.17145817 \\ \text { secondary } & 0.1906 & 0.1906 & 0.1906 & 0.07870433 & 0.07870433 & 0.07870433 \\ \text { secondary } & 0.2818 & 0.3248 & 0.3248 & 0.19240256 & 0.19069799 & 0.19069799 \\ \text { generalist } & 0.3506 & 0.4656 & 0.4656 & 0.28838253 & 0.3292956 & 0.3292956 \\ \text { crop } & 0.1928 & 0.243 & 0.2679 & 0.12086031 & 0.12199536 & 0.1187623 \\ \text { generalist } & 0.3433 & 0.3892 & 0.3825 & 0.26158129 & 0.25490702 & 0.25035111 \\ \text { generalist } & 0.2147 & 0.2147 & 0.2147 & 0.10383378 & 0.10383378 & 0.10383378 \\ \text { generalist } & 0.2092 & 0.2092 & 0.2092 & 0.0883476 & 0.0883476 & 0.0883476 \\ \text { generalist } & 0.2147 & 0.2147 & 0.2147 & 0.0762881 & 0.0762881 & 0.0762881 \\ \text { pioneer } & 0.1476 & 0.1476 & 0.1476 & 0.04428711 & 0.04428711 & 0.04428711 \\ \text { pioneer } & 0.3145 & 0.3145 & 0.3145 & 0.18552986 & 0.18552986 & 0.18552986 \\ \text { pioneer } & 0.2763 & 0.427 & 0.4645 & 0.18542956 & 0.22595909 & 0.2456065 \\ \text { shrub } & 0.344 & 0.344 & 0.344 & 0.19488844 & 0.19488844 & 0.19488844 \\ \text { crop } & 0.2239 & 0.243 & 0.2679 & 0.14366226 & 0.13461489 & 0.13438751 \\ \text { secondary } & 0.5452 & 0.5452 & 0.5452 & 0.30099779 & 0.30099779 & 0.30099779 \\ \text { generalist } & 0.197 & 0.2352 & 0.3173 & 0.08840243 & 0.09384975 & 0.0976707 \\ \text { pioneer } & 0.3123 & 0.3263 & 0.3263 & 0.14645462 & 0.14417115 & 0.14417115 \\ \text { generalist } & 0.2912 & 0.3373 & 0.3825 & 0.13490303 & 0.14344944 & 0.14344944 \\ \text { generalist } & 0.3239 & 0.3892 & 0.3825 & 0.21707746 & 0.23483685 & 0.22860497 \\ \text { pioneer } & 0.2896 & 0.427 & 0.4645 & 0.18589422 & 0.2230118 & 0.24564008 \\ \text { pioneer } & 0.4972 & 0.4972 & 0.4972 & 0.3057178 & 0.3057178 & 0.3057178 \\ \text { crop } & 0.1949 & 0.243 & 0.2679 & 0.1293608 & 0.12906465 & 0.13010645\end{array}$




\begin{tabular}{|c|c|c|c|c|c|c|c|c|c|c|}
\hline H & J & HJ3 & Rauvolfia sumatrana & generalist & 0.1685 & 0.1685 & 0.1685 & 0.06334664 & 0.06334664 & 0.06334664 \\
\hline $\mathrm{H}$ & J & HJ3 & Macaranga bancana & pioneer & 0.4221 & 0.427 & 0.4645 & 0.27766883 & 0.26295717 & 0.28256736 \\
\hline $\mathrm{H}$ & J & HJ3 & Parkia speciosa & generalist & 0.2044 & 0.2352 & 0.3173 & 0.08717218 & 0.09298973 & 0.09929943 \\
\hline $\mathrm{H}$ & J & HJ3 & Hymenodictyon orixense & pioneer & 0.2876 & 0.3263 & 0.3263 & 0.13370878 & 0.13595335 & 0.13595335 \\
\hline H & J & HJ3 & Dillenia excels & secondary & 0.4121 & 0.4121 & 0.4121 & 0.16198272 & 0.16198272 & 0.16198272 \\
\hline $\mathrm{H}$ & J & HJ3 & Alstonia scholaris & generalist & 0.3455 & 0.3892 & 0.3825 & 0.25385082 & 0.24850167 & 0.24481071 \\
\hline H & J & $\mathrm{HJ} 4$ & Hevea brasiliensis & crop & 0.1712 & 0.243 & 0.2679 & 0.11237394 & 0.12109682 & 0.11997195 \\
\hline H & J & $\mathrm{HJ} 4$ & Alstonia scholaris & generalist & 0.3113 & 0.3892 & 0.3825 & 0.22328799 & 0.2350187 & 0.23053818 \\
\hline H & J & $\mathrm{HJ} 4$ & Parkia speciosa & generalist & 0.178 & 0.2352 & 0.3173 & 0.08099475 & 0.09339848 & 0.10322155 \\
\hline $\mathrm{H}$ & J & $\mathrm{HJ} 4$ & Hymenodictyon orixense & pioneer & 0.29 & 0.3263 & 0.3263 & 0.13542242 & 0.1391274 & 0.1391274 \\
\hline H & J & $\mathrm{HJ} 4$ & Alstonia angustiloba & generalist & 0.2871 & 0.3373 & 0.3825 & 0.13315942 & 0.14262352 & 0.14262352 \\
\hline $\mathrm{H}$ & J & $\mathrm{HJ} 4$ & Macaranga bancana & pioneer & 0.381 & 0.427 & 0.4645 & 0.24490527 & 0.25778 & 0.28507089 \\
\hline H & J & $\mathrm{HJ} 4$ & Artocarpus elasticus & secondary & 0.332 & 0.332 & 0.332 & 0.30576242 & 0.30576242 & 0.30576242 \\
\hline $\mathrm{H}$ & 0 & HO1 & Elaeis guineensis & crop & 0.2332 & 0.3185 & 0.3185 & 0.13433164 & 0.14147553 & 0.14147553 \\
\hline $\mathrm{H}$ & 0 & $\mathrm{HO} 1$ & Ottochloa sp. I & grass & 0.1616 & 0.1616 & 0.3707 & 0.15887435 & 0.15887435 & 0.23576172 \\
\hline H & $\mathrm{O}$ & $\mathrm{HO} 1$ & Oxalis sp. & herb & 0.0458 & 0.0458 & 0.0458 & 0.01382461 & 0.01382461 & 0.01382461 \\
\hline H & $\mathrm{O}$ & $\mathrm{HO} 1$ & Stachytarpheta jamaicensis & herb & 0.0936 & 0.149 & 0.149 & 0.02541785 & 0.0285194 & 0.0285194 \\
\hline H & 0 & HO1 & Axonopus compressus & grass & 0.1178 & 0.1229 & 0.1535 & 0.03664538 & 0.03445773 & 0.03729676 \\
\hline H & 0 & HO1 & Phyllanthus urinaria & herb & 0.169 & 0.169 & 0.169 & 0.05948086 & 0.05948086 & 0.05948086 \\
\hline H & $\mathrm{O}$ & $\mathrm{HO} 1$ & Asystasia indica & herb & 0.2992 & 0.4538 & 0.4392 & 0.25535099 & 0.44178391 & 0.45650011 \\
\hline H & 0 & HO1 & Centotheca lappacea & grass & 0.2062 & 0.3216 & 0.3154 & 0.20151097 & 0.24537444 & 0.23582064 \\
\hline $\mathrm{H}$ & 0 & HO1 & Spermacoce alata & herb & 0.0831 & 0.4412 & 0.4412 & 0.02314503 & 0.07996084 & 0.07996084 \\
\hline H & 0 & $\mathrm{HO} 2$ & Elaeis guineensis & crop & 0.2822 & 0.3185 & 0.3185 & 0.15687347 & 0.15139964 & 0.15139964 \\
\hline $\mathrm{H}$ & $\mathrm{O}$ & $\mathrm{HO} 2$ & Nephrolepis acutifolia & fern & 0.2149 & 0.2597 & 0.2597 & 0.06825539 & 0.06767188 & 0.06767188 \\
\hline H & 0 & $\mathrm{HO} 2$ & Clidemia hirta & herb & 0.3032 & 0.3701 & 0.4715 & 0.1367085 & 0.16047048 & 0.1862683 \\
\hline $\mathrm{H}$ & 0 & $\mathrm{HO} 2$ & Axonopus compressus & grass & 0.0333 & 0.1229 & 0.1535 & 0.01367258 & 0.02504257 & 0.02880634 \\
\hline H & 0 & $\mathrm{HO} 2$ & Centotheca lappacea & grass & 0.251 & 0.3216 & 0.3154 & 0.25056122 & 0.26268999 & 0.253319 \\
\hline $\mathrm{H}$ & 0 & $\mathrm{HO} 2$ & Rolandra fructicosa & shrub & 0.0713 & 0.0713 & 0.0713 & 0.03043291 & 0.03043291 & 0.03043291 \\
\hline
\end{tabular}




\begin{tabular}{|c|}
\hline $\mathrm{H}$ \\
\hline $\mathrm{H}$ \\
\hline $\mathrm{H}$ \\
\hline $\mathrm{H}$ \\
\hline $\mathrm{H}$ \\
\hline $\mathrm{H}$ \\
\hline $\mathrm{H}$ \\
\hline $\mathrm{H}$ \\
\hline $\mathrm{H}$ \\
\hline $\mathrm{H}$ \\
\hline $\mathrm{H}$ \\
\hline $\mathrm{H}$ \\
\hline $\mathrm{H}$ \\
\hline $\mathrm{H}$ \\
\hline $\mathrm{H}$ \\
\hline $\mathrm{H}$ \\
\hline $\mathrm{H}$ \\
\hline $\mathrm{H}$ \\
\hline $\mathrm{H}$ \\
\hline $\mathrm{H}$ \\
\hline $\mathrm{H}$ \\
\hline $\mathrm{H}$ \\
\hline $\mathrm{H}$ \\
\hline $\mathrm{H}$ \\
\hline $\mathrm{H}$ \\
\hline $\mathrm{H}$ \\
\hline $\mathrm{H}$ \\
\hline $\mathrm{H}$ \\
\hline
\end{tabular}

\author{
$\mathrm{HO} 2$ Spermacoce alata \\ $\mathrm{HO} 2$ Melastoma malabathricum \\ $\mathrm{HO} 2$ Asystasia indica \\ $\mathrm{HO} 2$ Goniophlebium verrucosum \\ $\mathrm{HO} 3$ Elaeis guineensis \\ $\mathrm{HO} 3$ Nephrolepis acutifolia \\ $\mathrm{HO} 3$ Clidemia hirta \\ $\mathrm{HO} 3$ Asystasia indica \\ $\mathrm{HO} 3$ Goniophlebium verrucosum \\ $\mathrm{HO} 3$ Axonopus compressus \\ $\mathrm{HO} 3$ Melastoma malabathricum \\ $\mathrm{HO} 3$ Stachytarpheta jamaicensis \\ $\mathrm{HO} 3$ Centotheca lappacea \\ $\mathrm{HO} 3$ Sauropus sp. \\ $\mathrm{HO} 4$ Elaeis guineensis \\ $\mathrm{HO} 4$ Nephrolepis acutifolia \\ $\mathrm{HO} 4$ Asystasia indica \\ $\mathrm{HO} 4$ Axonopus compressus \\ $\mathrm{HO} 4$ Spermacoce alata \\ HO4 Scleria bancana \\ $\mathrm{HO} 4$ Ageratum conyzoides \\ $\mathrm{HO} 4$ Centotheca lappacea \\ HR1 Hevea brasiliensis \\ HR1 Centotheca lappacea \\ HR1 Asystasia indica \\ HR1 Clidemia hirta \\ HR1 Centrosema pubescens \\ HR1 Macaranga bancana
}

$\begin{array}{cccc}\text { herb } & 0.5082 & 0.4412 & 0.4412 \\ \text { herb } & 0.3101 & 0.3262 & 0.3262 \\ \text { herb } & 0.2286 & 0.4538 & 0.4392 \\ \text { fern } & 0.4597 & 0.4956 & 0.4956 \\ \text { crop } & 0.2103 & 0.3185 & 0.3185 \\ \text { fern } & 0.2256 & 0.2597 & 0.2597 \\ \text { herb } & 0.2878 & 0.3701 & 0.4715 \\ \text { herb } & 0.1617 & 0.4538 & 0.4392 \\ \text { fern } & 0.4506 & 0.4956 & 0.4956 \\ \text { grass } & 0.1179 & 0.1229 & 0.1535 \\ \text { herb } & 0.2465 & 0.3262 & 0.3262 \\ \text { herb } & 0.1152 & 0.149 & 0.149 \\ \text { grass } & 0.2976 & 0.3216 & 0.3154 \\ \text { shrub } & 0.2282 & 0.2282 & 0.2988 \\ \text { crop } & 0.2806 & 0.3185 & 0.3185 \\ \text { fern } & 0.2082 & 0.2597 & 0.2597 \\ \text { herb } & 0.112 & 0.4538 & 0.4392 \\ \text { grass } & 0.0176 & 0.1229 & 0.1535 \\ \text { herb } & 0.1195 & 0.4412 & 0.4412 \\ \text { grass } & 0.3493 & 0.3493 & 0.4024 \\ \text { herb } & 0.1898 & 0.1898 & 0.1898 \\ \text { grass } & 0.2338 & 0.3216 & 0.3154 \\ \text { crop } & 0.1374 & 0.2286 & 0.2679 \\ \text { grass } & 0.2054 & 0.2743 & 0.3154 \\ \text { herb } & 0.1374 & 0.2054 & 0.4392 \\ \text { herb } & 0.2054 & 0.4607 & 0.4715 \\ \text { herb } & 0.1616 & 0.1616 & 0.1616 \\ \text { pioneer } & 0.4389 & 0.4255 & 0.4645\end{array}$

$\begin{array}{ccc}0.20834109 & 0.17594895 & 0.17594895 \\ 0.24324744 & 0.23809085 & 0.23735865 \\ 0.13039231 & 0.22877911 & 0.20074524 \\ 0.30898718 & 0.3018612 & 0.3018612 \\ 0.12768781 & 0.14182862 & 0.14182862 \\ 0.06837787 & 0.06732349 & 0.06732349 \\ 0.14048558 & 0.16225963 & 0.18108851 \\ 0.10738285 & 0.23158807 & 0.205845 \\ 0.26972353 & 0.28326263 & 0.28326263 \\ 0.05493697 & 0.04837922 & 0.05586637 \\ 0.19784499 & 0.21658443 & 0.21790999 \\ 0.03109498 & 0.03120856 & 0.03120856 \\ 0.23759437 & 0.28328253 & 0.28305084 \\ 0.09593996 & 0.09593996 & 0.10952466 \\ 0.14906422 & 0.15402062 & 0.15402062 \\ 0.06887144 & 0.0680237 & 0.0680237 \\ 0.06334165 & 0.20440244 & 0.17502603 \\ 0.0050007 & 0.0203258 & 0.02575729 \\ 0.04266674 & 0.08340333 & 0.08340333 \\ 0.23841495 & 0.23841495 & 0.4226923 \\ 0.06503689 & 0.06503689 & 0.06503689 \\ 0.20672777 & 0.24782186 & 0.23600144 \\ 0.07720291 & 0.10776065 & 0.11471144 \\ 0.20141337 & 0.2152498 & 0.22541713 \\ 0.11286234 & 0.13050326 & 0.1980675 \\ 0.22492935 & 0.21334253 & 0.21113999 \\ 0.05659835 & 0.05659835 & 0.05659835 \\ 0.22002666 & 0.29759241 & 0.25476365\end{array}$




\begin{tabular}{|c|c|c|c|}
\hline $\mathrm{H}$ & $\mathrm{R}$ & HR1 & Imperata cylindrical \\
\hline $\mathrm{H}$ & $\mathrm{R}$ & HR1 & Ottochloa sp. II \\
\hline $\mathrm{H}$ & $\mathrm{R}$ & HR1 & Scleria bancana \\
\hline $\mathrm{H}$ & $\mathrm{R}$ & HR1 & Axonopus compressus \\
\hline $\mathrm{H}$ & $\mathrm{R}$ & HR2 & Hevea brasiliensis \\
\hline $\mathrm{H}$ & $\mathrm{R}$ & $\mathrm{HR} 2$ & Asystasia indica \\
\hline $\mathrm{H}$ & $\mathrm{R}$ & HR2 & Clidemia hirta \\
\hline $\mathrm{H}$ & $\mathrm{R}$ & HR2 & Bauhinia sembifida \\
\hline $\mathrm{H}$ & $\mathrm{R}$ & HR2 & Clerodendrum sp. \\
\hline $\mathrm{H}$ & $\mathrm{R}$ & HR2 & Ottochloa sp. I \\
\hline $\mathrm{H}$ & $\mathrm{R}$ & HR2 & Scleria bancana \\
\hline $\mathrm{H}$ & $\mathrm{R}$ & HR2 & Centotheca lappacea \\
\hline $\mathrm{H}$ & $\mathrm{R}$ & HR2 & Spatholobus ferrugineus \\
\hline $\mathrm{H}$ & $\mathrm{R}$ & HR2 & Lantana camara \\
\hline $\mathrm{H}$ & $\mathrm{R}$ & HR3 & Hevea brasiliensis \\
\hline $\mathrm{H}$ & $\mathrm{R}$ & HR3 & Centotheca lappacea \\
\hline $\mathrm{H}$ & $\mathrm{R}$ & HR3 & Macaranga bancana \\
\hline $\mathrm{H}$ & $\mathrm{R}$ & HR3 & Clidemia hirta \\
\hline $\mathrm{H}$ & $\mathrm{R}$ & HR3 & Parkia speciosa \\
\hline $\mathrm{H}$ & $\mathrm{R}$ & HR3 & Ottochloa sp. I \\
\hline $\mathrm{H}$ & $\mathrm{R}$ & HR3 & Mikania micrantha \\
\hline $\mathrm{H}$ & $\mathrm{R}$ & HR3 & Dicranopteris linearis \\
\hline $\mathrm{H}$ & $\mathrm{R}$ & HR3 & Sauropus sp. \\
\hline $\mathrm{H}$ & $\mathrm{R}$ & HR4 & Hevea brasiliensis \\
\hline $\mathrm{H}$ & $\mathrm{R}$ & HR4 & Scleria bancana \\
\hline $\mathrm{H}$ & $\mathrm{R}$ & HR4 & Melastoma malabathricum \\
\hline $\mathrm{H}$ & $\mathrm{R}$ & HR4 & Clidemia hirta \\
\hline $\mathrm{H}$ & $\mathrm{R}$ & HR4 & Alstonia scholaris \\
\hline
\end{tabular}

\begin{tabular}{|c|c|c|c|c|c|c|}
\hline grass & 0.1436 & 0.2847 & 0.2847 & 0.1534894 & 0.1534894 & 0.1534894 \\
\hline grass & 0.335 & 0.335 & 0.3707 & 0.40497273 & 0.40497273 & 0.35233464 \\
\hline grass & 0.2847 & 0.229 & 0.4024 & 0.08722684 & 0.12645848 & 0.21538625 \\
\hline grass & 0.4142 & 0.1083 & 0.1535 & 0.0309949 & 0.03291856 & 0.03808281 \\
\hline crop & 0.1878 & 0.2286 & 0.2679 & 0.11983274 & 0.11811944 & 0.12396777 \\
\hline herb & 0.1856 & 0.2054 & 0.4392 & 0.11920398 & 0.13350719 & 0.19361855 \\
\hline herb & 0.2852 & 0.4607 & 0.4715 & 0.16303147 & 0.18576407 & 0.18161679 \\
\hline herb & 0.1167 & 0.1167 & 0.1167 & 0.03877918 & 0.03877918 & 0.03877918 \\
\hline shrub & 0.1689 & 0.1689 & 0.1689 & 0.06351184 & 0.06351184 & 0.06351184 \\
\hline grass & 0.308 & 0.3209 & 0.3209 & 0.22289127 & 0.27302513 & 0.27302513 \\
\hline grass & 0.1392 & 0.229 & 0.4024 & 0.10051969 & 0.12660596 & 0.21830075 \\
\hline grass & 0.2974 & 0.2743 & 0.3154 & 0.28872406 & 0.26700742 & 0.27475892 \\
\hline shrub & 0.2904 & 0.2904 & 0.2904 & 0.12747 & 0.12747 & 0.12747 \\
\hline herb & 0.1053 & 0.1053 & 0.1053 & 0.03343924 & 0.03343924 & 0.03343924 \\
\hline crop & 0.197 & 0.2286 & 0.2679 & 0.12555474 & 0.12105902 & 0.12570234 \\
\hline grass & 0.1583 & 0.2743 & 0.3154 & 0.15927939 & 0.20307551 & 0.21415305 \\
\hline pioneer & 0.2232 & 0.4255 & 0.4645 & 0.14949162 & 0.26418108 & 0.34403783 \\
\hline herb & 0.4218 & 0.4607 & 0.4715 & 0.24531547 & 0.22958438 & 0.22602485 \\
\hline generalist & 0.1041 & 0.1041 & 0.3173 & 0.05740575 & 0.05740575 & 0.0906271 \\
\hline grass & 0.1608 & 0.3209 & 0.3209 & 0.15478942 & 0.24076635 & 0.24076635 \\
\hline herb & 0.2893 & 0.2893 & 0.2893 & 0.11467491 & 0.11467491 & 0.11467491 \\
\hline fern & 0.2845 & 0.2845 & 0.2845 & 0.13770395 & 0.13770395 & 0.13770395 \\
\hline shrub & 0.273 & 0.273 & 0.2988 & 0.12020398 & 0.12020398 & 0.12101815 \\
\hline crop & 0.1496 & 0.2286 & 0.2679 & 0.1015181 & 0.10825394 & 0.11338377 \\
\hline grass & 0.2492 & 0.229 & 0.4024 & 0.18727322 & 0.17503004 & 0.25231313 \\
\hline herb & 0.2274 & 0.2274 & 0.2274 & 0.19767778 & 0.19767778 & 0.21872622 \\
\hline herb & 0.2684 & 0.4607 & 0.4715 & 0.15801276 & 0.18591233 & 0.18311173 \\
\hline generalist & 0.2492 & 0.2492 & 0.3825 & 0.18706089 & 0.18706089 & 0.21402421 \\
\hline
\end{tabular}




\begin{tabular}{|c|c|c|c|c|c|c|c|c|c|c|}
\hline $\mathrm{H}$ & $\mathrm{R}$ & HR4 & Lygodium circinatum & fern & 0.3822 & 0.3822 & 0.3822 & 0.17372441 & 0.17372441 & 0.17372441 \\
\hline $\mathrm{H}$ & $\mathrm{R}$ & HR4 & Lygodium cf. saliciforum & fern & 0.3034 & 0.3034 & 0.3034 & 0.09299372 & 0.09299372 & 0.09299372 \\
\hline $\mathrm{H}$ & $\mathrm{R}$ & HR4 & Mussaendra frondosa & herb & 0.3514 & 0.3514 & 0.3514 & 0.16230556 & 0.16230556 & 0.16230556 \\
\hline $\mathrm{H}$ & $\mathrm{R}$ & HR4 & Axonopus compressus & grass & 0.0517 & 0.1083 & 0.1535 & 0.02121927 & 0.028288 & 0.04460865 \\
\hline $\mathrm{H}$ & $\mathrm{R}$ & HR4 & Centotheca lappacea & grass & 0.2056 & 0.2743 & 0.3154 & 0.19070667 & 0.21258076 & 0.22412918 \\
\hline
\end{tabular}


Appendix 3: GPS data (latitude and longitude) per plot.

\begin{tabular}{|c|c|c|}
\hline Plot & Latitude & Longitude \\
\hline BF1 & -1.98333 & 102.75 \\
\hline BF2 & -1.96667 & 102.75 \\
\hline BF3 & -1.94275 & 102.58132 \\
\hline BF4 & -1.94195 & 102.58063 \\
\hline $\mathrm{BJ} 2$ & -2.03048 & 102.77132 \\
\hline $\mathrm{BJ} 3$ & -2.06297 & 102.80097 \\
\hline BJ4 & -2.01592 & 102.75342 \\
\hline BJ5 & -2.14282 & 102.85218 \\
\hline $\mathrm{BO} 2$ & -2.09187 & 102.8023 \\
\hline $\mathrm{BO} 3$ & -2.08523 & 102.78908 \\
\hline BO4 & -2.09528 & 102.78322 \\
\hline BO5 & -2.0767 & 102.77287 \\
\hline BR1 & -2.07555 & 102.79187 \\
\hline BR2 & -2.07088 & 102.79182 \\
\hline BR3 & -2.05042 & 102.75337 \\
\hline BR4 & -2.1082 & 102.7908 \\
\hline HF1 & -1.90988 & 103.2662 \\
\hline HF2 & -1.88352 & 103.26768 \\
\hline HF3 & -1.85772 & 103.3079 \\
\hline HF4 & -1.78687 & 103.27057 \\
\hline HJ1 & -1.91098 & 103.2667 \\
\hline $\mathrm{HJ} 2$ & -1.87903 & 103.27457 \\
\hline HJ3 & -1.85967 & 103.30058 \\
\hline $\mathrm{HJ} 4$ & -1.80507 & 103.26445 \\
\hline $\mathrm{HO} 1$ & -1.92778 & 103.25938 \\
\hline $\mathrm{HO} 2$ & -1.82553 & 103.29423 \\
\hline $\mathrm{HO}$ & -1.84972 & 103.29942 \\
\hline $\mathrm{HO} 4$ & -1.78537 & 103.27692 \\
\hline HR1 & -2.17862 & 103.33337 \\
\hline HR2 & -2.16353 & 103.33423 \\
\hline HR3 & -2.1784 & 103.33283 \\
\hline HR4 & -2.18755 & 103.3426 \\
\hline
\end{tabular}


Appendix 4: Morisita-Horn results with fragment pool approach at $\alpha-, \beta-, \gamma$-level and true turnover $\beta$ - differentiation.

\begin{tabular}{|c|c|c|c|c|c|c|}
\hline Region & System & Plot & $C(\alpha$-level) & $C(\beta$-level) & $C$ ( $\gamma$-level) & true $\beta$-level \\
\hline $\mathrm{H}$ & $\mathrm{O}$ & HO1 & 0.13043305 & 0.11750192 & 0.11093238 & 0.019500663 \\
\hline $\mathrm{H}$ & $\mathrm{O}$ & HO1 & 0.07864655 & 0.11791648 & 0.11320725 & 0.0345607 \\
\hline $\mathrm{H}$ & 0 & HO1 & 0.07903686 & 0.11200986 & 0.10772619 & 0.028689331 \\
\hline $\mathrm{H}$ & 0 & HO1 & 0.08732677 & 0.11575109 & 0.10977185 & 0.022445078 \\
\hline $\mathrm{H}$ & $\mathrm{O}$ & HO1 & 0.08142171 & 0.12419325 & 0.11769898 & 0.036277269 \\
\hline $\mathrm{H}$ & 0 & HO1 & 0.07860183 & 0.1257256 & 0.11753476 & 0.038932931 \\
\hline $\mathrm{H}$ & $\mathrm{O}$ & HO1 & 0.08374432 & 0.12470817 & 0.11712145 & 0.033377133 \\
\hline $\mathrm{H}$ & 0 & HO1 & 0.08819036 & 0.13049076 & 0.12179337 & 0.033603009 \\
\hline $\mathrm{H}$ & 0 & HO1 & 0.09234387 & 0.13733761 & 0.12506712 & 0.032723255 \\
\hline $\mathrm{H}$ & 0 & HO1 & 0.08508151 & 0.12433807 & 0.11751612 & 0.032434604 \\
\hline $\mathrm{H}$ & $\mathrm{O}$ & $\mathrm{HO} 2$ & 0.15571275 & 0.13202714 & 0.10292206 & 0.05279069 \\
\hline $\mathrm{H}$ & $\mathrm{O}$ & $\mathrm{HO} 2$ & 0.14935566 & 0.13397207 & 0.10685411 & 0.042501553 \\
\hline $\mathrm{H}$ & $\mathrm{O}$ & $\mathrm{HO} 2$ & 0.14903368 & 0.12881998 & 0.10722984 & 0.041803845 \\
\hline $\mathrm{H}$ & 0 & $\mathrm{HO} 2$ & 0.15785139 & 0.12484601 & 0.11111763 & 0.046733755 \\
\hline $\mathrm{H}$ & $\mathrm{O}$ & $\mathrm{HO} 2$ & 0.15443383 & 0.13360187 & 0.10876396 & 0.045669872 \\
\hline $\mathrm{H}$ & 0 & $\mathrm{HO} 2$ & 0.1459575 & 0.1290802 & 0.10530428 & 0.040653226 \\
\hline $\mathrm{H}$ & $\mathrm{O}$ & $\mathrm{HO} 2$ & 0.15385333 & 0.13729108 & 0.11077176 & 0.043081571 \\
\hline $\mathrm{H}$ & $\mathrm{O}$ & $\mathrm{HO} 2$ & 0.14473865 & 0.1334357 & 0.10484592 & 0.039892732 \\
\hline $\mathrm{H}$ & $\mathrm{O}$ & $\mathrm{HO} 2$ & 0.14578919 & 0.12649058 & 0.10516899 & 0.040620198 \\
\hline $\mathrm{H}$ & 0 & $\mathrm{HO} 2$ & 0.17246074 & 0.16581272 & 0.12334938 & 0.049111359 \\
\hline $\mathrm{H}$ & 0 & $\mathrm{HO} 3$ & 0.13492754 & 0.12267963 & 0.10505347 & 0.029874075 \\
\hline $\mathrm{H}$ & $\mathrm{O}$ & $\mathrm{HO} 3$ & 0.12718744 & 0.12243338 & 0.1042976 & 0.022889833 \\
\hline $\mathrm{H}$ & 0 & $\mathrm{HO} 3$ & 0.14251427 & 0.12884828 & 0.10436237 & 0.038151897 \\
\hline $\mathrm{H}$ & $\mathrm{O}$ & $\mathrm{HO} 3$ & 0.14241351 & 0.12806189 & 0.10570909 & 0.03670442 \\
\hline $\mathrm{H}$ & $\mathrm{O}$ & $\mathrm{HO} 3$ & 0.12926003 & 0.12597669 & 0.10525124 & 0.024008796 \\
\hline $\mathrm{H}$ & $\mathrm{O}$ & $\mathrm{HO} 3$ & 0.13034586 & 0.12703111 & 0.10616174 & 0.024184119 \\
\hline $\mathrm{H}$ & 0 & $\mathrm{HO} 3$ & 0.13371778 & 0.12993501 & 0.10619052 & 0.027527255 \\
\hline $\mathrm{H}$ & $\mathrm{O}$ & $\mathrm{HO} 3$ & 0.13542946 & 0.13104936 & 0.11032725 & 0.025102206 \\
\hline $\mathrm{H}$ & 0 & $\mathrm{HO} 3$ & 0.14938165 & 0.1404353 & 0.12349895 & 0.025882699 \\
\hline $\mathrm{H}$ & 0 & $\mathrm{HO} 3$ & 0.17080367 & 0.14771558 & 0.12976784 & 0.041035826 \\
\hline $\mathrm{H}$ & 0 & $\mathrm{HO} 4$ & 0.09224727 & 0.08506613 & 0.10601823 & 0.013770965 \\
\hline $\mathrm{H}$ & $\mathrm{O}$ & $\mathrm{HO} 4$ & 0.08896739 & 0.09223849 & 0.10920724 & 0.020239849 \\
\hline $\mathrm{H}$ & 0 & $\mathrm{HO} 4$ & 0.09381326 & 0.09671113 & 0.11397494 & 0.020161685 \\
\hline $\mathrm{H}$ & $\mathrm{O}$ & $\mathrm{HO} 4$ & 0.08810106 & 0.09259113 & 0.10956319 & 0.021462127 \\
\hline $\mathrm{H}$ & $\mathrm{O}$ & $\mathrm{HO} 4$ & 0.11951021 & 0.09664155 & 0.10217333 & 0.017336875 \\
\hline $\mathrm{H}$ & 0 & $\mathrm{HO} 4$ & 0.08633924 & 0.09123486 & 0.10771839 & 0.02137915 \\
\hline $\mathrm{H}$ & $\mathrm{O}$ & $\mathrm{HO} 4$ & 0.08071778 & 0.08816022 & 0.106539 & 0.025821226 \\
\hline $\mathrm{H}$ & $\mathrm{O}$ & $\mathrm{HO} 4$ & 0.08764673 & 0.09198621 & 0.10932854 & 0.021681816 \\
\hline $\mathrm{H}$ & $\mathrm{O}$ & $\mathrm{HO} 4$ & 0.08707575 & 0.09334494 & 0.1124315 & 0.025355751 \\
\hline $\mathrm{H}$ & 0 & $\mathrm{HO} 4$ & 0.12569044 & 0.09927763 & 0.10939717 & 0.016293266 \\
\hline $\mathrm{H}$ & $\mathrm{R}$ & HR1 & 0.18647679 & 0.13776695 & 0.11125241 & 0.075224382 \\
\hline $\mathrm{H}$ & $\mathrm{R}$ & HR1 & 0.15185728 & 0.14055213 & 0.10673675 & 0.045120532 \\
\hline
\end{tabular}




\begin{tabular}{|c|c|c|c|c|c|c|}
\hline $\mathrm{H}$ & $\mathrm{R}$ & HR1 & 0.13818056 & 0.13241799 & 0.10005322 & 0.038127345 \\
\hline $\mathrm{H}$ & $\mathrm{R}$ & HR1 & 0.16169686 & 0.1251495 & 0.10111022 & 0.060586648 \\
\hline $\mathrm{H}$ & $\mathrm{R}$ & HR1 & 0.13701619 & 0.12522087 & 0.09732195 & 0.039694242 \\
\hline $\mathrm{H}$ & $\mathrm{R}$ & HR1 & 0.13740119 & 0.12501056 & 0.1001765 & 0.03722469 \\
\hline $\mathrm{H}$ & $\mathrm{R}$ & HR1 & 0.15619561 & 0.14778537 & 0.11151586 & 0.044679759 \\
\hline $\mathrm{H}$ & $\mathrm{R}$ & HR1 & 0.14254576 & 0.12699461 & 0.10090159 & 0.041644172 \\
\hline $\mathrm{H}$ & $\mathrm{R}$ & HR1 & 0.12758972 & 0.11791104 & 0.09698587 & 0.030603847 \\
\hline $\mathrm{H}$ & $\mathrm{R}$ & HR1 & 0.14121076 & 0.12399435 & 0.1015931 & 0.039617661 \\
\hline $\mathrm{H}$ & $\mathrm{R}$ & HR2 & 0.11879386 & 0.13773355 & 0.09586526 & 0.022928606 \\
\hline $\mathrm{H}$ & $\mathrm{R}$ & HR2 & 0.1105749 & 0.1310265 & 0.09210095 & 0.01847395 \\
\hline $\mathrm{H}$ & $\mathrm{R}$ & HR2 & 0.10631275 & 0.12897745 & 0.09161147 & 0.014701282 \\
\hline $\mathrm{H}$ & $\mathrm{R}$ & HR2 & 0.12103518 & 0.13832601 & 0.09524055 & 0.02579463 \\
\hline $\mathrm{H}$ & $\mathrm{R}$ & HR2 & 0.10822332 & 0.13446031 & 0.09394154 & 0.014281778 \\
\hline $\mathrm{H}$ & $\mathrm{R}$ & HR2 & 0.15918597 & 0.15922945 & 0.10274608 & 0.056439895 \\
\hline $\mathrm{H}$ & $\mathrm{R}$ & HR2 & 0.11280423 & 0.13619988 & 0.09610435 & 0.016699875 \\
\hline $\mathrm{H}$ & $\mathrm{R}$ & HR2 & 0.11268074 & 0.12825443 & 0.08998809 & 0.022692658 \\
\hline $\mathrm{H}$ & $\mathrm{R}$ & HR2 & 0.11183987 & 0.12689928 & 0.08815924 & 0.02368063 \\
\hline $\mathrm{H}$ & $\mathrm{R}$ & HR2 & 0.10536543 & 0.134539 & 0.09481858 & 0.010546854 \\
\hline $\mathrm{H}$ & $\mathrm{R}$ & HR3 & 0.12825674 & 0.12360332 & 0.08241356 & 0.045843172 \\
\hline $\mathrm{H}$ & $\mathrm{R}$ & HR3 & 0.1250164 & 0.1267752 & 0.08420324 & 0.040813164 \\
\hline $\mathrm{H}$ & $\mathrm{R}$ & HR3 & 0.12205912 & 0.12203049 & 0.08201853 & 0.040040596 \\
\hline $\mathrm{H}$ & $\mathrm{R}$ & HR3 & 0.12695228 & 0.12096864 & 0.08138619 & 0.045566089 \\
\hline $\mathrm{H}$ & $\mathrm{R}$ & HR3 & 0.12112027 & 0.12144779 & 0.0821418 & 0.038978474 \\
\hline $\mathrm{H}$ & $\mathrm{R}$ & HR3 & 0.14864802 & 0.12027321 & 0.07750784 & 0.071140175 \\
\hline $\mathrm{H}$ & $\mathrm{R}$ & HR3 & 0.14071531 & 0.12017598 & 0.07927176 & 0.061443552 \\
\hline $\mathrm{H}$ & $\mathrm{R}$ & HR3 & 0.13601908 & 0.12280594 & 0.08281895 & 0.053200137 \\
\hline $\mathrm{H}$ & $\mathrm{R}$ & HR3 & 0.15564224 & 0.1571951 & 0.09609526 & 0.059546983 \\
\hline $\mathrm{H}$ & $\mathrm{R}$ & HR3 & 0.16392054 & 0.16130042 & 0.09602005 & 0.067900492 \\
\hline $\mathrm{H}$ & $\mathrm{R}$ & HR4 & 0.15000795 & 0.10533803 & 0.09211729 & 0.057890659 \\
\hline $\mathrm{H}$ & $\mathrm{R}$ & HR4 & 0.14633669 & 0.11081664 & 0.09634706 & 0.049989627 \\
\hline $\mathrm{H}$ & $\mathrm{R}$ & HR4 & 0.16432704 & 0.11746119 & 0.0932552 & 0.071071844 \\
\hline $\mathrm{H}$ & $\mathrm{R}$ & HR4 & 0.15743116 & 0.11736499 & 0.09453092 & 0.062900244 \\
\hline $\mathrm{H}$ & $\mathrm{R}$ & HR4 & 0.14662995 & 0.10855453 & 0.09241596 & 0.054213992 \\
\hline $\mathrm{H}$ & $\mathrm{R}$ & HR4 & 0.15149268 & 0.11420475 & 0.09620352 & 0.055289154 \\
\hline $\mathrm{H}$ & $\mathrm{R}$ & HR4 & 0.13929452 & 0.10275333 & 0.09088713 & 0.048407394 \\
\hline $\mathrm{H}$ & $\mathrm{R}$ & HR4 & 0.15441832 & 0.11478146 & 0.09455488 & 0.059863441 \\
\hline $\mathrm{H}$ & $\mathrm{R}$ & HR4 & 0.13641027 & 0.10701575 & 0.09224738 & 0.044162896 \\
\hline $\mathrm{H}$ & $\mathrm{R}$ & HR4 & 0.14310235 & 0.10470184 & 0.09298626 & 0.05011609 \\
\hline $\mathrm{H}$ & $\mathrm{J}$ & $\mathrm{HJ1}$ & 0.14982039 & 0.17116902 & 0.11643113 & 0.033389252 \\
\hline $\mathrm{H}$ & $\mathrm{J}$ & $\mathrm{HJ} 1$ & 0.12738511 & 0.14410359 & 0.09953657 & 0.027848532 \\
\hline $\mathrm{H}$ & $\mathrm{J}$ & $\mathrm{HJ} 1$ & 0.12416481 & 0.14084818 & 0.09864825 & 0.025516563 \\
\hline $\mathrm{H}$ & $\mathrm{J}$ & $\mathrm{HJ1}$ & 0.12645964 & 0.14230959 & 0.10052509 & 0.025934549 \\
\hline $\mathrm{H}$ & $\mathrm{J}$ & $\mathrm{HJ1}$ & 0.13427851 & 0.1404123 & 0.09707343 & 0.037205074 \\
\hline $\mathrm{H}$ & $\mathrm{J}$ & HJ1 & 0.12850051 & 0.14853403 & 0.1044893 & 0.024011213 \\
\hline
\end{tabular}




\begin{tabular}{|c|c|c|c|c|c|c|}
\hline H & J & HJ1 & 0.12854196 & 0.14272442 & 0.09961293 & 0.028929025 \\
\hline H & $\mathrm{J}$ & HJ1 & 0.13745985 & 0.15062022 & 0.10377972 & 0.033680129 \\
\hline H & J & HJ1 & 0.12644821 & 0.14250291 & 0.10067973 & 0.025768476 \\
\hline $\mathrm{H}$ & $\mathrm{J}$ & HJ1 & 0.13970244 & 0.16264323 & 0.1142235 & 0.025478944 \\
\hline $\mathrm{H}$ & J & $\mathrm{HJ} 2$ & 0.21802425 & 0.14372354 & 0.0841053 & 0.133918952 \\
\hline $\mathrm{H}$ & J & $\mathrm{HJ} 2$ & 0.18453429 & 0.15087172 & 0.09199337 & 0.092540921 \\
\hline H & $\mathrm{J}$ & $\mathrm{HJ} 2$ & 0.19920107 & 0.14690438 & 0.08970426 & 0.109496811 \\
\hline H & J & $\mathrm{HJ} 2$ & 0.21140906 & 0.15865046 & 0.09863197 & 0.112777085 \\
\hline H & J & $\mathrm{HJ} 2$ & 0.19956814 & 0.14832583 & 0.08813309 & 0.111435054 \\
\hline H & J & $\mathrm{HJ} 2$ & 0.19284871 & 0.16085289 & 0.09827957 & 0.094569137 \\
\hline H & J & $\mathrm{HJ} 2$ & 0.17815926 & 0.14099558 & 0.08489827 & 0.093260994 \\
\hline $\mathrm{H}$ & J & HJ2 & 0.18203427 & 0.15422763 & 0.09531743 & 0.086716835 \\
\hline $\mathrm{H}$ & J & $\mathrm{HJ} 2$ & 0.18747841 & 0.14168482 & 0.08672755 & 0.10075086 \\
\hline $\mathrm{H}$ & $\mathrm{J}$ & $\mathrm{HJ} 2$ & 0.20603162 & 0.15374975 & 0.09449387 & 0.111537749 \\
\hline H & J & HJ3 & 0.17174822 & 0.16424766 & 0.10299278 & 0.068755448 \\
\hline H & $\mathrm{J}$ & HJ3 & 0.17274825 & 0.17217242 & 0.10889481 & 0.063853439 \\
\hline $\mathrm{H}$ & J & HJ3 & 0.17527442 & 0.17319638 & 0.10757467 & 0.06769975 \\
\hline $\mathrm{H}$ & J & HJ3 & 0.16591418 & 0.15618731 & 0.1003749 & 0.065539285 \\
\hline $\mathrm{H}$ & J & HJ3 & 0.16619798 & 0.16220612 & 0.10489718 & 0.061300801 \\
\hline H & $\mathrm{J}$ & HJ3 & 0.16488407 & 0.16148616 & 0.10177471 & 0.063109355 \\
\hline $\mathrm{H}$ & J & HJ3 & 0.15379973 & 0.15129081 & 0.096747 & 0.05705273 \\
\hline $\mathrm{H}$ & J & HJ3 & 0.1534807 & 0.14243621 & 0.08960676 & 0.063873945 \\
\hline $\mathrm{H}$ & J & HJ3 & 0.16625995 & 0.1462217 & 0.09337049 & 0.072889452 \\
\hline $\mathrm{H}$ & $\mathrm{J}$ & HJ3 & 0.16149533 & 0.15363117 & 0.09828535 & 0.063209972 \\
\hline $\mathrm{H}$ & J & $\mathrm{HJ} 4$ & 0.18221271 & 0.13845989 & 0.08131287 & 0.100899838 \\
\hline $\mathrm{H}$ & J & $\mathrm{HJ} 4$ & 0.17400724 & 0.13723671 & 0.08342569 & 0.090581549 \\
\hline $\mathrm{H}$ & J & $\mathrm{HJ} 4$ & 0.17377022 & 0.14914203 & 0.09113534 & 0.082634881 \\
\hline $\mathrm{H}$ & $\mathrm{J}$ & $\mathrm{HJ} 4$ & 0.16954629 & 0.14581693 & 0.09065228 & 0.078894013 \\
\hline $\mathrm{H}$ & J & $\mathrm{HJ} 4$ & 0.1992442 & 0.14779716 & 0.089443 & 0.1098012 \\
\hline $\mathrm{H}$ & J & $\mathrm{HJ} 4$ & 0.17216148 & 0.1393489 & 0.08711035 & 0.085051129 \\
\hline $\mathrm{H}$ & J & HJ4 & 0.20804478 & 0.15319028 & 0.09440509 & 0.113639686 \\
\hline $\mathrm{H}$ & $\mathrm{J}$ & HJ4 & 0.15671008 & 0.1374399 & 0.08484238 & 0.071867707 \\
\hline $\mathrm{H}$ & J & $\mathrm{HJ} 4$ & 0.17625757 & 0.15519204 & 0.09431237 & 0.081945198 \\
\hline $\mathrm{H}$ & $\mathrm{J}$ & $\mathrm{HJ} 4$ & 0.18713762 & 0.15011621 & 0.0917122 & 0.095425414 \\
\hline $\mathrm{H}$ & $\mathrm{F}$ & HF1 & 0.15217761 & 0.0527634 & 0.02963162 & 0.12254599 \\
\hline $\mathrm{H}$ & $\mathrm{F}$ & HF1 & 0.15759898 & 0.05143172 & 0.03820156 & 0.119397426 \\
\hline $\mathrm{H}$ & $\mathrm{F}$ & HF1 & 0.18202104 & 0.05998287 & 0.04643754 & 0.135583502 \\
\hline $\mathrm{H}$ & $\mathrm{F}$ & HF1 & 0.19255751 & 0.080287 & 0.04540942 & 0.147148087 \\
\hline $\mathrm{H}$ & $\mathrm{F}$ & HF1 & 0.14478422 & 0.05164515 & 0.02867913 & 0.11610509 \\
\hline $\mathrm{H}$ & $\mathrm{F}$ & HF1 & 0.14213134 & 0.04666598 & 0.0258997 & 0.11623164 \\
\hline $\mathrm{H}$ & $\mathrm{F}$ & HF1 & 0.14991075 & 0.0494874 & 0.0284627 & 0.121448047 \\
\hline $\mathrm{H}$ & $\mathrm{F}$ & HF1 & 0.16657475 & 0.05384782 & 0.02930773 & 0.137267024 \\
\hline $\mathrm{H}$ & $\mathrm{F}$ & HF1 & 0.15724204 & 0.0567792 & 0.03073549 & 0.126506548 \\
\hline $\mathrm{H}$ & $\mathrm{F}$ & HF1 & 0.13413041 & 0.04313492 & 0.02415783 & 0.109972579 \\
\hline
\end{tabular}




\begin{tabular}{|c|c|c|c|c|c|c|}
\hline $\mathrm{H}$ & $\mathrm{F}$ & HF2 & 0.1392598 & 0.0841401 & 0.08535279 & 0.053907006 \\
\hline $\mathrm{H}$ & $\mathrm{F}$ & HF2 & 0.1486269 & 0.09361388 & 0.09372109 & 0.054905812 \\
\hline $\mathrm{H}$ & $\mathrm{F}$ & HF2 & 0.13711236 & 0.08375676 & 0.08855946 & 0.048552896 \\
\hline $\mathrm{H}$ & $\mathrm{F}$ & HF2 & 0.13885329 & 0.08065115 & 0.08424607 & 0.054607223 \\
\hline $\mathrm{H}$ & $\mathrm{F}$ & HF2 & 0.15377681 & 0.09184697 & 0.09476893 & 0.059007879 \\
\hline $\mathrm{H}$ & $\mathrm{F}$ & HF2 & 0.15093697 & 0.09111916 & 0.09380359 & 0.05713338 \\
\hline $\mathrm{H}$ & $\mathrm{F}$ & HF2 & 0.1522911 & 0.08814966 & 0.0884168 & 0.063874296 \\
\hline $\mathrm{H}$ & $\mathrm{F}$ & HF2 & 0.1451656 & 0.09023808 & 0.09040149 & 0.054764116 \\
\hline $\mathrm{H}$ & $\mathrm{F}$ & HF2 & 0.15060065 & 0.09004088 & 0.0906652 & 0.059935442 \\
\hline $\mathrm{H}$ & $\mathrm{F}$ & HF2 & 0.14954952 & 0.09356037 & 0.0951208 & 0.054428721 \\
\hline $\mathrm{H}$ & $\mathrm{F}$ & HF3 & 0.17347826 & 0.11215511 & 0.11215511 & 0.061323148 \\
\hline $\mathrm{H}$ & $\mathrm{F}$ & HF3 & 0.16049713 & 0.10735323 & 0.10735323 & 0.053143893 \\
\hline $\mathrm{H}$ & $\mathrm{F}$ & HF3 & 0.14990812 & 0.09108376 & 0.09108376 & 0.05882436 \\
\hline $\mathrm{H}$ & $\mathrm{F}$ & HF3 & 0.14484477 & 0.09192719 & 0.09192719 & 0.05291758 \\
\hline $\mathrm{H}$ & $\mathrm{F}$ & HF3 & 0.15855539 & 0.10005422 & 0.10005422 & 0.058501168 \\
\hline $\mathrm{H}$ & $\mathrm{F}$ & HF3 & 0.15678829 & 0.09698456 & 0.09698456 & 0.059803724 \\
\hline $\mathrm{H}$ & $\mathrm{F}$ & HF3 & 0.156075 & 0.10262864 & 0.10262864 & 0.053446364 \\
\hline $\mathrm{H}$ & $\mathrm{F}$ & HF3 & 0.15697083 & 0.09664845 & 0.09664845 & 0.060322383 \\
\hline $\mathrm{H}$ & $\mathrm{F}$ & HF3 & 0.15766355 & 0.1002815 & 0.1002815 & 0.057382047 \\
\hline $\mathrm{H}$ & $\mathrm{F}$ & HF3 & 0.15770811 & 0.08791395 & 0.08791395 & 0.069794161 \\
\hline $\mathrm{H}$ & $\mathrm{F}$ & HF4 & 0.17179735 & 0.09901183 & 0.09901183 & 0.072785519 \\
\hline $\mathrm{H}$ & $\mathrm{F}$ & HF4 & 0.16920137 & 0.10050578 & 0.10050578 & 0.068695588 \\
\hline $\mathrm{H}$ & $\mathrm{F}$ & HF4 & 0.16904086 & 0.09520505 & 0.09520505 & 0.073835805 \\
\hline $\mathrm{H}$ & $\mathrm{F}$ & HF4 & 0.17201121 & 0.10063213 & 0.10063213 & 0.071379082 \\
\hline $\mathrm{H}$ & $\mathrm{F}$ & HF4 & 0.17168145 & 0.10105189 & 0.10105189 & 0.070629557 \\
\hline $\mathrm{H}$ & $\mathrm{F}$ & HF4 & 0.17133423 & 0.10162511 & 0.10162511 & 0.06970912 \\
\hline $\mathrm{H}$ & $\mathrm{F}$ & HF4 & 0.18134231 & 0.1050806 & 0.1050806 & 0.076261716 \\
\hline $\mathrm{H}$ & $\mathrm{F}$ & HF4 & 0.16282853 & 0.10675288 & 0.10675288 & 0.056075651 \\
\hline $\mathrm{H}$ & $\mathrm{F}$ & HF4 & 0.16892111 & 0.10821972 & 0.10821972 & 0.060701389 \\
\hline $\mathrm{H}$ & $\mathrm{F}$ & HF4 & 0.1607492 & 0.09730505 & 0.09730505 & 0.063444146 \\
\hline B & $\mathrm{O}$ & $\mathrm{BO} 2$ & 0.13372879 & 0.07767692 & 0.07123988 & 0.062488906 \\
\hline B & $\mathrm{O}$ & $\mathrm{BO} 2$ & 0.12709883 & 0.07901571 & 0.06806161 & 0.059037227 \\
\hline B & $\mathrm{O}$ & $\mathrm{BO} 2$ & 0.1611791 & 0.10379331 & 0.08290427 & 0.078274824 \\
\hline B & $\mathrm{O}$ & $\mathrm{BO} 2$ & 0.13955368 & 0.08940961 & 0.08105013 & 0.058503555 \\
\hline B & $\mathrm{O}$ & $\mathrm{BO} 2$ & 0.13646414 & 0.08765164 & 0.07295077 & 0.063513367 \\
\hline B & $\mathrm{O}$ & $\mathrm{BO} 2$ & 0.12265083 & 0.07363384 & 0.06847676 & 0.054174075 \\
\hline B & $\mathrm{O}$ & $\mathrm{BO} 2$ & 0.13425994 & 0.08328286 & 0.07398275 & 0.060277187 \\
\hline B & $\mathrm{O}$ & $\mathrm{BO} 2$ & 0.14432312 & 0.09575666 & 0.08029486 & 0.064028266 \\
\hline B & $\mathrm{O}$ & $\mathrm{BO} 2$ & 0.16164782 & 0.10358417 & 0.08025266 & 0.081395167 \\
\hline B & $\mathrm{O}$ & $\mathrm{BO} 2$ & 0.13121054 & 0.08889321 & 0.07478462 & 0.056425919 \\
\hline B & $\mathrm{O}$ & $\mathrm{BO} 3$ & 0.12568258 & 0.11576661 & 0.10248589 & 0.023196687 \\
\hline B & $\mathrm{O}$ & $\mathrm{BO} 3$ & 0.11438525 & 0.11293151 & 0.10290228 & 0.011482978 \\
\hline B & $\mathrm{O}$ & $\mathrm{BO} 3$ & 0.11440696 & 0.10661714 & 0.09824632 & 0.016160636 \\
\hline B & $\mathrm{O}$ & $\mathrm{BO} 3$ & 0.11581013 & 0.10961774 & 0.10209018 & 0.013719945 \\
\hline
\end{tabular}




\begin{tabular}{|c|c|c|c|c|c|c|}
\hline B & 0 & BO3 & 0.10704829 & 0.11170953 & 0.09877153 & 0.008276751 \\
\hline B & 0 & ВО3 & 0.10493552 & 0.10775093 & 0.09905509 & 0.005880432 \\
\hline B & 0 & ВО3 & 0.10926946 & 0.11038153 & 0.10092819 & 0.008341263 \\
\hline B & 0 & BO3 & 0.12050995 & 0.11097282 & 0.10619065 & 0.014319299 \\
\hline B & 0 & ВО3 & 0.116591 & 0.11238624 & 0.10926708 & 0.007323917 \\
\hline B & 0 & BO3 & 0.10949679 & 0.11035962 & 0.10031661 & 0.009180182 \\
\hline B & 0 & BO4 & 0.19849013 & 0.10869442 & 0.08608498 & 0.112405153 \\
\hline B & 0 & BO4 & 0.16574164 & 0.0983326 & 0.08563486 & 0.080106781 \\
\hline B & 0 & BO4 & 0.14922476 & 0.0934486 & 0.08535311 & 0.063871651 \\
\hline B & 0 & BO4 & 0.20838732 & 0.10550901 & 0.07539166 & 0.132995658 \\
\hline B & 0 & BO4 & 0.17245304 & 0.11732372 & 0.09516 & 0.077293036 \\
\hline B & $\mathrm{o}$ & BO4 & 0.16881185 & 0.11103959 & 0.09687348 & 0.071938373 \\
\hline B & 0 & BO4 & 0.15764679 & 0.0914322 & 0.08787123 & 0.069775562 \\
\hline B & $\mathrm{o}$ & BO4 & 0.16179451 & 0.08948023 & 0.08075223 & 0.081042285 \\
\hline B & $\mathrm{o}$ & BO4 & 0.15832276 & 0.09838757 & 0.08701462 & 0.071308145 \\
\hline B & 0 & BO4 & 0.15130771 & 0.10140441 & 0.08902293 & 0.062284776 \\
\hline B & 0 & BO5 & 0.14332231 & 0.13487839 & 0.11841378 & 0.024908522 \\
\hline B & 0 & BO5 & 0.13045603 & 0.11856847 & 0.10922312 & 0.021232904 \\
\hline B & 0 & BO5 & 0.16836568 & 0.15189228 & 0.12243839 & 0.045927287 \\
\hline B & 0 & BO5 & 0.15048657 & 0.13939894 & 0.12139146 & 0.029095115 \\
\hline B & $\mathrm{o}$ & BO5 & 0.13520836 & 0.11814862 & 0.10847716 & 0.026731199 \\
\hline B & 0 & BO5 & 0.13420891 & 0.12437951 & 0.11038816 & 0.023820744 \\
\hline B & 0 & BO5 & 0.14523625 & 0.12148584 & 0.10553728 & 0.039698965 \\
\hline B & 0 & BO5 & 0.18347732 & 0.15472119 & 0.12177612 & 0.061701195 \\
\hline B & 0 & BO5 & 0.13280679 & 0.13233105 & 0.11081044 & 0.021996355 \\
\hline B & 0 & BO5 & 0.13570379 & 0.12404466 & 0.10741549 & 0.0282883 \\
\hline B & $\mathrm{R}$ & BR1 & 0.17724239 & 0.15301143 & 0.09720604 & 0.080036353 \\
\hline B & $\mathrm{R}$ & BR1 & 0.16881241 & 0.14197146 & 0.0936577 & 0.075154716 \\
\hline B & $\mathrm{R}$ & BR1 & 0.16685177 & 0.14377945 & 0.09507628 & 0.071775483 \\
\hline B & $\mathrm{R}$ & BR1 & 0.17687091 & 0.13970608 & 0.09606917 & 0.08080174 \\
\hline B & $\mathrm{R}$ & BR1 & 0.19177515 & 0.16327198 & 0.10583293 & 0.08594222 \\
\hline B & $\mathrm{R}$ & BR1 & 0.16176174 & 0.1391074 & 0.09390094 & 0.067860798 \\
\hline B & $\mathrm{R}$ & BR1 & 0.1635059 & 0.13957111 & 0.09323046 & 0.070275434 \\
\hline B & $\mathrm{R}$ & BR1 & 0.16106859 & 0.13931587 & 0.09154598 & 0.069522613 \\
\hline B & $\mathrm{R}$ & BR1 & 0.18512405 & 0.15284751 & 0.10069577 & 0.084428281 \\
\hline B & $\mathrm{R}$ & BR1 & 0.16952818 & 0.14211544 & 0.09726097 & 0.072267207 \\
\hline B & $\mathrm{R}$ & BR2 & 0.18251613 & 0.14411492 & 0.08735357 & 0.095162562 \\
\hline B & $\mathrm{R}$ & BR2 & 0.15662399 & 0.13937514 & 0.08331486 & 0.073309127 \\
\hline B & $\mathrm{R}$ & BR2 & 0.15236115 & 0.14704224 & 0.08924492 & 0.063116238 \\
\hline B & $\mathrm{R}$ & BR2 & 0.14199277 & 0.14203175 & 0.0874435 & 0.054549273 \\
\hline B & $R$ & BR2 & 0.14704711 & 0.13998887 & 0.08437053 & 0.062676574 \\
\hline B & $R$ & BR2 & 0.13205339 & 0.1308323 & 0.08063604 & 0.051417348 \\
\hline B & $\mathrm{R}$ & BR2 & 0.13218503 & 0.12639909 & 0.07786605 & 0.054318977 \\
\hline B & $\mathrm{R}$ & BR2 & 0.14135755 & 0.13656419 & 0.08471976 & 0.056637791 \\
\hline
\end{tabular}




\begin{tabular}{|c|c|c|c|c|c|c|}
\hline B & $\mathrm{R}$ & BR2 & 0.13974121 & 0.13861348 & 0.08550527 & 0.054235947 \\
\hline B & $\mathrm{R}$ & BR2 & 0.13940683 & 0.13621733 & 0.08213541 & 0.057271424 \\
\hline B & $\mathrm{R}$ & BR3 & 0.16912255 & 0.13741418 & 0.07960254 & 0.089520016 \\
\hline B & $\mathrm{R}$ & BR3 & 0.13980149 & 0.14026288 & 0.08476262 & 0.055038869 \\
\hline B & $\mathrm{R}$ & BR3 & 0.1322066 & 0.13328166 & 0.08043355 & 0.051773051 \\
\hline B & $\mathrm{R}$ & BR3 & 0.13381558 & 0.14985407 & 0.08714988 & 0.046665702 \\
\hline B & $\mathrm{R}$ & BR3 & 0.13193678 & 0.15575216 & 0.08913142 & 0.042805353 \\
\hline B & $\mathrm{R}$ & BR3 & 0.1464526 & 0.1544074 & 0.08902281 & 0.057429787 \\
\hline B & $\mathrm{R}$ & BR3 & 0.14317084 & 0.1426888 & 0.08349935 & 0.059671492 \\
\hline B & $\mathrm{R}$ & BR3 & 0.13002277 & 0.14898102 & 0.08561862 & 0.044404147 \\
\hline B & $\mathrm{R}$ & BR3 & 0.12296671 & 0.12437611 & 0.0758128 & 0.047153917 \\
\hline $\mathrm{B}$ & $\mathrm{R}$ & BR3 & 0.14148782 & 0.16240264 & 0.09108072 & 0.050407102 \\
\hline B & $\mathrm{R}$ & BR4 & 0.1259397 & 0.12799641 & 0.07116096 & 0.054778744 \\
\hline B & $\mathrm{R}$ & BR4 & 0.12640838 & 0.12014934 & 0.06731217 & 0.059096217 \\
\hline B & $\mathrm{R}$ & BR4 & 0.1217708 & 0.11901693 & 0.0648764 & 0.056894402 \\
\hline B & $\mathrm{R}$ & BR4 & 0.11842742 & 0.12201632 & 0.06439043 & 0.05403699 \\
\hline B & $\mathrm{R}$ & BR4 & 0.12602856 & 0.13001209 & 0.06639179 & 0.059636771 \\
\hline B & $\mathrm{R}$ & BR4 & 0.12790797 & 0.11871339 & 0.06497219 & 0.062935772 \\
\hline B & $\mathrm{R}$ & BR4 & 0.14165937 & 0.12107193 & 0.06345604 & 0.07820333 \\
\hline B & $\mathrm{R}$ & BR4 & 0.14936197 & 0.11928872 & 0.05918485 & 0.090177118 \\
\hline B & $\mathrm{R}$ & BR4 & 0.13216027 & 0.13115731 & 0.06824481 & 0.063915461 \\
\hline B & $\mathrm{R}$ & BR4 & 0.11013203 & 0.11205245 & 0.05931984 & 0.050812192 \\
\hline B & $J$ & $\mathrm{BJ} 2$ & 0.14373047 & 0.12674176 & 0.07814209 & 0.065588384 \\
\hline B & $J$ & BJ2 & 0.13787952 & 0.13896742 & 0.08774382 & 0.050135703 \\
\hline B & $J$ & BJ2 & 0.13739171 & 0.1308382 & 0.08063751 & 0.056754194 \\
\hline B & $J$ & BJ2 & 0.13674487 & 0.131779 & 0.0809531 & 0.055791769 \\
\hline B & $J$ & BJ2 & 0.14786406 & 0.13353176 & 0.07897214 & 0.068891914 \\
\hline B & $J$ & BJ2 & 0.14594068 & 0.13672696 & 0.0835527 & 0.062387976 \\
\hline B & $J$ & $\mathrm{BJ} 2$ & 0.13012088 & 0.12562105 & 0.07753286 & 0.052588021 \\
\hline B & $J$ & BJ2 & 0.13602418 & 0.13664388 & 0.08414141 & 0.051882773 \\
\hline B & J & BJ2 & 0.14117625 & 0.13896661 & 0.08338711 & 0.057789142 \\
\hline B & $\mathrm{J}$ & BJ2 & 0.15235262 & 0.15053167 & 0.09044835 & 0.061904275 \\
\hline B & $J$ & BJ3 & 0.18747693 & 0.18940585 & 0.1074416 & 0.080035332 \\
\hline B & $J$ & BJ3 & 0.15791424 & 0.16353185 & 0.09216649 & 0.065747754 \\
\hline B & $J$ & BJ3 & 0.14398938 & 0.15769739 & 0.08776443 & 0.056224948 \\
\hline B & $J$ & BJ3 & 0.14266303 & 0.16223502 & 0.09269293 & 0.049970103 \\
\hline B & $J$ & BJ3 & 0.1833403 & 0.17723678 & 0.09765876 & 0.085681533 \\
\hline B & $J$ & BJ3 & 0.14402383 & 0.16564097 & 0.09630398 & 0.047719849 \\
\hline B & $J$ & BJ3 & 0.14258182 & 0.16139535 & 0.09340331 & 0.049178513 \\
\hline B & $J$ & BJ3 & 0.14049985 & 0.15857983 & 0.0921226 & 0.048377249 \\
\hline B & $J$ & BJ3 & 0.14938968 & 0.16380855 & 0.09436817 & 0.055021512 \\
\hline $\mathrm{B}$ & $\mathrm{J}$ & BJ3 & 0.16244945 & 0.16367735 & 0.09400598 & 0.068443464 \\
\hline B & $J$ & BJ4 & 0.19473535 & 0.15888449 & 0.09116712 & 0.103568234 \\
\hline B & $J$ & BJ4 & 0.19546623 & 0.16081194 & 0.08996525 & 0.105500978 \\
\hline
\end{tabular}




\begin{tabular}{|c|c|c|c|c|c|c|}
\hline B & J & BJ4 & 0.18436021 & 0.15476846 & 0.08578123 & 0.098578983 \\
\hline B & J & BJ4 & 0.25180048 & 0.21131117 & 0.11774387 & 0.134056615 \\
\hline B & J & BJ4 & 0.17813731 & 0.16261531 & 0.08984213 & 0.088295185 \\
\hline B & J & BJ4 & 0.18643922 & 0.16583569 & 0.09337333 & 0.093065888 \\
\hline B & J & BJ4 & 0.18999737 & 0.16529961 & 0.09227597 & 0.097721406 \\
\hline B & J & BJ4 & 0.17706976 & 0.16432579 & 0.09291001 & 0.084159749 \\
\hline B & J & BJ4 & 0.19041051 & 0.16402229 & 0.09047004 & 0.099940466 \\
\hline$B$ & $\mathrm{~J}$ & $\mathrm{BJ} 4$ & 0.19834111 & 0.16469233 & 0.0932697 & 0.10507141 \\
\hline B & J & BJ5 & 0.2112312 & 0.10174875 & 0.06009221 & 0.151138992 \\
\hline B & J & BJ5 & 0.16937597 & 0.09284451 & 0.05636373 & 0.113012249 \\
\hline B & J & BJ5 & 0.17860096 & 0.09812737 & 0.05990723 & 0.118693729 \\
\hline B & J & BJ5 & 0.16690557 & 0.09327371 & 0.05606318 & 0.110842388 \\
\hline B & J & BJ5 & 0.16325249 & 0.08838193 & 0.0525796 & 0.110672892 \\
\hline B & J & BJ5 & 0.17761658 & 0.08921844 & 0.05353472 & 0.124081867 \\
\hline B & J & BJ5 & 0.18317765 & 0.1157317 & 0.07553568 & 0.107641976 \\
\hline B & J & BJ5 & 0.17021052 & 0.10326859 & 0.06395719 & 0.106253328 \\
\hline B & J & BJ5 & 0.17025188 & 0.09121513 & 0.05479196 & 0.115459927 \\
\hline B & $\mathrm{J}$ & BJ5 & 0.17845633 & 0.09375284 & 0.05673719 & 0.121719136 \\
\hline B & $\mathrm{F}$ & BF1 & 0.10165495 & 0.05564251 & 0.05526781 & 0.04638714 \\
\hline B & $\mathrm{F}$ & BF1 & 0.10810478 & 0.05505266 & 0.05672821 & 0.051376572 \\
\hline B & $\mathrm{F}$ & BF1 & 0.09884914 & 0.05151578 & 0.05691622 & 0.041932915 \\
\hline B & $\mathrm{F}$ & BF1 & 0.10822696 & 0.04911774 & 0.05767269 & 0.050554268 \\
\hline B & $\mathrm{F}$ & BF1 & 0.10841179 & 0.05313106 & 0.06044283 & 0.047968957 \\
\hline B & $\mathrm{F}$ & BF1 & 0.1124515 & 0.0538317 & 0.05684821 & 0.055603294 \\
\hline B & $\mathrm{F}$ & BF1 & 0.1056256 & 0.05110647 & 0.05824944 & 0.047376154 \\
\hline B & $\mathrm{F}$ & BF1 & 0.10906556 & 0.05900094 & 0.05911228 & 0.049953272 \\
\hline B & $\mathrm{F}$ & BF1 & 0.10156058 & 0.0507697 & 0.05667212 & 0.044888459 \\
\hline B & $\mathrm{F}$ & BF1 & 0.11488952 & 0.05306547 & 0.05878794 & 0.056101573 \\
\hline B & $\mathrm{F}$ & BF2 & 0.15884283 & 0.07217073 & 0.07235811 & 0.086484717 \\
\hline B & $\mathrm{F}$ & BF2 & 0.1803889 & 0.07514255 & 0.07536912 & 0.105019789 \\
\hline B & $\mathrm{F}$ & BF2 & 0.1602927 & 0.07218333 & 0.07221469 & 0.088078003 \\
\hline B & $\mathrm{F}$ & BF2 & 0.19625225 & 0.10691514 & 0.10691514 & 0.089337106 \\
\hline B & $\mathrm{F}$ & BF2 & 0.15665738 & 0.0675886 & 0.06762212 & 0.089035262 \\
\hline B & $\mathrm{F}$ & BF2 & 0.15122443 & 0.06806948 & 0.06821955 & 0.083004879 \\
\hline B & $\mathrm{F}$ & BF2 & 0.16787534 & 0.08762648 & 0.08762648 & 0.080248861 \\
\hline B & $\mathrm{F}$ & BF2 & 0.14820356 & 0.0624094 & 0.06254852 & 0.085655037 \\
\hline B & $\mathrm{F}$ & BF2 & 0.14961831 & 0.06642658 & 0.06642658 & 0.083191733 \\
\hline B & $\mathrm{F}$ & BF2 & 0.16485477 & 0.06515486 & 0.06515486 & 0.099699905 \\
\hline B & $\mathrm{F}$ & BF3 & 0.13601005 & 0.07432161 & 0.07432161 & 0.06168844 \\
\hline B & $\mathrm{F}$ & BF3 & 0.14267748 & 0.07817785 & 0.07817785 & 0.064499629 \\
\hline B & $\mathrm{F}$ & BF3 & 0.13554675 & 0.07690095 & 0.07690095 & 0.058645799 \\
\hline B & $\mathrm{F}$ & BF3 & 0.1314298 & 0.07405538 & 0.07405538 & 0.057374418 \\
\hline B & $\mathrm{F}$ & BF3 & 0.12830792 & 0.07768437 & 0.07768437 & 0.050623554 \\
\hline B & $\mathrm{F}$ & BF3 & 0.17281637 & 0.08857428 & 0.08857428 & 0.084242095 \\
\hline
\end{tabular}




\begin{tabular}{lllrrrr} 
B & F & BF3 & 0.14093053 & 0.07578348 & 0.07578348 & 0.065147044 \\
B & F & BF3 & 0.15351182 & 0.08208582 & 0.08208582 & 0.071426 \\
B & F & BF3 & 0.13376361 & 0.07735648 & 0.07735648 & 0.056407125 \\
B & F & BF3 & 0.13573409 & 0.07484174 & 0.07484174 & 0.060892351 \\
\hline B & F & BF4 & 0.14937285 & 0.07717844 & 0.07717844 & 0.072194411 \\
B & F & BF4 & 0.13903309 & 0.07564685 & 0.07564685 & 0.063386244 \\
B & F & BF4 & 0.13281275 & 0.07028071 & 0.07028071 & 0.062532034 \\
B & F & BF4 & 0.1341068 & 0.06730191 & 0.06761974 & 0.066487066 \\
B & F & BF4 & 0.1381212 & 0.0698549 & 0.0698549 & 0.068266305 \\
B & F & BF4 & 0.16505766 & 0.0830477 & 0.0830477 & 0.082009956 \\
B & F & BF4 & 0.1590891 & 0.08673285 & 0.08673285 & 0.072356252 \\
B & F & BF4 & 0.16020135 & 0.08458413 & 0.08458413 & 0.075617225 \\
B & F & BF4 & 0.14495415 & 0.06969449 & 0.07014469 & 0.074809455 \\
B & F & BF4 & 0.14899476 & 0.07767499 & 0.07767499 & 0.071319769 \\
\hline
\end{tabular}




\section{APPENDIX}

Appendix 5a: Summary statistic results for the best-fit linear mixed effect model using the fragment pool approach ( $\alpha$-level: within plot, $\beta$-level: within land-use system, $\gamma$-level: within region). Genetic diversity AIC for $\alpha$-level $=-1712.34, \beta$-level $=-$ 1944.634, $\nu$-level $=-2189.653$. Significant $p$-values in bold.

\begin{tabular}{|c|c|c|c|c|c|c|}
\hline Level & Fixed effects & $\begin{array}{c}\text { Random } \\
\text { effect }\end{array}$ & Estimate & Std. Error & t-value & p-value \\
\hline \multicolumn{7}{|l|}{$\alpha$} \\
\hline & Intercept & Region/plot & 0.1486 & 0.0079 & 18.7209 & 0.0000 \\
\hline & $\begin{array}{l}\text { Jungle } \\
\text { rubber }\end{array}$ & Region/plot & 0.0190 & 0.0112 & 1.6961 & 0.1009 \\
\hline & Oil palm & Region/plot & -0.0179 & 0.0112 & -1.5906 & 0.1229 \\
\hline & Rubber & Region/plot & -0.0065 & 0.0112 & -0.5767 & 0.5688 \\
\hline \multicolumn{7}{|l|}{$\beta$} \\
\hline & Intercept & Region/plot & 0.0802 & 0.0062 & 12.98 & 0.0000 \\
\hline & $\begin{array}{l}\text { Jungle } \\
\text { rubber }\end{array}$ & Region/plot & 0.0669 & 0.0087 & 7.6635 & 0.0000 \\
\hline & Oil palm & Region/plot & 0.0355 & 0.0087 & 4.0673 & 0.0004 \\
\hline & Rubber & Region/plot & 0.0503 & 0.0087 & 5.7620 & 0.0000 \\
\hline \multicolumn{7}{|c|}{5} \\
\hline & Intercept & Region/plot & 0.0753 & 0.0056 & 13.4478 & 0.0000 \\
\hline & $\begin{array}{l}\text { Jungle } \\
\text { rubber }\end{array}$ & Region/plot & 0.0126 & 0.0079 & 1.5932 & 0.1223 \\
\hline & Oil palm & Region/plot & 0.0258 & 0.0079 & 3.2497 & 0.0030 \\
\hline & Rubber & Region/plot & 0.0117 & 0.0079 & 1.4796 & 0.1501 \\
\hline
\end{tabular}

Appendix 5b: Summary statistics of the Tukey-post-hoc test for the influence of land-use change on genetic differentiation based on the results of the linear mixed effect model using the fragment pool approach, at three spatial scales ( $\alpha$-level: within plot, $\beta$-level: within land-use system, $\gamma$-level: within region). Significant $p$-values in bold

\begin{tabular}{cccccc}
\hline Level & $\begin{array}{c}\text { Response } \\
\text { variables }\end{array}$ & Estimate & $\begin{array}{c}\text { Standard } \\
\text { Error }\end{array}$ & z-value & p-value \\
\hline$\alpha$ & & & & & \\
\hline & J-F & 0.0190 & 0.0112 & 1.696 & 0.3257 \\
O-F & -0.0179 & 0.0112 & -1.591 & 0.384 \\
R-F & -0.0065 & 0.0112 & -0.577 & 0.9391 \\
O-J & -0.0368 & 0.0112 & -3.287 & $\mathbf{0 . 0 0 5 6}$ \\
& R-J & -0.0255 & 0.0112 & -2.273 & 0.1044 \\
& R-O & 0.0114 & 0.0112 & 1.014 & 0.7413 \\
\hline$\beta$ & & & & & \\
\hline & J-F & 0.0667 & 0.0087 & 7.664 & $<0.001$ \\
& O-F & 0.0355 & 0.0087 & 4.067 & $<0.001$ \\
& R-F & 0.0503 & 0.0087 & 5.762 & $<\mathbf{0 . 0 0 1}$ \\
& O-J & -0.0314 & 0.0087 & -3.596 & $\mathbf{0 . 0 0 1 9}$ \\
& R-J & -0.0166 & 0.0087 & -1.901 & 0.2274 \\
R-O & 0.0148 & 0.0087 & 1.695 & 0.3263 \\
\hline V & & & & \\
\hline & J-F & 0.0126 & 0.0079 & 1.593 & 0.3823 \\
& O-F & 0.0257 & 0.0079 & 3.250 & $\mathbf{0 . 0 0 6 5}$ \\
& R-F & 0.0117 & 0.0079 & 1.480 & 0.4498 \\
& O-J & 0.0131 & 0.0079 & 1.656 & 0.3471 \\
R-J & -0.0009 & 0.0079 & -0.114 & 0.9995 \\
& R-O & -0.0140 & 0.0079 & -1.770 & 0.2879 \\
\hline
\end{tabular}


Appendix 6a: Statistics of the best-fit linear mixed effect model results for the species approach ( $\alpha$-level: within plot, $\beta$ level: within land-use system, $\gamma$-level: within region). AIC for $\alpha$-level $=-601.2809, \beta$-level $=-562.1553, \gamma$-level $=-550.0745$. Significant $p$-values in bold.

\begin{tabular}{|c|c|c|c|c|c|c|}
\hline Level & Fixed effect & $\begin{array}{c}\text { Random } \\
\text { effect }\end{array}$ & Estimate & Std. Error & t-value & p-value \\
\hline \multicolumn{7}{|l|}{$\alpha$} \\
\hline & Intercept & Region/plot & 0.1505 & 0.0093 & 16.0508 & 0.0000 \\
\hline & $\begin{array}{l}\text { Jungle } \\
\text { rubber }\end{array}$ & Region|plot & 0.0146 & 0.0135 & 1.0780 & 0.2902 \\
\hline & Oil palm & Region|plot & -0.0140 & 0.0129 & -1.0787 & 0.2899 \\
\hline & Rubber & Region/plot & -0.0046 & 0.0129 & -0.3542 & 0.7258 \\
\hline \multicolumn{7}{|c|}{ o } \\
\hline & Intercept & Region/plot & 0.1576 & 0.0101 & 15.6692 & 0.0000 \\
\hline & $\begin{array}{l}\text { Jungle } \\
\text { rubber }\end{array}$ & Region|plot & 0.0178 & 0.0145 & 1.2299 & 0.2290 \\
\hline & Oil palm & Region|plot & 0.00002 & 0.0139 & 0.0018 & 0.9986 \\
\hline & Rubber & Region/plot & 0.0010 & 0.0138 & -0.0732 & 0.9421 \\
\hline \multicolumn{7}{|l|}{$\gamma$} \\
\hline & Intercept & Region/plot & 0.1597 & 0.0103 & 15.5308 & 0.0000 \\
\hline & $\begin{array}{l}\text { Jungle } \\
\text { rubber }\end{array}$ & Region |plot & 0.0183 & 0.0148 & 1.2382 & 0.2259 \\
\hline & Oil palm & Region|plot & 0.0023 & 0.0142 & 0.1621 & 0.8723 \\
\hline & Rubber & Region|plot & 0.0059 & 0.0141 & 0.4189 & 0.6785 \\
\hline
\end{tabular}

Appendix 6b: Summary statistics of the Tukey post-hoc test for the influence of land-use change on genetic differentiation based on the results of the linear mixed effect model using the species approach, at all three spatial scales ( $\alpha$-level: within plot, $\beta$-level: within land-use system, $\gamma$-level: within region). Significant $p$-values in bold.

\begin{tabular}{|c|c|c|c|c|c|}
\hline Level & $\begin{array}{l}\text { Response } \\
\text { variables }\end{array}$ & Estimate & $\begin{array}{c}\text { Standard } \\
\text { Error }\end{array}$ & z-value & p-value \\
\hline \multicolumn{6}{|l|}{$\alpha$} \\
\hline & $J-F$ & 0.0145 & 0.0135 & 1.078 & 0.703 \\
\hline & O-F & -0.0140 & 0.0129 & -1.079 & 0.702 \\
\hline & $R-F$ & -0.0045 & 0.0129 & -0.354 & 0.985 \\
\hline & O-J & -0.0285 & 0.0132 & -2.157 & 0.135 \\
\hline & R-J & -0.0191 & 0.0131 & -1.457 & 0.464 \\
\hline & $\mathrm{R}-\mathrm{O}$ & 0.0094 & 0.0126 & 0.751 & 0.876 \\
\hline \multicolumn{6}{|l|}{$\beta$} \\
\hline & $J-F$ & $1.784 \mathrm{e}-2$ & $1.451 \mathrm{e}-02$ & 1.230 & 0.608 \\
\hline & $\mathrm{O}-\mathrm{F}$ & $2.483 e-05$ & $1.394 \mathrm{e}-02$ & 0.002 & 1.0000 \\
\hline & $\mathrm{R}-\mathrm{F}$ & $-1.011 e-03$ & $1.381 \mathrm{e}-02$ & -0.073 & 1.0000 \\
\hline & O-J & $-1.782 \mathrm{e}-02$ & $1.422 \mathrm{e}-02$ & -1.253 & 0.593 \\
\hline & R-J & $-1.885 e-02$ & $1.409 \mathrm{e}-02$ & -1.338 & 0.539 \\
\hline & $\mathrm{R}-\mathrm{O}$ & $-1.036 \mathrm{e}-03$ & $1.351 \mathrm{e}-02$ & -0.077 & 1.0000 \\
\hline \multicolumn{6}{|l|}{$\gamma$} \\
\hline & $J-F$ & 0.0184 & 0.0148 & 1.238 & 0.602 \\
\hline & O-F & 0.0023 & 0.0142 & 0.162 & 0.998 \\
\hline & $\mathrm{R}-\mathrm{F}$ & 0.0059 & 0.0141 & 0.419 & 0.975 \\
\hline & O-J & -0.0160 & 0.0145 & -1.104 & 0.687 \\
\hline & R-J & -0.0124 & 0.0144 & -0.864 & 0.823 \\
\hline & $\mathrm{R}-\mathrm{O}$ & -0.0036 & 0.0138 & 0.261 & 0.994 \\
\hline
\end{tabular}




\section{APPENDIX}

Appendix 7a: Statistics of the best-fit linear mixed effect model results for the Shannon Index ( $\alpha$-level: within plot, $\beta$-level: within land-use system, $\gamma$-level: within region). AIC for $\alpha$-level $=-460.7372, \beta$-level $=-423.6388, \gamma$-level $=-430.0219$.

Significant $p$-values in bold.

\begin{tabular}{|c|c|c|c|c|c|c|}
\hline Level & Fixed effect & $\begin{array}{c}\text { Random } \\
\text { effect }\end{array}$ & Estimate & Std. Error & t-value & p-value \\
\hline \multicolumn{7}{|l|}{$\alpha$} \\
\hline & Intercept & Region/plot & 0.2849 & 0.0120 & 23.6003 & 0.0000 \\
\hline & $\begin{array}{l}\text { Jungle } \\
\text { rubber }\end{array}$ & Region|plot & 0.0051 & 0.0174 & 0.2952 & 0.7700 \\
\hline & Oil palm & Region/plot & -0.0530 & 0.0167 & -3.1722 & 0.0037 \\
\hline & Rubber & Region/plot & -0.0474 & 0.0165 & -2.8661 & 0.0078 \\
\hline \multicolumn{7}{|l|}{$\beta$} \\
\hline & Intercept & Region/plot & 0.3340 & 0.0129 & 25.8829 & 0.0000 \\
\hline & $\begin{array}{l}\text { Jungle } \\
\text { rubber }\end{array}$ & Region/plot & 0.0001 & 0.0186 & 0.0098 & 0.9922 \\
\hline & Oil palm & Region/plot & -0.0281 & 0.0178 & -1.5732 & 0.1269 \\
\hline & Rubber & Region/plot & -0.0574 & 0.0177 & -3.2460 & 0.0030 \\
\hline \multicolumn{7}{|l|}{$\gamma$} \\
\hline & Intercept & Region/plot & 0.3395 & 0.0127 & 26.6111 & 0.0000 \\
\hline & $\begin{array}{l}\text { Jungle } \\
\text { rubber }\end{array}$ & Region|plot & 0.0086 & 0.0183 & 0.4688 & 0.6428 \\
\hline & Oil palm & Region/plot & -0.0218 & 0.0176 & -1.2345 & 0.2273 \\
\hline & Rubber & Region/plot & -0.0306 & 0.0175 & -1.7491 & 0.0912 \\
\hline
\end{tabular}

Appendix 7b: Summary statistics of the Tukey post-hoc test for the influence of land-use change on genetic diversity based on the results of the linear mixed effect model using the Shannon Index, at all three spatial scales ( $\alpha$-level: within plot, $\beta$ level: within land-use system, $\gamma$-level: within region). Significant $p$-values in bold.

\begin{tabular}{cccccc}
\hline Level & $\begin{array}{c}\text { Response } \\
\text { variables }\end{array}$ & Estimate & $\begin{array}{c}\text { Standard } \\
\text { Error }\end{array}$ & z-value & p-value \\
\hline$\alpha$ & & & & & \\
\hline & J-F & 0.0051 & 0.0174 & 0.295 & 0.9910 \\
& O-F & -0.0530 & 0.0167 & -3.172 & $\mathbf{0 . 0 0 8 0}$ \\
R-F & -0.0474 & 0.0165 & -2.866 & $\mathbf{0 . 0 2 1 6}$ \\
& O-J & -0.0581 & 0.0170 & -3.410 & $\mathbf{0 . 0 0 3 6}$ \\
& R-J & -0.0526 & 0.0169 & -3.111 & $\mathbf{0 . 0 1 0 2}$ \\
& R-O & 0.0055 & 0.0162 & 0.344 & 0.9860 \\
\hline N & & & & \\
\hline & J-F & 0.0002 & 0.0186 & 0.010 & 1.0000 \\
& O-F & -0.0281 & 0.0178 & -1.573 & 0.3938 \\
& R-F & -0.0574 & 0.0177 & -3.246 & $\mathbf{0 . 0 0 6 3}$ \\
& O-J & -0.0283 & 0.0182 & -1.552 & 0.4063 \\
& R-J & -0.0576 & 0.0180 & -3.190 & $\mathbf{0 . 0 0 7 8}$ \\
& R-O & -0.0293 & 0.0173 & -1.695 & 0.3261 \\
\hline V & & & & \\
\hline & J-F & 0.0086 & 0.0183 & 0.469 & 0.966 \\
& O-F & -0.0218 & 0.0176 & -1.235 & 0.605 \\
& R-F & -0.0306 & 0.0175 & -1.749 & 0.298 \\
& O-J & -0.0304 & 0.0180 & -1.688 & 0.330 \\
& R-J & -0.0392 & 0.0178 & -2.196 & 0.124 \\
R-O & -0.0088 & 0.0171 & -0.514 & 0.956 \\
\hline
\end{tabular}




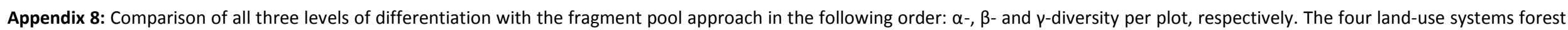
$(\mathrm{F}$, green), jungle rubber $(\mathrm{J}, \mathrm{red})$, oil palm $(\mathrm{O}$, yellow), rubber $(\mathrm{R}$, blue) in two regions Bukit Dua Belas landscape (B, bright colours) and Harapan landscape ( $\mathrm{H}$, dark colours).

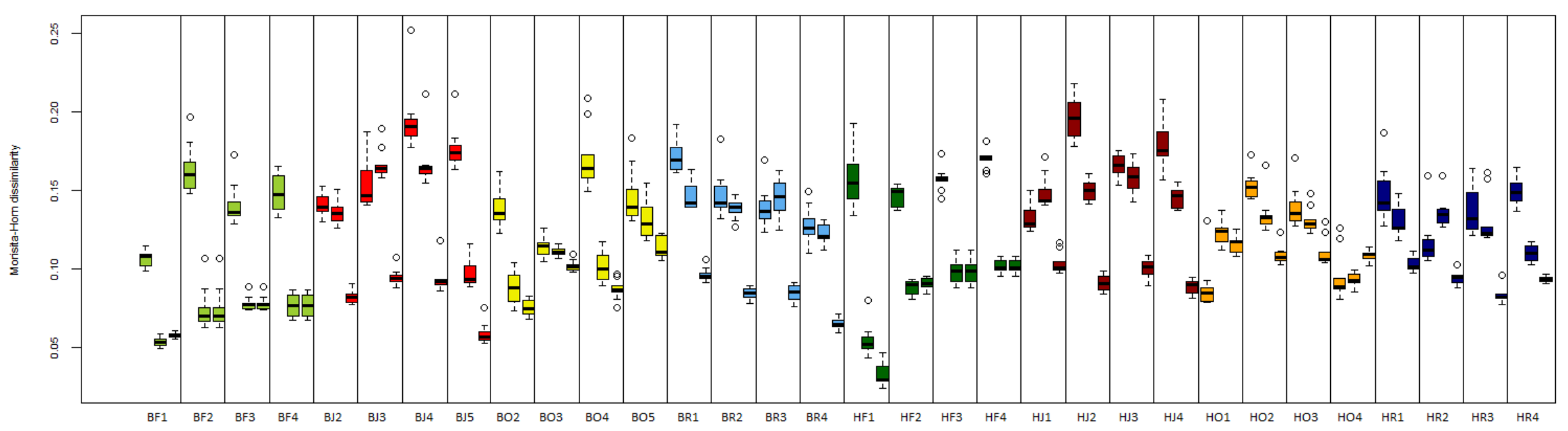




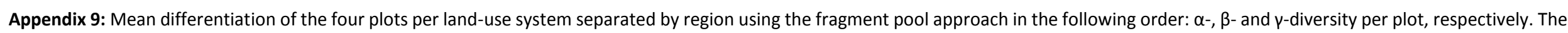
four land-use systems forest (Fgreen), jungle rubber (red), oil palm (yellow), rubber (blue) in two regions Bukit Dua Belas landscape (bright colours) and Harapan landscape (dark colours).

FOREST

JUNGLE RUBBER

OIL PALM

RUBBER

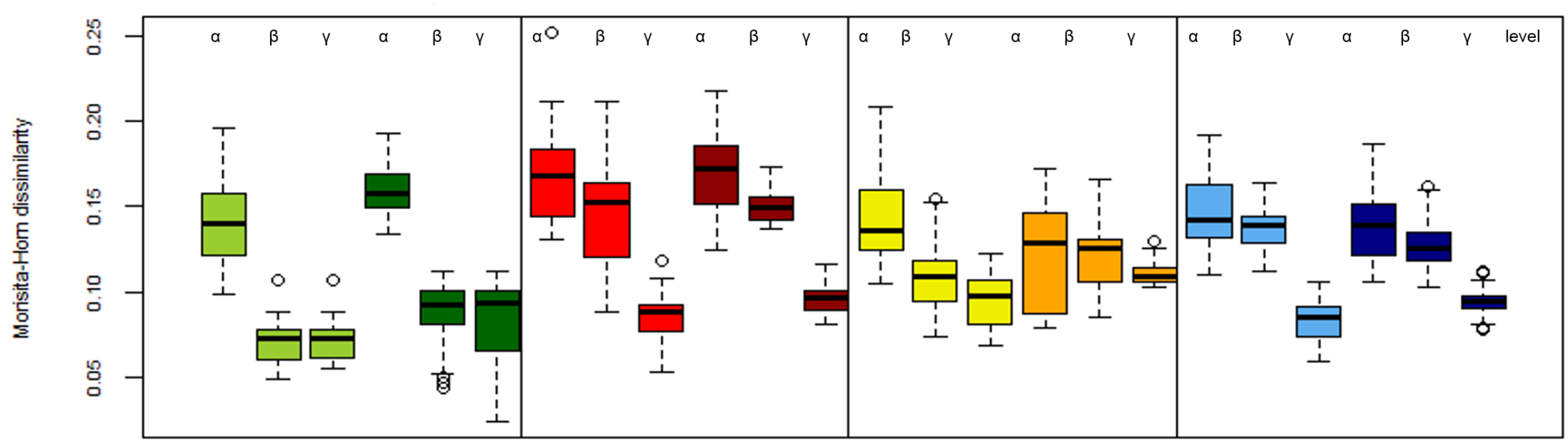




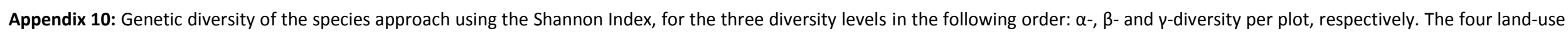
systems forest ( $F$, green), jungle rubber (J, red), oil palm ( $\mathrm{O}$, yellow), rubber ( $R$, blue) in two regions Bukit Dua Belas landscape (B, bright colours) and Harapan landscape ( $H$, dark colours).

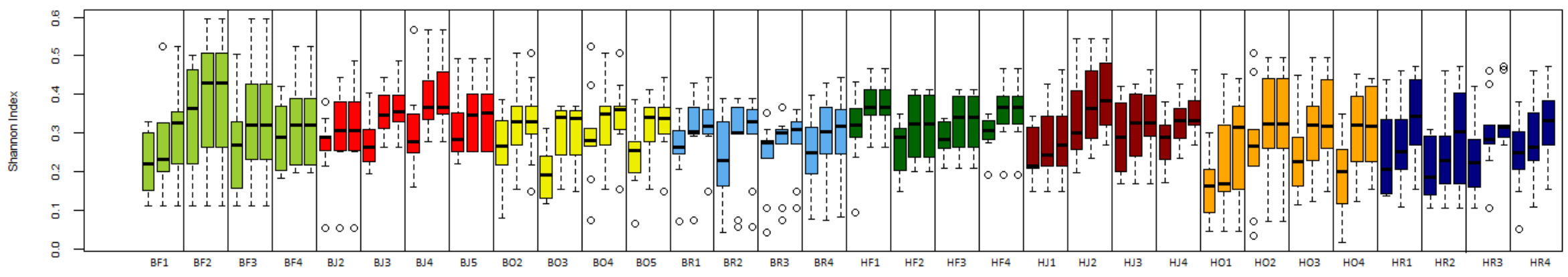




\section{CURRICULUM VITAE}

Name: Natalie Breidenbach

E-mail: natalie.breidenbach@posteo.de,nbreide@gwdg.de

Date of birth: 13.06.1984 in Mainz, Germany

\section{EDUCATION}

2012- 2016

PhD student in the Section "Forest Genetic and Forest

Tree breeding" at Büsgen Institute University of Göttingen

2004-2011

University of Greifswald, Diplom Biology

Major: botany, landscape ecology and nature conservation, and ecology

Thesis topic: "Development of a microsatellite-based genotyping method for the investigation of genetic causes for growth types of Picea glauca (Alaska, USA) responding to climate change"

Nov. 2010-

Febr. 2011

Student assistant at the department of Botany University of Greifswald

Dez 2008-

Apr. 2009

Internship concerning $\mathrm{CO}_{2}$ flux dependency on different species and densities of agricultural used plants at the Hebrew University of Jerusalem, Faculty of Agriculture, Food and Environment in Rehovot, Israel

2007

Project about halophytes in sabkhas, salt deserts and

beaches of the Sultanate of Oman

2003-2004

Volunteer work in a home for disabled people

2003

Abitur, receiving general qualification for university entrance 
GRANTS

$2008 / 2009$

Travelling support for the internship in Israel by the DAAD

2014

Göttingen International conference travel grant for travel to

the ATBC conference in Cairns, Australia

\section{CONFERENCE PRESENTATIONS}

Breidenbach N, Siregar I Z, Finkeldey R (2016) Change of genetic diversity in dominant plant species communities in tropical lowland rainforest transformation systems in Sumatra (Indonesia). The Annual Conference of the Society for Tropical Ecology, Göttingen, Germany (23.-26.02.2016). Poster presentation.

Breidenbach N, Siregar I Z, Rahayu S, Finkeldey R (2014) Plant genetic diversity in tropical lowland rainforest transformation systems in Sumatra (Indonesia). The Annual Conference of the Society for Tropical Ecology, Zürich, Switzerland (07.-10.04.2015). Oral presentation.

Breidenbach N, Siregar I Z, Finkeldey R (2015) Is the intraspecific plant diversity associated with the plant species diversity? The $1^{\text {st }}$ Annual Meeting in Conservation Genetics, Birmensdorf Zwitzerland (28.-30.01.2015). Poster presentation.

Breidenbach N, Siregar I Z, Finkeldey R (2014) Pflanzengenetische Diversität in tropischen Tieflandregenwald Transformationssystemen. The $13^{\text {th }}$ Forstwissenschaftliche Tagung, Tharandt/Dresden, Germany (17.-20.09.2014). Poster presentation.

Breidenbach N, Siregar I Z, Rahayu S, Finkeldey R (2014) Pflanzengenetische Diversität in tropischen Tieflandregenwald Transformationssystemen. The $4^{\text {th }}$ Sektionstagung „Forstgenetik/Forstpflanzenzüchtung“, Teisendorf Germany (10.-12.09.2014). Poster presentation

Breidenbach N, Rahayu S, Siregar I Z, Finkeldey R (2014) Plant genetic diversity in tropical lowland rainforest transformation systems, Sumatra (Indonesia). The $51^{\text {st }}$ Annual Meeting for the Association of Tropical Biology and Conservation, Cairns, Australia (20.-24.07.2014). Oral presentation.

Breidenbach N, Rahayu S, Siregar I Z, Finkeldey R (2013) Plant genetic diversity in tropical lowland rainforest transformation systems, an introduction. The $9^{\text {th }}$ International Flora Malesiana Symposium. Bogor, Indonesia (27-31.08.2013).

Oral presentation. 


\section{PUBLICATIONS}

Hodač L, Bahrul Ulum F, Opfermann N, Breidenbach N, Hojsgaard D, Sudarmiyati

Tjitrosoedirdjo S, Vornam B, Finkeldey R, Hörandl E. Population Genetic Structure and

Reproduction Strategy of the Introduced Gras Centotheca lappacea in Tropical Land-use Systems in Sumatra (PLOS ONE 2016)

\section{Submitted:}

Clough Y, Krishna VV, Corre MD, Darras K, Denmead LH, Meijide A, Moser S, Musshoff O, Steinebach S, Veldkamp E, Allen K, Barnes AD, Breidenbach N, Brose U, Buchori D, Daniel R, Finkeldey R, Harahap I, Hertel D, Holtkamp AM, Hörandl E, Jaya INS, Jochum M, Klarner B, Knohl A, Kotowska MM, Krashevska V, Kreft H, Kurniawan S, Leuschner C, Maraun M, Melati DN, Opfermann N, Pérez-Cruzado C, Prabowo WE, Rembold K, Rizali A, Rubiana R, Schneider D, Tjitrosoedirdjo SS, Tjoa A, Tscharntke T, Scheu S. Land-use choices follow profitability and affect biodiversity and ecological functions in Indonesian smallholder landscapes.

\section{LANGUAGE SKILLS}

German (native language), English, Indonesian, Spanish 